THE DEVELOPMENT AND VALIDATION OF

THE GAME USER EXPERIENCE SATISFACTION SCALE (GUESS)

\author{
A Dissertation by \\ Mikki Hoang Phan \\ Master of Arts, Wichita State University, 2012 \\ Bachelor of Arts, Wichita State University, 2008 \\ Submitted to the Department of Psychology \\ and the faculty of the Graduate School of \\ Wichita State University \\ in partial fulfillment of \\ the requirements for the degree of \\ Doctor of Philosophy
}

May 2015 
(C) Copyright 2015 by Mikki Phan

All Rights Reserved 


\section{THE DEVELOPMENT AND VALIDATION OF \\ THE GAME USER EXPERIENCE SATISFACTION SCALE (GUESS)}

The following faculty members have examined the final copy of this dissertation for form and content, and recommend that it be accepted in partial fulfillment of the requirements for the degree of Doctor of Philosophy with a major in Psychology.

Barbara S. Chaparro, Committee Chair

Joseph Keebler, Committee Member

Jibo He, Committee Member

Darwin Dorr, Committee Member

Jodie Hertzog, Committee Member

Accepted for the College of Liberal Arts and Sciences

Ronald Matson, Dean

Accepted for the Graduate School

Abu S. Masud, Interim Dean 


\section{DEDICATION}

To my parents for their love and support, and all that they have sacrificed so that my siblings and I can have a better future 
Video games open worlds.

- Jon-Paul Dyson 


\section{ACKNOWLEDGEMENTS}

Althea Gibson once said, "No matter what accomplishments you make, somebody helped you." Thus, completing this long and winding Ph.D. journey would not have been possible without a village of support and help.

While words could not adequately sum up how thankful I am, I would like to start off by thanking my dissertation chair and advisor, Dr. Barbara Chaparro. Thank you for being the candle that illuminates my path to Ph.D. success. Without you and Dr. Alex Chaparro, I would not have discovered the field of human factors psychology. Both of you have saved me from a career that might bring me a lot of money, but which brought me no joy. Dr. C., thank you for your endless amount of patience, guidance, and support. Thank you for always making yourself available whenever I needed you, and knowing precisely what to say whenever one of my dissertation fears kicked in. You are and always will be the heroine in my book!

To the rest of my dissertation committee (Drs. Joseph Keebler, Jibo He, Darwin Dorr, and Jodie Hertzog) I extend my deepest gratitude for your time, support, and thoughtful comments/suggestions. Specifically, I would like to thank further Dr. Joseph Keebler for sharing his statistical knowledge and expertise. Dr. Keebler, thank you for your words of encouragement and continuous reassurance about the quality of my research - I always slept a little better at night after conversing with you!

This dissertation would also not have been possible without a group of people who, despite being extremely busy, took the time to provide detailed feedback about my research. And for this, they will always have my gratitude and a special place in my heart-thank you Dr. 
Davin Pavlas, Dr. Rochelle Edwards, Dr. Amanda Smith, Dustin Smith, Neethan Siva, Gigi Phan, Peter Phan, Duc Nguyen, C.J. Randall, and Erin Gannon. I also would like to thank Drs. Wijnand IJsselsteijn and Frans Mäyrä for providing me a copy of their gaming scale/questionnaire.

Next, I would like to send a heartfelt thanks to those who have helped me in sharing my gaming surveys as well as to the owners/administrators who have allowed me to share my surveys on their forums/websites. Particularly, I want to thank Dr. Charles Burdsal for making the WSU panels via Qualtrics possible. Additionally, I want to thank the following people who were instrumental in helping me recruit more respondents: Mr. Norman Bent, Christina Siu, Dominic Canare, Nicole Stahl, Dustin Smith, Neethan Siva, Seth Correa, Duc Nguyen, Peter Phan, and Jacqueline Huynh. I apologized that I could not list everyone's name, but please know that your help is very much appreciated!

Although they may not be directly involved in my dissertation, I would especially like to thank the people who were influential in motivating me to pursue an advanced education. Thank you, Mses. Vanessa Souriya-Mnirajd, Shukura Bakari-Cozart, and LaWanda Holt-Fields for believing in me and for encouraging me to join the McNair Scholars Program, which had become a life-changing experience. Another important mentor in my life that I would like to acknowledge is Dr. Deema de Silva. Thank you for taking me under your wings and showing me that I too can fly.

I am also extremely thankful for my family for their unconditional love and support during this long journey. Thank you to my Ba and Ma for instilling in me the value of hard work and a good education early in life. I am forever grateful for their decision to abandon everything 
in their homeland and move to a foreign place in search of a better future for their children. Despite not knowing much about the HF psychology doctorate they have remained supportive of my "professional student" status for most of my grad school years. And they have only asked when I am going to get a real job every once in a while. In addition to my parents, I would like to thank my siblings, my sister-in-law, and my aunt and uncle for their constant support and encouragement. Like my parents, they did not ask (excessively) the grad-student-mostforbidden question, "When are you going to graduate?"

Aside from my immediate family, I would like to thank all of my friends for their love and support, as well as patience during my years in graduate school. Thank you for being a source of joy and welcomed distraction whenever I needed a break from work. And thank you for being understanding when I could not hang out (for what felt like a century) due to school and work.

Of the friends who I held near and dear to my heart, I especially want to acknowledge two individuals who I considered as my "brother and sister from another mother" and soon-tobe Drs., Jennifer Teves and Bobby Nguyen. Thank you for embarking on this Ph.D. adventure with me, and for always being there to lend your listening ears and shoulders to lean on when I felt stressed and tired. Most of all thank you for the much-needed laughter during the difficult times. I would not be able to make it this far without both of your company. I love both of you very much, and I cannot wait to celebrate your future successes!

Finally, this dissertation would not have even begun if it were not for a video game that changed a young girl's world 23 years ago. Thank you creators of Tetris for igniting my love for video games, and for showing me that a good video game can make all the difference. 
ABSTRACT

Since the 1970's, video games have grown to become a ubiquitous form of digital entertainment. As the demand for video games continues to increase, video game developers and designers are facing the difficult task of creating games that are not only enjoyable to play, but marketable in a highly competitive industry. In order to improve the success of commercial video games, some game companies have turned to using a variety of game evaluation methodologies to improve their game's design.

The most common form of game evaluation in the video game industry is called playtesting, which involves the players providing feedback about a game after they have played it for a period of time. However, meaningful results are difficult to obtain from a playtesting session without a properly constructed gaming questionnaire or scale. Thus, there is a need for a psychometrically validated, comprehensive, gaming scale that is appropriate for playtesting and game evaluation purposes.

Following the current best practices of scale development and validation, this research employed a mixed-methods design that consisted of a five-step plan to develop and validate a new satisfaction scale for gaming. As a result, a new instrument measuring video game satisfaction called the Game User Experience Satisfaction Scale (GUESS) with nine subscales emerged. In general, the GUESS was demonstrated to have good content validity and internal consistency, as well as satisfactory convergent and discriminant validity. Furthermore, the GUESS was developed and validated based on the assessments of over 450 unique video game titles across a number of popular genres (e.g., Role-Playing, Action Adventure). Thus, it can be applied across many types of video games in the industry. 


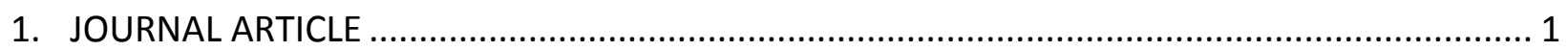

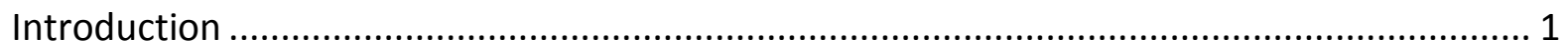

Usability Testing of Video Games.............................................................................. 2

Heuristic Evaluation of Video Games ......................................................................... 4

Playtesting and Gaming Scales/Questionnaires.......................................................... 5

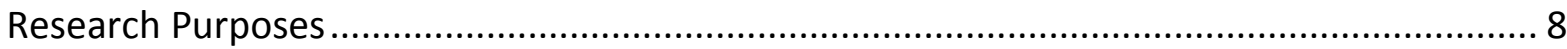

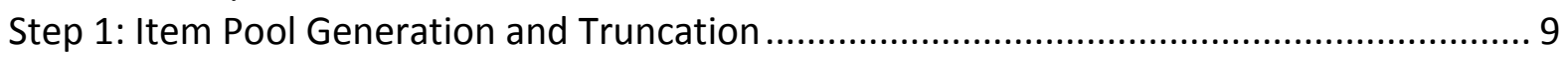

Steps 2 and 3: Expert Review of Item Pool and Questionnaire Pilot Study ......................... 12

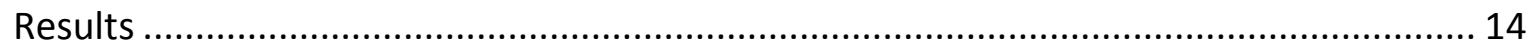

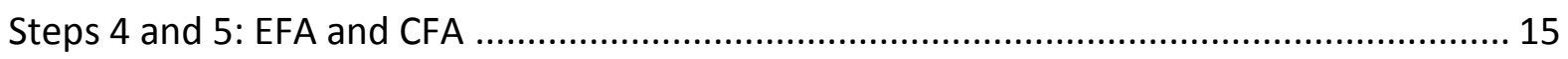

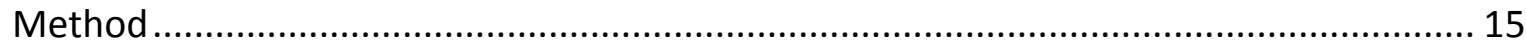

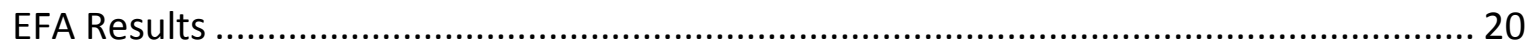

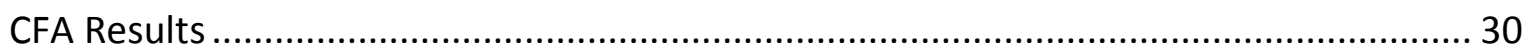

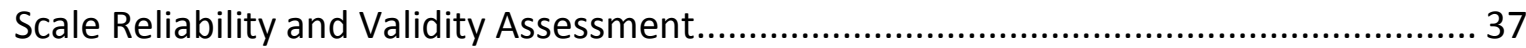

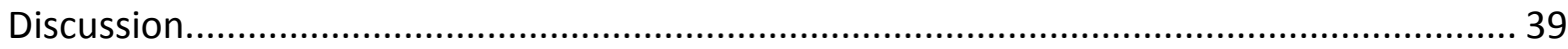

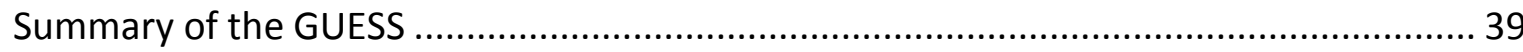

Practical Applications of the GUESS ....................................................................... 40

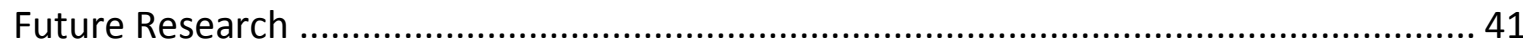

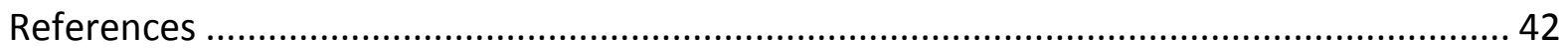

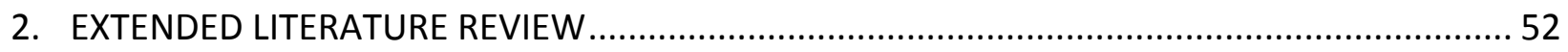

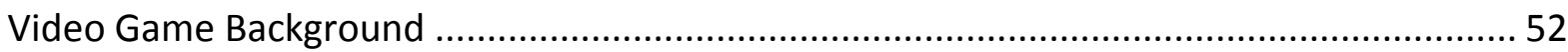

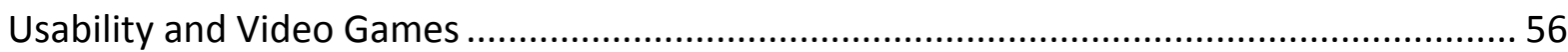

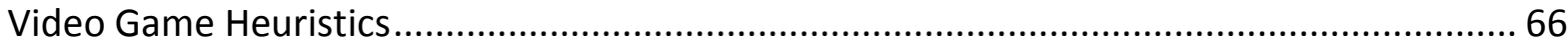

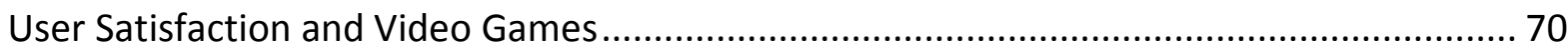

Theoretical Considerations in Measuring Video Game Satisfaction .................................... 74

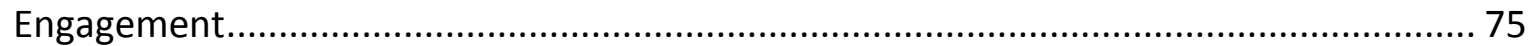

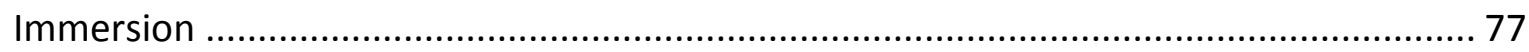

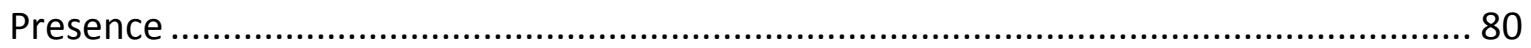

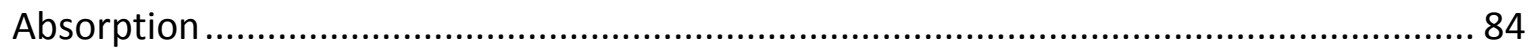

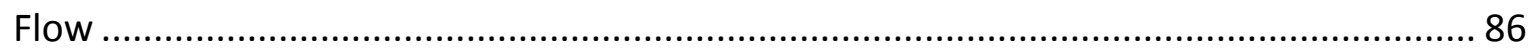

3. ITEM POOL GENERATION, EXPERT REVIEW, \& PILOT STUDY .............................................. 96

General Scale Design and Development Procedure ............................................................ 96

Step 1: Item Pool Generation ..................................................................................... 98

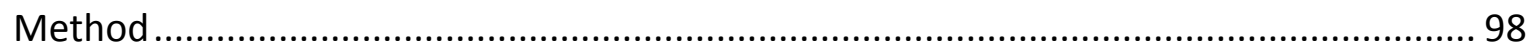




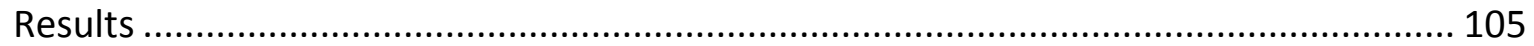

Step 2: Expert Review of Item Pool ............................................................................ 107

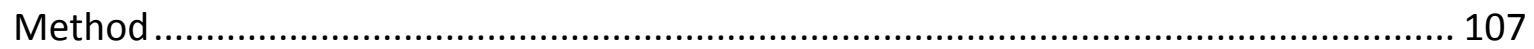

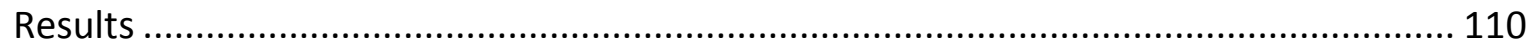

Step 3: Questionnaire Pilot Study ....................................................................... 111

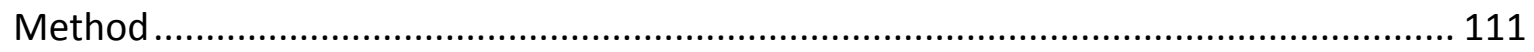

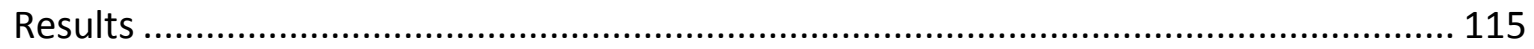

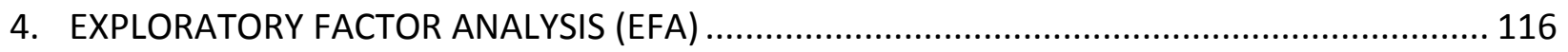

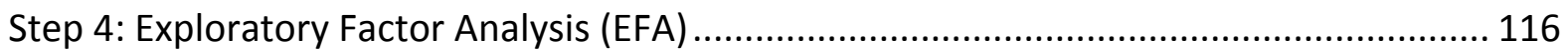

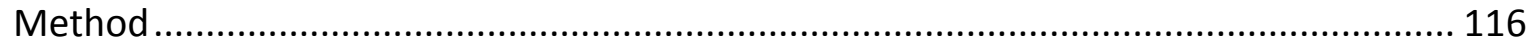

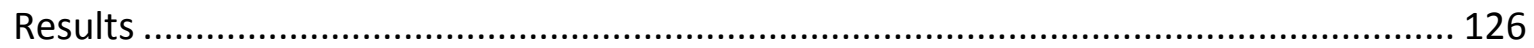

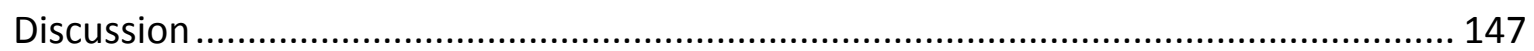

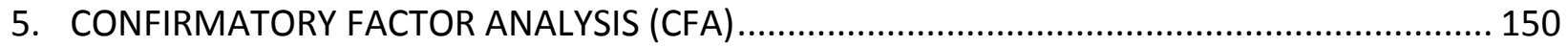

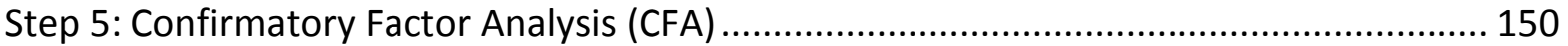

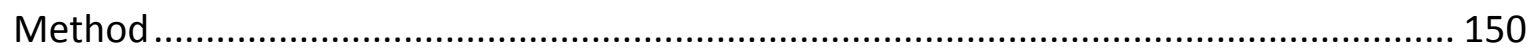

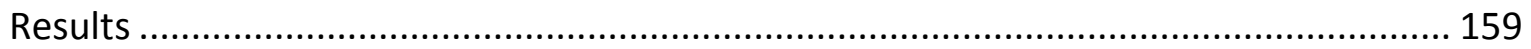

Scale Reliability and Validity Assessment......................................................... 181

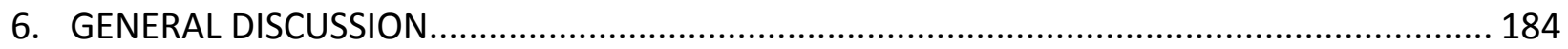

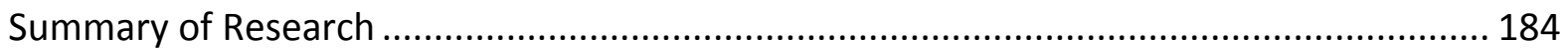

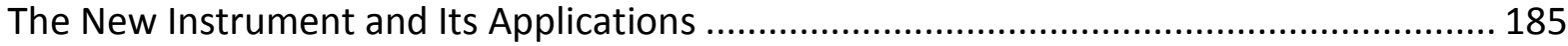

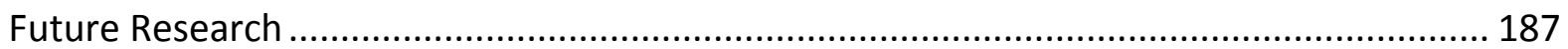

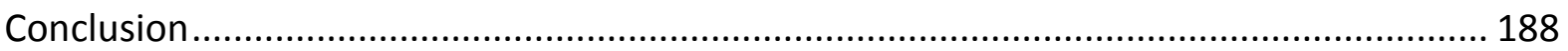

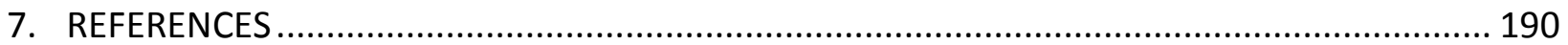

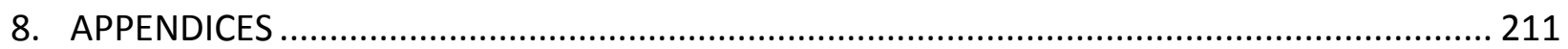

A. Strengths and Weaknesses of Existing Gaming Scales ........................................ 212

B. Chen and Colleagues' (2011) Paradigm of Engagement...................................... 220

C. Ermi and Mäyrä (2005) SCI Paradigm .............................................................. 221

D. Existing Questionnaires' Key Dimensions ......................................................... 222

E. Item Pool Used in the Expert Review Phase ......................................................... 230

F. Expert Review: Consent Form................................................................................. 240 


\section{TABLE OF CONTENTS (continued)}

Chapter Page

G. Instructions for the Selection of a Video Game to Evaluate ............................... 242

H. Questions about the Game under Evaluation .............................................. 243

I. Expert Review: A Screenshot of an Evaluation Page ............................................. 244

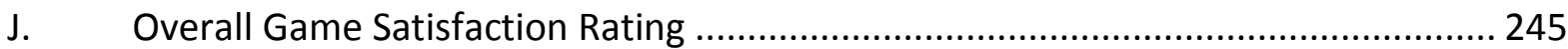

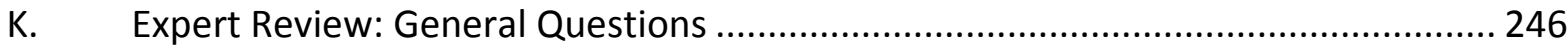

L. Expert Review: Demographics Questions ......................................................... 247

M. Revised Item Pool after Expert Review............................................................. 250

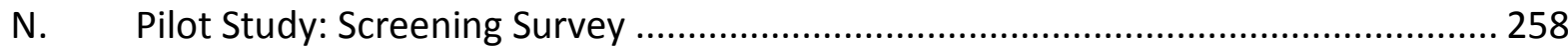

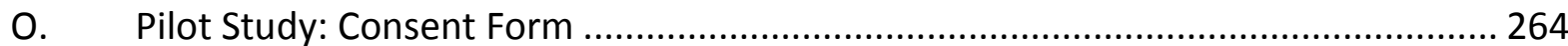

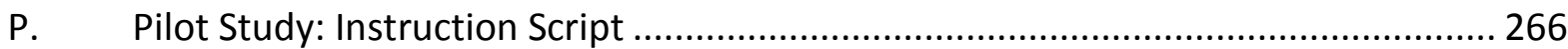

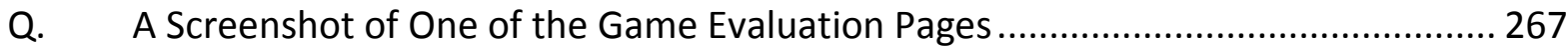

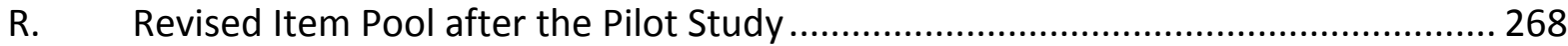

S. $\quad$ EFA Study: Unique Video Game Titles Evaluated ................................................. 274

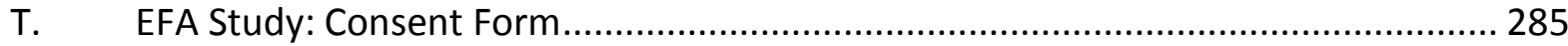

U. $\quad$ EFA and CFA Studies: Demographics Questions .............................................. 287

V. $\quad$ EFA Study: Skewess and Kurtosis Values of Items ............................................. 289

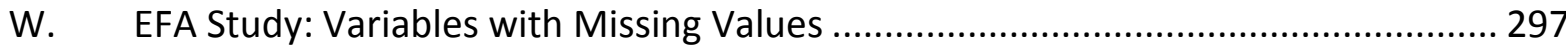

X. EFA Study: Item that Were Removed ............................................................... 301

Y. $\quad$ EFA Study: Pattern Matrix Loadings for the 9-Factor Solution................................ 303

Z. $\quad$ EFA Study: Structure Matrix Loadings for the 9-Factor Solution........................... 308

AA. CFA Study: Unique Video Game Titles Evaluated ................................................ 313

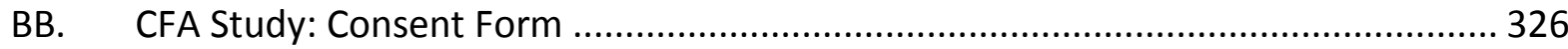

CC. CFA Study: Skewness and Kurtosis Values of Items........................................... 328

DD. CFA Study: List of All Variables with Missing Values ........................................... 332

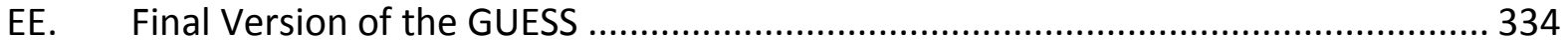




\section{LIST OF TABLES}

Table

Page

1. Overview of the Number of Items Derived from Each Source .................................... 11

2. Demographics of Participants in the EFA and CFA Studies........................................ 16

3. Overview of the Games Evaluated in the EFA and CFA Studies ................................. 18

4. Overview of the Genres Represented in the EFA and CFA Studies ............................ 19

5. 9-Factor Solution: Summary of Eigenvalues and Cronbach's Alpha............................. 26

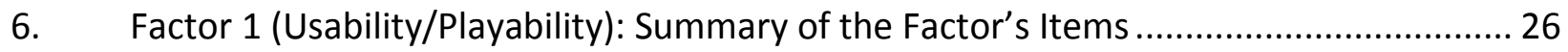

7. Factor 2 (Narratives): Summary of the Factor's Items ................................................. 27

8. Factor 3 (Play Engrossment): Summary of the Factor's Items .................................. 27

9. Factor 4 (Enjoyment): Summary of the Factor's Items ........................................... 28

10. Factor 5 (Creative Freedom): Summary of the Factor's Items. .................................... 28

11. Factor 6 (Audio Aesthetics): Summary of the Factor's Items ..................................... 28

12. Factor 7 (Personal Gratification): Summary of the Factor's Items .............................. 29

13. Factor 8 (Social Connectivity): Summary of the Factor's Items..................................... 29

14. Factor 9 (Visual Aesthetics): Summary of the Factor's Items ..................................... 29

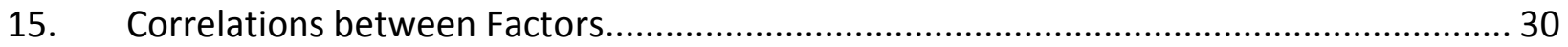

16. Guidelines for Overall Model Fit Assessment and Model Comparison .......................... 34

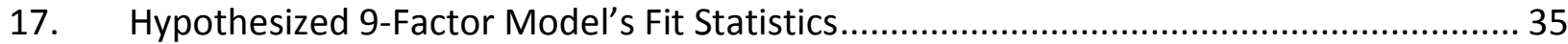

18. Comparison of Chi-square and CFI Fit Indices across Models ..................................... 37

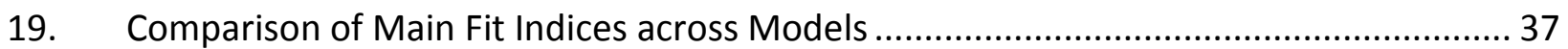




\section{LIST OF TABLES (continued)}

Table

Page

20. Comparison of Cronbach's Alpha across EFA and CFA Studies ................................... 38

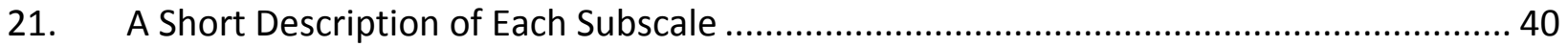

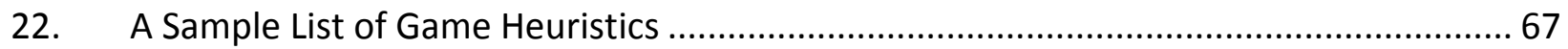

23. Witmer and Singer's (1998) Hypothesized Factors that Influence Presence .................. 82

24. Jone's (1998) Mapping of the Eight Elements of Flow to Computer Games ................. 91

25. Overview of the Questionnaires Used in the Item Pool Generation............................ 99

26. Overview of the Reviewed Game Heuristics for the Item Pool Generation................... 101

27. Overview of Number of Items Derived from Each Source ....................................... 105

28. Background Information of the Expert Panel .................................................... 108

29. Background Information of the Pilot Participants ................................................ 112

30. Demographics of Participants in the EFA Study ..................................................... 118

31. Overview of the Video Game Genres Represented in the EFA Study ........................ 123

32. EFA Study: Variables with Over $10 \%$ of Missing Values ...................................... 128

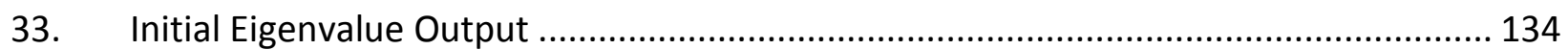

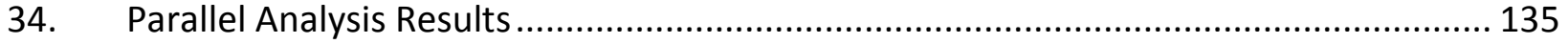

35. 9-Factor Solution: Summary of Eigenvalues and Cronbach's Alphas .......................... 139

36. Factor 1 (Usability/Playability): Summary of the Factor's Items ................................ 140

37. Factor 2 (Narratives): Summary of the Factor's Items ............................................. 141

38. Factor 3 (Play Engrossment): Summary of the Factor's Items .................................. 142 


\section{LIST OF TABLES (continued)}

Table

Page

39. Factor 4 (Enjoyment): Summary of the Factor's Items. 142

40. Factor 5 (Creative Freedom): Summary of the Factor's Items 143

41. Factor 6 (Audio Aesthetics): Summary of the Factor's Items 143

42. Factor 7 (Personal Gratification): Summary of the Factor's Items 144

43. Factor 8 (Social Connectivity): Summary of the Factor's Items 144

44. Factor 9 (Visual Aesthetics): Summary of the Factor's Items 145

45. Factor Correlations and Correlations with Overall Game Satisfaction ......................... 146

46. Demographics of Participants in the CFA Study ................................................. 152

47. Overview of the Video Games Genres Represented in the CFA Study ....................... 157

48. CFA Study: Variables with Over $10 \%$ of Missing Values ........................................... 161

49. Guidelines for Overall Model Fit Assessment and Model Comparison ......................... 166

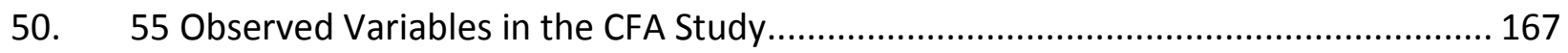

51. Hypothesized 9-Factor Model's Fit Statistics.................................................. 170

52. Unstandardized and Standardized Factor Loadings .......................................... 171

53. Covariances and Correlations between Factors …............................................. 173

54. Chi-square and CFI Fit Indices across Models ....................................................... 175

55. Main Fit Indices across models ......................................................................... 176

56. Cronbach's Alphas across EFA and CFA Studies .................................................. 182

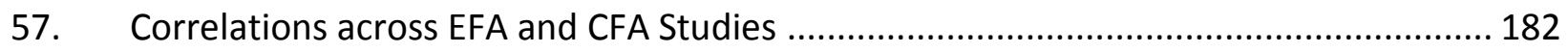




\section{LIST OF TABLES (continued)}

Table

Page

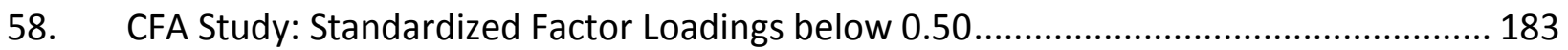




\section{LIST OF FIGURES}

Figure $\quad$ Page

1. The most widely accepted usability paradigm (ISO 9241-11; 1998) ............................ 58

2. Abran and colleagues' (2003) Enhanced Model of Usability......................................59

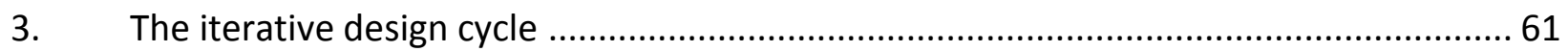

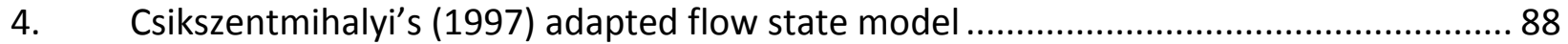

5. The adopted seven-point, unipolar scale with response anchors.............................. 97

6. Gaming devices participants reported to frequently use to play video games ............ 120

7. Game genres participants reported to frequently play............................................ 120

8. The last time participants reported to play the game they evaluated........................ 121

9. The total time participants spent playing the game they evaluated ......................... 122

10. The type of platform participants used to play the game they evaluated .................... 122

11. Participants' overall level of satisfaction with the game they evaluated..................... 124

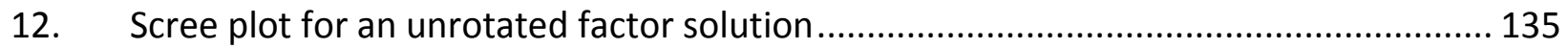

13. Gaming devices participants reported to frequently use to play video games ............ 153

14. Game genres participants reported to frequently play.......................................... 153

15. The last time participants reported to play the game they evaluated........................ 154

16. The total time participants spent playing the game they evaluated ........................... 155

17. The total time participants spent playing the game they evaluated ......................... 155

18. Participants' overall level of satisfaction with the game they evaluated..................... 158

19. A visual representation of the hypothesized 9 -factor model................................... 169 


\section{LIST OF FIGURES (continued)}

Figure

Page

20. A visual representation of the 9-factor (uncorrelated) model ................................ 177

21. A visual representation of the 8 -factor model ................................................. 178

22. A visual representation of the 7 -factor model ....................................................... 179

23. A visual representation of the 1 -factor model ...................................................... 180 


\section{CHAPTER 1}

\section{JOURNAL ARTICLE}

\section{Introduction}

Ever since Computer Space and Pong reached the mainstream in the 1970s, video games have become one of the most popular forms of digital entertainment in the world. The video game industry has grown extensively since then, and video game enthusiasts are no longer restricted to just a few game titles that can only be played on one device. In particular, there has been well over a thousand new video games released each year from a growing list of genres (e.g., Action, Role-Playing, Strategy) for the past 20 years (MobyGames, 2015). Moreover, these video games can be played on a multitude of platforms (e.g., personal computers, consoles, mobile phones).

With so many video games released each year and a variety of ways to play them, it is easy to see why video games are now appealing to a wider range of demographics rather than just the traditional teenage male audience of the past. This increasing popularity of video games has also helped the video game industry become a thriving, multi-billion dollar business. The Entertainment Software Association (ESA, 2014) reported that close to 60\% of Americans play video games, and over $\$ 21$ billion has been spent on the video game industry in the U.S. alone. Additionally, nearly $40 \%$ of gamers are over 35 years old, and almost half of video game players and purchasers are females. Finally, a leading information technology research company has predicted that the worldwide spending on video games will increase by $\$ 32$ billion between 2012 to 2015 (Gartner, 2013). 
As the demand for video games increases, game developers and designers are facing the difficult task of creating games that are not only enjoyable to play, but marketable in a highly competitive industry. The task of developing well-received games is further challenged by the different perspectives on the essential elements that constitute a "good game". Interviews with video game designers have revealed that they have different (often abstract) philosophies concerning quality game design (Aycock, 1992). Some game designers believe the main element of exceptional games is that they are fun while others believe the best games are the ones that are simple to play.

Yet, there remains a lack of consensus among video game aficionados in deciding what features are crucial to the construction of good or successful video games. Some believe that great games are those that offer many interesting decisions for the player to make (Shelley, 2001; Totilo, 2012). Some consider commercial or universal appeal and originality to be the key factors in the making of successful games (Chalker, 2008; Shelley, 2001; Totilo, 2012). Furthermore, other game-making professionals cited having attractive graphics, quality sound and music, accessible gameplay, and/or easy to understand game rules as the crucial building blocks of a highly satisfying game.

\section{Usability Testing of Video Games}

In an effort to create better games through more objective means, some game companies have looked at other fields like usability, user experience (UX), and psychology for guidance. The term usability as understood by the general public refers to the ease of use or the degree of user friendliness of a tool or product. However, to usability researchers and practitioners the term refers to a multi-dimensional concept comprising elements such as learnability, efficiency, 
user performance, and satisfaction (Abran, Khelifi, Suryn, \& Seffah, 2003; Hornbæk, 2006). One of the most popular methods frequently employed in the field of usability to evaluate a product or system is called usability testing. Usability testing typically involves bringing in potential users of the product or system and have them evaluate it as they performed a set of tasks.

One of the first companies to understand the importance of usability and research in game development was Microsoft. Since 1995, Microsoft has been one of the major companies that has begun to integrate usability into their game making division (Fulton, 2002). One novel way in which Microsoft has applied usability in the video game setting was to use the feedback obtained from usability sessions to test whether their first Halo game effectively delivered the experience it was designed to deliver (Pagulayan, Steury, Fulton, \& Romero, 2005). The results obtained from the usability sessions led to several design changes in the game, and the improvements made resulted in higher game satisfaction.

Aside from Microsoft, Disney has also taken initiatives to implement usability testing in their game development process. Usability testing was first conducted in the development of Pure (an off-road, trick-racing game) by Disney's Black Rock Studio (McAllister \& White, 2010). After its release, Pure was well received by the game critics. The Game Director, Jason Avent, attributed the game's success to both his talented team and the usability tests that were conducted during the game development. Avent further added that the usability evaluations were crucial in identifying major issues within the game, as well as helping to improve the Metacritic review score from $75 \%$ to $85 \%$.

Outside of Microsoft and Disney, researchers have also demonstrated that usability methods (e.g., usability testing and think-aloud protocol) were useful in detecting both minor 
and major issues found in popular massively multiplayer online role-playing games (MMORPGs;

Cornett, 2004; Song, Lee, \& Hwang, 2007). Based on the task completion rate and subjective comments, Cornett (2004) was able to pinpoint 17 usability issues in four popular MMORPGs (i.e., EverQuest, Anarchy Online, Dark Age of Camelot, and Neverwinter Nights). Of the 17 issues, 11 were identified as critical and major gaming issues that could cause players to stop playing and seek assistance or slow game progress. Song et al. (2007) employed a similar methodology and uncovered 18 critical issues in World of Warcraft (WOW). Notably, the issues found in these games were deemed to be detrimental to newcomers of the genre and the overall recruitment of new players to the genre (Cornett, 2004; Song et al., 2007).

\section{Heuristic Evaluation of Video Games}

In addition to usability testing, some game companies have relied on another form of video game evaluation called heuristic evaluation or expert review. Whereas usability testing mainly involves players providing feedback as they play the game, heuristic evaluation typically involves one to three trained evaluators using a design checklist and scrutinizes whether the game has followed all of the criteria in the checklist. In recent years, conducting a heuristic evaluation on a video game has become more feasible as the number of video game heuristics between different genres has grown. Specifically, researchers have developed separate lists of heuristics for mobile (Korhonen \& Koivisto, 2006), mobile multi-player (Korhonen \& Koivisto, 2007), networked multiplayer (Pinelle, Wong, Stach, \& Gutwin, 2009), real-time strategy (RTS; Sweetser, Johnson, \& Wyeth, 2012; Sweetser \& Wyeth, 2005), health/fitness (Papaloukas, Patriarcheas, \& Xenos, 2009), social (Paavilainen, 2010; Papaloukas et al., 2009), instructional (Tan, Goh, Ang, \& Huan, 2010), and educational (Omar \& Jaafar, 2010) games. 
In general, there are a number of positive aspects about heuristic evaluation that might make it more appealing to conduct than usability testing. First, heuristic evaluation is considered to be helpful in identifying the quick and major fixes (Stafford, Preisz, \& Greenwood-Ericksen, 2010). Second, heuristic evaluation is often less costly than usability testing because it involves fewer people and resources (most heuristics are freely available online). Third, with the existence of various lists of game heuristics it has lessened the difficulty in evaluating a video game of a particular genre.

Despite the benefits of conducting heuristic evaluation, some researchers have cautioned about the potential issues of using the game heuristics for game design and evaluation purposes (Stafford et al., 2010; White, Mirza-Babaei, McAllister, \& Good, 2011). For example, heuristics can be difficult to apply effectively without prior training or experience. Heuristic evaluation can suffer from the problem of evaluator's bias and yield unfruitful results when the people who are creating the game are doing the evaluations. In addition, with a lack of response options and the ambiguity of some of the heuristics it can be difficult for evaluators to determine whether particular guidelines have been correctly implemented in a game or not (Stafford et al., 2010). Lastly, there is the issue of a lack of agreement among evaluators when they used the same game heuristics (White et al., 2011).

\section{Playtesting and Gaming Scales/Questionnaires}

Aside from usability testing and heuristic evaluation, another common method of assessing video games in the industry is called playtesting. Traditional playtesting is much like traditional usability testing in the sense that players are brought in a lab space to play a game and provide feedback (Collins, 1997; Fulton, 2002). However, usability testing is typically more structured 
than playtesting with specific tasks (e.g., adjust camera angle, open the mini-map), measures (e.g., time on task, error rates), and procedures (e.g., think-aloud protocol) clearly defined. In playtesting, the one defined measure is usually a questionnaire administered at the end of the session to obtain the player's feedback about the game.

Results obtained from playtesting sessions can help game developers build better games by providing insights into the players' attitudes, preferences, and behaviors. Playtesting results also let game companies know whether their games were played as intended. Additionally, feedback gathered from playtesting sessions tended to carry more weight with game developers and designers since it came directly from the target population. However, gathering quality feedback from participants is imperative in the process of extracting meaningful results from playtesting sessions. Consequently, the type and quality of gaming questionnaire used is an important criterion in any playtesting sessions.

Currently, there is a growing number of questionnaires or scales in the video game literature such as the Gameplay Experience Questionnaire (Ermi \& Mäyrä, 2005), the Game Experience Questionnaire (IJsselsteijn, de Kort, \& Poels, 2008), and the Play Experience Scale (Pavlas, Jentsch, Salas, Fiore, \& Sims, 2012). However, the majority of the questionnaires are not suitable for playtesting purposes for a number of reasons. First, most strictly focus on a particular aspect of the video game experience (e.g., play, social presence) while others neglect other important gaming dimensions (e.g., usability, social interaction). Also, the majority of the existing questionnaires are based on a limited number of video game titles or genres (e.g., educational). In addition, some of the questionnaires have not been validated, or the details of how the questionnaires were developed and validated have not been made publically available. 
Moreover, many of the questionnaires were developed primarily for academic research purposes, and thus, do not translate well to game evaluation usage in the industry settings. Specifically, some of the questionnaires contain items that are awkwardly phrased (e.g., "I lost myself into pondering the puzzles and mental challenges of the game."), difficult to understand (e.g., "I feel viscerally involved in the game."), or less applicable outside of the academic settings (e.g., "I felt like I had to do well, or the experimenter would judge me."). Lastly, similar to other fields of study (e.g., usability) there is a lack of scientific rigor in the development and validation of the existing questionnaires or scales in the video game domain.

Despite the many research articles that offer "best practices" for scale development and validation (e.g., Cabrera-Nguyen, 2010; Hinkin, 1998; Worthington \& Whittaker, 2006), the majority of game researchers do not follow these guidelines during the scale development process. For instance, factor analysis is considered to be one of the best methods for scale development and validation, with experts strongly advising all new scales undergo an exploratory factor analysis followed by confirmatory factor analysis. Nevertheless, very few researchers adopt this practice when creating new gaming scales. Additionally, both EFA and CFA are complex and iterative procedures that require clear justification and documentation for each major analytic decision (e.g., which extraction method and why). Again, very few researchers abide by these guidelines when developing their gaming scale or questionnaire. Altogether, this lack of adherence to the best practices of scale development can severely threaten the reliability and validity of existing questionnaires in the field. 


\section{Research Purposes}

There is a need for a psychometrically validated, comprehensive, gaming scale that is appropriate for playtesting and game evaluation purposes. Thus, the purpose of this research is two-fold: 1) to uncover the crucial factors that contribute to a satisfying gaming experience across many video games and genres and 2) to develop and validate a new instrument that comprehensively measures video game satisfaction based on these key factors. Similar to how "satisfaction" is defined in the UX field (Albert \& Tullis, 2013), for the purpose of this research video game satisfaction will be defined as the degree to which the player feels gratified with his or her experience while playing a video game.

In order to enhance the quality of the new instrument, the process of developing and validating this new scale closely followed current best practices of scale development and validation. As a result, a mixed-methods design was used in the construction and validation of the new scale consisting of the following five steps:

1. Item Pool Generation: Multiple resources (e.g., past established scale and heuristics) were drawn upon to generate an item pool for the scale.

2. Expert Review of Item Pool: The item pool was presented to a panel of eight experts with expertise in video games and/or questionnaire design.

3. Questionnaire Pilot Study: The scale was piloted with 16 participants from four groups of self-identified gamers (i.e., Newbie/Novice, Casual, Mid-core/Core, and Hardcore/Expert). 
4. Exploratory Factor Analysis (EFA): The questionnaire was distributed to different gamers in an online survey $(N=629)$. EFA was performed to identify the underlying factors and reduce the number of items on the scale.

5. Confirmatory Factor Analysis (CFA): Another independent sample of video game players $(N=771)$ were surveyed using the revised scale from the EFA. Additionally, CFA was conducted to further validate the scale.

\section{Step 1: Item Pool Generation and Truncation}

The literature has indicated that there many are many elements (e.g., aesthetics, usability, and freedom) that contribute to video game enjoyment and satisfaction. However, these elements have been scattered across an array of research concerning different aspects of video games (e.g., engagement, flow, and play). As a result, the first step in developing a comprehensive measure of video game satisfaction is to consult existing research concerning video game experience and satisfaction.

Specifically, 13 existing questionnaires that measure important constructs related to the gaming experience (e.g., cognitive absorption, immersion, and enjoyment) were consulted in the generation of potential items for the new scale. Additionally, 15 lists of game heuristics covering a variety of genres were also examined in the process of generating the item pool. Finally, three popular user satisfaction questionnaires that have been freely available in the $\mathrm{HCl}$ domain were also consulted during the process. The three satisfaction questionnaires are the: System Usability Scale (SUS; Brooke, 1996), Questionnaire for User Interface Satisfaction (QUIS; Chin et al., 1988), and Computer System Usability Questionnaire (CSUQ; Lewis, 1995). These questionnaire and game heuristics were selected mainly because they were available at the 
time the item pool generation was conducted. In total, these different sources provided an extensive pool containing approximately 875 possible items.

After the initial item pool had been generated, the item pool underwent an iterative series of modification and refinement. First, all items were individually screened for redundancy and any items that were similarly phrased (e.g., "I enjoyed the game." and "I liked the game.") were reduced to a single item. Any items that were considered to be too vague (e.g., "I feel different.") or genre-specific (e.g., "I want to know more about the knowledge taught.") were removed from the pool. Furthermore, any items that were deemed as not contributing to the overall assessment of video game design or the gaming experience were also deleted (e.g., "I am familiar with the cultural background."). All in all, the pool was continually examined for multiple rounds to ascertain that each item had unique contribution and was relevant to the evaluation of video game satisfaction.

Items in the pool also underwent several phases of inspection to ensure that all items were adequately worded. Any items that were too long, awkwardly phrased, or difficult to understand were modified or eliminated. The items were also reviewed to ensure that there was variety in the content, that different game elements (e.g., graphics, sound) were well represented, and items were applicable across many genres (e.g., Fighting, Strategy). New items were also created in cases where the researchers felt an important aspect or feature of video games was missing from the item pool. At the end of the iterative process of modification and refinement, 116 items were retained for the expert review phase. The items were obtained from 29 unique sources, half of which were from the aforementioned questionnaires while the remaining were from lists of game heuristics. Additionally, nine items were created by the 
researchers in this study. Table 1 presents an overview of the number of items derived from

each source.

Table 1. Overview of the Number of Items Derived from Each Source.

\begin{tabular}{llc}
\hline Source & Name of Questionnaire/List of Heuristics & \# of Items \\
\hline Agarwal \& Karahanna (2000) & Cognitive Absorption Scale & 12 \\
Brockmyer et al. (2009) & Game Engagement Questionnaire & 4 \\
Brooke (1996) & System Usability Scale & 1 \\
Calvillo-Gámez, Cairns, \& Cox & Core Elements of the Gaming Experience & 17 \\
(2010) & Questionnaire & \\
Chen et al. (2005) & Gaming Engagement Questionnaire & 5 \\
Chin et al. (1988) & Questionnaire for User Interface Satisfaction & 1 \\
Choi \& Kim (2004) & Online Game Experience Questionnaire* & 5 \\
Clanton (1998) & Computer Game Design Principles & 1 \\
Desurvire, Caplan, \& Toth & Heuristics for Evaluating Playability & 16 \\
(2004) & & \\
Desurvire \& Wiberg (2009) & Game Playability Principles & 15 \\
Ermi \& Mäyrä (2005) & Gameplay Experience Questionnaire & 7 \\
Federoff (2002) & Game Heuristics & 8 \\
Fu, Su, \& Yu (2009) & EGameFlow & 10 \\
IJsselsteijn et al. (2008) & Game Experience Questionnaire & 10 \\
Jennett et al. (2008) & Immersion Questionnaire & 9 \\
Korhonen \& Koivisto (2006) & Playability Heuristics for Mobile Games & 7 \\
Lewis (1995) & Computer System Usability Questionnaire & 3 \\
Omar \& Jaafar (2010) & Heuristics Evaluation for Educational Games & 1 \\
Paavilainen (2010) & Heuristics for Social Games & 3 \\
Papaloukas et al. (2009) & Heuristics for New Genre Games & 3 \\
Parnell (2009) & Gameplay Scale & 10 \\
Pavlas et al. (2012) & Play Experience Scale & 3 \\
Pinelle, Wong, \& Stach (2008) & Game Usability Heuristics & 4 \\
Qin, Rau, \& Salvendy (2009) & Player Immersion in Computer Game Narrative & 6 \\
Sweetser \& Wyeth (2005) & Questionnaire & \\
Sweetser et al. (2012) & GameFlow & 5 \\
Tan et al. (2010) & GameFlow & 5 \\
Witmer \& Singer (1998) & Instructional Game Evaluation Framework & 7 \\
Current research & Presence Questionnaire & 4 \\
\hline
\end{tabular}

*The questionnaire was not formally named. Thus, for the sake of identification a generic name was chosen.

Note. Some of the items were derived from multiple sources. 


\section{Steps 2 and 3: Expert Review of Item Pool and Questionnaire Pilot Study}

One important measure of a quality scale is content validity (Hinkin, 1995; 1998; Jensen, 2003; Worthington \& Whittaker, 2006). A common method to measure content validity is to have experts examine the pool of items before administering the questionnaire to a large population (Cabrera-Nguyen, 2010; Jensen, 2003).

Participants. Eight participants from two groups of experts were involved in the review of the item pool. The first group consisted of four evaluators who had previous experience with questionnaire design and development. The second group consisted of three experienced gamers who had diverse experience in playing different types of games (e.g., Fighting, Sports) on various gaming platforms (e.g., mobile, console), and had been playing video games for at least 15 years. One participant was both a scale/questionnaire and a video game expert. Two of the scale/questionnaire experts worked as research managers in a reputable video game company. In addition, two of the video game experts have been involved in the business of buying and selling games for over three years.

After the expert review phase, 16 face-to-face pilot sessions were conducted among four self-identified groups of gamers (i.e., newbie/novice, casual, core/mid-core, and hardcore/expert). There were equal number of gamers from each group (Mean Age $=23.13$ years old; $S D=6.86)$. Half of the gamers $(n=8)$ recruited for the pilot study were females, and nine of the gamers were non-native English speakers. This specific group of gamers were purposely selected to ensure that all items on the questionnaire could easily be understood by a wide range of gamers with different gaming backgrounds and experience, including English as 
a Second Language (ESL) gamers. Pilot participants were recruited from an existing pool of people who had completed a general gaming survey.

Materials. Qualtrics ${ }^{\circledR}$, an online survey tool, was used to create the questionnaire and capture the questionnaire responses. The online questionnaire contained demographic questions and a series of statements from the revised item pool on a seven-point, unipolar scale with response anchors ( 1 = Strongly Disagree; $7=$ Strongly Agree; Vagias, 2006). At the end of the scale was an "N/A" option for instances in which a statement does not apply to a particular video game. Procedure. After reading the study's consent form, participants were first asked to enter the title of the video game that they want to evaluate. Before the evaluation process, participants were asked to provide some basic information about the video game (e.g., the platform they used to play the game). Participants then proceeded to the game evaluation phase where they were asked to indicate their level of agreement with each statement about the game on the seven-point Likert scale. To minimize scrolling, the series of statements were divided and randomized into a set of about five statements per page.

In general, participants were informed that the purpose of the study was to gather their feedback to improve the design of the survey. The expert review phase was conducted online as well as with all experts leaving their comments and suggestions via the questionnaire. In particular, the experts were asked to scrutinize each statement and identify any problematic statements in terms of wording issues and perceived relevancy to video game satisfaction, along with suggestions for improvements on each of the evaluation pages. Near the end of the survey, final comments about the entire questionnaire and basic demographics information were gathered. The entire questionnaire took about 60-90 minutes to complete in the expert 
review phase and participants were offered a \$30 Amazon gift card upon the completion of the survey.

In contrast to the expert review phase, the pilot study was conducted in person and participants were instructed to "think-aloud" when they encountered particular words or statements that were difficult to interpret. After completing the online questionnaire, participants were presented with a paper copy of the survey in which they were asked to revisit problematic items and clarify why they were problematic, as well as offer suggestions for improvements. Participants were also asked to provide final comments about the questionnaire and their thoughts about its adequacy in measuring video game satisfaction. Each of the pilot sessions took approximately 25-35 minutes, and participants were awarded course credit for their participation.

\section{Results}

In general, participants from both studies commented that there was a good representation of different video game elements among the items and the item pool was comprehensive in measuring game satisfaction. However, there were some statements that needed to be revised because they were grammatically complex or contained unclear wordings. Additionally, some items were removed from the pool because they were deemed to be too similar with another item in the pool or too abstract to comprehend. Comments and suggestions gathered from both studies helped improve the comprehension of the game statements and reduced the list of statements from 116 to 100 . 


\section{Steps 4 and 5: EFA and CFA}

\section{Method}

After the survey links were closed, a total of 1465 surveys were collected in the EFA study and 1317 in the CFA study. During the screening and cleaning process $57.1 \%(n=836)$ of the surveys in the EFA study and $41.5 \%(n=546)$ in the CFA study were identified as containing non-valid responses. Non-valid responses generally consisted of participants who did not follow the instructions on the questionnaire (e.g., evaluated more than one video game in a single submission, submitted multiple submissions). Submitted surveys were also removed from further analyses if they did not meet one of the pre-established criteria: 1) completed in less than 10 minutes (for EFA study) and 5 minutes (for CFA study), 2) the game evaluated had not been played in the last three months, and 3) the game evaluated had less than 10 hours of play. These criteria were set to prevent low-quality responses, and to ensure participants had adequate experience and knowledge with the game they evaluated. Finally, any surveys that were identified to be from the same participant in the EFA study were removed from the CFA study to ensure two independent samples were collected.

Participants. Table 2 provides a summary of participants' demographics for both studies. A total of 629 and 771 valid questionnaires were retained for the EFA and CFA final analyses, respectively. Survey respondents in both studies were similar in demographics. Particularly, the average age of participants was around 25 years old, and the majority of participants had at least some college education. Participants in both studies tended to identify themselves either as a "Casual" or "Mid-core/Core" video game players. On average, participants reported 
spending at least five hours per week playing video games. Additionally, respondents in both studies had various occupations such as students, teachers, engineers, and designers.

Table 2. Demographics of Participants in the EFA $(N=629)$ and CFA $(N=771)$ Studies.

\begin{tabular}{lcc}
\hline Variable & EFA Value & CFA Value \\
\hline Mean Age in years (SD) & $24.61(7.18)$ & $25.87(7.97)$ \\
Age Range & $18-61$ & $18-60$ \\
Gender (\%) & & \\
Male & 58.0 & 62.6 \\
$\quad$ Female & 42.0 & 37.4 \\
Ethnicity (\%) & & \\
$\quad$ American Indian/Alaskan Native & 1.4 & 2.7 \\
Asian/Pacific Islander & 13.5 & 11.5 \\
Black/African American & 5.6 & 3.2 \\
Hispanic/Latino & 8.7 & 5.8 \\
White (not of Hispanic origin) & 63.4 & 70.6 \\
Biracial/Multiracial/Mixed & 4.9 & 2.9 \\
I do not wish to answer. & 2.4 & 3.2 \\
Education Level (\%) & & \\
Some high school & 3.2 & 2.1 \\
High school graduate or GED & 14.0 & 10.0 \\
Some college & 49.1 & 46.2 \\
College graduate (2- and 4-year degree) & 27.0 & 33.9 \\
Post-graduate degree (MA, PhD, Law, or Medical) & 6.7 & 7.9 \\
Type of Video Game Player (\%) & & \\
Newbie/Novice & 6.5 & 5.8 \\
Casual & 39.9 & 36.3 \\
Mid-core/Core & 38.3 & 38.9 \\
Hardcore/Expert & 15.3 & 18.9 \\
Mean Hours Spent Playing Game per Week (\%) & & \\
Less than 1 hour & 6.7 & 6.0 \\
1 to 4 hours & 22.3 & 22.6 \\
5 to 9 hours & 24.0 & 23.7 \\
10 to 19 hours & 23.4 & 23.9 \\
20 to 29 hours & 14.8 & 14.8 \\
30 to 39 hours & 2.9 & 3.6 \\
More than 40 hours & 6.0 & 5.4 \\
\hline
\end{tabular}


Video Games. The majority of the video games participants chose to evaluate were games played within last month. In addition, many participants reported spending at least 20 hours playing the video game that they had evaluated. The majority of video games selected were either played on a computer device (e.g., laptop, desktop) or a console device (e.g., Xbox 360, Nintendo Wii). Given the pre-established criteria for data retention (i.e., played within the last three months and for at least 10 hours), it was expected that many of the video games evaluated in both studies would be games which participants liked rather than disliked. The mean ratings for overall game satisfaction ( 1 = Extremely Dissatisfied; 7 = Extremely Satisfied) confirmed prior expectations with the majority of participants choosing to evaluate a video game they liked $\left(M_{\mathrm{EFA}}=6.33, S D_{\mathrm{EFA}}=0.85 ; M_{\mathrm{CFA}}=6.38, S D_{\mathrm{CFA}}=0.76\right)$. Table 3 provides a summary of the video games evaluated in the EFA and CFA studies. 
Table 3. Overview of the Games Evaluated in the EFA $(N=629)$ and CFA $(N=771)$ Studies.

\begin{tabular}{|c|c|c|}
\hline Variable & EFA \% & CFA \% \\
\hline \multicolumn{3}{|l|}{ Last Time Played } \\
\hline Today & 25.4 & 25.7 \\
\hline Yesterday & 25.9 & 31.6 \\
\hline Last week & 30.0 & 27.4 \\
\hline Last month & 14.3 & 11.7 \\
\hline About 2-3 months ago & 4.3 & 3.6 \\
\hline \multicolumn{3}{|l|}{ Total Time Spent Playing } \\
\hline 10 to 19 hours & 14.8 & 13.2 \\
\hline 20 to 39 hours & 21.0 & 20.0 \\
\hline 40 to 79 hours & 20.8 & 19.1 \\
\hline 80 to 120 hours & 12.1 & 10.9 \\
\hline More than 120 hours & 31.3 & 36.8 \\
\hline \multicolumn{3}{|l|}{ Gaming Device Used } \\
\hline A computer device (e.g., laptop, desktop) & 36.6 & 42.5 \\
\hline A console device (e.g., Xbox 360, Nintendo Wii) & 48.5 & 41.1 \\
\hline A handheld gaming device (e.g., Game Boy Advance) & 5.1 & 4.0 \\
\hline A mobile device (e.g., smartphone, tablet) & 9.4 & 12.3 \\
\hline Other (e.g., Arcade) & 0.5 & 0.0 \\
\hline \multicolumn{3}{|l|}{ Overall Satisfaction Level } \\
\hline Extremely Dissatisfied & 0.5 & 0.3 \\
\hline Dissatisfied & 0.3 & 0.4 \\
\hline Somewhat Dissatisfied & 0.8 & 0.3 \\
\hline Neither Satisfied nor Dissatisfied & 1.3 & 1.0 \\
\hline Somewhat Satisfied & 6.2 & 4.7 \\
\hline Satisfied & 43.6 & 44.9 \\
\hline Extremely Satisfied & 47.4 & 48.5 \\
\hline
\end{tabular}

In both studies, approximately $40 \%$ of the games evaluated were from unique video game titles. Approximately $66 \%$ of the 312 game titles evaluated in the CFA study were not evaluated in the EFA study. Overall, the video games evaluated in both studies covered a variety of popular genres (e.g., Action, Sports, and Simulation). Table 4 presents an overview of all of the video game genres. 
Table 4. Overview of the Genres Represented in the EFA $(N=629)$ and CFA Studies $(N=771)$.

\begin{tabular}{lcc}
\hline Main Genre & EFA \% & CFA \% \\
\hline Action (e.g., Destiny, New Super Mario Bros. Wii, Dynasty Warriors 6) & 26.1 & 24.8 \\
Action Adventure (e.g., Minecraft, Grand Theft Auto V, The Last of Us) & 17.2 & 16.0 \\
Driving/Racing (e.g., Mario Kart Wii, Forza Horizon 2, Gran Turismo) & 3.3 & 3.2 \\
Fighting (e.g., Super Smash Bros. for Wii U, Skullgirls, Mortal Kombat) & 2.4 & 0.9 \\
Music/Dance (e.g., Guitar Hero, Taiko Drum Master, Just Dance 2015) & 1.7 & 0.6 \\
Puzzle/Card/Board (e.g., Candy Crush Saga, Words With Friends, Tetris) & 5.6 & 4.7 \\
Role-Playing (e.g., World of Warcraft, Dark Souls, Pokemon X) & 20.5 & 20.4 \\
Simulation (e.g., The Sims 3, Space Engineers, Tropico 5) & 4.9 & 4.2 \\
Sports (e.g., NBA 2K15, FIFA 15, SSX) & 6.7 & 6.1 \\
Strategy (e.g., DotA 2, Sid Meier's Civilization V, League of Legends) & 11.0 & 16.6 \\
Trivia/Game Show (e.g., Trivia Crack, QuizUp, You Don't Know Jack) & 0.0 & 1.9 \\
Other (e.g., Wii Fit, Mario Party, Clicker Heroes) & 0.6 & 0.6 \\
\hline
\end{tabular}

Note. Each video game title was categorized under one main genre. Various popular gaming websites (e.g., GameFaqs.com, Metacritic.com, and IGN.com) were consulted during the game genre classification process.

Materials. Qualtrics ${ }^{\circledR}$ Online Survey Software was used to create the questionnaire for the EFA and CFA studies. The questionnaire contained the following sections:

1. Consent form

2. Title of the game under evaluation (participants entered the name in a text field)

3. Basic questions about the game (e.g., "When was the last time you played this game?")

4. Game evaluation statements

a. The series of statements were randomized and displayed five statements per page to minimize scrolling

b. Each statement was evaluated on a seven-point Likert scale ( 1 = Strongly Disagree; 7 = Strongly Agree; "N/A" option at the end of the scale)

5. Overall satisfaction rating ( 1 = Extremely Dissatisfied; 7 = Extremely Satisfied)

6. Basic demographic questions (e.g., age, gender) 
Procedure. Information about the study and the survey link were shared with a portion of students at a Midwestern university via an online research participation system and Qualtrics Panels. Links to the study were also shared on various popular social networking, Internet, and gaming websites (e.g., Facebook, Reddit.com, GameFaqs.com). The survey links were open for 52 days in the EFA study and 40 days in the CFA study. All participants who completed the survey and left their contact information were eligible to receive a $\$ 50$ Amazon gift card. The EFA and CFA studies raffled 10 and 20 gift cards, respectively. Participants were informed that their contact information would be used only for the purpose of selecting gift card winners.

\section{EFA Results}

IBM SPSS Statistics 22 and Microsoft Excel 2013 were used to analyze the data. Normality. Visual assessment of the histograms and results of the Shapiro-Wilk tests revealed that the majority of the items had a negatively skewed distribution, which is consistent with participants' overall level of satisfaction with the game they evaluated. The majority of the data was considered moderately skewed (i.e., skewness $<|2|$ and kurtosis $<7$; Finney \& DiStefano, 2013). Due to the exploratory nature of this study, the data was not transformed.

Untransformed data allowed for easier interpretations of the results. Additionally, researchers have noted that, in practice, factor analysis is often conducted on severely skewed and kurtotic data (Muthén \& Kaplan, 1985; Wang, Fan, \& Willson, 1996). Moreover, Norris and Aroian (2004) have demonstrated that, in relation to Cronbach's alpha $(\alpha)$ and Pearson productmoment correlation, data transformations are not always desirable when item responses are skewed. 
Missing Data. "N/A" responses were treated as missing values. In total, there was about 3.1\% of the data missing, which has been deemed as inconsequential (Bennett, 2001; Peng, Harwell, Liou, \& Ehman, 2006; Schafer, 1999). Results of Little's MCAR test $\left[\chi^{2}(26826, N=629)=\right.$ $30,195.76, p<.05]$ suggested that the data was not missing completely at random. The missing data issue appeared to affect many variables and cases. Approximately $94.0 \%$ of variables ( $n=$ $94)$ and $56.8 \%$ of cases $(n=357)$ contained at least one missing value. The percentage of missing values for each variable or item ranges from $0.2 \%$ to $18.1 \%$. Since all of the variables contained less than $20 \%$ of missing values none was removed from the initial stage of data analyses.

Several traditional missing data techniques (e.g., listwise deletion, mean substitution) were considered for handling missing values. The final decision was to use the Expectation Maximization (EM; Dempster, Laird, \& Rubin, 1977) method via SPSS Missing Value Analysis (MVA) add-on module to replace the missing values. The EM method has been considered to be most appropriate for non-hypothesis testing analyses such as EFA and internal consistency calculations (Enders, 2003; Schlomer, Bauman, \& Card, 2010). Experts tended to agree that the EM method is superior to traditional missing data techniques (Enders, 2003; Fox-Wasylyshyn \& El-Masri, 2005; Graham, 2009; Musil, Warner, Yobas, \& Jones, 2002), and that this method outperformed other methods (e.g., iterative stochastic regression imputation) under non-ideal conditions (e.g., non-normally distributed data; Gold \& Bentler, 2000). Experts also are likely to recommend using maximum-likelihood-based methods (e.g., EM) over other traditional methods when data is not missing completely at random and when dealing with over $10 \%$ of missing data (Roth, 1994; Tsikriktsis, 2005). 
Factorability. Multiple criteria were used to determine the factorability of the data. In terms of the adequacy of the sample size, experts tended to agree that having a sample size of at least 300 cases is desirable for factor analysis (Tabachnick \& Fidell, 2007; Worthington \& Whittaker, 2006). Kass and Tinsley (1979) stated that test parameters tend to be stable once sample size reaches 300 participants regardless of the case-to-item or participant-to-variable ratio. Moreover, according to Comrey and Lee's (1992) sample size classification, this study's sample size $(N=629)$ falls in the "very good" range.

In addition to the sample size, the correlation matrix between the items was inspected to determine the appropriateness of using factor analysis. The majority of the items have intercorrelations above $|0.30|$, and were deemed suitable for factor analysis (Field, 2009; Tabachnick \& Fidell, 2007). One item, which refers to having an option to skip non-playable content (e.g., video sequences) in the game, did not have adequate intercorrelations with any of the other items. Thus, it was removed from subsequent analyses.

The Kaiser-Meyer-Olkin (KMO) and Bartlett's test of sphericity results also supported factor analysis. The KMO exceeded the minimum value of 0.60 , and at 0.93 was regarded as "superb" (Hutcheson \& Sofroniou, 1999; Tabachnick \& Fidell, 2007). The Bartlett's test of sphericity revealed the desirable significant $\chi^{2}$ statistic, $\chi^{2}(4851)=32,138.92, p<.001$, which indicated that the correlational matrix is significantly different from an identity matrix.

Finally, the anti-image correlation matrix, communalities, and factor loadings were examined to evaluate scale factorability. None of the items were removed from the study at this point because all of the diagonal elements were 0.75 or above (Field, 2009). Initial data explorations also revealed that many items had communalities in the 0.50 range with each 
factor containing at least three items with factor loadings above $|0.50|$. Taking into account the sample size of over 600 , these results contribute to the overall confidence that conducting a factor analysis is appropriate (MacCallum, Wildaman, Zhang, \& Hong, 1999; Russell, 2002; Worthington \& Whittaker, 2006).

Factor Extraction. Due to the data not being normally distributed, principal axis factoring (PAF) was chosen as the main extraction method (Costello \& Osborne, 2005; Fabrigar, Wegener, MacCallum, \& Strahan, 1999). In terms of the rotation method, an initial EFA showed that there were some inter-factor correlations at 0.32 or above. This information provided adequate ground to use an oblique rotation (Costello \& Osborne, 2005; Fabrigar et al., 1999; Tabachnick \& Fidell, 2007; Treiblmaier \& Filzmoser, 2010; Worthington \& Whittaker, 2006). Specifically, following the recommendation made by researchers (e.g., Fabrigar et al., 1999; Matsunaga, 2010; Russell, 2002) the promax rotation (kappa $=4$ ) was selected.

Multiple factor-retention strategies were adopted for determining the number of factors to retain. These strategies included the Kaiser-Guttman criterion, the Cattell's scree test, and Horn's parallel analysis. Based on the Kaiser-Guttman criterion there were 22 factors to retain. Visual inspection of the scree plot suggested a 6-factor solution. In comparison to other factor extraction methods, Horn's parallel analysis is often regarded as one of the best methods for determining the correct factor solution (Franklin, Gibson, Robertson, Pohlmann, \& Fralish, 1995; Henson \& Roberts, 2006; Matsunaga, 2010; Russell, 2002; Zygmon \& Smith, 2014). Results obtained from the parallel analysis conducted via O'connor's (2000) SPSS syntax revealed that there were 9 underlying factors. 
In addition to the three above mentioned strategies, other criteria were used to guide the process of factor retention. Specifically, factors with fewer than three items would be deemed as unstable, and thus, be rejected (Costello \& Osborne, 2005; Hinkin, 1995; Russell, 2002). Finally, good factors typically have simple structure and are easy to explain. Thus, factors that were difficult to interpret would not be retained.

In the process of factor interpretation, both the pattern matrix and structure matrix were examined. However, the primary focus of analysis was on the pattern matrix because it provides clearer results regarding which item load uniquely on which factor (Costello \& Osborne, 2005; Field, 2009; Hair, Black, Babin, Anderson, \& Tatham, 2006; Russell, 2002; Tabachnick \& Fidell, 2007). In terms of the cutoff value for item loading, the $|0.40|$ value was selected because it is the most common value and it falls in the recommend range of cutoff values (Hinkin, 1995; 1998; Field, 2009; Matsunaga, 2010; Nunnally, 1978; Tabachnick \& Fidell, 2007).

Item Removal. In order to improve the clarity of the data structure, a procedure of item removal was implemented. Several criteria were taken into consideration for deleting an item. In general, items that are candidates for deletion consist of items that: have a communality coefficient below 0.30 , contain factor loadings below $|0.40|$, crossload on two or more factors with loading values greater than $|0.32|$, make little or no contribution to the internal consistency of the scale scores, have low conceptual relevance to a factor, and/or are not conceptually consistent with other items loaded on the same factor (Costello \& Osborne, 2005; Worthington \& Whittaker, 2006; Tabachnick \& Fidell, 2007). Importantly, an EFA and 
Cronbach's $\alpha$ were run each time an item is deleted to ensure that the deleted item would not have a major effect on the factor structure and the internal consistency of the scale.

Based on the established criteria, 44 items were removed from further analyses at this stage. In addition to the first item that was removed at the beginning of the study, a total of 45 items were eliminated from the EFA study. The Cronbach's $\alpha$ for the remaining 55 items was 0.93 , which exceeds the 0.70 acceptable threshold and indicates "excellent" internal consistency (George \& Mallery, 2003; Hinkin, 1995; Nunnally, 1978). 9-Factor Solution. After problematic items were removed from the study, the 9-factor solution was revealed to be the most parsimonious and conceptually relevant solution. The 9-factor solution aligned with the parallel analysis results and explained approximately $49.3 \%$ of the total variance. The Cronbach's alpha for each factor or subscale surpasses the 0.70 acceptable threshold (see Table 5), with seven of the subscales containing alpha in the "good" range (George \& Mallery, 2003; Hinkin, 1995; Nunnally, 1978). The nine factors were named: Usability/Playability, Narratives, Play Engrossment, Enjoyment, Creative Freedom, Audio Aesthetics, Personal Gratification, Social Connectivity, and Visual Aesthetics. Tables 6-14 present in detail the items that loaded on each factor along with each item's mean, standard deviation, loading value on the pattern and structure matrices, and communality coefficient $\left(h^{2}\right)$. 
Table 5. 9-Factor Solution: Summary of Eigenvalues and Cronbach's Alpha.

\begin{tabular}{lcccc}
\hline Factor Number & \# of Items & \multicolumn{2}{c}{ Varimax Rotation* } & Cronbach's $\alpha$ \\
\cline { 3 - 4 } & & Eigenvalues & \% of Variance & \\
\hline Factor 1: Usability/Playability & 11 & 4.06 & 7.4 & 0.84 \\
Factor 2: Narratives & 7 & 3.82 & 6.9 & 0.85 \\
Factor 3: Play Engrossment & 8 & 3.71 & 6.7 & 0.84 \\
Factor 4: Enjoyment & 5 & 3.04 & 5.5 & 0.81 \\
Factor 5: Creative Freedom & 7 & 3.03 & 5.5 & 0.85 \\
Factor 6: Audio Aesthetics & 4 & 3.02 & 5.5 & 0.88 \\
Factor 7: Personal Gratification & 6 & 2.69 & 4.9 & 0.77 \\
Factor 8: Social Connectivity & 4 & 2.50 & 4.5 & 0.83 \\
Factor 9: Visual Aesthetics & 3 & 1.26 & 2.3 & 0.75 \\
\hline
\end{tabular}

*For estimation purposes, eigenvalues based on the varimax rotation were used since SPSS cannot calculated eigenvalues when factors are correlated.

Table 6. Factor 1 (Usability/Playability): Summary of the Factor's Items.

\begin{tabular}{|c|c|c|c|c|c|}
\hline \multirow[b]{2}{*}{ Item } & \multirow[b]{2}{*}{ Mean } & \multirow[b]{2}{*}{ SD } & \multicolumn{2}{|c|}{ Factor Loadings } & \multirow[b]{2}{*}{$h^{2}$} \\
\hline & & & Pattern & Structure & \\
\hline I think it is easy to learn how to play the game. & 5.68 & 1.50 & 0.77 & 0.64 & 0.51 \\
\hline I find the controls of the game to be straightforward. & 6.13 & 1.12 & 0.69 & 0.67 & 0.48 \\
\hline $\begin{array}{l}\text { I always know how to achieve my goals/objectives in } \\
\text { the game. }\end{array}$ & 5.67 & 1.28 & 0.66 & 0.61 & 0.40 \\
\hline I find the game's interface to be easy to navigate. & 5.93 & 1.09 & 0.64 & 0.67 & 0.48 \\
\hline $\begin{array}{l}\text { I do not need to go through a lengthy tutorial or read } \\
\text { a manual to play the game. }\end{array}$ & 5.76 & 1.49 & 0.56 & 0.48 & 0.28 \\
\hline I find the game's menus to be user friendly. & 5.83 & 1.15 & 0.53 & 0.58 & 0.36 \\
\hline I feel the game trains me well in all of the controls. & 5.60 & 1.32 & 0.52 & 0.55 & 0.34 \\
\hline $\begin{array}{l}\text { I always know my next goal when I finish an event in } \\
\text { the game. }\end{array}$ & 5.46 & 1.40 & 0.47 & 0.48 & 0.30 \\
\hline $\begin{array}{l}\text { I feel the game provides me the necessary } \\
\text { information to accomplish a goal within the game. }\end{array}$ & 5.68 & 1.18 & 0.47 & 0.59 & 0.40 \\
\hline $\begin{array}{l}\text { I think the information provided in the game (e.g., } \\
\text { onscreen messages, help) is clear. }\end{array}$ & 5.88 & 1.05 & 0.43 & 0.56 & 0.38 \\
\hline I feel very confident while playing the game. & 5.56 & 1.18 & 0.41 & 0.54 & 0.42 \\
\hline
\end{tabular}


Table 7. Factor 2 (Narratives): Summary of the Factor's Items.

\begin{tabular}{|c|c|c|c|c|c|}
\hline \multirow[b]{2}{*}{ Item } & \multirow[b]{2}{*}{ Mean } & \multirow[b]{2}{*}{ SD } & \multicolumn{2}{|c|}{ Factor Loadings } & \multirow[b]{2}{*}{$h^{2}$} \\
\hline & & & Pattern & Structure & \\
\hline $\begin{array}{l}\text { I think the characters in the game are well } \\
\text { developed. }\end{array}$ & 5.17 & 1.61 & 0.84 & 0.76 & 0.60 \\
\hline $\begin{array}{l}\text { I am captivated by the game's story from the } \\
\text { beginning. }\end{array}$ & 5.14 & 1.62 & 0.84 & 0.85 & 0.73 \\
\hline I enjoy the fantasy or story provided by the game. & 5.79 & 1.28 & 0.61 & 0.75 & 0.63 \\
\hline I can identify with the characters in the game. & 4.55 & 1.72 & 0.60 & 0.56 & 0.37 \\
\hline I am emotionally moved by the events in the game. & 4.15 & 1.82 & 0.58 & 0.65 & 0.50 \\
\hline $\begin{array}{l}\text { I am very interested in seeing how the events in the } \\
\text { game will progress. }\end{array}$ & 5.88 & 1.25 & 0.51 & 0.70 & 0.57 \\
\hline I can clearly understand the game's story. & 5.91 & 1.22 & 0.48 & 0.48 & 0.31 \\
\hline
\end{tabular}

Table 8. Factor 3 (Play Engrossment): Summary of the Factor's Items.

\begin{tabular}{|c|c|c|c|c|c|}
\hline \multirow[b]{2}{*}{ Item } & \multirow[b]{2}{*}{ Mean } & \multirow[b]{2}{*}{ SD } & \multicolumn{2}{|c|}{ Factor Loadings } & \multirow[b]{2}{*}{$h^{2}$} \\
\hline & & & Pattern & Structure & \\
\hline $\begin{array}{l}\text { I feel detached from the outside world while playing } \\
\text { the game. }\end{array}$ & 4.27 & 1.80 & 0.76 & 0.67 & 0.48 \\
\hline $\begin{array}{l}\text { I do not care to check events that are happening in } \\
\text { the real world during the game. }\end{array}$ & 4.07 & 1.82 & 0.75 & 0.61 & 0.44 \\
\hline $\begin{array}{l}\text { I cannot tell that I am getting tired while playing the } \\
\text { game. }\end{array}$ & 4.22 & 1.91 & 0.67 & 0.62 & 0.40 \\
\hline $\begin{array}{l}\text { Sometimes I lose track of time while playing the } \\
\text { game. }\end{array}$ & 5.67 & 1.46 & 0.61 & 0.68 & 0.51 \\
\hline $\begin{array}{l}\text { I temporarily forget about my everyday worries while } \\
\text { playing the game. }\end{array}$ & 5.32 & 1.47 & 0.56 & 0.64 & 0.43 \\
\hline $\begin{array}{l}\text { I tend to spend more time playing the game than I } \\
\text { have planned. }\end{array}$ & 5.28 & 1.60 & 0.52 & 0.58 & 0.38 \\
\hline $\begin{array}{l}\text { I can block out most other distractions when playing } \\
\text { the game. }\end{array}$ & 5.49 & 1.34 & 0.49 & 0.59 & 0.40 \\
\hline $\begin{array}{l}\text { Whenever I stopped playing the game I cannot wait } \\
\text { to start playing it again. }\end{array}$ & 4.78 & 1.50 & 0.49 & 0.64 & 0.46 \\
\hline
\end{tabular}


Table 9. Factor 4 (Enjoyment): Summary of the Factor's Items.

\begin{tabular}{lcccccc}
\hline & & \multicolumn{3}{c}{ Factor Loadings } & \\
\cline { 5 - 6 } Item & Mean & SD & Pattern & Structure & $h^{2}$ \\
\hline I think the game is fun. & 6.50 & 0.81 & 0.88 & 0.86 & 0.75 \\
I enjoy playing the game. & 6.51 & 0.76 & 0.86 & 0.85 & 0.73 \\
I feel bored while playing the game. & 2.45 & 1.46 & -0.58 & -0.55 & 0.32 \\
I am likely to recommend this game to others. & 6.27 & 1.06 & 0.58 & 0.70 & 0.52 \\
If given the chance, I want to play this game again. & 6.31 & 1.02 & 0.55 & 0.68 & 0.54 \\
\hline
\end{tabular}

Table 10. Factor 5 (Creative Freedom): Summary of the Factor's Items.

\begin{tabular}{lcccccc}
\hline & & \multicolumn{3}{c}{ Factor Loadings } \\
\cline { 5 - 6 } Item & Mean & SD & Pattern & Structure & $h^{2}$ \\
\hline I feel the game allows me to be imaginative. & 5.38 & 1.54 & 0.90 & 0.76 & 0.61 \\
I feel creative while playing the game. & 4.91 & 1.60 & 0.86 & 0.76 & 0.60 \\
I feel the game gives me enough freedom to act how & 5.51 & 1.46 & 0.62 & 0.61 & 0.42 \\
I want. & & & & & & \\
I feel the game allows me to express myself. & 4.62 & 1.64 & 0.61 & 0.68 & 0.52 \\
I feel I can explore things in the game. & 5.66 & 1.47 & 0.44 & 0.61 & 0.44 \\
I feel my curiosity is stimulated as the result of & 5.42 & 1.41 & 0.43 & 0.67 & 0.54 \\
playing the game. & & & & & \\
I think the game is unique or original. & 5.60 & 1.51 & 0.43 & 0.57 & 0.42 \\
\hline
\end{tabular}

Table 11. Factor 6 (Audio Aesthetics): Summary of the Factor's Items.

\begin{tabular}{|c|c|c|c|c|c|}
\hline \multirow[b]{2}{*}{ Item } & \multirow[b]{2}{*}{ Mean } & \multirow[b]{2}{*}{ SD } & \multicolumn{2}{|c|}{ Factor Loadings } & \multirow[b]{2}{*}{$h^{2}$} \\
\hline & & & Pattern & Structure & \\
\hline I enjoy the sound effects in the game. & 5.88 & 1.29 & 0.87 & 0.89 & 0.80 \\
\hline I enjoy the music in the game. & 5.68 & 1.53 & 0.76 & 0.80 & 0.66 \\
\hline $\begin{array}{l}\text { I feel the game's audio (e.g., sound effects, music) } \\
\text { enhances my gaming experience. }\end{array}$ & 5.92 & 1.43 & 0.76 & 0.78 & 0.63 \\
\hline $\begin{array}{l}\text { I think the game's audio fits the mood or style of the } \\
\text { game. }\end{array}$ & 6.17 & 1.04 & 0.63 & 0.73 & 0.58 \\
\hline
\end{tabular}


Table 12. Factor 7 (Personal Gratification): Summary of the Factor's Items.

\begin{tabular}{|c|c|c|c|c|c|}
\hline \multirow[b]{2}{*}{ Item } & \multirow[b]{2}{*}{ Mean } & \multirow[b]{2}{*}{ SD } & \multicolumn{2}{|c|}{ Factor Loadings } & \multirow[b]{2}{*}{$h^{2}$} \\
\hline & & & Pattern & Structure & \\
\hline $\begin{array}{l}\text { I am in suspense about whether I will succeed in the } \\
\text { game. }\end{array}$ & 5.06 & 1.73 & 0.70 & 0.60 & 0.42 \\
\hline $\begin{array}{l}\text { I feel successful when I overcome the obstacles in } \\
\text { the game. }\end{array}$ & 6.19 & 0.92 & 0.66 & 0.68 & 0.48 \\
\hline I want to do as well as possible during the game. & 6.20 & 1.02 & 0.62 & 0.63 & 0.45 \\
\hline $\begin{array}{l}\text { I am very focused on my own performance while } \\
\text { playing the game. }\end{array}$ & 5.83 & 1.18 & 0.57 & 0.61 & 0.43 \\
\hline $\begin{array}{l}\text { I feel the game constantly motivates me to proceed } \\
\text { further to the next stage or level. }\end{array}$ & 5.81 & 1.24 & 0.57 & 0.67 & 0.51 \\
\hline $\begin{array}{l}\text { I find my skills gradually improve through the course } \\
\text { of overcoming the challenges in the game. }\end{array}$ & 6.23 & 1.00 & 0.48 & 0.55 & 0.36 \\
\hline
\end{tabular}

Table 13. Factor 8 (Social Connectivity): Summary of the Factor's Items.

\begin{tabular}{|c|c|c|c|c|c|}
\hline \multirow[b]{2}{*}{ Item } & \multirow[b]{2}{*}{ Mean } & \multirow[b]{2}{*}{ SD } & \multicolumn{2}{|c|}{ Factor Loadings } & \multirow[b]{2}{*}{$h^{2}$} \\
\hline & & & Pattern & Structure & \\
\hline $\begin{array}{l}\text { I find the game supports social interaction (e.g., chat) } \\
\text { between players. }\end{array}$ & 4.78 & 1.93 & 0.84 & 0.83 & 0.72 \\
\hline I like to play this game with other players. & 5.28 & 1.97 & 0.75 & 0.76 & 0.63 \\
\hline $\begin{array}{l}\text { I am able to play the game with other players if I } \\
\text { choose. }\end{array}$ & 5.61 & 1.89 & 0.71 & 0.72 & 0.54 \\
\hline I enjoy the social interaction within the game. & 4.86 & 1.58 & 0.64 & 0.65 & 0.54 \\
\hline
\end{tabular}

Table 14. Factor 9 (Visual Aesthetics): Summary of the Factor's Items.

\begin{tabular}{lcccccc}
\hline & & & \multicolumn{3}{c}{ Factor Loadings } & \\
\cline { 5 - 6 } Item & Mean & SD & Pattern & Structure & $h^{2}$ \\
\hline I enjoy the game's graphics. & 6.19 & 1.00 & 0.64 & 0.70 & 0.53 \\
$\begin{array}{l}\text { I think the graphics of the game fit the mood or style } \\
\text { of the game. }\end{array}$ & 6.27 & 0.89 & 0.63 & 0.68 & 0.51 \\
\begin{tabular}{l} 
I think the game is visually appealing. \\
\hline
\end{tabular} & 6.25 & 1.03 & 0.59 & 0.61 & 0.40 \\
\hline
\end{tabular}


In order to develop a better understanding about the relationship among the factors, Pearson's correlation tests were also conducted to assess the relationship among the nine factors. Results indicated that there is a significant positive relationship among all of the factors. Table 15 presents the correlation results between factors.

Table 15. Correlations between Factors $(N=629, d f=627)$.

\begin{tabular}{|c|c|c|c|c|c|c|c|c|c|}
\hline Factor & 1: UP & $2: N$ & 3: PE & 4: $E$ & 5: CF & $6: A A$ & 7: PG & 8: SC & 9: VA \\
\hline 1: UP & 1.00 & & & & & & & & \\
\hline $2: N$ & $0.29^{* *}$ & 1.00 & & & & & & & \\
\hline 3: PE & $0.26^{* *}$ & $0.39^{* *}$ & 1.00 & & & & & & \\
\hline 4: E & $0.36^{* *}$ & $0.47^{* *}$ & $0.41^{* *}$ & 1.00 & & & & & \\
\hline 5: CF & $0.21^{* *}$ & $0.65^{* *}$ & $0.44^{* *}$ & $0.46^{* *}$ & 1.00 & & & & \\
\hline 6: AA & $0.23^{* *}$ & $0.44^{* *}$ & $0.29^{* *}$ & $0.37^{* *}$ & $0.38^{* *}$ & 1.00 & & & \\
\hline 7:PG & $0.31^{* *}$ & $0.39^{* *}$ & $0.45^{* *}$ & $0.47^{* *}$ & $0.38^{* *}$ & $0.38^{* *}$ & 1.00 & & \\
\hline 8: SC & $0.15^{* *}$ & $0.09^{*}$ & $0.08^{*}$ & $0.15^{* *}$ & $0.18^{* *}$ & $0.18^{* *}$ & $0.27^{* *}$ & 1.00 & \\
\hline 9: VA & $0.34^{* *}$ & $0.45^{* *}$ & $0.28^{* *}$ & $0.46^{* *}$ & $0.37^{* *}$ & $0.52^{* *}$ & $0.38^{* *}$ & $0.11^{* *}$ & 1.00 \\
\hline
\end{tabular}

\section{CFA Results}

The primary goal of the CFA phase was to assess how well the 9-factor solution derived from the EFA phase fit a new sample of observed data. In order to further enhance the construct validity of the adjusted model, the hypothesized 9-factor model was also compared with other alternative models via goodness-of-fit statistics (Cabrera-Nguyen, 2010; Worthington \& Whittaker, 2006). Specifically, the hypothesized full model was evaluated against the following models: 9-uncorrelated-factor, 8-factor, 7-factor, and 1-factor. IBM SPSS Statistics 22, SPSS Amos 22, and Microsoft Excel 2013 were used to analyze the data. 
Normality. Similar to the EFA study, the histograms and Shapiro-Wilk tests revealed that the majority of the items had a negatively skewed distribution. The majority of the data can be considered moderately skewed with skewness and kurtosis values less than $|2|$ and 7 , respectively (Finney \& DiStefano, 2013). Again, the decision was made to keep the data untransformed.

Missing Data. "N/A" responses were treated as missing values, and the total amount of missing data (3.3\%) was not considered as problematic. Results of Little's MCAR test $\left[\chi^{2}(10943, N=\right.$ $771)=12,063.03, p<.05]$ suggested that the data was not missing completely at random. Approximately $96.4 \%$ of variables $(n=53)$ and $43.7 \%$ of cases $(n=337)$ contained at least one missing value. The percentage of missing values for each variable ranges from $0.1 \%$ to $16.9 \%$. Estimation Method. Given that the data did not follow normal distributions, several estimation methods (e.g., asymptotically distribution free, ADF; unweighted least square, ULS) were considered. Maximum likelihood (ML) estimator was ultimately chosen due to the extremely large sample size (several thousands) requirement for the ADF estimator (Curran, West, \& Finch, 1996; Hu, Bentler, \& Kano, 1992; Muthén \& Kaplan, 1992). Additionally, the ULS estimator was not chosen because it offers very limited number of goodness-of-fit indices on AMOS.

There are three important considerations in using the ML estimator since it assumes that data is normally distributed. First, inflated chi-square statistics could potentially lead to the over-rejection of models (Benson \& Fleishman, 1994; Brown, 2014; Curran et al., 1996; Hu et al., 1992; Kenny, 2014). Second, underestimation of some fit indices (e.g., GFI, CFI) could cause plausible models being rejected (Brown, 2014; Finney \& DiStefano, 2013). Third, standard errors 
of parameter estimates would be underestimated (Benson \& Fleishman, 1994; Brown, 2014;

Finney \& DiStefano, 2013; Russell, 2002).

Despite these issues, research has shown that there is very little negative effect on the quality of the parameter estimates under non-normal conditions (Brown, 2014; Enders, 2006; Fan, Wang, \& Thompson, 1997). In addition, many research studies have shown that the ML estimator can be robust in different situations (e.g., mild to moderate violations of normality; Chou, Bentler, \& Satorra, 1991; Fan, Thompson, \& Wang, 1999; Fan et al., 1997; Finney \& DiStefano, 2013; Matsunaga, 2010). Furthermore, Finney and DiStefano (2013) consider the ML estimator to be an appropriate estimation method when data is moderately skewed (skewness $<|2|$ and kurtosis $<7)$, as is the case with the current data.

Method for Addressing Missing Data. In dealing with the missing data, AMOS' full information maximum likelihood (FIML) estimation was used as the primary missing data estimation method to produce the majority of the CFA results (e.g., parameter estimates, chi-square test). FIML has been demonstrated to generate unbiased parameter estimates and standard errors, and valid model fit information when data is not missing completely at random and across different normality conditions (Dong \& Peng, 2013; Enders, 2001; Enders \& Bandalos, 2001; Hallgren \& Witkiewitz, 2013).

While FIML is one of the most pragmatic approaches in dealing with missing data, it does not generate a standardized residual covariance matrix, therefore, it does not allow for post-hoc model modifications. Also, some of the analyses (e.g., standardized root mean square residual, internal reliability) are not possible via AMOS' FIML. As a result, the EM method via SPSS MVA add-on module was used to generate results where the FIML method cannot be 
applied. In general, research has shown that ML-based methods (e.g., EM, FIML) produces similar results (Dong \& Peng, 2013; Graham, Olchowski, \& Gilreath, 2007; Schafer \& Graham, 2002).

Model Fit Assessment. In terms of evaluating a model fit, experts typically recommend using two to three other fit indices (e.g., RMSEA, SRMR, and CFI) in determining overall model fit (Hu \& Bentler, 1999; Kline, 2005; Worthington \& Whittaker, 2006). Experts also recommend not relying on the chi-square test statistic when studies have large sample sizes (e.g., over 200) and data is non-normal (Byrne, 2010; Hu \& Bentler, 1999; Kline, 2005; Russell, 2002; Worthington \& Whittaker, 2006). Additionally, Kenny (2014) has advised against using the CFI fit index when RMSEA value of null model is below 0.158 since the CFI fit statistic tends to be very low under this condition. Given that the study has a large sample size $(N=771)$, non-normal data, and the null model's RMSEA value was 0.121 ( $90 \%$ Confidence Interval: $0.119,0.122)$, these fit statistics were reported, but not used in the overall assessment of model fit.

Instead, three goodness-of-fit indices were mainly used to assess overall model fit: root mean square error of approximation (RMSEA; Steiger \& Lind, 1980), standardized root mean square residual (SRMR), and Hoelter's Critical N (CN; Hoelter, 1983). Generally, RMSEA values less than .05 indicates close approximate fit while values between .05 and .08 indicates adequate fit (Browne \& Cudeck, 1993; Fabrigar et al., 1999). Additionally, SRMR values less than .10 indicates acceptable model fit (Kline, 2005; Worthington \& Whittaker, 2006). However, Hu and Bentler (1999) have suggested a more stringent cut-off of .06 or below and .08 or below to indicate good fit for RMSEA and SRMR statistics, respectively. Lastly, Hoelter's CN is considered appropriate to interpret when the chi-square statistic is significant and $N$ is greater than 200 
(Kenny, 2014). CN values over 200 signify the sample size and model fit are adequate while values below 75 signify unacceptable model fit and sample size (Byrne, 2010; Kenny, 2014).

The three specified fit indices (i.e., RMSEA, SRMR, and Hoelter's CN) were also used to compare the hypothesized 9-factor model against alternative models. Specifically, the model with lower RMSEA and SRMR, and higher Hoelter's CN values would be deemed as the better model. Along with the three specified fit indices, the Expected Cross-Validation Index (ECVI; Browne \& Cudeck, 1989) fit index and the chi-square difference $\left(\Delta \chi^{2}\right)$ test statistic were used in the comparison of different models. The ECVI does not have a fix range of values and is most useful for comparing alternative models (Byrne, 2010; Fabrigar et al., 1999).

Generally, the model with the smallest ECVI value has the highest chance of being replicated, and would be considered as the best model for replication purposes. Finally, the chisquare difference test was used to compare the fit between the hypothesized 9-factor model against a reduced model (e.g., 8-factor model). A significant statistic $(p<.05)$ typically suggests that the full model is the better model. Table 16 provides a summary of the guidelines for assessing overall model fit and comparing the hypothesized models to alternative models.

Table 16. Guidelines for Overall Model Fit Assessment and Model Comparison.

\begin{tabular}{ll}
\hline Fit Statistic & Fit Recommendation(s) \\
\hline RMSEA & Adequate: .06 to $.08 ;$ Good: $\leq .06$ \\
SRMR & Adequate: .08 to $.10 ;$ Good: $\leq .08$ \\
Hoelter's CN & Adequate: $>200 ;$ Unacceptable: $<75$ \\
ECVI & Preferred: The smallest value \\
$\Delta \chi^{2}$ & Preferred: $p<.05$ \\
\hline
\end{tabular}

Hypothesized 9-Factor Model Fit Assessment. The 9-factor solution derived from the EFA study was used in this study as the hypothesized full model. The full model consists of the following 
unobserved latent factors: Usability/Playability (11 items), Narratives (7 items), Play Engrossment (8 items), Enjoyment (5 items), Creative Freedom (7 items), Audio Aesthetics (4 items), Personal Gratification (6 items), Social Connectivity (4 items); Visual Aesthetics (3 items). Each item is considered as an observed or measured variable in confirmatory factor analysis. Although the covariance matrix showed that the relationship between two pairs of factors (Social Connectivity and Narratives; Social Connectivity and Play Engrossment) were not statistically significant, for simplicity sake all of the latent factors were allowed to covary with each other.

Results revealed that the hypothesized 9-factor model has an overall good fit with the new data sample. As expected, the chi-square statistic, $\chi^{2}(1394, N=771)=4,428.63, p<.001$, was significant due to the large sample size and non-normal distribution. Additionally, the CFI value (0.82) was very low due to the small RMSEA value (.121) of the null model stated earlier. However, the three primary goodness-of-fit indices (i.e., RMSEA, SRMR, and Hoelter's CN) all suggested that there is a good fit between the full 9-factor model and the observed data (see Table 17).

Table 17. Hypothesized 9-Factor Model's Fit Statistics $(N=771)$.

\begin{tabular}{ll}
\hline Fit Index & Value \\
\hline$\chi^{2}$ & $(1394)=4,428.63, p<.001$ \\
CFI & 0.82 \\
RMSEA $(90 \%$ CI) & $.053(.051, .055)$ \\
SRMR & 0.07 \\
Hoelter's .05; .01 & 258,265 \\
\hline
\end{tabular}

Model Comparison. The hypothesized 9-factor model was compared against four alternative models in terms of overall model fit. All the models have the same number of cases 
$(N=771)$ and observed variables or items $(N=55)$. The first alternative model consisted of the same nine factors with the same corresponding measured variable. However, none of the factors in the model were allowed to covary with each other. The 8- and 7-models were based on the results derived from the EFA study. The 8-factor solution combined the Visual and Audio Aesthetics factors into a single factor. The 7-factor solution not only grouped Visual and Audio Aesthetics factors together, but it further combined the Narratives and Creative Freedom factors into one factor.

As expected, the large sample size and small RMSEA value of the null model resulted in statistically significant chi-square and substandard CFI values across all alternative models (see Table 18). In comparison to the four alternative models, the specified 9-factor model had the lowest RMSEA and SRMR values, and highest Hoelter's CN values. Additionally, the specified 9factor model had the best fit in terms of its EVCI values. Finally, the chi-square difference tests conducted resulted in statistically significant results between the hypothesized 9-factor model and each of the alternative models. Overall, results from the goodness-of-fit statistics suggested that the specified 9-factor solution is the most appropriate model. Table 19 presents the main fit statistics for all five models. 
Table 18. Comparison of Chi-square and CFI Fit Indices across Models ( $N=771)$.

\begin{tabular}{lcc}
\hline Model & $\chi^{2}$ & CFI \\
\hline 9 factors (correlated) & $\chi^{2}(1394)=4,428.63, p<.001$ & 0.82 \\
9 factors (uncorrelated) & $\chi^{2}(1430)=6,380.73, p<.001$ & 0.71 \\
8 factors (combined AA \& VA) & $\chi^{2}(1402)=5,026.64, p<.001$ & 0.79 \\
7 factors (combined AA \& VA; N \& CF) & $\chi^{2}(1409)=5,5502.14, p<.001$ & 0.76 \\
1 factor & $\chi^{2}(1430)=10,731.93, p<.001$ & 0.46 \\
\hline
\end{tabular}

Note. $\mathrm{AA}=$ Audio Aesthetics, $\mathrm{VA}=$ Visual Aesthetics, $\mathrm{N}=$ Narratives, and $\mathrm{CF}=$ Creative Freedom.

Table 19. Comparison of Main Fit Indices across Models $(N=771)$.

\begin{tabular}{|c|c|c|c|c|c|}
\hline Model & $\begin{array}{l}\text { RMSEA } \\
(90 \% \mathrm{Cl})\end{array}$ & SRMR & $\begin{array}{l}\text { Hoelter's } \\
.05 ; .01 \\
\end{array}$ & $\begin{array}{c}\mathrm{EVCl} \\
(90 \% \mathrm{Cl})\end{array}$ & $\Delta \chi^{2}$ \\
\hline 9 factors (correlated) & $\begin{array}{c}.053 \\
(.051, .055)\end{array}$ & 0.07 & $258 ; 265$ & $\begin{array}{c}6.27 \\
(6.02,6.54)\end{array}$ & $\mathrm{N} / \mathrm{A}$ \\
\hline $\begin{array}{l}9 \text { factors } \\
\text { (uncorrelated) }\end{array}$ & $\begin{array}{c}.067 \\
(.065, .069)\end{array}$ & 0.19 & $184 ; 188$ & $\begin{array}{c}8.72 \\
(8.40,9.04)\end{array}$ & $\begin{aligned} \Delta \chi^{2}(36) & =1,952.10, \\
p & <.001\end{aligned}$ \\
\hline $\begin{array}{l}8 \text { factors (combined } \\
\text { AA \& VA) }\end{array}$ & $\begin{array}{c}.058 \\
(.056, .060)\end{array}$ & 0.08 & $229 ; 235$ & $\begin{array}{c}7.03 \\
(6.75,7.32)\end{array}$ & $\begin{array}{c}\Delta \chi^{2}(8)=599.01 \\
p<.001\end{array}$ \\
\hline $\begin{array}{l}7 \text { factors (combined } \\
\text { AA \& VA; N \& CF) }\end{array}$ & $\begin{array}{c}.061 \\
(.060, .063)\end{array}$ & 0.08 & $210 ; 215$ & $\begin{array}{c}7.63 \\
(7.34,7.93)\end{array}$ & $\begin{aligned} \Delta \chi^{2}(15) & =1,073.51, \\
p & <.001\end{aligned}$ \\
\hline 1 factor & $\begin{array}{c}.092 \\
(.090, .094)\end{array}$ & 0.10 & $109 ; 112$ & $\begin{array}{c}14.37 \\
(13.94,14.80)\end{array}$ & $\begin{aligned} \Delta \chi^{2}(36) & =6,303.31, \\
p & <.001\end{aligned}$ \\
\hline
\end{tabular}

Note. $\mathrm{AA}=$ Audio Aesthetics, $\mathrm{VA}=$ Visual Aesthetics, $\mathrm{N}=$ Narratives, and $\mathrm{CF}=$ Creative Freedom.

\section{Scale Reliability and Validity Assessment}

After the assessment of model fit, it is important to re-examine the reliability of the scale and assess the convergent and discriminant validity of the scale based on parameter estimates (Cabrera-Nguyen, 2010). Results revealed that the internal validity of the scale is consistent across the EFA and CFA studies. Although there was a small fluctuation in the Cronbach's $\alpha$ from the EFA study to the CFA study, the Cronbach's $\alpha$ for all factors or subscales stayed in the 
same acceptable or good range across the two studies. The overall Cronbach's $\alpha$ of the scale also remained in the excellent range in the CFA study as it did in the EFA study (see Table 20).

Table 20. Comparison of Cronbach's Alpha across EFA $(N=629)$ and CFA $(N=771)$ Studies.

\begin{tabular}{lcc}
\hline Factor & $\begin{array}{c}\text { EFA Study } \\
\text { Cronbach's } \alpha\end{array}$ & $\begin{array}{c}\text { CFA Study } \\
\text { Cronbach's } \alpha\end{array}$ \\
\hline Factor 1: Usability/Playability & 0.84 & 0.83 \\
Factor 2: Narratives & 0.85 & 0.85 \\
Factor 3: Play Engrossment & 0.84 & 0.81 \\
Factor 4: Enjoyment & 0.81 & 0.80 \\
Factor 5: Creative Freedom & 0.85 & 0.86 \\
Factor 6: Audio Aesthetics & 0.88 & 0.89 \\
Factor 7: Personal Gratification & 0.77 & 0.72 \\
Factor 8: Social Connectivity & 0.83 & 0.86 \\
Factor 9: Visual Aesthetics & 0.75 & 0.79 \\
Entire Scale & 0.93 & 0.92 \\
\hline
\end{tabular}

Next, standardized factor loadings were examined to investigate convergent validity. Experts have suggested that factor loadings below 0.40 are weak and those above 0.70 are strong (Cabrera-Nguyen, 2010; Garson, 2010; Hair et al., 2006). All of the factor loadings were above 0.40 , with the majority of loadings above 0.50 . In addition, correlations among the factor in the CFA study were examined to assess discriminant validity of the scale. Generally, factor correlations below 0.80 or 0.85 suggest good discriminant validity (Brown, 2014; CabreraNguyen, 2010; Garson, 2010; Kline, 2005). All of the factor correlations were below the 0.80 benchmark, with the two strongest factor correlations between Narratives and Creative Freedom $(r=0.70)$, and Enjoyment and Personal Gratification $(r=0.71)$.

Finally, an alternative, but less robust measure of discriminant validity is to compare the model fit between two similar models (e.g., 1-factor vs. 2-factor; Hair et al., 2006). As chisquare difference tests had revealed, the hypothesized 9-factor model provided a significantly 
better fit than the 8-factor and other models. Altogether, results demonstrated that the 9factor solution has adequate convergent and discriminant validity.

\section{Discussion}

\section{Summary of the GUESS}

At present, there is a need for a psychometrically validated and comprehensive gaming scale that is appropriate for playtesting and game evaluation purposes. In order to meet this need, a new gaming scale called the Game User Experience Satisfaction Scale (GUESS) was developed based on a rigorous system of scale development and validation. In this pursuit, numerous resources (e.g., existing game scales and heuristics) concerning video game enjoyment and satisfaction were gathered to generate an initial item pool for the scale. The item pool then underwent multiple iterative phases of modification and refinement before and after the expert review and pilot testing phases. Once refined, the scale was administered to two large, independent samples of over 600 video game players who evaluated over 450 unique video across a number of popular genres (e.g., Role-Playing, Action Adventure). Exploratory factor analysis and confirmatory factor analysis were performed on the data to uncover the underlying factors and further validate the scale.

The GUESS consists of 55 items with 9 subscales, and generally takes around 5-10 minutes to complete. The subscales include Usability/Playability, Narratives, Play Engrossment, Enjoyment, Creative Freedom, Audio Aesthetics, Personal Gratification, Social Connectivity, and Visual Aesthetics. Table 21 provides a brief description of each subscale. 
Table 21. A Short Description of Each Subscale.

\begin{tabular}{|c|c|}
\hline Subscale & Description \\
\hline Usability/Playability & $\begin{array}{l}\text { The ease in which the game can be played with clear } \\
\text { goals/objectives in mind, and with minimal cognitive interferences } \\
\text { or obstructions from the user interfaces and controls. }\end{array}$ \\
\hline Narratives & $\begin{array}{l}\text { The story aspects of the game (e.g., events and characters) and } \\
\text { their abilities to capture the player's interest, and shape the } \\
\text { player's emotions. }\end{array}$ \\
\hline Play Engrossment & $\begin{array}{l}\text { The degree to which the game can hold the player's attention and } \\
\text { interest. }\end{array}$ \\
\hline Enjoyment & $\begin{array}{l}\text { The amount of pleasure and delight that was perceived by the } \\
\text { player as a result of playing the game. }\end{array}$ \\
\hline Creative Freedom & $\begin{array}{l}\text { The extent to which the game is able to foster the player's } \\
\text { creativity and curiosity, and allows the player to freely express his } \\
\text { or her individuality while playing the game. }\end{array}$ \\
\hline Audio Aesthetics & $\begin{array}{l}\text { The different auditory aspects of the game (e.g., sound effects) } \\
\text { and how much they enrich the gaming experience. }\end{array}$ \\
\hline Personal Gratification & $\begin{array}{l}\text { The motivational aspects of the game (e.g., challenge) that } \\
\text { promote the player's sense of accomplishment, and the desire to } \\
\text { succeed and continue playing the game. }\end{array}$ \\
\hline Social Connectivity & $\begin{array}{l}\text { The degree to which the game facilitates social connection } \\
\text { between players through its tools and features. }\end{array}$ \\
\hline Visual Aesthetics & $\begin{array}{l}\text { The graphics of the game and how attractive they appeared to the } \\
\text { player. }\end{array}$ \\
\hline
\end{tabular}

Based on the studies conducted, the GUESS was found to have strong psychometric properties. Results from the expert review phase indicated that the GUESS has high content validity. Both of the EFA and CFA studies demonstrated that the GUESS has good internal consistency. Finally, results obtained from the CFA study provided supporting evidence to the construct validity of the GUESS. Specifically, the GUESS was determined to have satisfactory convergent and discriminant validity.

\section{Practical Applications of the GUESS}

Based on the pilot study, the GUESS is appropriate to administer to different video game players with various gaming experience (e.g., Newbie/Novice, Hardcore/Expert). Results further 
suggest the GUESS can easily be understood by ESL gamers, and thus, respondents do not need to be a native English speaker to use the GUESS. A final strength of the GUESS is that it was developed and validated based on the assessments of a large number of video games from a variety of genres. Therefore, it can be applied to many types of video games in the industry.

For video game practitioners who would like to use the GUESS, it is recommended that the items on the scale be randomized and separated into a set of five items per page. In terms of scoring the GUESS, it is recommended that the ratings of all the items per factor be averaged to obtain an average score of each subscale. Additionally, the average score of each subscale can be added together in order to obtain a composite score of video game satisfaction.

Right now there is little information on the scoring standard of the GUESS since it has just been developed. Thus, it is currently recommend that the GUESS be used to compare different video games of the same genre, and the game with the highest score can be considered as more satisfying to play. Alternatively, the GUESS can be used to compare video games from the same series or from different versions to determine whether the latest series or version is perceived to be an improvement over the old ones. Finally, if there is a game being evaluated without any narratives or social components video game practitioners have the option of removing the Narratives or Social Connectivity subscales from the overall scale. However, it is generally recommended that the entire scale be kept intact for more accurate results.

\section{Future Research}

In general, the process of validating a new instrument does not stop after a confirmatory factor analysis. Thus, more research is needed to further validate and extend the applicability of the 
GUESS to different types of games and gamer populations. Specifically, future research needs to assess the scale in terms of criterion-related validity. For example, future studies can examine how well the score obtained from the GUESS can predict the player's performance within the game, the likelihood that the player will continue playing the game, as well as level of review scores from critics.

To date, the GUESS has only been administered to video game players who are at least 18 years old with some high school education. Consequently, researchers might be interested in evaluating the appropriateness of the GUESS with younger populations with lower education levels. Additionally, the games evaluated in this research mostly consisted of popular commercial games that were designed purely to entertain. As a result, it is not known how applicable the GUESS will be in evaluating serious games (e.g., educational). Finally, the majority of the games evaluated in this research were games that participants generally liked rather than disliked. Thus, future studies should consider using the GUESS to evaluate games that are not very well-liked.

\section{References}

Abran, A., Khelifi, A., Suryn, W., \& Seffah, A. (2003). Usability meanings and interpretations in ISO standards. Software Quality Journal, 11(4), 325-338.

Agarwal, R., \& Karahanna, E. (2000). Time flies when you're having fun: Cognitive absorption and beliefs about information technology usage. MIS Quarterly, 24(4), 665-694.

Albert, W., \& Tullis, T. (2013). Measuring the user experience: Collecting, analyzing, and presenting usability metrics. Waltham, MA: Morgan Kaufmann.

Aycock, H. (1992). Principles of good game design. Business Source Premier, 14(1), 94-98.

Bennett, D. A. (2001). How can I deal with missing data in my study? Australian and New Zealand Journal of Public Health, 25(5), 464-469. 
Benson, J., \& Fleishman, J. A. (1994). The robustness of maximum likelihood and distributionfree estimators to non-normality in confirmatory factor analysis. Quality and Quantity, 28(2), 117-136.

Brockmyer, J. H., Fox, C. M., Curtiss, K. A., McBroom, E., Burkhart, K. M., \& Pidruzny, J. N. (2009). The development of the Game Engagement Questionnaire: A measure of engagement in video game-playing. Journal of Experimental Social Psychology, 45(4), 624634.

Brooke, J. (1996). SUS-A quick and dirty usability scale. In P.W. Jordan, B. Thomas, B. A. Weerdmeester, \& I.L. McClelland (Eds.), Usability evaluation in industry (pp. 189 - 194). London: Taylor \& Francis.

Brown, T. A. (2014). Confirmatory factor analysis for applied research (2nd ed.). New York, NY: The Guilford Pres

Browne, M. W., \& Cudeck, R. (1989). Single sample cross-validation indices for covariance structures. Multivariate Behavioral Research, 24(4), 445-455.

Browne, M.W., \& Cudeck, R. (1993). Alternative ways of assessing model fit. In K. A. Bollen \& J. S. Long (Eds.), Testing structural equation models (pp. 136-162). Newbury Park, CA: Sage.

Byrne, B.M. (2010). Structural equation modeling with AMOS: Basic concepts, applications, and programming (2nd ed.). New York, NY: Taylor \& Francis Group.

Cabrera-Nguyen, P. (2010). Author guidelines for reporting scale development and validation results in the Journal of the Society for Social Work and Research. Journal of the Society for Social Work and Research, 1(2), 99-103.

Calvillo-Gámez, E. H., Cairns, P., \& Cox, A. L. (2010). Assessing the core elements of the gaming experience. In R. Bernhaupt (Ed.), Evaluating user experience in games (pp. 47-71). New York, NY: Springer.

Chalker, D. (2008, July 3). Reiner Knizia: "Creation of a successful game". Critical Hits. Retrieved from http://www.critical-hits.com/blog/2008/07/03/reiner-knizia-creation-ofa-successful-game/

Chen, M., Kolko, B., Cuddihy, E., \& Medina, E. (2005). Modelling and measuring engagement in computer games. In Proceedings of the Conference for the Digital Games Research Association. 
Chin, J. P., Diehl, V. A., \& Norman, K. L. (1988, May). Development of an instrument measuring user satisfaction of the human-computer interface. In Proceedings of the SIGCHI Conference on Human Factors in Computing Systems (pp. 213-218). ACM.

Choi, D., \& Kim, J. (2004). Why people continue to play online games: In search of critical design factors to increase customer loyalty to online contents. CyberPsychology \& Behavior, 7(1), 11-24.

Chou, C. P., Bentler, P. M., \& Satorra, A. (1991). Scaled test statistics and robust standard errors for non-normal data in covariance structure analysis: a Monte Carlo study. British Journal of Mathematical and Statistical Psychology, 44(2), 347-357.

Clanton, C. (1998, April). An interpreted demonstration of computer game design. In CHI 98 Conference Summary on Human Factors in Computing Systems (pp. 1-2). ACM.

Collins, J. (1997, July 7). Conducting in-house play testing. Gamasutra. Retrieved from http://www.gamasutra.com/view/feature/3211/

Comrey, A. L., \& Lee, H. B. (1992). A first course in factor analysis (2nd ed.). Hilldsale, NJ: Lawrence Erlbaum Associates.

Cornett, S. (2004, April). The usability of massively multiplayer online roleplaying games: designing for new users. In Proceedings of the SIGCHI Conference on Human Factors in Computing Systems (pp. 703-710). ACM.

Costello, A. B. \& Osborne, J. W. (2005). Best practices in exploratory factor analysis: Four recommendations for getting the most from your analysis. Practical Assessment, Research \& Evaluation, 10(7), 1-9.

Curran, P. J., West, S. G., \& Finch, J. F. (1996). The robustness of test statistics to nonnormality and specification error in confirmatory factor analysis. Psychological Methods, 1(1), 16.

Dempster, A. P., Laird, N. M., \& Rubin, D. B. (1977). Maximum likelihood from incomplete data via the EM algorithm. Journal of the Royal Statistical Society. Series B (Methodological), 38(1), 1-38.

Desurvire, H., Caplan, M., \& Toth, J. A. (2004, April). Using heuristics to evaluate the playability of games. In CHI'O4 extended abstracts on Human factors in computing systems (pp. 1509-1512). ACM.

Desurvire, H., \& Wiberg, C. (2009). Game usability heuristics (play) for evaluating and designing better games: The next iteration. In A. A. Ozok \& P. Zaphiris (Eds.), Online communities and social computing (pp. 557-566). New York, NY: Springer. 
Dong, Y., \& Peng, C. Y. J. (2013). Principled missing data methods for researchers. SpringerPlus, 2(1), 1-17.

Enders, C. K. (2001). The impact of non-normality on full information maximum-likelihood estimations for structural equation models with missing data. Psychological Methods, $6(4), 352-370$.

Enders, C. K. (2003). Using the expectation maximization algorithm to estimate coefficient alpha for scales with item-level missing data. Psychological Methods, 8(3), 322-337.

Enders, C. K. (2006). Analyzing structural equation models with missing data. In G.R. Hancock \& R.O. Mueller (Eds.), Structural Equation Modeling: A Second Course (pp. 315-344). Greenwich, CT: Information Age Publishing, Inc.

Enders, C. K., \& Bandalos, D. L. (2001). The relative performance of full information maximum likelihood estimation for missing data in structural equation models. Structural Equation Modeling, 8(3), 430-457.

Entertainment Software Association (ESA, 2014). 2014 Sales demographic and usage data: Essential facts about the computer and video game industry. Retrieved from http://www.theesa.com/wp-content/uploads/2014/10/ESA_EF_2014.pdf

Ermi, L., \& Mäyrä, F. (2005). Fundamental components of the gameplay experience: Analysing immersion. In S. Castell \& J. Jenson, (Eds.), The Proceedings of the DiGRA Conference Changing Views: Worlds in Play (pp. 15-27).

Fabrigar, L. R., Wegener, D. T., MacCallum, R. C., \& Strahan, E. J. (1999). Evaluating the use of exploratory factor analysis in psychological research. Psychological Methods, 4(3), 272-299.

Fan, X., Thompson, B., \& Wang, L. (1999). Effects of sample size, estimation methods, and model specification on structural equation modeling fit indexes. Structural Equation Modeling: A Multidisciplinary Journal, 6(1), 56-83.

Fan, X., Wang, L., \& Thompson, B. (1997, March). Effects of data nonnormality and other factors on fit indices and parameter estimates for true and misspecified SEM models. Paper presented at the American Educational Research Association Annual Meeting, Chicago, IL.

Federoff, M. A. (2002). Heuristics and usability guidelines for the creation and evaluation of fun in video games (Master's thesis). Available from CiteSeerX database. 
Field, A. P. (2009). Discovering statistics using SPSS (3 ${ }^{\text {rd }}$ ed.). Los Angeles, CA: Sage.

Finney, S. J., \& DiStefano, C. (2013). Nonnormal and categorical data in structural equation modeling. In G. R. Hancock \& R. O. Mueller (Eds.), Structural equation modeling: $A$ second course (2nd ed.) (pp. 269-314). Charlotte, NC: IAP.

Fox-Wasylyshyn, S. M., \& El-Masri, M. M. (2005). Handling missing data in self-report measures. Research in Nursing \& Health, 28(6), 488-495.

Franklin, S. B., Gibson, D. J., Robertson, P. A., Pohlmann, J. T., \& Fralish, J. S. (1995). Parallel analysis: a method for determining significant principal components. Journal of Vegetation Science, 6(1), 99-106.

Fu, F. L., Su, R. C., \& Yu, S. C. (2009). EGameFlow: A scale to measure learners' enjoyment of elearning games. Computers \& Education, 52(1), 101-112.

Fulton, B. (2002, March 21). Beyond psychological theory: Getting data that improves games. Gamasutra. Retrieved from http://www.gamasutra.com/view/feature/131412/

Gartner (2013). Gartner says worldwide video game market to total \$93 billion in 2013. Retrieved from http://www.gartner.com/newsroom/id/2614915

George, D., \& Mallery, P. (2003). SPSS for Windows step by step: A simple guide and reference, 11.0 update $\left(4^{\text {th }}\right.$ ed.). Boston, MA: Allyn \& Bacon.

Gold, M. S., \& Bentler, P. M. (2000). Treatments of missing data: A Monte Carlo comparison of RBHDI, iterative stochastic regression imputation, and expectationmaximization. Structural Equation Modeling, 7(3), 319-355.

Graham, J. W. (2009). Missing data analysis: Making it work in the real world. Annual Review of Psychology, 60, 549-576.

Graham, J. W., Olchowski, A. E., \& Gilreath, T. D. (2007). How many imputations are really needed? Some practical clarifications of multiple imputation theory. Prevention Science, 8(3), 206-213.

Hair, J. F., Black, W. C., Babin, B. J., Anderson, R. E., \& Tatham, R. L. (2006). Multivariate data analysis ( $6^{\text {th }}$ ed.). Upper Saddle River, N.J.: Pearson Education Inc.

Hallgren, K. A., \& Witkiewitz, K. (2013). Missing data in alcohol clinical trials: A comparison of methods. Alcoholism: Clinical and Experimental Research, 37(12), 2152-2160. 
Henson, R. K., \& Roberts, J. K. (2006). Use of exploratory factor analysis in published research common errors and some comment on improved practice. Educational and Psychological measurement, 66(3), 393-416.

Hinkin, T. R. (1995). A review of scale development practices in the study of organizations. Journal of Management, 21(5), 967-988.

Hinkin, T. R. (1998). A brief tutorial on the development of measures for use in survey questionnaires. Organizational Research Methods, 1(1), 104-121.

Hoelter, J. W. (1983). The analysis of covariance structures goodness-of-fit indices. Sociological Methods \& Research, 11(3), 325-344.

Hornbæk, K. (2006). Current practice in measuring usability: Challenges to usability studies and research. International Journal of Human-Computer Studies, 64(2), 79-102.

Hu, L-T. \& Bentler, P.M., (1999). Cutoff criteria for fit indexes in covariance structure analysis: Conventional criteria versus new alternatives. Structural Equation Modeling, 6, 1-55.

Hu, L. T., Bentler, P. M., \& Kano, Y. (1992). Can test statistics in covariance structure analysis be trusted? Psychological Bulletin, 112(2), 351-362.

Hutcheson, G. D., \& Sofroniou, N. (1999). The multivariate social scientist. London, England: Sage.

IJsselsteijn, W. A., Poels, K., \& de Kort, Y. A. W. (2008). Measuring player experiences in digital Games: Development of the Game Experience Questionnaire (GEQ). Manuscript in preparation.

Jennett, C., Cox, A. L., Cairns, P., Dhoparee, S., Epps, A., Tijs, T., \& Walton, A. (2008). Measuring and defining the experience of immersion in games. International Journal of HumanComputer Studies, 66(9), 641-661.

Jensen, M. P. (2003). Questionnaire validation: A brief guide for readers of the research literature. The Clinical Journal of Pain, 19(6), 345-352.

Kass, R. A., \& Tinsley, H. E. A. (1979). Factor analysis. Journal of Leisure Research, 11, 120-138.

Kenny, D. A (2014, October 6). Measuring model fit. Retrieved from http://davidakenny.net/cm/fit.htm

Kline, R. B. (2005). Principles and practice of structural equations modeling (2nd ed.). New York, NY: The Guilford Press. 
Korhonen, H., \& Koivisto, E. M. (2006, September). Playability heuristics for mobile games. In Proceedings of the 8th Conference on Human-Computer Interaction with Mobile Devices and Services (pp. 9-16). ACM.

Korhonen, H., \& Koivisto, E. M. (2007, September). Playability heuristics for mobile multi-player games. In Proceedings of the 2nd International Conference on Digital Interactive Media in Entertainment and Arts (pp. 28-35). ACM.

Lewis, J. R. (1995). IBM computer usability satisfaction questionnaires: Psychometric evaluation and instructions for use. International Journal of Human-Computer Interaction, 7(1), 57-78.

MacCallum, R. C., Wildaman, K. F., Zhang, S., \& Hong, S. (1999). Sample size in factor analysis. Psychological Methods, 4(1), 84-89.

Matsunaga, M. (2010). How to factor-analyze your data right: Do's, don'ts, and howto's. International Journal of Psychological Research, 3(1), 97-110.

McAllister, G., \& White, G. R. (2010). Video game development and user experience. In R. Bernhaupt (Ed.), Evaluating user experience in games (pp. 107-128). New York, NY: Springer.

MobyGames (2015). MobyStats. Retrieved from http://www.mobygames.com/moby_stats

Musil, C. M., Warner, C. B., Yobas, P. K., \& Jones, S. L. (2002). A comparison of imputation techniques for handling missing data. Western Journal of Nursing Research, 24(7), 815-829.

Muthén, B., \& Kaplan, D. (1985). A comparison of some methodologies for the factor analysis of non-normal Likert variables. British Journal of Mathematical and Statistical Psychology, 38(2), 171-189.

Muthén, B., \& Kaplan, D. (1992). A comparison of some methodologies for the factor analysis of non-normal Likert variables: A note on the size of the model. British Journal of Mathematical and Statistical Psychology, 45(1), 19-30.

Norris, A. E., \& Aroian, K. J. (2004). To transform or not transform skewed data for psychometric analysis: That is the question! Nursing Research, 53(1), 67-71.

Nunnally, J. C (1978). Psychometric theory (2 ${ }^{\text {nd }}$ ed.). New York, NY: McGraw-Hill.

O'connor, B. P. (2000). SPSS and SAS programs for determining the number of components using parallel analysis and Velicer's MAP test. Behavior Research Methods, Instruments, \& Computers, 32(3), 396-402. 
Omar, H., \& Jaafar, A. (2010, March). Heuristics evaluation in computer games. In International Conference on Information Retrieval \& Knowledge Management, (CAMP), (pp. 188-193). IEEE.

Paavilainen, J. (2010, May). Critical review on video game evaluation heuristics: Social games perspective. In Proceedings of the International Academic Conference on the Future of Game Design and Technology (pp. 56-65). ACM.

Pagulayan, R. J., Steury, K. R., Fulton, B., \& Romero, R. L. (2005). Designing for fun: User-testing case studies. In M. A. Blythe, K. Overbeeke, A. F. Monk, \& P. C. Wright (Eds.), Funology: From usability to enjoyment (pp. 137-150). Boston, MA: Kluwer Academic Publishers.

Papaloukas, S., Patriarcheas, K., \& Xenos, M. (2009, September). Usability assessment heuristics in new genre videogames. In Proceedings of the 2009 13th Panhellenic Conference on Informatics (pp. 202-206). IEEE.

Parnell, M. J. (2009). Playing with scales: Creating a measurement scale to assess the experience of video games. (Master's thesis). Available from http://www.ucl.ac.uk/uclic/

Pavlas, D., Jentsch, F., Salas, E., Fiore, S. M., \& Sims, V. (2012). The Play Experience Scale Development and Validation of a Measure of Play. Human Factors: The Journal of the Human Factors and Ergonomics Society, 54(2), 214-225.

Peng, C.-Y. J., Harwell, M., Liou, S.-M., \& Ehman, L. H. (2006). Advances in missing data methods and implications for educational research. In S. Sawilowsky (Ed.), Real data analysis (pp. 31-78). Greenwich, CT: Information Age.

Pinelle, D., Wong, N., \& Stach, T. (2008, April). Heuristic evaluation for games: Usability principles for video game design. In Proceedings of the SIGCHI Conference on Human Factors in Computing Systems (pp. 1453-1462). ACM.

Pinelle, D., Wong, N., Stach, T., \& Gutwin, C. (2009, May). Usability heuristics for networked multiplayer games. In Proceedings of the ACM 2009 International Conference on Supporting Group Work (pp. 169-178). ACM.

Qin, H., Rau, P.-L. P., \& Salvendy, G. (2009). Measuring player immersion in the computer game narrative. International Journal of Human-Computer Interaction, 25(2), 107-133.

Roth, P. L. (1994). Missing data: A conceptual review for applied psychologists. Personnel Psychology, 47(3), 537-560.

Russell, D. W. (2002). In search of underlying dimensions: The use (and abuse) of factor analysis in Personality and Social Psychology Bulletin. Personality and Social Psychology Bulletin, 28(12), 1629-1646. 
Schafer, J. L. (1999). Multiple imputation: A primer. Statistical Methods in Medical Research, 8(1), 3-15.

Schafer, J. L., \& Graham, J. W. (2002). Missing data: Our view of the state of the art. Psychological Methods, 7(2), 147-177.

Schlomer, G. L., Bauman, S., \& Card, N. A. (2010). Best practices for missing data management in counseling psychology. Journal of Counseling Psychology, 57(1), 1-10.

Shelley, B. (2001, August 15). Guidelines for developing successful games. Gamasutra. Retrieved from http://www.gamasutra.com/view/feature/131450/

Song, S., Lee, J., \& Hwang, I. (2007). A new framework of usability evaluation for massively multi-player online game: Case study of "World of Warcraft" game. In Human-Computer Interaction. $\mathrm{HCl}$ Applications and Services (pp. 341-350). Springer Berlin Heidelberg.

Stafford, S., Preisz, E., \& Greenwood-Ericksen, A. (2010, September 10). Usability breakthroughs: Four techniques to improve your game. Gamasutra. Retrieved from http://www.gamasutra.com/view/feature/134501/

Steiger, J. H., \& Lind, J. C. (1980, June). Statistically based tests for the number of common factors. Paper presented at the Psychometric Society annual meeting, lowa City, IA.

Sweetser, P., Johnson, D. M., \& Wyeth, P. (2012). Revisiting the GameFlow model with detailed heuristics. Journal: Creative Technologies, 2012(3).

Sweetser, P., \& Wyeth, P. (2005). GameFlow: A model for evaluating player enjoyment in games. Computers in Entertainment (CIE), 3(3), 1-24.

Tabachnick, B. G., \& Fidell, L. S. (2007). Using multivariate statistics (5 ${ }^{\text {th }}$ ed.). Boston, MA: Pearson.

Tan, J. L., Goh, D. H. L., Ang, R. P., \& Huan, V. S. (2010, October). Usability and playability heuristics for evaluation of an instructional game. In World Conference on E-Learning in Corporate, Government, Healthcare, and Higher Education (Vol. 2010, No. 1, pp. 363373).

Totilo, S. (2012, July 9). The difference between a good video game and a bad one. Kotaku. Retrieved from http://kotaku.com/5924387/the-difference-between-a-good-videogame-and-a-bad-one

Treiblmaier, H., \& Filzmoser, P. (2010). Exploratory factor analysis revisited: How robust methods support the detection of hidden multivariate data structures in IS research. Information \& Management, 47(4), 197-207. 
Tsikriktsis, N. (2005). A review of techniques for treating missing data in OM survey research. Journal of Operations Management, 24(1), 53-62.

Wang, L., Fan, X., \& Willson, V. L. (1996). Effects of nonnormal data on parameter estimates and fit indices for a model with latent and manifest variables: An empirical study. Structural Equation Modeling: A Multidisciplinary Journal, 3(3), 228-247.

White, G. R., Mirza-Babaei, P., McAllister, G., \& Good, J. (2011, May). Weak inter-rater reliability in heuristic evaluation of video games. In CHI'11 Extended Abstracts on Human Factors in Computing Systems (pp. 1441-1446). ACM.

Witmer, B. G., \& Singer, M. J. (1998). Measuring presence in virtual environments: A presence questionnaire. Presence: Teleoperators and Virtual Environments, 7(3), 225-240.

Worthington, R. L., \& Whittaker, T. A. (2006). Scale development research a content analysis and recommendations for best practices. The Counseling Psychologist, 34(6), 806-838.

Zygmon, C., \& Smith, M. R. (2014). Robust factor analysis in the presence of normality violations, missing data, and outliers: Empirical questions and possible solutions. The Quantitative Methods for Psychology, 10(1), 40-55. 


\section{CHAPTER 2}

\section{EXTENDED LITERATURE REVIEW}

\section{Video Game Background}

Ever since Computer Space and Pong were released commercially in the 1970s, video games have grown to be a widely accepted form of digital entertainment around the world. Today, video games are a thriving, multi-billion dollar industry that appeals to a broad range of demographics - not just the traditional teenage male audience of the past. The Entertainment Software Association (ESA, 2014) reported that close to $60 \%$ of Americans play video games, and over \$21 billion have been spent on the video game industry in the U.S. alone. Additionally, nearly $40 \%$ of gamers are over 35 years old, and almost half of video game players and purchasers are females. A leading information technology research company has predicted that the worldwide spending on video games will increase by \$32 billion from 2012 to 2015 (Gartner, 2013).

The popularity of video games has not only generated much attention from the general public and media, but video gaming as a research topic has garnered considerable interest within the academic community. In the past 30 years, there have been numerous research articles written about video games. However, many published papers have primarily focused on reporting the adverse effects of playing video games. Specifically, from the mid-1990s to the mid-2000s video game researchers were captivated by topics such as the relationship between video games and violent behaviors (Anderson, 2004; Anderson \& Bushman, 2001; Dill \& Dill, 1998; Griffiths, 1999), video game addiction (Fisher, 1994; Grüsser, Thalemann, \& Griffiths, 2006; Tejeiro Salguero \& Morán, 2002), and the negative effects of video games on physical and 
mental well-being (Anand, 2007; Chan \& Rabinowitz, 2006; Fling et al., 1992; Vandewater, Shim, \& Caplovitz, 2004).

Despite the overwhelming interest in the harmful effects of video games, there has been a growing body of literature within the research domain that focuses on the benefits of playing video games. Numerous cross-sectional, training, and physiological studies have provided converging evidence that playing video games can improve one's sensory, cognitive, and perceptual abilities (Bavelier, Green, Pouget, \& Schrater, 2012; Latham, Patston, \& Tippett, 2013; Spence \& Feng, 2010). The beneficial effects observed from video games are not limited to basic abilities such as visuomotor coordination and speed (Griffith, Voloschin, Gibb, \& Bailey, 1983; Yuji, 1996), contrast sensitivity (Li, Polat, Makous, \& Bavelier, 2009), and multiple object tracking (Green \& Bavelier, 2006), but they also extend to more complex and high-level skills like creativity (Jackson, 2012) and decision making (Green, Pouget, \& Bavelier, 2010). Moreover, research has shown that, aside from healthy young adults, children and people with developmental disorders (Franceschini et al., 2013; Li, Ngo, Nguyen, \& Levi, 2011) as well as older adults (Anguera et al., 2013; Basak, Boot, Voss, \& Kramer, 2008) can also reap similar benefits by playing video games.

In the recent years, research findings on the positive effects of video games have started to reach different popular media outlets such as TV, newspapers or magazines, and social media (Gallagher, 2013; Guarini, 2013; Reilly, 2012; Shapiro, 2013; TEDxTalks, 2012). Slowly, people have become more interested in video games as they find more reasons to play them. Importantly, parents are noticing of the positive effects video games have on children. ESA 
(2014) reported that over $55 \%$ of parents in the U.S. believing that video games help children learn and stimulate their mind, as well as help children stay connected with family and friends.

As the demand for video games increases, game producers, designers, and developers will further face the challenge of creating games that are enticing and enjoyable to play. However, creating a game that people want to play is not an easy task. A quick look at the landscape of commercially released games alone shows that, for over 20 years, the game market is saturated with more than 1,000 new video games each year (MobyGames, 2015). This saturation problem creates a challenging task for the average gamer when trying to narrow down the games to play and purchase. In addition, it contributes to the construction of a highly competitive industry with a reported 95\% failure rate for newcomers (International Game Developers Association [IGDA], 2004).

In the quest to develop games that will be well received by game players, game creators tend to look at previous commercially successful games for winning strategies. Yet, what qualities are common among video game series that have sold over 100 million copies such as Super Mario, Final Fantasy, Call of Duty, The Sims, and Grand Theft Auto (Newberry, 2013; Nintendo, 2011; Sinclair, 2010; Square Enix, 2013)? And what sets Candy Crush Saga apart from other similar concept games (e.g., Jewel Mania, Full Bloom) for it to become the most popular social game in 2013 with over 50 million monthly active users (Lafferty, 2013)? Indeed, devising the winning formula is a daunting task considering that there are many different elements that vary between past successful games (e.g., platform, genre, plot, and graphics).

It is of no surprise then to hear working professionals in the video game industry refer to the process of designing good games as more of an art than science (Chalker, 2008; Schell, 
2008). Ask anyone heavily involved in video games about what she or he would consider are the driving qualities of good games versus bad games and there will likely be a myriad of answers. This is because such discussion tends to be deemed as a matter of personal taste or "in the eye of the beholder". Nevertheless, that has not deterred video game enthusiasts from formulating their opinions on the so-called subjective matter.

Interviews with video game designers have revealed that they have different philosophies concerning quality game design (Aycock, 1992). Some game designers believe fun is the key element in the making of exceptional games. However, fun is as much of an abstract term as good, and thus, game designers continue to struggle defining the essential elements of fun. Other game-developing professionals think the best games are the ones that are simple to play (e.g., Tetris, Pong). Similar to fun, simplicity is another difficult concept to grasp in game design as it can vary in terms of game control, rules, storyline, interface, et cetera. Last but not least, some designers would not consider a game to be good or successful without taking into account game plot and technology.

Over the years, there remains a lack of consensus among video game aficionados in deciding what features are essential to the success of video games. Some people believed that good games are ones that offer many interesting decisions for the player to make (Shelley, 2001; Totilo, 2012). Still, there are others who believed that there are other essential features that most successful games shared with each other. For instance, some game developers considered commercial or universal appeal and originality to be the key factors in the making of successful games (Chalker, 2008; Shelley, 2001; Totilo, 2012). Additionally, other game-making 
professionals cited having attractive graphics, quality sound and music, accessible gameplay, and/or easy to understand game rules as the crucial building blocks of a highly satisfying game.

It is of no surprise that the lack of agreement on the principles of video game design persists as there is still an ongoing disagreement about the definition of various video game terminologies. For example, through interviews with different video game companies Collins (1997) found that working professionals have trouble defining "gameplay," a term that is commonly used in the industry. Similar to good game principles, the definition of gameplay also changes depending on the individual and game company. In short, the problem of unclear terminology and design standards presents a difficult hurdle to overcome for many game developers whose aim is simply to create excellent games for people to enjoy.

\section{Usability and Video Games}

In an effort to help game developers and designers create better games, researchers have suggested that the video game industry integrates usability in the video game making process (Federoff, 2002; Laitinen, 2005). In comparison with other applied fields (e.g., architecture, aerospace engineering, marketing), usability is a recently established field that mostly started in the 1980s (Sauro, 2013). Much of the history of usability is closely tied with the history of earlier fields of human factors and ergonomics (HFES). HFES are cross-disciplined fields that mainly focus on improving user safety, performance, and satisfaction with any tools and in any environments (Wickens, Lee, Liu, \& Gordon-Becker, 2003).

For the general public, the term usability represents the ease of use or the degree of user friendliness of a tool or product. However, to usability researchers and practitioners the term refers to a multi-dimensional concept comprising of elements such as learnability, 
efficiency, user performance, and satisfaction (Abran, Khelifi, Suryn, \& Seffah, 2003; Hornbæk, 2006). Being one of the young and emerging fields, the field of usability also suffers similar problems of inconsistent definitions and lack of standardization as in the video game industry. These problems are mainly due to usability being a context-dependent concept. Thus, depending on the target audience, tasks, and environments the properties of usability will be altered.

Within the International Organization for Standardization (ISO), there were two different paradigms for usability (Abran et al., 2003). The lesser-known paradigm was developed by software engineering experts and is product-focused (ISO/IEC 9126, 2001). The more widely accepted paradigm was developed by Human-Computer Interaction $(\mathrm{HCl})$ experts and is process-focused (ISO 9241, 1992; 2010). Within the ISO/IEC 9126 standards, usability is defined by five attributes: understandability, learnability, operability, attractiveness, and usability compliance (ISO/IEC 9126-1, 2001). Conversely, the ISO 9241 standards defined usability by three attributes: effectiveness, efficiency, and satisfaction (ISO 9241-11, 1998; see Figure 1). Recently, to improve consistency among the standards the ISO replaced the ISO/IEC 9126 with the ISO/IEC 25010 (2011). The ISO/IEC 25010 (2011) has four usability attributes (effectiveness, efficiency, satisfaction, and usability compliance) of which three are from the ISO 9241-11. 


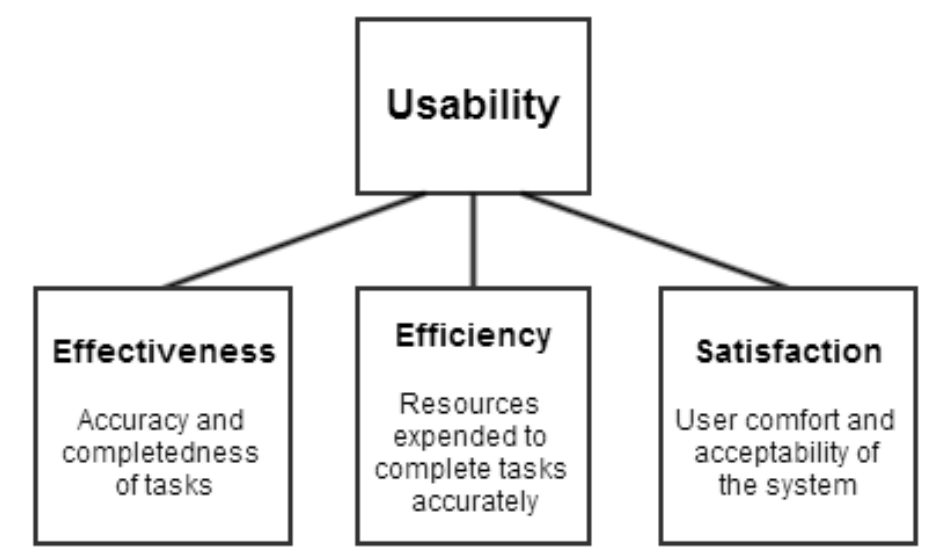

Figure 1. The most widely accepted usability paradigm (ISO 9241-11; 1998).

Aside from the ISO, other usability researchers and experts also came up with their individual definition of usability (Abran et al., 2003). One of the better-known definitions was formulated by one of the most influential researchers in the field of usability, Jakob Nielsen. According to Nielsen (1994), usability is defined by five components: learnability, memorability, efficiency, errors, and satisfaction. In order to resolve this discrepancy in defining usability Abran and colleagues (2003) have proposed a normative paradigm of usability (Enhanced Model of Usability; see Figure 2). This model combined the five essential characteristics of usability that are frequently embedded in the different usability definitions. Those five components are effectiveness, efficiency, satisfaction, security, and learnability. 


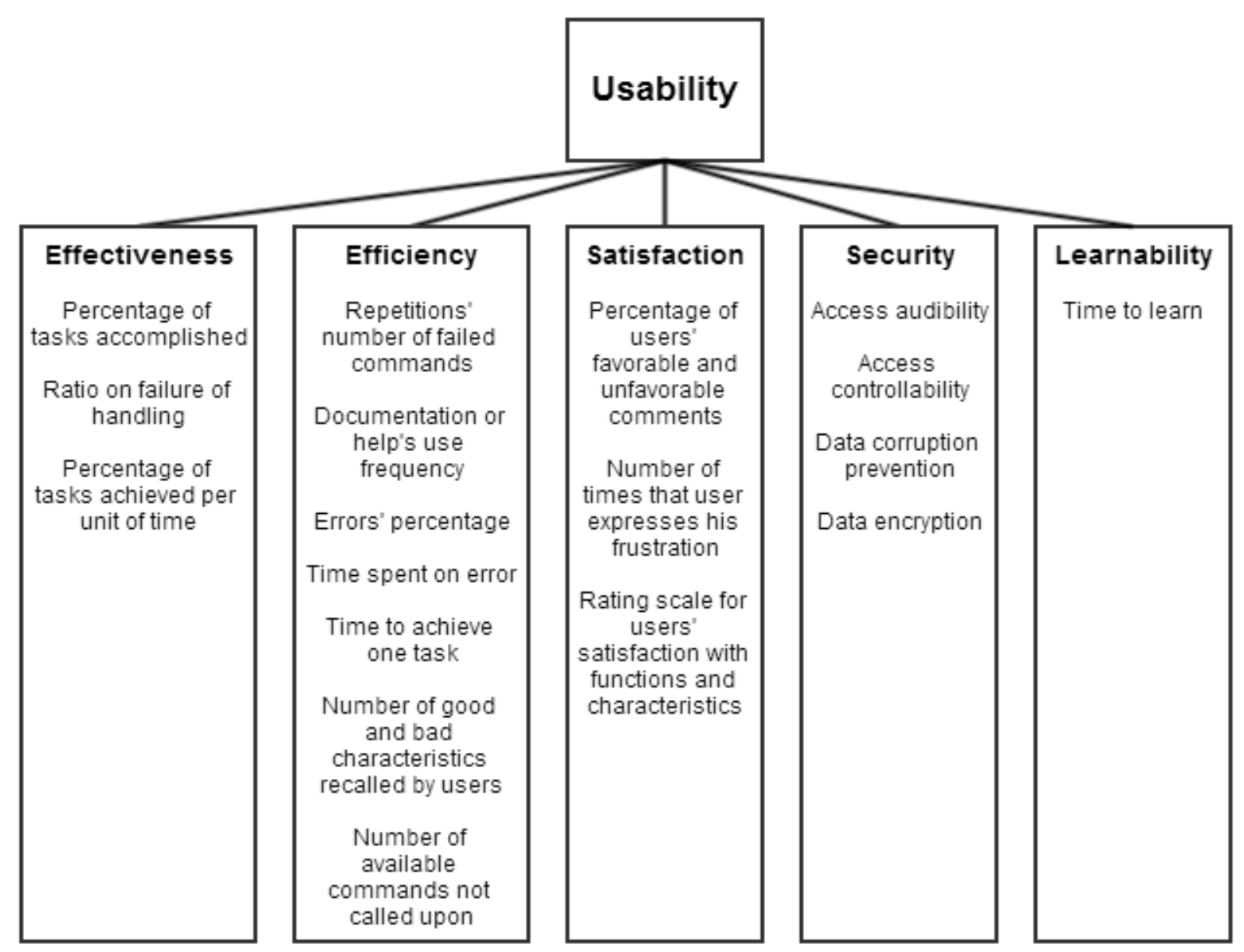

Figure 2. Abran and colleagues' (2003) Enhanced Model of Usability.

Despite the Enhanced Model of Usability (Abran et al., 2003) being a more comprehensive paradigm, much of the usability profession still broadly embrace and use the ISO 9241-11 (1998) usability paradigm. Although many professionals have adopted the same usability definition (i.e., ISO 9241-11), there are still discrepancies among these practitioners in relation to how they assess and measure usability. Hornbæk (2006) reviewed 180 published usability studies and discovered that there was a multitude of measures (e.g., recall, mental effort) that researchers have used to assess the three principal factors of usability.

Importantly, many of the measures were not standardized measures that raised validity and reliability concerns (Hornbæk, 2006). This was especially true for measures that intended 
to evaluate user satisfaction. According to Hornbæk, the majority of the studies failed to use one of the validated questionnaires available in the fields such as the Questionnaire for User Interface Satisfaction (QUIS; Chin, Diehl, \& Norman, 1988). Instead, much of the examined studies devised their own question or questions to measure different aspects of interface satisfaction (e.g., fun, engagement, intuitive). This problem led Hornbæk to demand more research be conducted to validate and standardize the existing stock of satisfaction questionnaires.

Although the issues that Hornbæk (2006) highlighted have yet to be resolved, the usability field has a lot to offer to the video game industry in terms of video game design and evaluation. In particular, discount usability methods (e.g., heuristic evaluation, cognitive walkthrough) can help game developers assess different game interfaces at relatively low cost (Stafford, Preisz, \& Greenwood-Ericksen, 2010). Additionally, there is a multitude of established usability measures (e.g., perceived mental workload, satisfaction scales) that can serve as useful references in the game evaluation process. Moreover, the common practice of usability testing (i.e., bringing in potential users of the system and have them use and evaluate it) can help game companies identify crucial design issues that the developer team might not be aware (Davis, Steury, \& Pagulayan, 2005; Fulton, 2002; Laitinen, 2005).

It is important to note that in addition to being relatively young fields, there are some commonality between the video game and usability fields. Both fields, for instance, has an obsession with catering to the users’ wants and needs (Jørgensen, 2004). Aside from being user-centered, both areas greatly value the iterative design approach in the process of building products like video games (Clanton, 1998). This method mainly involves iterative testing and 
refining of products from the early stage of conception to the later phase of development and prior to the official release date in order to improve product quality while lowering product cost (see Figure 3).

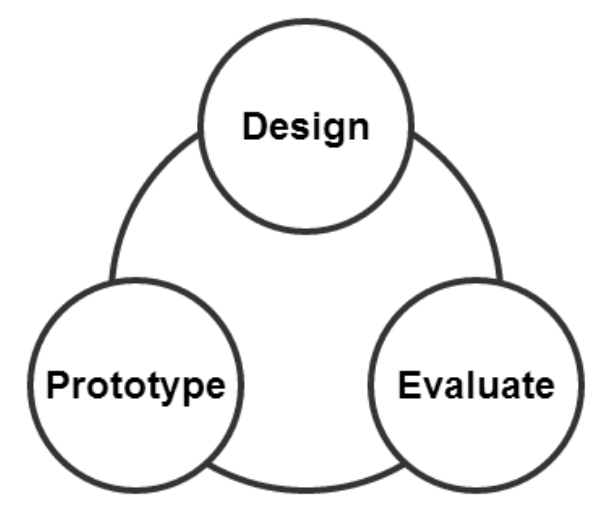

Figure 3. The iterative design cycle.

In relation to the evaluation process, the video game industry employs a method that is similar in nature to usability testing called playtesting. At a high level, traditional playtesting is much like traditional usability testing in the sense that game players are brought in a lab space to play a game and provide feedback (Collins, 1997; Fulton, 2002). However, usability testing is typically more structured than playtesting with specific tasks (e.g., adjust camera angle, open the mini-map), measures (e.g., time on task, error rates), and procedures (e.g., think-aloud protocol) clearly defined. In playtesting, the defined measure is usually a questionnaire administered at the end of the session to gauge the player's behaviors, attitudes, and preferences.

Standard usability testing also involves a highly trained moderator to interact with the participants throughout the testing session by guiding each participant through the evaluation process and probing participants with questions along the way. In standard playtesting there is 
minimal interaction between the moderator and the participants aside from the beginning of the session in which the moderator gives the introductory instructions. As a result, usability sessions tend to provide more insights into user feedback and experience than playtest sessions (Davis et al., 2005). Another significant difference between usability testing and playtesting is that more participants are needed for playtesting than usability testing. Typically, 25-35 participants for playtesting (each session last about one hour) versus 6-9 participants for usability testing (each session last about 2 hours; Fulton, 2002). In general, the standard usability testing does not require many users to test a system. Past research have found that running 5-6 users is sufficient to uncover the majority of usability-related issues (Lewis, 1982; Virzi, 1990; 1992).

Although both of the video game and usability fields shared some core characteristics, there has been very little interaction between the two fields until the recent years (Jørgensen, 2004). In particular, there has been a rise in research that attempted to integrate the key components of usability and the different usability techniques in the evaluation of video games (e.g., Bekker, Baauw, \& Barendregt, 2008; Cornett, 2004; Moreno-Ger, Torrente, Hsieh, \& Lester, 2012; Young, 2011). Overall, the majority of research was successful in applying standard usability measures and methods to identify critical game interface and usabilityrelated issues.

Specifically, researchers were able to detect both minor and major issues found in popular massively multiplayer online role-playing games (MMORPGs) through the implementation of usability testing and think-aloud protocol (Cornett, 2004; Song, Lee, \& Hwang, 2007). Cornett (2004) had 19 participants played one of four games (i.e., EverQuest, 
Anarchy Online, Dark Age of Camelot, and Neverwinter Nights), and asked them to complete various tasks related to the game (e.g., purchase an item from a vendor). During the process of playing the game, all participants were asked to think aloud their thoughts and voice any issues that they encountered in the game. Based on the task completion rate and subjective comments, Cornett was able to pinpoint 17 usability issues in the games. Of the 17 issues, six were critical issues (i.e., caused players to stop playing and sought assistance), five were major issues (i.e., slowed game progress or necessitated assistance), and six were minor issues (i.e., temporary issues that could be resolved by limited prompting).

Song et al. (2007) employed a similar methodology and have 18 participants played one of the most commercially success MMORPGs, World of Warcraft (WOW). They were able to uncover 18 issues in WOW. Using a similar severity scale as Cornett (2004), Song and colleagues were able to categorize eight out of 18 issues at a critical level. Across both studies, many of the identified issues were traditional usability issues (e.g., text readability or legibility, lack of feedback, lack of help or tutorials) that can commonly be found in other domains (e.g., website, productivity software). Even so, there were some issues that were unique to the video game environment (e.g., difficulty in changing camera view, difficulty in interacting with non-playable characters). In sum, these two studies demonstrated that traditional usability testing can serve as a powerful technique to uncover serious issues within a game. Notably, the issues found in MMORPGs were deemed to be detrimental to newcomers of the genre and the overall recruitment of new players to the genre (Cornett, 2004; Song et al., 2007).

More video game companies are starting to recognize the benefits of usability, and have employed usability professionals to help with game research and development. One of the first 
companies to understand the importance of usability in game development was Microsoft.

Since 1995, Microsoft has been one of the major companies that have begun to integrate usability into their game making division (Fulton, 2002). Currently, Microsoft has an independent research team consisting of approximately 20 professionals that help Microsoft evaluate game usability and conduct game-related research (Microsoft, 2013). This investment in usability and game research appeared to be a good decision for Microsoft, since it is currently one of the leaders in the video game business with their hit console series and bestselling game franchises and titles (e.g., Halo, Kinect Adventure).

One novel way in which Microsoft has applied usability in the video game setting was to use the feedback obtained from usability sessions to test whether a game effectively delivered the experience it was designed to deliver (Pagulayan, Steury, Fulton, \& Romero, 2005). During the development of the first title in the popular First-Person Shooter (FPS) Halo series, usability testing was conducted to confirm that the players' experience of the game matches the designers' intended experience. Results revealed that certain aspect of the game did not work like it was planned.

The game was designed to be the most fun when the players fought the enemy at a specific short range. However, novice players tended to fire their assault rifles from a considerable distance-longer than the intended range. Consequently, the designers made several changes in the game to ensure that players will engage in combat at a close distance. Some of those changes include having the enemy run and take shelter when shots were fired at a long range, and displaying aiming reticle to provide explicit feedback that shots will be more accurate in short range. Subsequent tests confirmed that the adjustments made were 
successful in getting players closer to the intended shooting range. Also, players perceived the game to be more enjoyable than before.

Aside from Microsoft, Disney also took initiatives to implement usability testing in their game development process. Usability testing was first conducted in the development of Pure (an off-road, trick-racing game) by Disney's Black Rock Studio (McAllister \& White, 2010). Usability tests were first ran among company staff who were not a part of the development team and then the testing expanded out to the general population of game players. Over the 4month evaluation course, the company had recruited about 100 participants to partake in the usability tests. Data from the testing allowed the designers to estimate a learning curve, which helped fine-tune the balance of challenge and engagement levels and motivate players to continue playing the game in order to increase their performance.

After its release, Pure was well received by the game critics. Pure also won awards for being the best racing/driving game at major video game events and networks (e.g., Electronic Entertainment Expo, IGN). The Game Director, Jason Avent, attributed the game's success to both his talented team and the usability tests that were employed during the game development (McAllister \& White, 2010). Avent further added that the usability evaluations were crucial in identifying major issues within the game, as well as helping to improve the Metacritic review score from $75 \%$ to $85 \%$. In short, the case studies from Microsoft and Disney have demonstrated that usability can play an integral role in the success of video games. Specifically, well-executed usability tests can give rich and detailed insights into the major gaming issues that were overlooked by the developer team. Not to mention, results obtained 
from usability tests often can be translated into actionable steps that are useful in improving game satisfaction.

Unfortunately, not all game companies shared the same value for usability as Microsoft or Disney. One of the main reasons being that some companies do not have enough knowledge about usability research and exposure to the usability field. Consequently, they failed to see how usability can fit in game design and how usability can be beneficial to the game development process. Another major reason is that many video game companies are small businesses consisting of only a few team members. Thus, these companies are limited by the amount of available resources and budget to implement usability research and techniques fully in the game development cycle.

\section{Video Game Heuristics}

In order to help small video game companies increased their likelihood of success, some video game developers and researchers have started to compile formal game design guidelines to help independent game developers and companies produce better games. One notable effort is the 400 Project led by two reputable game designers, Noah Falstein and Hal Barwood. This is an ambitious project that started in 2001 in which both designers were trying to collect 400 rules of good game design from their game making experience as well as from other game designers. Although the over-100-rules document is still available online, the project has not been active for over seven years (Barwood \& Falstein, 2006).

Additionally, a growing number of papers have been published in recent years about the heuristics of video game design (e.g., Desurvire, Caplan, \& Toth, 2004; Desurvire \& Wiberg, 2009; Korhonen, 2011; Pinelle, Wong, \& Stach, 2008; Rodio \& Bastien, 2013). The heuristics are 
serving as standard design guidelines to assist game making professionals and researchers in evaluating different video games. Typically, a list of heuristics will be used by a group of experts in a process called heuristic evaluation or expert review. In an expert review, evaluators used a design checklist and scrutinized a product to determine if it has followed all of the criteria in the checklist. Table 22 provides a sample list of game heuristics.

TABLE 22

A SAMPLE LIST OF GAME HEURISTICS (DESURVIRE ET AL., 2004)

\begin{tabular}{ll}
\hline Category & Heuristic and Description \\
\hline Game Play & $\begin{array}{l}\text { Provide clear goals, present overriding goal early as well as short-term } \\
\text { goals throughout play. }\end{array}$ \\
Game Play & $\begin{array}{l}\text { Player should not experience being penalized repetitively for the same } \\
\text { failure. }\end{array}$ \\
Game Story & $\begin{array}{l}\text { Player is interested in the story line. The story experience relates to their } \\
\text { real life and grabs their interest. }\end{array}$ \\
Game Story & $\begin{array}{l}\text { Player experiences fairness of outcomes. } \\
\text { Mechanics }\end{array}$ \\
Controls should be intuitive, and mapped in a natural way; they should \\
be customizable and default to industry standard settings. \\
Usability & $\begin{array}{l}\text { Shorten the learning curve by following the trends set by the gaming } \\
\text { industry to meet user's expectations. }\end{array}$ \\
Usability & Provide immediate feedback for user actions. \\
\end{tabular}

There are some considerable benefits to using these general guidelines for video game developers and companies. Particularly, the heuristics are freely available online, and they are useful in helping game makers identify the major and quick fixes (Stafford et al., 2010). In addition, the heuristics are applicable to a variety of video games. Researchers have developed separate lists of heuristics for mobile (Korhonen \& Koivisto, 2006), mobile multi-player (Korhonen \& Koivisto, 2007), networked multiplayer (Pinelle, Wong, Stach, \& Gutwin, 2009), 
real-time strategy (RTS; Sweetser, Johnson, \& Wyeth, 2012; Sweetser \& Wyeth, 2005), health/fitness (Papaloukas, Patriarcheas, \& Xenos, 2009), social (Paavilainen, 2010; Papaloukas et al., 2009), instructional (Tan, Goh, Ang, \& Huan, 2010), and educational (Omar \& Jaafar, 2010) games.

Unfortunately, heuristics alone cannot sufficiently help game developers improve their video game design or increase their games' success rate. Researchers have cautioned that there are potential issues that people must consider before planning to use the game heuristics for game design and evaluation purposes (Stafford et al., 2010; White et al., 2011). For example, heuristics can be difficult to apply effectively without prior training or experience. Also, using heuristics to evaluate a game can yield unfruitful results when the people who are creating the game are doing the evaluations. This is because such individuals tend to bring their biases of how the game should work in the evaluation process.

Then there are other issues that involve reliability and interpretation (Stafford et al., 2010; White et al., 2011). Due to having no response options and the ambiguity of some of the game heuristics, evaluators can struggle in determining whether particular guidelines have been correctly implemented in a game or not (Stafford et al., 2010). For instance, how should evaluators assess the statement of having animations that will not detract the players from the game? By "Yes" or "No" response, by 5-point or 10-point rating scale? In addition, research has shown that there is a lack of agreement among the people who evaluate games when they used the same game heuristics (White et al., 2011). Even with all issues considered, some game developers might be reluctant to use or adhere to the game heuristics as the heuristics can be perceived to be limiting their creativity (Farnsworth, 2007; Stafford et al., 2010). 
Due to a general lack of awareness about usability, it is often difficult for usabilityoriented techniques (e.g., heuristic evaluation and usability testing) to be widely adopted by professionals in the video game industry. In a case study, Melissa Federoff (2002) spent one week shadowing and observing different members of a leading game development firm in California. She found that the term usability was an unfamiliar concept among the majority of the team members. Additionally, the one member who was familiar with the term experienced great difficulty in relating usability to video games. For that member, usability is a concept that more applicable to the building of productivity software, and not for entertainment software such as video games.

Another study that sought insights from the professionals who worked in the game industry and found that there was a strong preference for using industry resources (e.g., websites, practices) over academic resources (e.g., research papers, techniques; Farnsworth, 2007). In particular, the game designers in the study reported to twice as likely to utilize industry resources over academic resources. In addition, the surveyed game designers were found to have overall less knowledge about usability-related techniques (e.g., design and usability heuristics). The designers were also reported to perceive the utility of such techniques to be significantly less than industry techniques (e.g., playtesting).

This issue of the game industry not understanding usability and recognizing the benefits of usability in the game development process might be due to the youth of the usability field and the term "usability" itself. The word usability denotes "use" and "usefulness", which operates well when people consider any tools and equipment in the realm of productivity (e.g., word processing programs, spreadsheets). On the other hand, with the exception of serious or 
applied games (e.g., educational, health), people do not usually regard video games in terms of use or usefulness. Instead, people tend to view video games through the entertainment mindset. After all, video games are not intended to be used, but to be played. And for play purposes, factors such as fun, immersion, and challenge can significantly influence the player's enjoyment of a game (Desurvire \& Wiberg, 2010; IJsselsteijn, de Kort, Poels, Jurgelionis, \& Bellotti, 2007; Sánchez, Vela, Simarro, \& Padilla-Zea, 2012; Song et al., 2007).

However, it is hard to assess a video game comprehensively through the traditional usability paradigms since essential game characteristics (e.g., fun, immersion) are not included (Hornbæk, 2006). Additionally, some traditional usability criteria do not completely work well with video games (Federoff, 2002; Song et al., 2007). Consider the typical usability measures of efficiency (e.g., percentage of task success rate) and effectiveness (e.g., time to complete a task), those measures are less relevant in the context of video games which place more emphasis on pleasurable aspects like novelty, exploration, discovery, and overcoming challenges (Davis et al., 2005; IJsselsteijn et al., 2007; Pagulayan, Keeker, Wixon, Romero, \& Fuller, 2003; Rajanen \& Marghescu, 2006; Song et al., 2007). In short, while having high task failure rate and long time on task are likely to indicate problematic products in the world of productivity software. However, in the gaming world they are likely to suggest that a video game is fun because it is challenging and immersive.

\section{User Satisfaction and Video Games}

Given that the primary goal of video games is to entertain the players, Federoff (2002) has suggested that user satisfaction be a crucial measure in the evaluation of video games. Satisfaction has always been a central theme in the $\mathrm{HCl}$ domain, especially in the user 
experience (UX) and usability fields (Albert \& Tullis, 2013; Bevan, 2009). For example, ISO 924111 (1998) defined satisfaction in relation to a user's comfort and acceptability of using a system. Recently, ISO/IEC 25010 (2011) defined satisfaction as the user's reaction and attitudes towards using a product or system.

There are four properties that ISO/IEC 25010 (2011) listed under satisfaction, which are usefulness, pleasure, comfort, and trust. Usefulness refers to the degree to which a system's functionality met a user's expectations. Pleasure involves a user's positive feelings when a system meets his or her personal needs. Comfort relates to a user's assessment regarding whether the physical comfort of a system is well suited for himself or herself. Finally, trust refers to the degree to which a user believe that a system will work appropriately.

Generally, satisfaction has been widely adopted as a broad term to describe a user's general feelings and experience with a particular system or product (Albert \& Tullis, 2013; Hornbæk, 2006; Wixom \& Todd, 2005). In particular, Albert and Tullis (2013) viewed satisfaction as "the degree to which the user was happy with his or her experience while performing the task" (p. 7). Consequently, in relation to video games, satisfaction will be defined as the degree to which the player feels gratified with his or her experience while playing a video game.

In both academic and professional worlds, user satisfaction is typically collected through some form of a survey or questionnaire, and is usually administered after the users have finished using a product, system, or service (Albert \& Tullis, 2013; Hornbæk, 2006; Wixom \& Todd, 2005). Some examples of well-known satisfaction questionnaires include: the System Usability Scale (SUS; Brooke, 1996), the Questionnaire for User Interface Satisfaction (QUIS; 
Chin et al., 1988), and the Computer System Usability Questionnaire (CSUQ; Lewis, 1995). These three questionnaires though similar in concept are different in terms of format (e.g., total number of items, response scale, and the number of subscales).

Many fields have successfully implemented satisfaction measures in the assessment of different products or systems. Thus, there is little reason to believe that measuring user satisfaction will not be a suitable method for the evaluation of video games. Albert and Tullis (2013) asserted that measuring satisfaction is a good way to obtain a summary about the entire user experience of a product or system. Measures of satisfaction were also thought to be most appropriate for products or systems where the users have a preference, such as in the case of video games. Moreover, other researchers have declared that the fact that there are many players ended up playing a particular game repeatedly and for an extended duration is a good indicator of user satisfaction (Febretti \& Garzotto, 2009).

While the terms user satisfaction are less frequently mentioned in the field of video games in comparison to the UX and usability fields, the acts of measuring the player's attitudes and reaction concerning a particular video game is not a foreign concept in the video game industry. Specifically, game developers have been known to rely on the feedback obtained from the gamers themselves to improve the design of a game in development (Fulton, 2002). This is typically done through some form of playtesting. In playtesting, a selected group of gamers are invited to come to a lab space to play the game or are provided with beta copies of the game to play at home. After the play session, feedback about the game will be elicited using a questionnaire (Collins, 1997; Fulton, 2002; Pagulayan et al., 2003). 
This method of collecting user evaluation of different video games through

questionnaires is a common practice among major video games companies (e.g., Microsoft). In particular, Microsoft game researchers tended to prefer using the survey technique than the traditional usability tests in assessing video game issues (Pagulayan et al., 2003). This is because traditional usability tests mainly focus on measuring user performance, which are better suited for productivity products or systems. On the other hand, surveys are primarily intended to measure the player's attitudes and expectations. Moreover, in the video game realm, attitude methodologies (e.g., surveys) are more appropriate than performance-based methodologies in capturing important and abstract gaming factors (e.g., fun, challenge, and immersion).

Overall, results obtained from playtesting sessions can help game developers build better games by providing insights into the game players' attitudes, preferences, and behaviors. Playtesting results also let game developers know whether their games were played as intended. Additionally, feedback gathered from playtesting sessions tended to carry more weight with game developers since it came directly from the target population. In order for game developers to obtain meaningful results from playtesting sessions, quality feedback must be gathered from participants. However, whether quality feedback can be obtained is largely depended on the type and quality of the questionnaire used in the sessions.

Measuring user satisfaction, thus, becomes the key to uncovering issues embedded in the game and improving the game's success. It is assumed that when players have a satisfying experience with the game in development that such game has adhered to sound design principles and will likely to perform well once it is released in the market. Currently, there exist various questionnaires or scales measuring different aspects of gaming. However, most are not 
suitable to be used in playtesting settings or to assess video game satisfaction comprehensively for a number of reasons such as:

- Measure only one aspect of gaming (e.g., social presence, narratives)

- Are limited to certain games or genres (e.g., Educational)

- Do not cover other important gaming aspects (e.g., usability, social interaction)

- Are developed strictly for research purposes and not for evaluation purposes

- Contain items that are difficult to understand or interpret

- Do not follow the "best practices" of scale development and validation

Appendix A provides a summary of the key strengths and weaknesses of many of the existing gaming questionnaires or scales based on the discussions in the literature concerning video games and scale development best practices.

\section{Theoretical Considerations in Measuring Video Game Satisfaction}

Similar to measuring satisfaction in other domains, measuring satisfaction for video games is not an easy and straightforward process. It is not as simple as asking a few questions regarding how much people like or dislike a certain game. This is because video game satisfaction is a multi-dimensional construct that involve different dimensions such as immersion, fun, aesthetics, and motivation (Federoff, 2002). Consequently, in order to develop a more comprehensive game questionnaire, it is essential to investigate some important concepts that have been frequently discussed in the video game literature in relation to game satisfaction and enjoyment. 


\section{Engagement.}

The term "engagement" has been frequently used in the literature to describe different concepts such as school engagement (Appleton, Christenson, Kim, \& Reschly, 2006), reading engagement (Douglas \& Hargadon, 2000), job engagement (Schaufeli \& Bakker, 2004), and audience engagement (Webster \& Ho, 1997). In the field of video games, there is a lack of consensus on the concrete definition of engagement (e.g., Brown \& Cairns, 2004; Downs, Verte, Howard, \& Loughnan, 2013; Jones, 1998; Mayes \& Cotton, 2001). Despite the various ways engagement is defined, the term is typically used in a generic context to depict a player's level of involvement in video games (Brockmyer et al., 2009; Parnell, 2009; Qin, Rau, \& Salvendy, 2009). Also, researchers tended to agree on the notion that engagement plays a significant role in game satisfaction and enjoyment, and that a deep level of engagement is an indicator of good games.

Researchers also tended to view engagement as a complex construct that consists of multiple dimensions. Wiebe, Lamb, Hardy, and Sharek (2014) conducted an exploratory factor analysis to extend the use of the original User Engagement Scale by O'Brien and Toms (2010) to the context of game-based settings. They found that game-play engagement was composed of four primary factors called focused attention, perceived usability, aesthetics, and satisfaction. Focused attention referred to the player's degree of concentration on the game itself while ignoring everything else. Perceived usability related to the general ease of use of the website interface in which the player interacted with to play games. Aesthetics centered on the visual appeal of the gaming website. Finally, satisfaction involved the degree to which the player thinks his or her gaming experience was enjoyable and worthwhile. 
Conversely, Chen, Kolko, Cuddihy, and Medina (2011) developed a more complex paradigm of engagement. According to the researchers, engagement was said to be caused three key factors: personal interest, attention, and immersion. Each of the factors was also theorized to be mediated by other relevant factors. For example, social relationship was thought to be the critical factor influencing personal interest. Attention and immersion were said to be influenced by multiple factors (e.g., challenge level; curiosity and level of exploration; interface usability; audio and visual fidelity). Currently, this paradigm is in a conceptual stage, and more research is needed to refine and validate it. Appendix B shows Chen and colleagues' (2011) paradigm of engagement.

Finally, engagement was also thought to be directly connected with other multifaceted concepts that have been frequently discussed in the literature (e.g., presence, cognitive absorption, flow, and immersion; Brockmyer et al., 2009; Qin et al., 2009). In particular, Brockmyer and colleagues (2009) considered terms such as presence and immersion to be narrower terms used to describe a certain degree of engagement when playing violent video games. Results from conducting classical and Rasch analyses suggested to these researchers that engagement can be conceptualized as a spectrum. For instance, at the lower end of engagement a player is said to experience simple immersion. As the level of engagement progress to the higher end where there is a distorted sense of consciousness, a player is thought to be experiencing what researchers typically characterized as flow and psychological absorption. Whether or not one shares these researchers' views, it is still necessary to examine these concepts that were considered to be closely related to the engagement construct in further details. 


\section{Immersion.}

Even though the term immersion is frequently used in the video game industry, it also suffers from similar definitional issues as engagement. Some researchers described immersion as the feeling of being fully submerged in a fictional gaming environment (Qin et al., 2009). Other researchers depicted immersion as being involved in one's gaming experience while possessing some awareness of the outside world (Brockmyer et al., 2009). Moreover, there is a tendency for researchers to use immersion synonymously with engagement (e.g., Brooks, 2003; Brown \& Cairns, 2004; Coomans \& Timmermans, 1997; Jennett et al., 2008). In relation to virtual reality and other conventional media (e.g., books and movies), immersion was characterized as the deep feeling of engagement in which an individual perceived the makebelieve world to be real (Coomans \& Timmermans, 1997).

Using Grounded Theory, Brown and Cairns (2004) constructed three levels of immersion called engagement, engrossment, and total immersion. Engagement is the first stage of immersion and is deemed as the lowest level of involvement. In order to enter this stage, two barriers involving gaming preference (access) and learning how to play the game (investment) must be overcome. As the player entered the engrossment stage, he or she becomes more absorbed in the game and gradually lose awareness of his or her surroundings. The primary barrier to overcome in this stage is game construction in which games with well-constructed features (e.g., graphics, sounds, and story) are likely to shape the gamer's emotions.

Finally, Brown and Cairns (2004) considered total immersion to be synonymous with the concept of presence, where the player perceived that he or she is enveloped by the game and detached from reality. The researchers considered total immersion as a fleeting experience, 
and in order for total immersion to occur two barriers concerning empathy and atmosphere must be cleared. Empathy refers to the player's attachment to the characters in the game and atmosphere refers to the game features being relevant to the activities and position of the characters in the game. According to these researchers, emotional involvement appears to be an essential characteristic in immersion. These researchers also expressed that immersion is not a required ingredient for game enjoyment, but a player is more likely to enjoy the game as he or she becomes more immersed in it.

Brown and Cairns' (2004) classification of immersion is useful in understanding the variations in the level of involvement a player may experience when playing video games. However, some researchers felt that it is too one-dimensional and not adequate to cover the different types of involvement. Specifically, researchers have asserted that immersion is a narrative-based experience, in which one becomes deeply involved with a scenario or plot (Brooks, 2003; Douglas \& Hargadon 2000; McMahan, 2003; Qin et al., 2009). McMahan (2003) has stated that for immersion to occur in 3-D computer games three conditions must be met. First, the game's conventions must match with user expectations. Second, user actions must have significant influence over the game's environment. Third, the game's conventions must be logical. All in all, McMahan considered narratives to be a crucial element in defining gaming conventions as well as helping users align their expectations appropriately with these conventions.

In an effort to acquire a more comprehensive understanding of immersion, Ermi and Mäyrä (2005) developed the SCI paradigm. The SCI paradigm was inspired bv observations of children playing games and interviews with game-playing children and their parents. In the $\mathrm{SCl}$ 
paradigm, the researchers classified immersion into three main groups: sensory, challengebased, and imaginative immersion. Sensory immersion involved the audio and visual aspects of a game that captured the player's interest and attention. Challenge-based immersion related to the balance between challenges and skills - games that managed to balance well these two features are thought to be highly immersive. Lastly, imaginative immersion comprised of the various narrative aspects of a game (e.g., characters, stories) that enthralled the player. In an effort to validate the $\mathrm{SCI}$ paradigm, these researchers developed an 18-item scale called Gameplay Experience Questionnaire to measure these three types of immersion. Appendix C provides an illustration of the $\mathrm{SCl}$ paradigm.

Although questionnaires can be used to measure immersions subjectively, Jennett and colleagues (2008) found that immersion can also be measured through objective metrics (i.e., task completion time and eye movements). Interestingly, results from their studies suggested that emotional involvement is an essential element in immersion which supported Brown and Cairns' (2004) assessments of immersion. These researchers also contended that immersion is its own distinct concept even though it share some similarities (e.g., temporal dissociation, loss awareness of the real world) with other engagement concepts (e.g., presence, flow, and cognitive absorption). Specifically, immersion was declared to be graded experience of engagement. Unlike flow, it is neither an optimal experience nor consist of all positive emotions. In general, these researchers maintained that immersion is the common experience of video game engagement and that it is an important element of a good gaming experience. 


\section{Presence.}

The term presence has its origin in the field of teleoperations, and much of the literature on presence tended to discuss it in the context of virtual reality environments (McMahan, 2003). Although presence as a concept has been conceptualized in different settings (Lombard \& Ditton, 1997), the term has generally been used to describe the psychological experience of "being there" in a non-physical or virtual world (McMahan, 2003; Qin et al., 2009). This description, on the surface, sounds like the concept of immersion, which has led researchers to use the two terms interchangeably in the gaming literature (Ermi \& Mäyrä, 2005; McMahan, 2003).

Nevertheless, some researchers have taken the view that presence and immersion are not equivalent in meanings-each term refers to a similar, but different concept. CalvilloGámez, Cairns, and Cox (2010) while viewing immersion and presence to be a sub-optimal gaming experience, defined immersion as "the sense of being away from the real word" and presence as "the sense of being inside a virtual world" (p. 52). Similarly, other researchers have adopted the view that presence is a different type of immersion (Alexander, Brunyé, Sidman, \& Weil, 2005; Taylor, 2002). According to these researchers, there are two types of immersion that involve the gaming experience: diegetic and situated. Diegetic immersion is the typical immersion in which the player gets wrapped up with the gaming experience. Situated immersion is presence and refers to a deeper stage of immersion where the player believes he or she is inside and a part of the game world. This feeling of being integrated into a virtual environment has also been mentioned under another label called "spatial presence" (Wirth et al., 2007). 
In relation virtual environments, presence has been described as the subjective sensation of being in a computer-generated environment instead of the place where one's body is physically situated (Witmer \& Singer 1998; Slater, Usoh, \& Steed, 1994). According to Witmer and Singer (1998), in order for presence to occur both involvement and immersion needed to occur. Involvement is when an individual devotes his or her focus and energy on a coherent set of virtual stimuli. Immersion is when a person feels himself or herself be surrounded by and a part of a continual stream of the virtual environment stimulus. In short, these researchers believed that a virtual environment that can generate a higher degree of involvement and immersion will ultimately lead to a greater sense of presence.

Witmer and Singer (1998) also postulated that there are four key factors that have an impact on presence called control, sensory, distractor, and realism. Table 23 presents a summary of the characteristics associated with each factor. Furthermore, both researchers perceived presence as a subjective experience that can be measured through questionnaires. As a result, they developed two questionnaires pertaining to presence. Deriving from the previously mentioned factors, the Presence Questionnaire (PQ) aimed at measuring an individual's level of presence in a virtual environment. Different from the $P Q$, the Immersive Tendencies Questionnaire (ITQ) was designed to measure an individual's capacity to be immersed in a virtual environment. 
TABLE 23

WITMER AND SINGER'S (1998) HYPOTHESIZED FACTORS THAT INFLUENCE PRESENCE

\begin{tabular}{|c|c|c|c|}
\hline Con & Sen & Distraction & Realism \\
\hline $\begin{array}{l}\text { - } \text { Degree of control } \\
\text { - } \text { Immediacy of } \\
\text { - Anticipation of } \\
\text { events } \\
\text { - } \text { Mode of control } \\
\text { - Physical } \\
\text { environment } \\
\text { modifiability }\end{array}$ & $\begin{array}{l}\text { - Sensory modality } \\
\text { - Environmental richness } \\
\text { - } \text { Multimodal } \\
\text { presentation } \\
\text { - Active search } \\
\text { - } \text { Consistency of } \\
\text { multimodal information } \\
\text { - Degree of movement } \\
\text { perception }\end{array}$ & $\begin{array}{ll}\text { - } & \text { Isolation } \\
\text { - } & \text { Selective } \\
& \text { attention } \\
\text { - } & \text { Interface } \\
& \text { awareness }\end{array}$ & $\begin{array}{ll}\text { - } & \text { Scene realism } \\
\text { - } & \text { Information } \\
\text { consistent with } \\
\text { objective world } \\
\text { - } & \text { Meaningfulness } \\
\text { of experience } \\
\text { - Separation } \\
\text { anxiety / } \\
\text { disorientation }\end{array}$ \\
\hline
\end{tabular}

However, some researchers did not agree that a complex concept such as presence can be measured by a subjective questionnaire alone (Slater, 1999; Slater \& Steed, 2000). For instance, Slater and Steed (2000) felt presence should be measured in a more objective manner (e.g., through body movement) rather than through a scale that "is based on subjective responses to various aspects of immersion" (p. 416). In addition, other researchers who viewed presence through a Gibsonian perspective declared that presence can be measured without involving the subjective thoughts (Zahorik \& Jenison, 1998). Particularly, presence was said to occur when the environment reacts to the actor's actions in a lawful manner. Hence, these researchers argued that presence should be measured by examining the degree of lawfulness between the actor's actions in the virtual environment and the physical world.

Although there is still a substantial debate on the term presence and how it should be measured, some researchers found the concept of presence to be pertinent to the gaming experience (e.g., Chen et al., 2011; Takatalo, Häkkinen, Komulainen, Särkelä, \& Nyman, 2006). Specifically, Takatalo and colleagues (2006) measured the gaming experience of PC and console 
players and found two separate constructs (i.e., involvement and presence) in the context of interactive gaming environments. Involvement relates to motivation and includes two distinct dimensions: importance and interest. Presence was categorized into two types: physical and social, and each type of presence was comprised of three principal components. Attention, perceptual realness, and spatial awareness were said to be the main components of physical presence while social richness, social realism, and co-presence were considered to be the main elements of social presence.

Conversely, some researchers have argued that presence is not an essential part of the gaming experience (e.g., Jennett et al., 2008; Parnell, 2009). Jennett and colleagues (2008) asserted that in evaluating the gaming experience measuring immersion is more important than presence. This is because immersion was thought to be a better indicator of game enjoyment than presence. For example, games with simple graphics (e.g., Tetris) will not likely lead the player to experience spatial presence (i.e., he or she is actually in the game world consisting of falling blocks). However, it will likely lead the player to experience the typical characteristic of immersion (e.g., loss of time, lack of awareness of the outside world). Similarly, a person can experience the feeling of "being there" in the virtual world through a headmounted display, but not feel that time has been lost if he or she is conducting a repetitive and uninteresting task.

Finally, Parnell (2009) stressed that when it comes to players describing their gaming experience as "being there" they are most likely not speaking in a literal sense but in a metaphorical sense. Thus, researchers should not misinterpret the "being there" narrative to signify spatial presence. All things considered; presence in relation to the gaming experience is 
more likely to be an extreme indicator of immersion. However, more research is needed in order to verify this as well as to resolve the discrepancies found in the presence literature.

\section{Absorption.}

The notion of absorption has a psychological basis and has often been discussed in the hypnosis and personality literature (e.g., Kremen \& Block, 2002; Nadon, Hoyt, Register, \& Kihlstrom, 1991). One of the initial conceptualizations of absorption was proposed by Tellegen and Atkinson (1974). According to Tellegen and Atkinson (1974), absorption was described to be a personality trait, which led an individual to experience episodes of complete concentration where all of his or her attentional resources were allocated to the item in focus. Absorption has been argued to be vital in the understanding of an individual's personal experience and cognition (Roche \& McConkey, 1990).

In the psychological context, researchers tended to use more specialized terms of absorption (i.e., psychological absorption or nonpathological absorption) to refer to the experience of total engagement that was described by Tellegen and Atkinson (1974). Additionally, when it comes to absorption, it is important to recognize that there are two distinct forms of absorption (state vs. trait). The key difference between absorption as a state versus a trait is that the former refers to an individual's tendency to become psychologically absorbed in a particular task while the latter refers to the experience of becoming absorbed in said activity (Roche \& McConkey, 1990). The Tellegen Absorption Scale by Tellegen and Atkinson (1974) is the first and only measure to be developed for assessing psychological absorption, and it was heavily focused on measuring traits rather than states of absorption. 
In relation to other engagement concepts, psychological absorption has been considered to be similar to flow. However, different from immersion and presence psychological absorption involves an altered state of consciousness (Brockmyer et al., 2009). In particular, Glicksohn and Avnon (1997) found that participants who had a high tendency for experiencing psychological absorption reported experiencing an altered state of consciousness when they played a virtual reality game. This altered state of consciousness was said to occur when there is a separation of thoughts, emotions, and experiences. As a result, players might experience difficulty connecting their feelings with their thoughts and make rational decisions (Brockmyer et al., 2009). Based on Brockmyer and colleagues (2009)'s Game Engagement Questionnaire, psychological absorption was considered to be the highest level of engagement that one can attain when playing video games.

Aside from psychological absorption, there is another concept of absorption called cognitive absorption that has been frequently mentioned in the video game literature. Cognitive absorption was theorized by Agarwal and Karahanna (2000) based on the work from three interrelated fields of study: psychological absorption, flow, and cognitive engagement. The concept of cognitive absorption was initially conceptualized to better understand user attitude towards informational technologies (e.g., the Web) in relation to perceived usefulness, ease of use, and intent to use. Cognitive absorption was defined as "a state of deep involvement with software" (p. 673).

According to Agarwal and Karahanna (2000), cognitive absorption is comprised of five major dimensions: temporal dissociation, focused immersion, heightened enjoyment, control, and curiosity. Temporal dissociation refers to the user's lack of awareness of how much time 
has passed when engaging in an activity. Focused immersion or total engagement relates to the user's ability to ignore other distractions and concentrate on the task at hand. Heightened enjoyment involves the user's positive emotions when using a software. Control represents the user's sense of control over his or her interaction with a software. Finally, curiosity refers to the user's cognitive curiosity while interacting with a software. Based on these five dimensions, the researchers developed a 20-item scale to measure cognitive absorption in the context of technology usage.

Currently, it is not clear as to how much of a role cognitive absorption contribute to the gaming experience. Jennett and colleagues (2008) argued that when it comes to the gaming experience measuring immersion is better than the cognitive absorption. They felt cognitive absorption only reflects an individual's attitude towards technology, but immersion involves the experience and specific instances of playing a game. However, Parnell (2009) suggested that cognitive absorption might have a large impact on game engagement because it has many similar characteristics as flow though in a milder and less optimal forms. Thus, cognitive absorption might be considered as the typical experience of engagement with a game, and is what researchers likely to measure when they thought they were investigating flow.

\section{Flow.}

One of the most influential theories about fun and happiness is the flow theory by Mihaly Csikszentmihalyi $(1975 ; 1990)$. The origin of the flow theory got its start when Csikszentmihalyi was studying the creative process of artists. In particular, he was fascinated by artists who were so profoundly involved with their work that they disregarded their basic needs 
(e.g., food, sleep). As a result of trying to understand more about this phenomenon that Csikszentmihalyi began his life-long research on the flow theory.

The term flow generally expresses intense feelings of enjoyment and fulfillment resulting from a successful balance between an individual's skills and the challenge level of the tasks. In order to experience flow an individual has to enter a subjective state called the flow state. The flow state is typically described as an optimal experience in which a person is so immersed in an activity that everything seems to fade away and nothing else matter except the action itself. This optimal experience is thought to be intrinsically motivated and extremely rewarding that any individual would want to pursue it as well as continue to maintain it.

In order to achieve the flow state, Csikszentmihalyi has proposed that three conditions must be met (Csikszentmihalyi, Abuhamdeh, \& Nakamura, 2005). First, the task that an individual is involved in must have unambiguous set of goals and measure of progression. Second, the task must provide clear and immediate feedback for actions. Third, the individual who is doing the task must have a sense of confidence that his or her skills are adequate to handle the task's challenges. According to the Csikszentmihalyi's flow state model (see Figure 4), the flow state will only occur when the activity's challenge level and one's skill level is perceived to be high. Any other combinations of challenge level and skill level will result in a sub-optimal experience (e.g., apathy, boredom). 


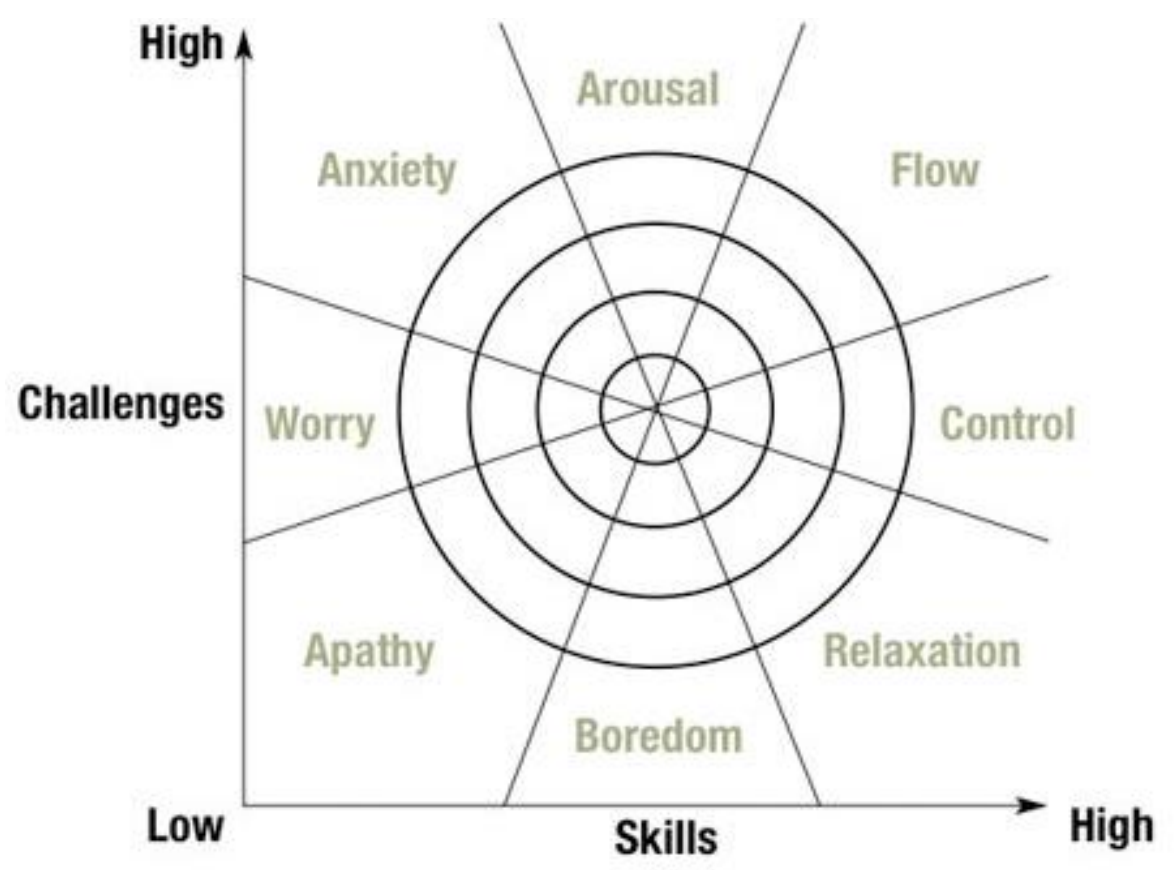

Figure 4. Csikszentmihalyi's (1997) adapted flow state model.

Once an individual entered the flow state or flow zone, he or she will experience the following characteristics that are deemed to be essential components of flow: intense concentration, time transformation, a sense of control, merging of action and awareness, loss of self-consciousness, and intrinsic reward (Csikszentmihalyi, 1990; Nakamura \& Csikszentmihalyi, 2002). Specifically, during the flow state an individual will devote all of his or her focused attention to the task or goal at hand, which leave little attentional resources available for other irrelevant activities. An individual in the flow zone also has a lack awareness of the passage of time. Thus, time appears to be speeding by-much quicker than usual.

In the course of the flow state, there is a strong sense of personal control, which allows an individual to feel that he or she can adequately handle whatever will happen next. As action and awareness merged into one, there is no longer a separation between the individual and the task at hand, and performing the task becomes almost effortless. Accompanying the merging of 
action and awareness is the lack of reflective self-consciousness where an individual no longer feels concern about his or her performance or appearance in front of other people. Finally, during the flow state an individual becomes intrinsically motivated. As a result, the activity is performed just for its own sake and not because of external motivators.

It is important to note that while all of the features listed are essential components of flow, yet not all the characteristics are needed in order for flow to occur. In addition, the flow experience is considered to be universal, irrespective of one's demographics (e.g., age, gender) - anyone can experience flow. Csikszentmihalyi also proposed that every individual has an innate ability to experience flow and that it is something hard-wired in the human brain. As long as the conditions are right, the flow state will be activated.

The flow theory has been studied and applied across multiple domains (e.g., sports, teaching, and creativity). In the $\mathrm{HCl}$ field, many researchers also adopted flow as a conceptual framework for fostering enjoyment, engagement, user satisfaction, and playfulness in various computer-mediated context (e.g., Gaggioli, Bassi, \& Fave, 2003; Ghani \& Deshpande, 1994; Hoffman \& Novak, 1996; Huang, 2003; Koufaris, 2002; Pace, 2004; Webster, Trevino, \& Ryan, 1993). For instance, Webster and colleagues (1993) used flow as a theoretical basis for measuring playfulness in $\mathrm{HCl}$. They found that it comprised of three major factors: attention focus, control, and cognitive enjoyment that combined from the original two factors called curiosity and intrinsic interest.

Hoffman and Novak (1996) incorporated the flow construct in the study of marketing in hypermedia computer-mediated environments (e.g., the Web). They proposed a complex model of flow where flow features (e.g., intrinsic motivation, attentional focus) were postulated 
to be the antecedents to flow instead of being the main dimensions of flow. Lastly, Gaggioli and colleagues (2003) have examined the flow experiences in the virtual environment context and used the Flow Questionnaire to assess the quality of experience in virtual environments.

Similar to other $\mathrm{HCl}$-related fields, the flow theory have been considered to be extremely pertinent in the studies of video game design and gaming experience. Notably, many researchers viewed the principles of flow to be the underlying mechanisms of game enjoyment and engagement (e.g., Chen, 2007; Choi \& Kim, 2004; Fang, Zhang, \& Chan, 2013; Fu, Su, \& Yu, 2009; Jones, 1998; Sherry, 2004; Sweetser \& Wyeth, 2005). Jones (1998) in determining the principles of engagement for computer-based learning environments offered a mapping of the eight essential elements of flow on to the computer game settings (see Table 24). 
TABLE 24

JONE'S (1998) MAPPING OF THE EIGHT ELEMENTS OF FLOW TO COMPUTER GAMES

\begin{tabular}{|c|c|}
\hline Element of Flow & Manifestation in a Game \\
\hline 1. Task that we can complete & $\begin{array}{l}\text { The use of levels in a game provide small sections that } \\
\text { lead to the completion of the entire task. }\end{array}$ \\
\hline 2. Ability to concentrate on task & $\begin{array}{l}\text { Creation of convincing worlds that draw users in. The } \\
\text { Dungeons and Labyrinths in Doom II help you suspend } \\
\text { your belief systems for a time. }\end{array}$ \\
\hline 3.Task has clear goals & $\begin{array}{l}\text { Survival, collection of points, gathering of objects and } \\
\text { artifacts, solving the puzzle. }\end{array}$ \\
\hline $\begin{array}{l}\text { 4. Task provides immediate } \\
\text { feedback }\end{array}$ & $\begin{array}{l}\text { Shoot people and they die. Find a clue, and you can put } \\
\text { it in your bag. }\end{array}$ \\
\hline $\begin{array}{l}\text { 5. Deep but effortless involvement } \\
\text { (losing awareness of worry and } \\
\text { frustration of everyday) }\end{array}$ & $\begin{array}{l}\text { The creation of environments that are far removed } \\
\text { from what we know to be real helps suspend belief } \\
\text { systems and take one away from the ordinary. }\end{array}$ \\
\hline $\begin{array}{l}\text { 6. Exercising a sense of control } \\
\text { over their actions }\end{array}$ & $\begin{array}{l}\text { Mastering the controls of the game, such as mouse } \\
\text { movement or keyboard combinations. }\end{array}$ \\
\hline $\begin{array}{l}\text { 7. Concern for self disappears } \\
\text { during flow, but sense of self is } \\
\text { stronger after flow activity }\end{array}$ & $\begin{array}{l}\text { Many games provide for an environment that is a } \\
\text { simulation of life and death. One can cheat death and } \\
\text { not really die. People stay up all night to play these } \\
\text { games. It is the creation of an integration of } \\
\text { presentation, problem, and control over the system } \\
\text { that promotes this. }\end{array}$ \\
\hline $\begin{array}{l}\text { 8. Sense of duration of time is } \\
\text { altered. }\end{array}$ & $\begin{array}{l}\text { Years can be played out in hours. Battles can be } \\
\text { conducted in minutes. The key point is that people can } \\
\text { stay up all night playing these games. }\end{array}$ \\
\hline
\end{tabular}

Sherry (2004) believed that the flow theory is very applicable to game enjoyment because video games have four important characteristics that make the flow state possible. First, video games have concrete goals and manageable rules. Second, video games allow 
customizations that can better fit a player's capabilities. Third, video games provide a player with clear feedback in terms of his or her game scores, statuses, and progress within the game. Fourth, video games contain numerous visual and audio effects which promote full concentration and reduce distractions while playing. In general, Sherry considered having an appropriate balance between the level of challenge and a player's skill level to be an essential game's component for inducing the flow experience.

Chen (2007) deemed a well-designed game as a game that can transport the players to their flow states or flow zones, and bring about the deep feelings of delight and enjoyment. In particular, Chen regarded the balancing between the player's abilities and the game's challenge to be an integral part in keeping game players inside the flow zone. The author suggested that different players (e.g., hardcore, novice) have different flow zones. Thus, it is important that video games adapt to these different zones of challenge and skills in order to maximize the number of players who will experience flow. Keeping the flow theory in mind, Chen also proposed a general guide for designing enjoyable games that will appeal to a broad range of players. The guide states the following: mix and match the major elements of flow, do not allow the user experience to fall outside of the flow zone, allow different players the ability to experience flow on their own terms, and prevent the flow experience from being interrupted by embedding choices inside the main actions or events.

Choi and Kim (2004) were interested in determining the key factors that were influencing people to continue to play certain online games. In the process, they proposed a theoretical model that included concepts of personal interaction, social interaction, flow, and customer loyalty. Overall, results revealed that flow was an important factor in affecting 
customer loyalty and that people will continue to play certain online games if they can have optimal experiences of gameplay. Importantly, personal interaction and social interaction were found to be two critical factors that were influencing optimal experience. Consequently, if a game does not have effective personal interaction and social interaction it will be difficult for the players to achieve optimal experience. Additionally, having appropriate goals, operators, and feedback will enhance personal interaction while having proper communication places and tools will increase the quality of social interaction.

In an attempt to build an understanding of enjoyment in computer games Sweetser and Wyeth (2005) constructed a list of game heuristics based on the flow theory and existing game usability and user experience literature. From this list of heuristics, the researchers were able to formulate a framework of player enjoyment called GameFlow. GameFlow consists of eight elements: concentration, challenge, skills, control, clear goals, feedback, immersion, and social interaction. Following the GameFlow framework Fu and colleagues (2009) developed and validated a scale called EGameFlow. The EGameFlow scale was designed to assess user enjoyment of e-learning games and comprised of eight dimensions: concentration, challenge, control, goal clarity, feedback, immersion, social interaction, and knowledge improvement.

More recently Fang and colleagues (2013) constructed and validated a 23-item instrument to measure the flow experience during computer gameplay using a card-sorting technique. Different from the other scales that measure the gaming experience, this is the first scale that closely followed the flow theory by measuring all of the key flow elements. This scale contained six sub-scales named: a challenging activity that requires skill, immersion, clear goals and feedback, concentration on the task at hand, the paradox of control, and autotelic 
experience. Interestingly, the three elements in flow theory (i.e., loss of self-consciousness, merging of action and awareness, and time transformation) were combined into a single factor called immersion by game players in this study. Fang and colleagues took this as evidence against Jennett and colleagues' (2008) claims that immersion is a vital concept in gaming and that it is distinct from other engagement concepts such as flow, presence, and cognitive absorption.

Although some researchers are absolutely convinced about the flow theory being the primary source to understand enjoyment in video games, other researchers have cautioned about relying solely on the flow theory as a comprehensive measure of the gaming experience. For instance, some researchers (e.g., Ermi \& Mäyrä, 2005; Jennett et al., 2008; Parnell, 2009) believed that flow-like experiences are fleeting in nature, and they are not representative of the typical gaming experience. Thus, the absence of flow does not automatically indicate that the gaming experience was not enjoyable or satisfactory.

Furthermore, researchers have remarked that while the connections between flow and enjoyment appeared to be straightforward at first glance, it is often quite complex in applied gaming research (Weibel, Wissmath, Habegger, Steiner, \& Groner, 2008; Wiebe et al., 2014). In particular, a study concerning online games found that players were more likely to report experiences of presence, flow, and enjoyment when they played against a human-controlled opponent than when they played against a computer-controlled opponent (Weibel et al., 2008). Additionally, while presence was reported to have the strongest effect, further analyses suggested that presence did not directly affect enjoyment, and that flow served as a mediator between the presence and enjoyment relationship. In general, researchers have advised that 
flow and enjoyment be considered and measured as separate constructs even though they appeared to be strongly related to each other (Boyle et al., 2011; Weibel et al., 2008).

Collectively, research on engagement have indicated a number of elements that can contribute to video game satisfaction. For example, focused attention appears to be the glue among the different engagement concepts (e.g., immersion, presence, flow). Along with focused attention is the narratives component that lead the player to be emotionally connected and deeply involved in a game. Challenge, skills, and social interaction are also needed to motivate the player to continue playing a game. In addition, audio and visual effects can help enhance the gaming experience and foster the "being there" feelings. Usability and playability are also important factors in influencing game satisfaction since they can present technical barriers to the players (e.g., control, goals, rules, and feedback) and prevent the players from truly enjoying a game. Last but not least, a sense of enjoyment is the central element in interacting with any form of media (e.g., video games) whose primary purpose is to entertain. 


\section{CHAPTER 3}

ITEM POOL GENERATION, EXPERT REVIEW, \& PILOT STUDY

\section{General Scale Design and Development Procedure}

In general, the scale development process is a multi-stage iterative procedure. The development of the GUESS aimed to closely follow existing guidelines and "best practices" for questionnaire design and development, as well as guidelines for reporting scale development and validation (e.g., Cabrera-Nguyen, 2010; Hinkin, 1998; Jensen, 2003; Lietz, 2008; Malhotra, 2006). For example, care was given to the selection of appropriate items for the GUESS scalerelying greatly on previously developed scales, and existing game design principles and theoretical frameworks in the literature. Also, where relevant, the source(s) from which each item on the scale was derived or modified was cited (Hinkin, 1995).

Aside from the item selection process, great attention was dedicated to the phrasing of each statement and the overall length of each item on the scale. Specifically, all statements on the scale were individually scrutinized to ensure that they are simply phrased and free of serious wording issues (e.g., double-barreled questions, leading questions, technical jargons, and grammatical complexities; Hinkin, 1998; Lietz, 2008; Malhotra, 2006). Such effort was made to minimize the cognitive demands on questionnaire respondents and enhance the overall quality of responses. Additionally, to further reduce cognitive load on the respondents the strategy of keeping the length of each item relatively short was adopted. Oppenheim (1992) has advised that each statement on a questionnaire does not exceed 20 words in length.

In terms of the number of response scale options, there is a general agreement in the literature that having five to seven options is an adequate number to retain reliability and 
validity without imposing cognitive burden on respondents due to having too many responses (Krosnick, 1999; Lietz, 2008; Preston \& Colman, 2000). Taking into account that the number of items will be smaller in the future as a result of factor analyses, a seven-point Likert scale was adopted to ensure that there will be enough points of discrimination on the new scale (Sauro, 2010). Vagias' (2006) seven-point, unipolar response anchors was selected for the levels of agreement in order to improve comprehension and response quality (Krosnick, 1999; Lietz, 2008). Finally, an "N/A" option was added at the end of the scale for cases where an item or statement does not apply to a particular video game (see Figure 5).

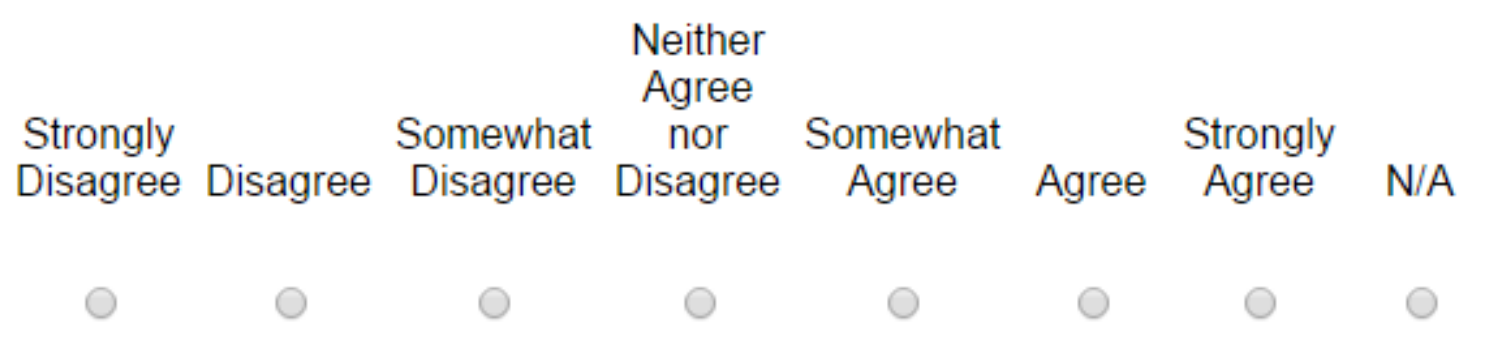

Figure 5. The adopted seven-point, unipolar scale with response anchors.

Another important consideration in designing a standardized scale is whether or not the scale will contain reverse-scored (negatively worded) items. Past studies tended to employ reversed-scoring method in an attempt to minimize acquiescence bias (the tendency for respondents to agree rather than disagree with all statements irrespective of content) and extreme response bias (the tendency to select all of the highest or lowest scores on a scale; Sauro \& Lewis, 2011). However, a number of studies have shown that such methods will likely introduce more errors in the data, and that the list of disadvantages outweigh the advantages (Hinkin, 1995; 1998; Lietz, 2008; Sauro \& Lewis, 2011). 
In particular, a series of studies have demonstrated that mixing negatively worded items with positively worded items reduces validity and reliability of responses and leads to more systematic and random errors in the scale (Hinkin, 1995; 1998; Lietz, 2008; Sauro \& Lewis, 2011). This in part can be attributed to the findings that negatively worded statements are often more difficult for people to interpret than positively worded statements, which in turn increases respondents likelihood to make response mistakes (Lietz, 2008). Recently, Sauro and Lewis (2011) confirmed that there was no detrimental effect in terms of acquiescence bias, extreme response bias, and reliability when they used all positive items versus reverse-scored items on the System Usability Scale (SUS). The researchers further recommended that new scales avoid alternating between positive and negatively worded statements to decrease the likelihood that respondents will misinterpret the items and forget to reverse their ratings, and scorers forget to reverse the scale during the scoring process. In light of these research findings, the strategy of having very few reverse-scored items on the GUESS was adopted.

\section{Step 1: Item Pool Generation}

\section{Method.}

Previous video game literature concerning motivations (e.g., Ryan, Rigby, \& Przybylski, 2006; Yee, 2006), engagement (e.g., Brockmyer et al., 2009; McMahan, 2003), enjoyment (e.g., Sweetser \& Wyeth, 2005), experience (e.g., Calvillo-Gámez et al., 2010), and usability and playability (e.g., Desurvire \& Wiberg, 2009; Sánchez et al., 2012) were consulted to guide the taxonomy of the GUESS. Additionally, the potential scale items were drawn from 13 existing questionnaires that measure important constructs related to the gaming experience (e.g., cognitive absorption, flow). Table 25 presents an overview of the key dimensions of the existing 
questionnaires. Appendix D provides a detailed description of each of the key dimensions. The majority of the questionnaires listed were developed based on the game-based environments. However, the Cognitive Absorption Scale (Agarwal \& Karahanna, 2000) and the Presence Questionnaire (Witmer \& Singer, 1998) were developed based on the World Wide Web and virtual environment, respectively.

TABLE 25

OVERVIEW OF THE QUESTIONNAIRES USED IN THE ITEM POOL GENERATION

\begin{tabular}{|c|c|c|c|}
\hline Source & $\begin{array}{l}\text { Number } \\
\text { of Items }\end{array}$ & Target Measure & Dimensions \\
\hline $\begin{array}{l}\text { Agarwal \& Karahanna } \\
\text { (2000) - Cognitive } \\
\text { Absorption Scale }\end{array}$ & 20 & Cognitive Absorption & $\begin{array}{l}\text { - } \text { Temporal Dissociation } \\
\text { - } \text { Focused Immersion } \\
\text { - } \text { Heightened Enjoyment } \\
\text { - Control } \\
\text { - Curiosity } \\
\end{array}$ \\
\hline $\begin{array}{l}\text { Brockmyer et al. } \\
\text { (2009) - Game } \\
\text { Engagement } \\
\text { Questionnaire (GEQ) }\end{array}$ & 19 & Engagement & - $\quad \mathrm{N} / \mathrm{A}$ \\
\hline $\begin{array}{l}\text { Calvillo-Gámez et al. } \\
\text { (2010) - Core } \\
\text { Elements of the } \\
\text { Gaming Experience } \\
\text { Questionnaire (CEGEQ) }\end{array}$ & 38 & Core Gaming Experience & $\begin{array}{l}\text { - } \text { Control } \\
\text { - Ownership } \\
\text { - Facilitators } \\
\text { - Game-Play } \\
\text { - Environment }\end{array}$ \\
\hline $\begin{array}{l}\text { Chen, Kolko, Cuddihy, } \\
\text { \& Medina (2005) - } \\
\text { Gaming Engagement } \\
\text { Questionnaire (GEQ) }\end{array}$ & 25 & Engagement & - $N / A$ \\
\hline $\begin{array}{l}\text { Choi \& Kim (2004) - } \\
\text { Online Game } \\
\text { Experience } \\
\text { Questionnaire* }\end{array}$ & 20 & $\begin{array}{l}\text { Optimal Gaming } \\
\text { Experience }\end{array}$ & $\begin{array}{ll}\text { - } & \text { Customer Loyalty } \\
\text { - } & \text { Flow } \\
\text { - } & \text { Personal Interaction } \\
\text { - } & \text { Social Interaction }\end{array}$ \\
\hline
\end{tabular}


TABLE 25 (continued)

OVERVIEW OF THE QUESTIONNAIRES USED IN THE ITEM POOL GENERATION

\begin{tabular}{|c|c|c|c|}
\hline Source & $\begin{array}{l}\text { Number } \\
\text { of Items }\end{array}$ & Target Measure & Dimensions \\
\hline $\begin{array}{l}\text { Ermi \& Mäyrä (2005) - } \\
\text { Gameplay Experience } \\
\text { Questionnaire }\end{array}$ & 18 & Immersion & $\begin{array}{l}\text { - Sensory Immersion } \\
\text { - Challenge-Based } \\
\text { Immersion } \\
\text { - Imaginative Immersion }\end{array}$ \\
\hline $\begin{array}{l}\text { Fu et al. (2009) - } \\
\text { EGameFlow }\end{array}$ & 42 & Enjoyment & $\begin{array}{ll}\text { - } & \text { Concentration } \\
\text { - } & \text { Goal Clarity } \\
\text { - } & \text { Feedback } \\
\text { - } & \text { Autonomy } \\
\text { - } & \text { Immersion } \\
\text { - } & \text { Social Interaction } \\
\text { - } & \text { Knowledge } \\
& \text { Improvement } \\
\end{array}$ \\
\hline $\begin{array}{l}\text { IJsselsteijn, de Kort, \& } \\
\text { Poels (2008) - Game } \\
\text { Experience } \\
\text { Questionnaire (GEQ) }\end{array}$ & 33 & Play Experience & $\begin{array}{ll}\text { - } & \text { Immersion } \\
\text { - } & \text { Flow } \\
\text { - } & \text { Competence } \\
\text { - } & \text { Positive Affect } \\
\text { - } & \text { Negative Affect } \\
\text { - } & \text { Tension } \\
\text { - } & \text { Challenge } \\
\end{array}$ \\
\hline $\begin{array}{l}\text { Jennett et al. (2008) - } \\
\text { Immersion } \\
\text { Questionnaire }\end{array}$ & 32 & Immersion & $\begin{array}{l}\text { - } \text { Cognitive Involvement } \\
\text { - } \text { Real World Dissociation } \\
\text { - } \text { Challenge } \\
\text { - } \quad \text { Conotional Involvement }\end{array}$ \\
\hline $\begin{array}{l}\text { Parnell (2009) - } \\
\text { Gameplay Scale }\end{array}$ & 26 & Game Quality/Appeal & $\begin{array}{ll}\text { - } & \text { Affective Experience } \\
\text { - } & \text { Focus } \\
\text { - } & \text { Playability Barriers } \\
\text { - Usability Barriers } \\
\end{array}$ \\
\hline $\begin{array}{l}\text { Pavlas, Jentsch, Salas, } \\
\text { Fiore, \& Sims, (2012) - } \\
\text { Play Experience Scale } \\
\text { (PES) }\end{array}$ & 16 & Play Experience & $\begin{array}{ll}\text { - } & \text { Freedom } \\
\text { - } & \text { No Extrinsic } \\
\text { - } & \text { Play-Direct } \\
\text { - } & \text { Autotelic-Focus }\end{array}$ \\
\hline
\end{tabular}


TABLE 25 (continued)

OVERVIEW OF THE QUESTIONNAIRES USED IN THE ITEM POOL GENERATION

\begin{tabular}{lcll}
\hline Source & $\begin{array}{c}\text { Number } \\
\text { of Items }\end{array}$ & Target Measure & Dimensions \\
\hline Qin et al. (2009) - & 27 & Narrative Immersion & $\bullet$ Curiosity \\
Player Immersion in & & & $\bullet$ Comprehension \\
Computer Game & & $\bullet$ Challenge and Skills \\
Narrative & & $\bullet$ Empathy \\
Questionnaire & & $\bullet$ Concentration \\
& & $\bullet$ Control \\
& & & $\bullet$ Familiarity \\
\hline Witmer \& Singer & 19 & Presence & $\bullet$ Involved/Control \\
(1998) - Presence & & & $\bullet$ Natural \\
Questionnaire (PQ) & & & $\bullet$ Interface Quality \\
\hline
\end{tabular}

*The questionnaire was not formally named. Thus, for the sake of identification a generic name was chosen.

Fifteen lists of game heuristics were also examined in the process of generating the item pool. These game heuristics were reviewed for the purposes of identifying and formulating an original list of items that have not been included in the previously mentioned gaming questionnaires. Specifically, items in this list are heavily focused on common usability and playability issues, which span across different video game platforms and genres. Table 26 provides a summary of the mentioned 15 lists of game heuristics.

TABLE 26

OVERVIEW OF THE REVIEWED GAME HEURISTICS FOR THE ITEM POOL GENERATION

\begin{tabular}{lcccc}
\hline Source & $\begin{array}{c}\text { Number } \\
\text { of Items }\end{array}$ & $\begin{array}{c}\text { Game } \\
\text { Platform(s) }\end{array}$ & $\begin{array}{c}\text { Game } \\
\text { Genre(s) }\end{array}$ & Main Categories \\
\hline Clanton (1998) - & 15 & PC & N/A & N/A \\
Computer Game & & & & \\
Design Principles & & & & \\
\hline
\end{tabular}


Table 26 (continued)

OVERVIEW OF THE REVIEWED GAME HEURISTICS FOR THE ITEM POOL GENERATION

\begin{tabular}{|c|c|c|c|c|}
\hline Source & $\begin{array}{l}\text { Number } \\
\text { of Items }\end{array}$ & $\begin{array}{c}\text { Game } \\
\text { Platform(s) }\end{array}$ & $\begin{array}{c}\text { Game } \\
\text { Genre(s) }\end{array}$ & Main Categories \\
\hline $\begin{array}{l}\text { Desurvire et al. } \\
\text { (2004) - } \\
\text { Heuristics for } \\
\text { Evaluating } \\
\text { Playability (HEP) }\end{array}$ & 43 & PC & $\mathrm{N} / \mathrm{A}$ & $\begin{array}{l}\text { - Game Play } \\
\text { - Game Story } \\
\text { - Mechanics } \\
\text { - Usability }\end{array}$ \\
\hline $\begin{array}{l}\text { Desurvire \& } \\
\text { Wiberg (2009) - } \\
\text { Game Playability } \\
\text { Principles (PLAY) }\end{array}$ & 48 & PC & $\begin{array}{l}\text { Action } \\
\text { Adventure, } \\
\text { Real-Time } \\
\text { Strategy (RTS), } \\
\text { First-Person } \\
\text { Shooter (FPS) }\end{array}$ & $\begin{array}{l}\text { - } \text { Game Play } \\
\text { - Coolness/Entertainment/ } \\
\text { Humor/ Emotional } \\
\text { Immersion } \\
\text { - Usability \& Game } \\
\text { Mechanics }\end{array}$ \\
\hline $\begin{array}{l}\text { Federoff (2002) - } \\
\text { Game Heuristics }\end{array}$ & 42 & PC & $\begin{array}{l}\text { Role-Playing, } \\
\text { Sports/Racing, } \\
\text { Shooter, } \\
\text { Action, } \\
\text { Strategy, } \\
\text { Adventure }\end{array}$ & $\begin{array}{ll}\text { - } & \text { Game Interface } \\
\text { - } & \text { Game Mechanics } \\
\text { - } & \text { Game Play } \\
\text { - } & \text { Mobility } \\
\text { - } & \text { Gameplay }\end{array}$ \\
\hline $\begin{array}{l}\text { Korhonen \& } \\
\text { Koivisto (2006) - } \\
\text { Playability } \\
\text { Heuristics for } \\
\text { Mobile Games }\end{array}$ & 29 & Mobile & $\begin{array}{c}\text { Combat, } \\
\text { Adventure, } \\
\text { Simulation, } \\
\text { Puzzle }\end{array}$ & $\begin{array}{l}\text { - } \text { Game Usability } \\
\text { - } \text { Mobility } \\
\text { - Gameplay }\end{array}$ \\
\hline $\begin{array}{l}\text { Korhonen \& } \\
\text { Koivisto (2007) - } \\
\text { Playability } \\
\text { Heuristics for } \\
\text { Mobile Multi- } \\
\text { Player Games }\end{array}$ & 8 & $\begin{array}{c}\text { Mobile } \\
\text { Multi- } \\
\text { player, PC, } \\
\text { Massively } \\
\text { Multiplayer } \\
\text { Online } \\
\text { (MMO) }\end{array}$ & $\begin{array}{c}\text { Strategy, } \\
\text { Racing, FPS }\end{array}$ & $\mathrm{N} / \mathrm{A}$ \\
\hline $\begin{array}{l}\text { Malone (1982) - } \\
\text { Heuristics for } \\
\text { Designing } \\
\text { Enjoyable User } \\
\text { Interfaces }\end{array}$ & 11 & PC & Educational & $\begin{array}{ll}\text { - } & \text { Challenge } \\
\text { - } & \text { Fantasy } \\
\text { - } & \text { Curiosity }\end{array}$ \\
\hline
\end{tabular}


Table 26 (continued)

OVERVIEW OF THE REVIEWED GAME HEURISTICS FOR THE ITEM POOL GENERATION

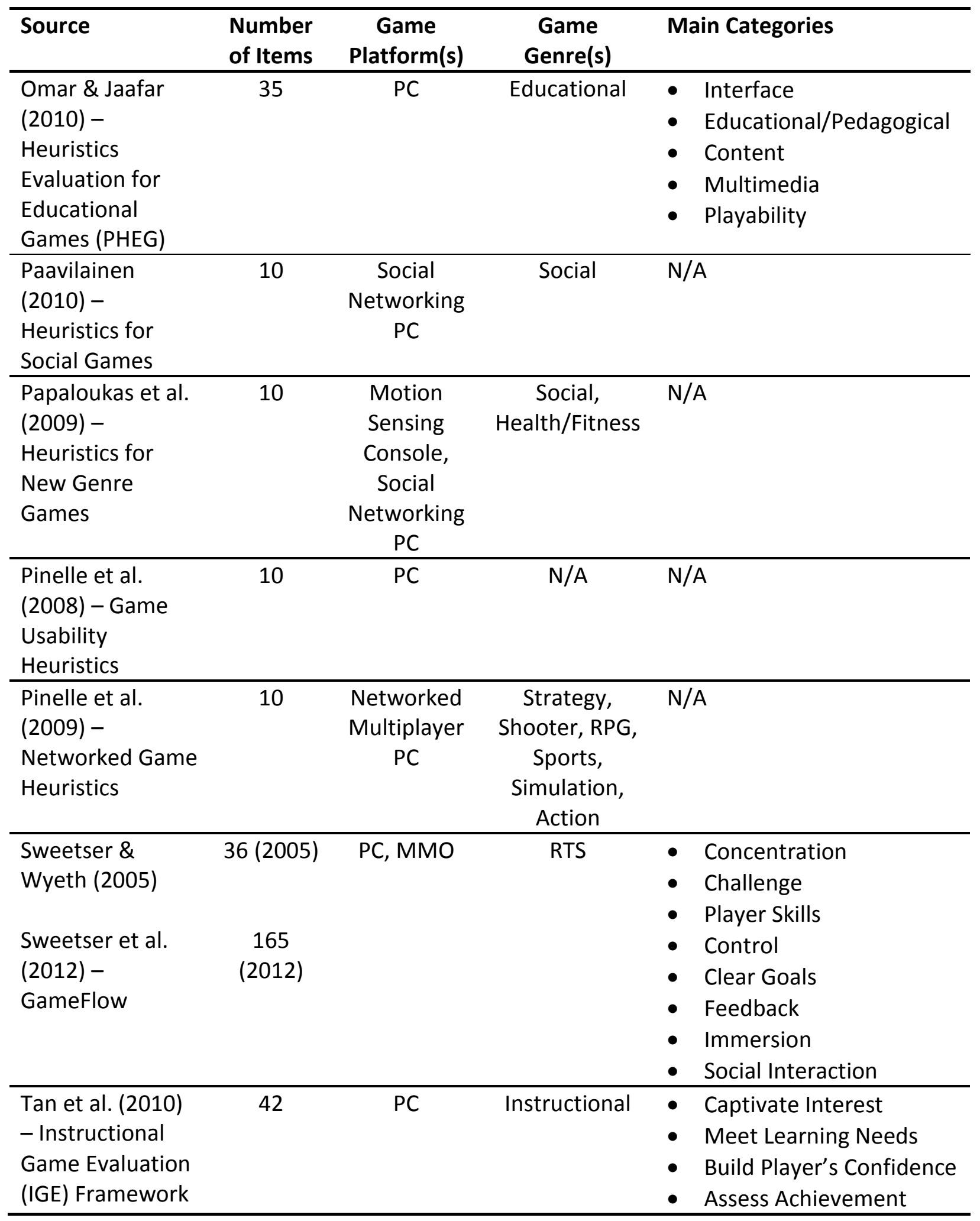


Finally, during the process of generating items three popular satisfaction questionnaires that have been freely available in the $\mathrm{HCl}$ domain were consulted to produce new items concerning general user satisfaction. These three satisfaction questionnaires are the: System Usability Scale (SUS; Brooke, 1996), Questionnaire for User Interface Satisfaction (QUIS; Chin et al., 1988), and Computer System Usability Questionnaire (CSUQ; Lewis, 1995). The SUS, QUIS, and CSUQ each consists of 10, 27, and 19 items, respectively. All of the items combined resulted in an initial pool of approximately 875 possible items.

After the initial item pool had been generated, the item pool underwent an iterative process of modification and refinement. First, all items were individually screened for redundancy and any items that were similarly phrased (e.g., "I enjoyed the game." and "I liked the game.") were reduced to a single item. Any items that were considered to be too vague (e.g., "I feel different.") or genre-specific (e.g., "I want to know more about the knowledge taught.") were removed from the pool. Furthermore, any items that were deemed as irrelevant or not contributing to the overall assessment of video game design or the gaming experience were also deleted (e.g., "I am familiar with the cultural background."). All in all, the pool was continually examined for several rounds to ascertain that each item was unique and relevant to the evaluation of video game satisfaction.

It was expected that more than a third of the items would be removed due to redundancy and irrelevancy. The remaining items further went through several phases of inspection to ensure that all items were adequately worded, grammatically correct, and flow well in a sentence. Any items that were too long, awkwardly phrased, or difficult to understand were modified or eliminated. Afterward, the item pool was reviewed again to ensure that there 
was variety in the content, that different game elements (e.g., graphics, sound) were well represented, and that all items were applicable across many genres (e.g., FPS, RPG, Fighting). New items were also created in cases where the researchers felt an important aspect or feature of video games was missing from the revised item pool.

\section{Results.}

After the initial steps of scale evaluation and refinement, 116 items were retained for the expert review stage. The 116 items were obtained or developed based on 29 unique sources, half of which were from the previously mentioned questionnaires while the remaining half were from the specified lists of game heuristics. Additionally, nine items were created by the researchers in this study. Table 27 presents a summary of the number of items that was developed from each source. Appendix E provides a detailed list of the 116 items, their assumed dimension(s), and their source(s). This list of statements was reviewed by a panel of experts in the next phase.

TABLE 27

OVERVIEW OF NUMBER OF ITEMS DERIVED FROM EACH SOURCE

Source

Agarwal \& Karahanna (2000)

Brockmyer et al. (2009)

Brooke (1996)

Calvillo-Gámez et al. (2010)

Chen et al. (2005)

Chin et al. (1988)

Choi \& Kim (2004)

Clanton (1998)
Name of Questionnaire/List of Heuristics Number of Items

Cognitive Absorption Scale 12

Game Engagement Questionnaire (GEQ) 4

System Usability Scale (SUS) 1

Core Elements of the Gaming Experience 17

Questionnaire (CEGEQ)

Gaming Engagement Questionnaire (GEQ) 5

Questionnaire for User Interface 1

Satisfaction (QUIS)

Online Game Experience Questionnaire* 5

Computer Game Design Principles

4

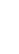

17

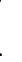
5 1 
TABLE 27 (continued)

OVERVIEW OF NUMBER OF ITEMS DERIVED FROM EACH SOURCE

\begin{tabular}{llc}
\hline Source & Name of Questionnaire/List of Heuristics & $\begin{array}{c}\text { Number } \\
\text { of Items }\end{array}$ \\
\hline Desurvire et al. (2004) & Heuristics for Evaluating Playability (HEP) & 16 \\
Desurvire \& Wiberg (2009) & Game Playability Principles (PLAY) & 15 \\
Ermi \& Mäyrä (2005) & Gameplay Experience Questionnaire & 7 \\
Federoff (2002) & Game Heuristics & 8 \\
Fu et al. (2009) & GGameFlow & 10 \\
IJsselsteijn et al. (2008) & Game Experience Questionnaire (GEQ) & 10 \\
Jennett et al. (2008) & Immersion Questionnaire & 9 \\
Korhonen \& Koivisto (2006) & Playability Heuristics for Mobile Games & 7 \\
Lewis (1995) & Computer System Usability Questionnaire & 3 \\
& (CSUQ) & \\
Omar \& Jaafar (2010) & Heuristics Evaluation for Educational & 1 \\
& Games (PHEG) & 3 \\
Paavilainen (2010) & Heuristics for Social Games & 3 \\
Papaloukas et al. (2009) & Heuristics for New Genre Games & 10 \\
Parnell (2009) & Gameplay Scale & 3 \\
Pavlas et al. (2012) & Play Experience Scale (PES) & 4 \\
Pinelle et al. (2008) & Game Usability Heuristics & 6 \\
Qin et al. (2009) & Player Immersion in Computer Game & \\
Sweetser \& Wyeth (2005) & Narrative Questionnaire & 5 \\
Sweetser et al. (2012) & GameFlow & 5 \\
Tan et al. (2010) & GameFlow & 7 \\
Witmer \& Singer (1998) & Instructional Game Evaluation (IGE) & \\
Current research & Framework & 4 \\
\hline
\end{tabular}

*The questionnaire was not formally named. Thus, for the sake of identification a generic name was chosen.

Note: Some of the items were derived from multiple sources. 


\section{Step 2: Expert Review of Item Pool}

\section{Method.}

One of the major concerns in developing quality scales is to ensure that such scale have content validity (Hinkin, 1995; 1998; Jensen, 2003; Worthington \& Whittaker, 2006). Content validity refers to the degree in which the items on the scale accurately reflect the domain of interest. One common method to measure content validity is to have experts examine the initial pool of items before administering the questionnaire to a large population (CabreraNguyen, 2010; Jensen, 2003). Having an expert panel reviewed the item pool would further ensure that the items on the scale are appropriate and pertinent to the comprehensive measurement of video game satisfaction.

Participants. Two groups of experts were involved in the review of the item pool. The first group consisted of evaluators who have knowledge and experience with questionnaire design and development. The second group consisted of experienced (i.e., hardcore/expert) gamers who had a diverse experience in playing different types of games (e.g., Fighting, Sports) on various gaming platforms (e.g., mobile, console). Additionally, each of the "video game experts" had been playing video games for at least 15 years. All experts were recruited through a personal network.

In total, there were eight experts $(N=8)$ who participated in this study. Three were video game experts and four were scale/questionnaire experts. One person was both a scale/questionnaire and a video game expert. Three of the scale/questionnaire experts hold a Ph.D. degree in the field of human factors psychology while the remaining two were graduate students in the same field. Two of the scale/questionnaire experts have worked as research 
managers in a reputable video game company. In addition, two of the video game experts have been involved in the business of buying and selling games for over three years. Table 28 shows a summary of the expert panel's background information.

TABLE 28

\section{BACKGROUND INFORMATION OF THE EXPERT PANEL}

\begin{tabular}{|c|c|}
\hline Variable & Value \\
\hline Total $(N)$ & 8 \\
\hline Mean Age in years $(S D)$ & $28.25(4.06)$ \\
\hline \multicolumn{2}{|l|}{ Gender } \\
\hline Male & 5 \\
\hline Female & 3 \\
\hline \multicolumn{2}{|l|}{ Expert Type } \\
\hline Video Game & 3 \\
\hline Scale/Questionnaire & 4 \\
\hline Both & 1 \\
\hline \multicolumn{2}{|l|}{ Education Level } \\
\hline Some college & 1 \\
\hline Bachelor's & 1 \\
\hline Master's & 3 \\
\hline Ph.D. & 3 \\
\hline \multicolumn{2}{|c|}{ Type of Video Game Player* } \\
\hline Newbie/Novice & 1 \\
\hline Casual & 1 \\
\hline Mid-core/Core & 2 \\
\hline Hardcore/Expert & 4 \\
\hline \multicolumn{2}{|c|}{ Mean Hours Spent Playing Game per Week } \\
\hline Less than 1 hour & 1 \\
\hline 1 to 4 hours & 1 \\
\hline 5 to 9 hours & 1 \\
\hline 10 to 19 hours & 2 \\
\hline 20 to 29 hours & 2 \\
\hline 30 to 39 hours & 1 \\
\hline
\end{tabular}

Materials. Qualtrics ${ }^{\circledR}$, an online survey tool, was used to create the questionnaire and capture the questionnaire responses. The online questionnaire contained a series of 116 
statements from the revised item pool on a seven-point Likert scale. Appendix E provides the detailed list of the 116 statements used in this study phase.

Procedure. At the beginning of the study, all participants were asked to read and acknowledge that they have read the study's consent form (see Appendix F). Then participants were asked to select a video game that they want to evaluate (see Appendix G for the instructions). Before the evaluation process, participants were asked to provide some basic information about the video game (see Appendix $\mathrm{H}$ ). Participants then proceeded to the game evaluation phase where they were asked to rate the game using a seven-point scale and provided feedback about a particular set of statements or items.

The 116 statements were divided into a set of five statements per page, with the last page containing the last six statements. The set of statements was randomized per page. Appendix I provides a screenshot of one of the evaluation pages. In terms of item evaluation, participants were asked to scrutinize every item on each page and identify any problematic items in terms of wording issues, and to offer suggestions for item improvements. Additionally, evaluators were asked to identify any items that they felt might not be relevant to video game satisfaction.

After the 116 statements have been reviewed, participants were asked to give an overall satisfaction rating of the game under evaluation on a seven-point Likert scale (see Appendix J). Following the overall game satisfaction rating, participants were asked to provide general comments about the entire questionnaire and its adequacy in measuring video game satisfaction (see Appendix K). Finally, participants were asked to provide some basic demographic information (see Appendix L). The entire questionnaire took about $60-90$ minutes 
to complete, and all participants were offered a \$30 Amazon gift card upon the completion of the survey.

\section{Results.}

In general, the expert review panel commented that the item pool was comprehensive in measuring game satisfaction. The panel also felt that there was a good representation of different video game elements among the items. However, there were some items that were identified by the panel to be unclear (e.g., "I was moved by the events in the game."). Based on the panel's suggestions items that contained unclear wordings were revised. Additionally, there were items that were identified to be grammatically complex or wordy (e.g., "I didn't feel the urge to stop playing the game at any point and check my surroundings."). In order to make all of the items more concise and less grammatical complex, the items were converted from past tenses into present tenses.

In total, there were 19 items that were removed from the pool after the expert review. The majority of the items that were deleted because there were better items in the pool that measure similar aspects of video games. A few items were deleted for being too abstract in wordings (e.g., "I felt spaced out when I'm playing the game."). Additionally, three new items were added in relation to the social aspects of gaming. All in all, the item pool after the expert review contained 100 items. These items were used in the following pilot study. Appendix M provides a detailed list of the items that were revised, added, and removed from the item pool. 


\section{Step 3: Questionnaire Pilot Study}

\section{Method.}

Participants. Prior to the large-scale data collection phases, 16 face-to-face pilot sessions were conducted among four self-identified groups of gamers (i.e., newbie/novice, casual, core/mid-core, and hardcore/expert). There were equal number of gamers from each group. Half of the gamers recruited for the pilot study were females. In addition, nine of the gamers were non-native English speakers. These specific group of gamers were purposely selected to ensure that all items on the questionnaire can easily be understood by a wide range gamers with different gaming background and experience, including English as a Second Language (ESL) gamers. In short, the purpose of conducting pilot interviews with an initial sample of gamers was to confirm whether the target respondents accurately interpret the items as they were intended.

With the exception of one participant, all participants recruited for the pilot sessions were college students from Wichita State University (WSU). WSU Psychology Experiment SignUp System (Sona System) was used to recruit participants. All participants were asked to complete a prior screening survey before they were invited to participate in the pilot study. In order for students to be invited to the study, they must meet one of the demographics criteria listed above (e.g., gender, ESL). They also must indicate on the screening survey (see Appendix $\mathrm{N})$ that they have played a video game within the last three months, and that they have spent at least 10 hours playing the specified game. The last two criteria were established to ensure that participants would have adequate memory and play experience of the game they were 
going to evaluate in the pilot study. A summary of the participants' background information is displayed in Table 29.

TABLE 29

BACKGROUND INFORMATION OF THE PILOT PARTICIPANTS

\begin{tabular}{lc}
\hline Variable & Value \\
\hline Total (N) & 16 \\
Mean Age in years (SD) & $23.13(6.86)$ \\
Mean Age First Played Video Games (SD) & $9.94(4.36)$ \\
Mean Rating for Overall Gaming Knowledge (SD) & $4.44(1.97)$ \\
(1 = Novice; 7 = Expert) & \\
Gender & \\
Male & 8 \\
Female & 8 \\
Ethnicity & \\
Asian/Pacific Islander & 7 \\
Black/African American & 1 \\
Hispanic/Latino & 3 \\
White (not of Hispanic origin) & 4 \\
I do not wish to answer. & 1 \\
Education Level & \\
High school graduate or GED & 5 \\
Some college & 5 \\
College graduate (2- and 4-year degree) & 5 \\
Post-graduate degree (MA, PhD, Law, Medical, or & 1 \\
Professional school) & \\
Type of Video Game Player* & \\
Newbie/Novice & \\
Casual & 4 \\
Mid-core/Core & 4 \\
Hardcore/Expert & 4 \\
Mean Hours Spent Playing Game per Week & 4 \\
Less than 1 hour & \\
1 to 4 hours & \\
5 to 9 hours & \\
10 to 19 hours & \\
\hline & \\
\hline
\end{tabular}


TABLE 29 (continued)

\section{BACKGROUND INFORMATION OF THE PILOT PARTICIPANTS}

\begin{tabular}{lc}
\hline Variable & Value \\
\hline Non-English Native Speakers & 9 \\
Years Speaking English & \\
Less than 1 year & 2 \\
5 to 6 years & 1 \\
7 to 9 years & 1 \\
10 to 14 years & 3 \\
15 to 19 years & 1 \\
More than 20 years & 1 \\
Native/First Language & \\
Mandarin & 4 \\
Spanish & 2 \\
Efik & 1 \\
Tagalog & 1 \\
Vietnamese & 1 \\
\hline
\end{tabular}

${ }^{*}$ According to how the participants identified themselves.

Materials. Once invited to the pilot session, participants were asked to complete an online survey via Qualtrics ${ }^{\circledR}$ on a PC while their activities and comments were monitored and noted in a separate document by an observer. The online questionnaire contained demographic questions and a series of 100 statements from the revised item pool based on the expert panel's comments. Appendix M provides the detailed list of the 100 statements used in the pilot study.

Procedure. Participants were first asked to read and acknowledge that they have read the study's consent form (see Appendix O). Then participants were given brief instructions about the study (see Appendix P for the study's script). In general, participants were informed that the purpose of the study is to gather their feedback to improve the design of the survey. While completing the survey, participants were instructed to "think-aloud" when they 
encountered particular words or statements that were difficult to interpret. An observer was nearby to type participants' comments on a laptop.

The first section of the survey asked participants to identify the name of the game that they want to evaluate (see Appendix G). The second section contained general questions about the game under evaluation (see Appendix H). The next section consisted of a series of 100 statements from the revised item pool after the expert review. Participants were asked to evaluate the game in accordance with each statement using the seven-point Likert scale (see Figure 5).

Similar to the expert review phase, the 100 statements were divided into a set of five statements per page. The set of statements were randomized per page. Care was given to the selection of the set of items per page in order to ensure that items that shared similar element did not appear on the same page or close to each other. Appendix Q provides a screenshot of one of the pages containing a set of five statements. After the last set of five statements, participants were asked to give an overall satisfaction rating of the game from "Extremely Satisfied" to "Extremely Dissatisfied" (see Appendix J).

After participants have finished completing the survey, they were presented with a paper copy of the survey in which they were asked to revisit the problematic items and clarify why they were problematic and offer suggestions to improve the item. Finally, participants were asked to provide additional feedback about the adequacy of the survey for measuring their level of satisfaction with the game they had evaluated. They were also asked whether there were other important gaming aspects that were missing from the survey. Each session 
took approximately 25-35 minutes, and participants were awarded course credit for their participation.

\section{Results.}

Before the survey would be largely distributed, the goal was to retain at least 40 items to ensure internal consistency, but no more than 100 items to minimize respondent fatigue (Hinkin, 1995; 1998). In general, the length of the survey was aimed to be close to the recommended time of survey completion of approximately 15-30 minutes, and no more than 50 minutes (Worthington \& Whittaker, 2006). Based on the 16 pilot sessions, the average duration of questionnaire completion was around 20 minutes, which indicated that the questionnaire was adequate in length.

In terms of participants' feedback about the questionnaire, the majority of participants thought the questionnaire was straightforward and easy to understand. They also felt the questionnaire was comprehensive in measuring different aspects related to video game satisfaction. However, there were six statements in which participants expressed some confusion over. Following participants' comments and suggestions, those items were revised accordingly. Appendix R presents a detailed list of how the item pool was changed after the pilot study. This new list of 100 statements would be used in the following exploratory factor analysis study. 


\section{CHAPTER 4}

\section{EXPLORATORY FACTOR ANALYSIS (EFA)}

\section{Step 4: Exploratory Factor Analysis (EFA)}

Some researchers have considered a sample size of at least 200-300 participants to be adequate for factor analysis technique, while other researchers used the 5:1 to 15:1 case-tovariable or response-to-item ratio as a common rule of thumb for assessing the adequacy of the sample size (Field, 2009; Hinkin, 1995; 1998; Tabachnick \& Fidell, 2007; Worthington \& Whittaker, 2006). Still, it has been suggested that only after the data has been analyzed will researchers know whether the sample size collected was appropriate for the study or not (Cabrera-Nguyen, 2010; Treiblmaier \& Filzmoser, 2010). Consequently, some researchers have recommended that scale development studies set a minimum sample size and try to obtain the largest sample possible, then determine whether additional data collection is needed based on initial factor analysis results (Cabrera-Nguyen, 2010; Worthington \& Whittaker, 2006). As a result, a minimum sample size of 300 participants was set for the exploratory factory analysis phase. Ultimately, the goal was to gather 600 completed questionnaires for this phase.

\section{Method.}

A total of 1465 surveys were collected after the survey links were closed. However, during the screening and cleaning process $57.1 \%(n=836)$ of the surveys was identified as containing non-valid responses. Thus, these surveys were removed from the final data set. In general, surveys were removed due to one of the following reasons:

- Surveys were incomplete-participants stopped taking the study's survey mid-point and never went back to complete it. 
- Participants entered a non-video game title in the survey.

- Two or more game titles were evaluated in a single submission.

- Surveys contained bias responses, in which participants selected the highest response on the rating scale for all items.

- Participants who completed the survey were less than 18 years old.

- The study was only approved by the WSU Institutional Review Board (IRB) to collect data from people who were at least 18 years old.

- Multiple survey submissions by the same participant.

- Each participant was allowed to submit one complete survey. Only the latest valid survey was retained in cases where more than one surveys were submitted by the same participant.

- The surveys were completed in less than 10 minutes.

- This guideline was enforced to prevent rush and low-quality responses. The previous pilot study has revealed that the average survey completion duration was around 20 minutes.

- The video game that was evaluated had not been played in the last three months.

- This rule was applied to ensure that participants had adequate memory of the game that they evaluated.

- The video game that was evaluated had less than 10 hours of play.

- Based on informal discussions with different video game players, it was determined that it is difficult for people to rate whether they like or dislike a game based on the 
first couple hours of play. Thus, this guide was established to ensure that participants had adequate experience with the game they evaluated.

Participants. After the data was screened and cleaned, a total of 629 questionnaires were retained for the final analyses. In short, the final data set was based on a sample size of 629 video game players, ages ranged from 18 to 61 years old $(M=24.61, S D=7.18)$. These video game players hold various occupations such as students, retail workers, designers, and researchers. Of the 629 survey respondents, about $42 \%$ were female gamers. Approximately 78\% identified themselves as either "Casual" or "Mid-core/Core" gamers.

The majority of respondents reported to spend, on average, at least five hours per week playing video games. Additionally, many respondents indicated that they frequently played video games on multiple gaming devices-mainly on console, computer, and mobile devices. Respondents also tended to play video games from different genres. The most popular genres reported being Action, Adventure, and Role-Playing. Table 30 provides a summary of participants' demographics. Figures 6 and 7 present a visual illustration of the gaming devices and game genres participants indicated to frequently play, respectively.

TABLE 30

DEMOGRAPHICS OF PARTICIPANTS IN THE EFA STUDY

\begin{tabular}{lc}
\hline Variable & Value \\
\hline Total $(N)$ & 629 \\
Mean Age in years $(S D)$ & $24.61(7.18)$ \\
Gender & \\
Male & $365(58.0 \%)$ \\
Female & $264(42.0 \%)$ \\
\hline
\end{tabular}


TABLE 30 (continued)

DEMOGRAPHICS OF PARTICIPANTS IN THE EFA STUDY

\begin{tabular}{lc}
\hline Variable & Value \\
\hline Ethnicity & \\
American Indian/Alaskan Native & $9(1.4 \%)$ \\
Asian/Pacific Islander & $85(13.5 \%)$ \\
Black/African American & $35(5.6 \%)$ \\
Hispanic/Latino & $55(8.7 \%)$ \\
White (not of Hispanic origin) & $399(63.4 \%)$ \\
Biracial/Multiracial/Mixed & $31(4.9 \%)$ \\
I do not wish to answer. & $15(2.4 \%)$ \\
Education Level & \\
Some high school & $20(3.2 \%)$ \\
High school graduate or GED & $88(14.0 \%)$ \\
Some college & $309(49.1 \%)$ \\
College graduate (2- and 4-year degree) & $170(27.0 \%)$ \\
Post-graduate degree (MA, PhD, Law, Medical, or & $42(6.7 \%)$ \\
Professional school) & \\
Type of Video Game Player* & \\
Newbie/Novice & $41(6.5 \%)$ \\
Casual & $251(39.9 \%)$ \\
Mid-core/Core & $241(38.3 \%)$ \\
Hardcore/Expert & $96(15.3 \%)$ \\
Mean Hours Spent Playing Game per Week & \\
Less than 1 hour & $42(6.7 \%)$ \\
1 to 4 hours & $140(22.3 \%)$ \\
5 to 9 hours & $151(24.0 \%)$ \\
10 to 19 hours & $147(23.4 \%)$ \\
20 to 29 hours & $93(14.8 \%)$ \\
30 to 39 hours & $18(2.9 \%)$ \\
More than 40 hours & $38(6.0 \%)$ \\
\hline
\end{tabular}

*According to how the participants identified themselves. 


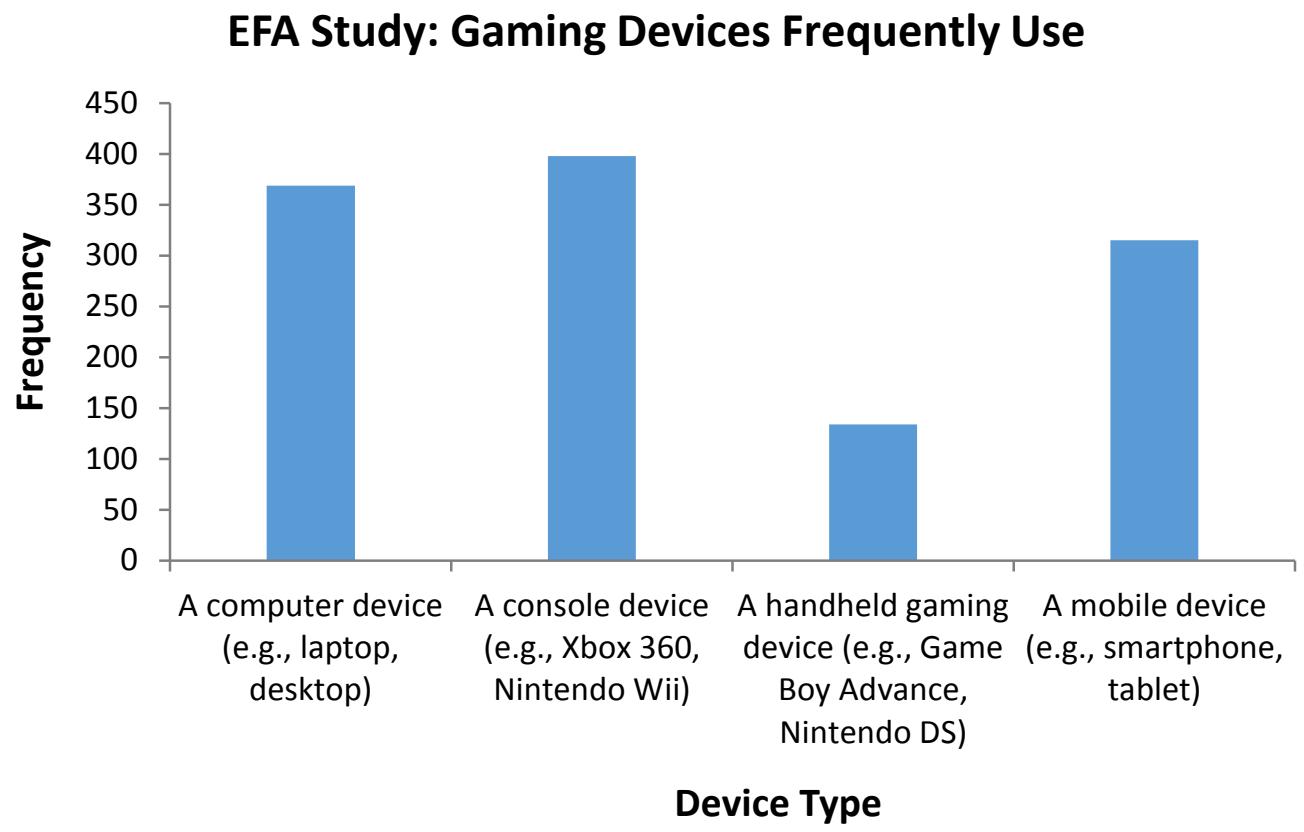

Figure 6. Gaming devices participants reported to frequently use to play video games. Note: Participants were allowed to select more than one response.

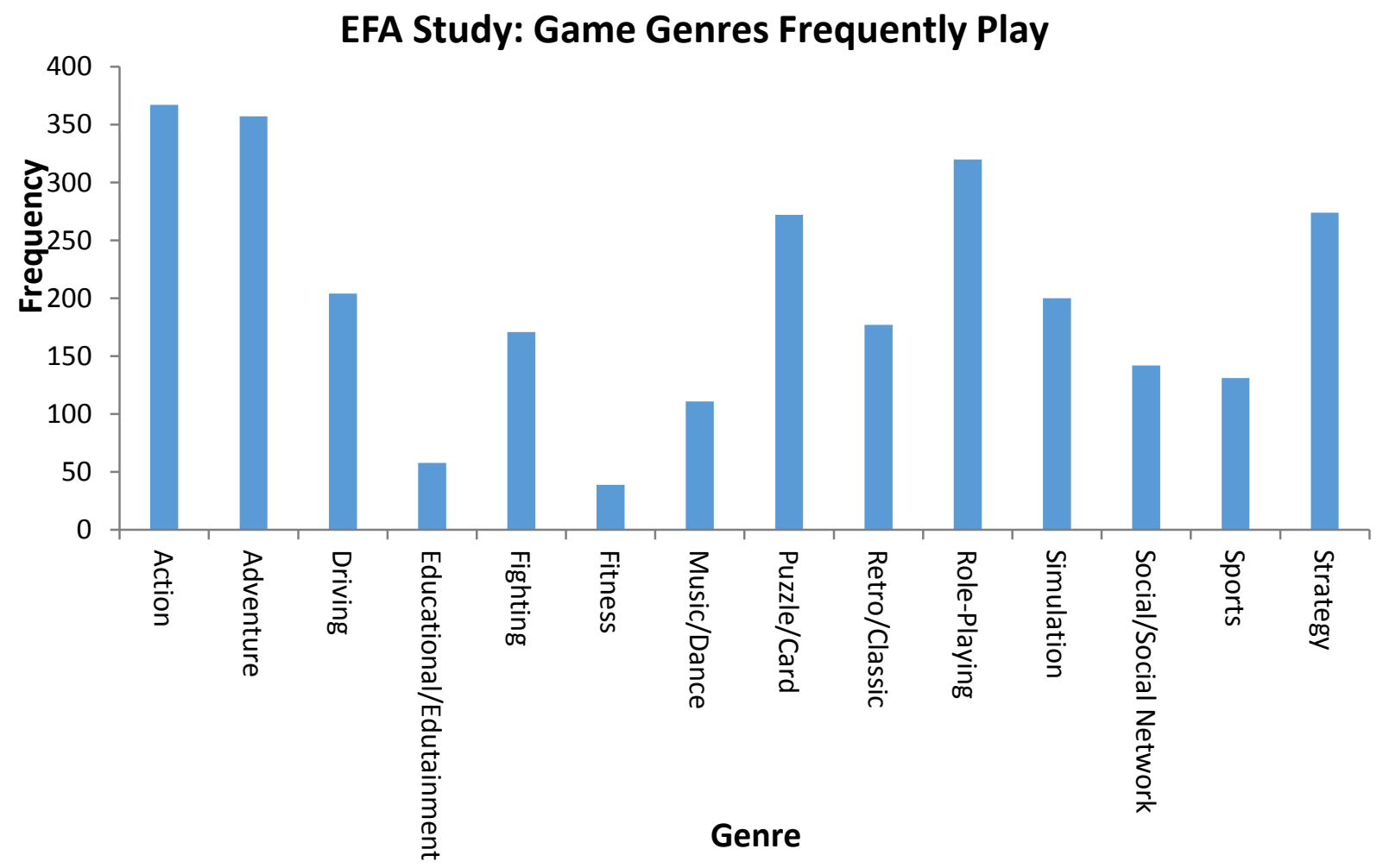

Figure 7. Game genres participants reported to frequently play.

Note: Participants were allowed to select more than one response. 
Video Games. The majority of the video games participants chose to evaluate were games played within the last month (see Figure 8). Additionally, many participants reported spending from 20 to 79 hours playing the video game that they evaluated. The majority of video games were either played on a computer device (e.g., laptop, desktop) or a console device (e.g., Xbox 360, Nintendo Wii). Figures 9 and 10 present a visual summary of the total time participants spent playing the game they evaluated and the type of gaming platform participants used to play the game, respectively.

\section{EFA Study: The Last Time Played the Game Under Evaluation}

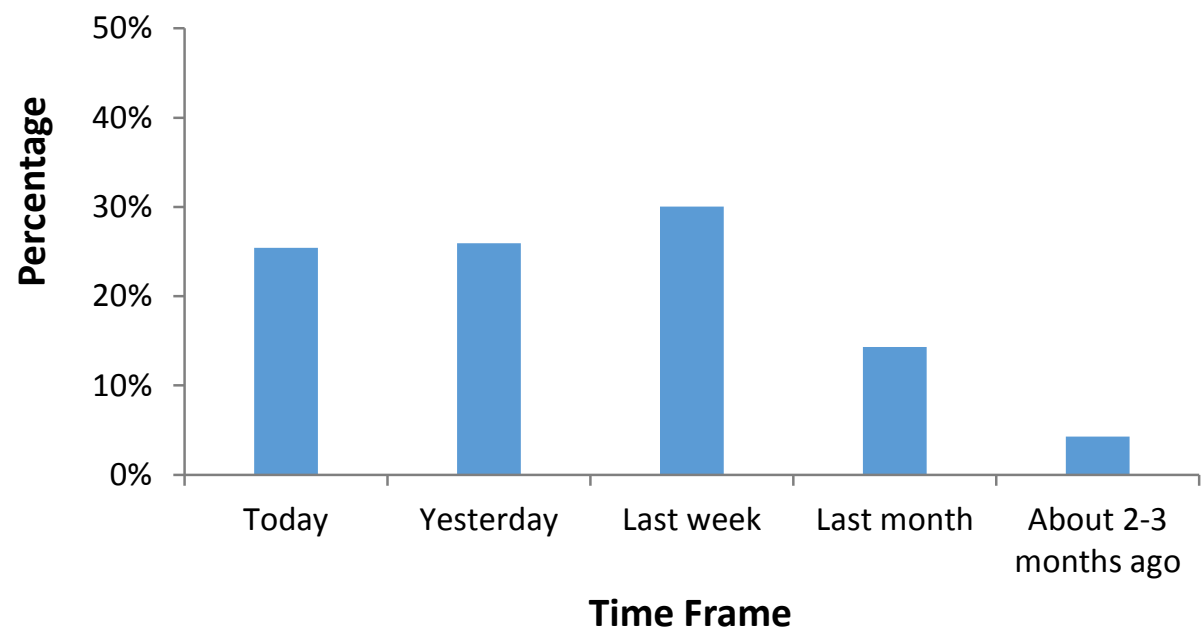

Figure 8. The last time participants reported to play the game they evaluated. 


\section{EFA Study: Total Time Spent Playing the Game Under Evaluation}

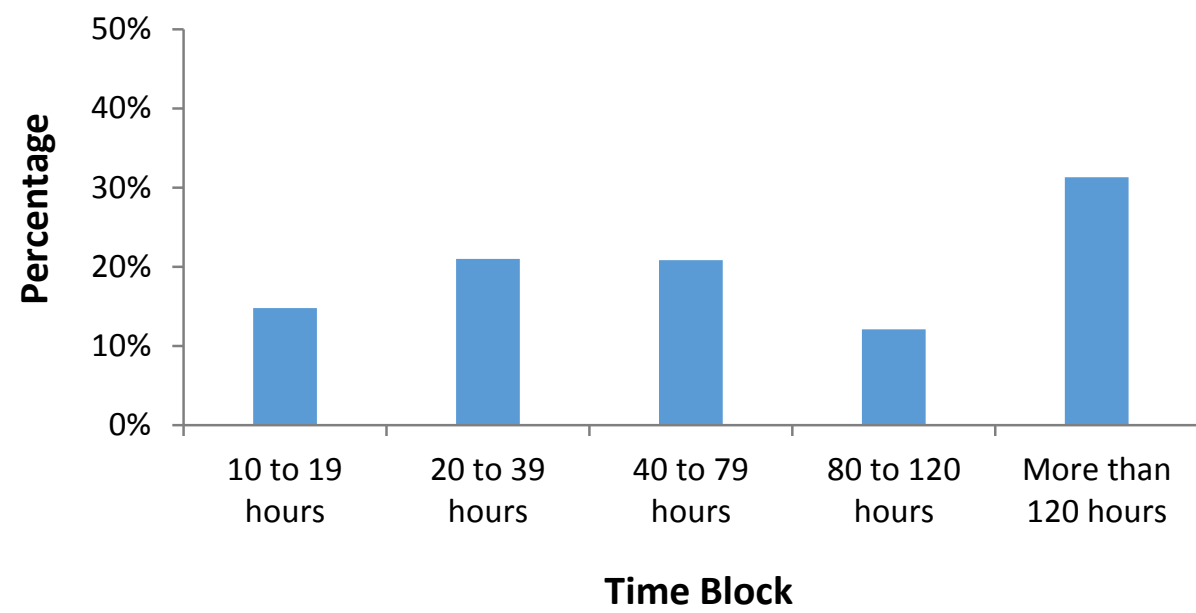

Figure 9. The total time participants spent playing the game they evaluated.

\section{EFA Study: Type of Gaming Device Used to Play the Game Under Evaluation}

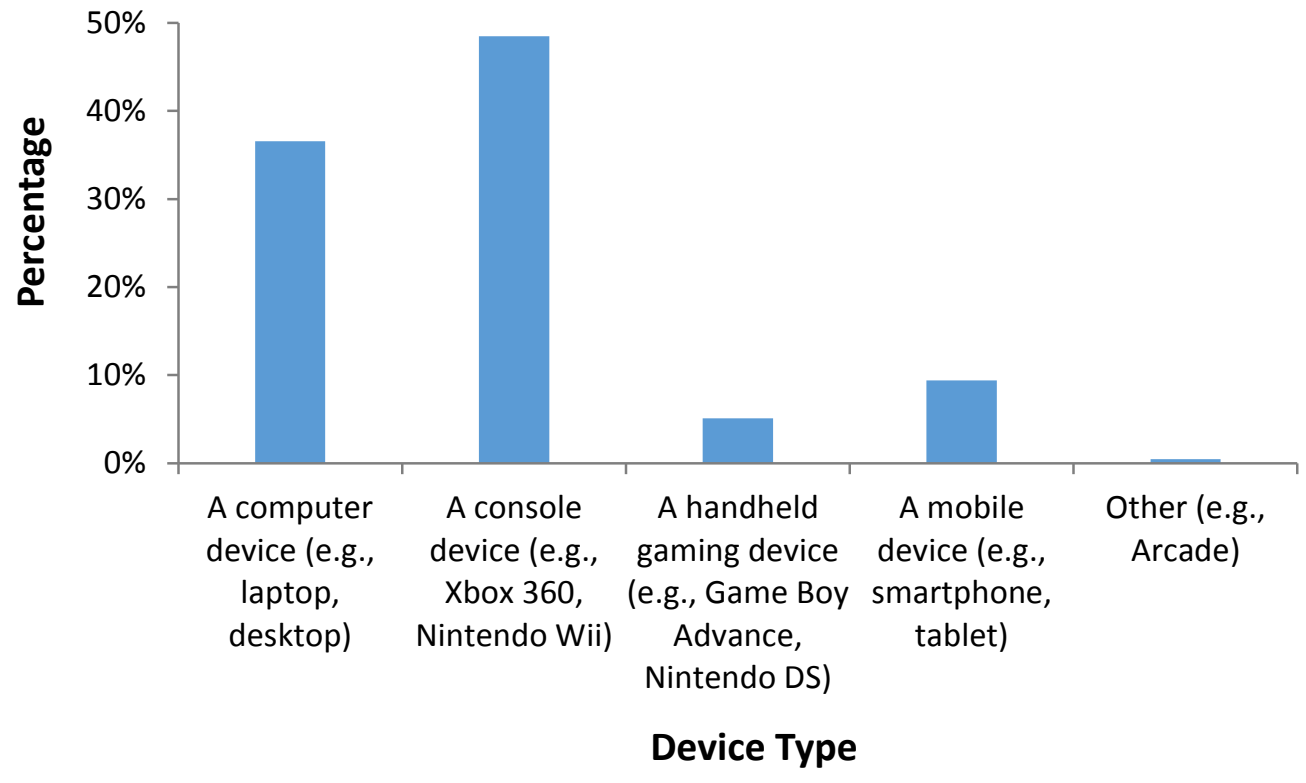

Figure 10. The type of platform participants used to play the game they evaluated.

Of the 629 video games participants selected to evaluate, 254 (40.4\%) were from unique video game titles. Appendix $\mathrm{S}$ provides a detailed list of all the video game titles along with the 
main genre and sub-genre they were classified under. The video games evaluated in this study covered a variety of popular genres (e.g., Action, Sports, Simulation, Driving/Racing). Specifically, many of the video games were classified to be either in the Action, RPG, or Action Adventure genre. Table 31 presents an overview of all of the video game genres represented in this study.

TABLE 31

OVERVIEW OF THE VIDEO GAME GENRES REPRESENTED IN THE EFA STUDY

\begin{tabular}{|c|c|c|}
\hline Main Genre & $n$ & Percent \\
\hline $\begin{array}{l}\text { Action (e.g., Destiny, World of Tanks, New Super Mario Bros. Wii, } \\
\text { Samurai Warriors 4) }\end{array}$ & 164 & $26.1 \%$ \\
\hline $\begin{array}{l}\text { Role-Playing (e.g., Mass Effect 3, World of Warcraft, The Elder Scrolls } \\
\text { V: Skyrim, Pokemon X) }\end{array}$ & 129 & $20.5 \%$ \\
\hline $\begin{array}{l}\text { Action Adventure (e.g., Minecraft, Grand Theft Auto V, Assassin's } \\
\text { Creed Unity, The Last of Us) }\end{array}$ & 108 & $17.2 \%$ \\
\hline $\begin{array}{l}\text { Strategy (e.g., DotA 2, Sid Meier's Civilization V, League of Legends, } \\
\text { Hay Day) }\end{array}$ & 69 & $11.0 \%$ \\
\hline Sports (e.g., NBA 2K15, Madden NFL 15, FIFA 15, Skate 2) & 42 & $6.7 \%$ \\
\hline $\begin{array}{l}\text { Puzzle/Card/Board (e.g., Candy Crush Saga, Words With Friends, } \\
\text { Tetris, Bubble Shooter) }\end{array}$ & 35 & $5.6 \%$ \\
\hline $\begin{array}{l}\text { Simulation (e.g., The Sims 3, Kim Kardashian Hollywood, Kerbal } \\
\text { Space Program, Tropico 5) }\end{array}$ & 31 & $4.9 \%$ \\
\hline $\begin{array}{l}\text { Driving/Racing (e.g., Mario Kart Wii, Forza Horizon 2, Hill Climb } \\
\text { Racing, iRacing) }\end{array}$ & 21 & $3.3 \%$ \\
\hline $\begin{array}{l}\text { Fighting (e.g., Super Smash Bros. for Wii U, Mortal Kombat vs. DC } \\
\text { Universe, SoulCalibur, Skullgirls) }\end{array}$ & 15 & $2.4 \%$ \\
\hline $\begin{array}{l}\text { Music/Dance (e.g., Guitar Hero, Rock Band, Taiko Drum Master, } \\
\text { Hatsune Miku Project Diva F) }\end{array}$ & 11 & $1.7 \%$ \\
\hline $\begin{array}{l}\text { Other (e.g., Wii Fit, Nancy Drew: Labyrinth of Lies, The Walking Dead: } \\
\text { The Game) }\end{array}$ & 4 & $0.6 \%$ \\
\hline
\end{tabular}

Note: Each video game title was categorized under one main genre. Various popular gaming websites (e.g., GameFaqs.com, Metacritic.com, and IGN.com) were consulted during the game genre classification process. 
Finally, the majority of the video games evaluated in this study were games that fell under the "Like" category rather than "Dislike". At the end of the game evaluation, the majority of participants indicated that, overall, they felt "Extremely Satisfied" or "Satisfied" with the game that they had evaluated. Figure 11 shows a visual breakdown of participants' overall level of satisfaction with the game they rated.

\section{EFA Study: Overall Satisfaction Level with the Game Under Evaluation}

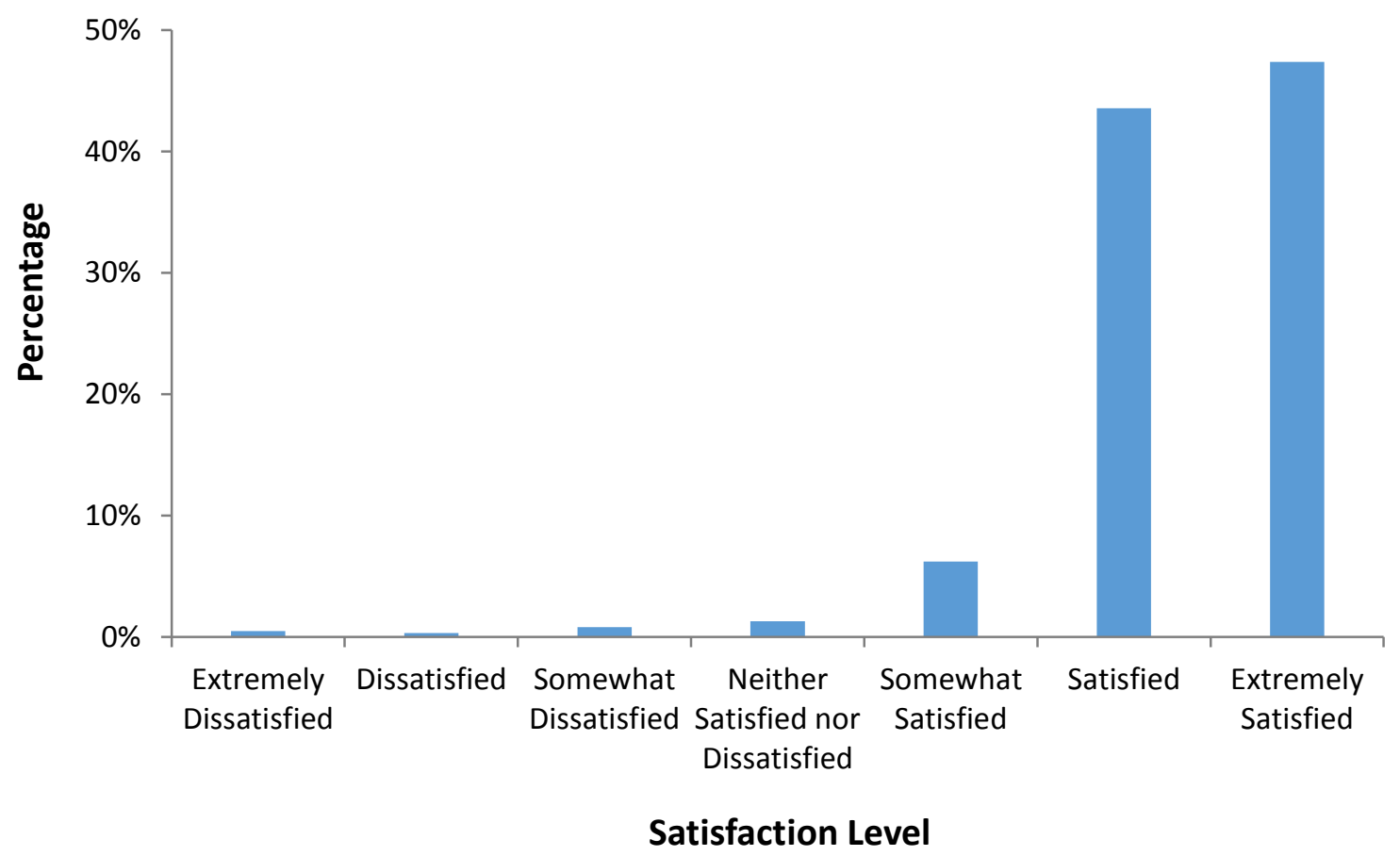

Figure 11. Participants' overall level of satisfaction with the game they evaluated.

Materials. Qualtrics ${ }^{\circledR}$ Online Survey Software was used to create the questionnaire for the EFA study. The first section of the questionnaire contained the consent form (see Appendix T). The second section asked participants to enter the name of the video game that they want 
to evaluate (see Appendix G). The third section asked participants three basic questions about the game (see Appendix $\mathrm{H}$ ):

- When was the last time you played this game?

- In TOTAL, approximately how many hours have you spent playing this game?

- What type of device platform do you MAINLY use to play this game?

The fourth section contained a series of 100 game evaluation statements on a sevenpoint Likert scale, with a "Not Applicable" or "N/A" option at the end of the scale. In order to minimize scrolling, a set of five statements were randomized and displayed per page. In order to prevent the issue of statements with similar elements appear near one another, great care was given in the selection of which five statements appear on which page. Appendix $Q$ and $R$ provide a screenshot of one of the game evaluation pages and the list of 100 statements used in this study, respectively.

The fifth section asked participants to give an overall satisfaction rating for the game that they have evaluated on a seven-point Likert scale with unipolar response anchors (see Appendix J). Finally, the last section contained basic demographic questions about the participants such as age, gender, and ethnicity. Appendix $U$ shows a list of all of the questions in the demographics section. After participants finished filling out the survey, they were brought to a separate section where they can enter their contact information if they want to enter in a raffle to win 1 of $10 \$ 50$ Amazon gift cards. The contact information are stored separately from the study data. Participants were informed that their contact information will not be used for other purposes except for the selection of gift card winners. 
Procedure. Information about the survey along with the survey link were shared various popular social networking sites (e.g., Facebook, Google+, and Twitter) and Internet websites (e.g., Craiglist.com, Reddit.com). Additionally, the survey link was shared on various gaming websites and forums (e.g., GameFaqs.com, ScrewAttack.com). A study invitation email was also sent to a sample of 750 students and staff at WSU via Qualtrics Panels. Last but not least, the survey link was posted on the WSU Sona System where participants were offered the options of receiving 2 Sona credits or a be entered in a random drawing to obtain 1 of $10 \$ 50$ Amazon gift cards. Participants outside of the Sona System were offered the opportunity to be entered in the same raffle to win 1 of $10 \$ 50$ Amazon gift cards.

The survey link was open for 52 days, from November 15, 2014 to January 4, 2015. After the data collection phase has ended, a random drawing was conducted to select the gift card recipients. All participants who completed the survey and indicated that they wanted to enter in the gift card raffle were eligible to receive a $\$ 50$ Amazon gift card. Survey respondents were notified via email if they had been selected to win a gift card. After gift card recipients have confirmed their email address, a $\$ 50$ gift card was sent from Amazon.com to their email address.

\section{Results.}

IBM SPSS Statistics 22 and Microsoft Excel 2013 were used to analyze the data.

Normality. Visual assessment of the histograms and results of the Shapiro-Wilk tests revealed that each of the 100 items deviated significantly from a normal distribution. The majority of the items has a negatively skewed distribution. In short, participants tended to give positive ratings about the game they evaluated. This finding is consistent with participants' report of overall 
game satisfaction near the end of the survey. The majority gave an overall high rating of "Satisfied" and "Extremely Satisfied". Additionally, the majority of the data was considered to be moderately skewed (i.e., skewness $<|2|$ and kurtosis $<7$; Finney \& DiStefano, 2013). In total, there are six variables with skewness value greater than $|2|$ and/or kurtosis value greater than 7 . Appendix $\mathrm{V}$ offers a detailed report of the skewness and kurtosis values of all the items.

Due a number of reasons, the decision was made to keep the data untransformed. Keeping the data untransformed aligned with the exploratory nature of this study and allowed for easier interpretation of the results. Additionally, untransformed data reflected the true nature of the data collected in this study, in which data was mostly based on games that were well-liked by participants. Researchers have observed that non-normal data is a common occurrence in survey research and social science research in general (Blanca, Arnau, López-Montiel, Bono, \& Bendayan, 2013; Dawes, 2007; Malgady, 2007). In practice, researchers often conducted factor analysis on severely non-normal data (Muthén \& Kaplan, 1985; Wang, Fan, \& Willson, 1996). Moreover, other researchers have demonstrated that in relation to Cronbach's alpha and Pearson product-moment correlation data transformations are not always an appropriate or desired option when item responses are skewed (Norris \& Aroian, 2004).

Missing Data. "N/A" responses were treated as missing values. In total, there was about $3.1 \%$ of the data missing, which has been deemed as inconsequential (Bennett, 2001; Peng, Harwell, Liou, \& Ehman, 2006; Schafer, 1999). Results of Little's MCAR test $\chi^{2}(26826, N=629)=$ $30,195.76, p<.05$ suggested that the data was not missing completely at random. The missing data issue appeared to affect many variables and cases.

Approximately $94.0 \%$ of variables $(n=94)$ and $56.8 \%$ of cases $(n=357)$ contained at least one missing value. The percentage of missing values for each variable or item ranges from 
$0.2 \%$ to $18.1 \%$. Since all of the variables contained less than $20 \%$ of missing values none was

removed from the initial stage of data analyses. Table 32 listed all of the variables that

contained over $10 \%$ of missing values with their mean and standard deviation. Appendix W

provides a complete list of all of the variables with missing values.

TABLE 32

EFA STUDY: VARIABLES WITH OVER 10\% OF MISSING VALUES

\begin{tabular}{lcccc}
\hline & \multicolumn{3}{c}{ Missing Values } & \\
\cline { 2 - 3 } Item & $\boldsymbol{n}$ & Percent & Mean & SD \\
\hline I enjoy the social interaction within the game. & 114 & $18.1 \%$ & 5.04 & 1.60 \\
I find the game supports social interaction (e.g., chat) & 95 & $15.1 \%$ & 4.94 & 1.97 \\
between players. & & & & \\
I am captivated by the game's story from the beginning. & 91 & $14.5 \%$ & 5.27 & 1.62 \\
I think it is easy to save the game at different stages. & 88 & $14.0 \%$ & 5.61 & 1.58 \\
I can easily skip any non-playable content (e.g., videos, story & 84 & $13.4 \%$ & 5.12 & 1.82 \\
scenes) that does not capture my interest. & & & & \\
I like to play this game with other players. & 80 & $12.7 \%$ & 5.47 & 1.97 \\
I can clearly understand the game's story. & 74 & $11.8 \%$ & 5.95 & 1.24 \\
I think the characters in the game are well developed. & 67 & $10.7 \%$ & 5.22 & 1.65 \\
I am able to play the game with other players if I choose. & 65 & $10.3 \%$ & 5.70 & 1.92 \\
I find social communities to be supported outside of the & 64 & $10.2 \%$ & 5.25 & 1.70 \\
games (e.g., online forums). & & & & \\
\hline
\end{tabular}

Several missing data techniques (e.g., listwise deletion, regression substitution) were considered for handling missing values. The final decision was to use the Expectation Maximization (EM; Dempster, Laird, \& Rubin, 1977) method via SPSS Missing Value Analysis (MVA) add-on module to replace the missing values. The EM method is a two-step iterative approach that belong with other maximum likelihood (ML) techniques. Like other $\mathrm{ML}$ techniques, the EM method functions by using observed data to estimate parameters and using the new calculations to estimate the missing values. 
The EM method has been considered to be most appropriate for non-hypothesis testing analyses such as EFA and internal consistency calculations (Enders, 2003; Schlomer, Bauman, \& Card, 2010). Numerous studies have agreed that that EM method is superior to traditional missing data techniques (e.g., pairwise deletion, mean substitution) by producing more accurate parameter estimations (Enders, 2003; Fox-Wasylyshyn \& El-Masri, 2005; Graham, 2009; Musil, Warner, Yobas, \& Jones, 2002). Moreover, research has demonstrated that EM methods outperformed other methods (i.e., resemblance-based hot-deck imputation, iterative stochastic regression imputation) under non-ideal conditions (e.g., small sample size, nonnormally distributed data; Gold \& Bentler, 2000). As a final point, researchers tended to recommend using ML-based methods (e.g., EM) over other traditional methods when dealing with more than $10 \%$ of missing data and when data is not missing completely at random (Roth, 1994; Tsikriktsis, 2005).

Factorability. Multiple criteria were used to determine the factorability of the data. One of the first thing considered is the adequacy of the sample size. Kass and Tinsley (1979) stated that test parameters tend to be stable once sample size reaches 300 participants regardless of the case-to-item or participant-to-variable ratio. Comrey and Lee (1992) classified a sample size of 100 as "poor", 300 as "good", and 500 as "very good". Other researchers also agreed that having a sample size of at least 300 cases is desirable for factor analysis (Tabachnick \& Fidell, 2007; Worthington \& Whittaker, 2006). Thus, the sample size of this study $(N=629)$ was deemed to be suitable for conducting an EFA.

Additionally, the correlation matrix between the items was inspected to determine the appropriateness of using factor analysis. Tabachnick and Fidell (2007) suggest researchers to 
reconsider using factor analysis if there is a low number of correlation coefficients above $|.30|$. Similarly, Field (2009) stated that factor analysis is appropriate when there is high intercorrelations among many of the items. The author went on to recommend that researchers consider removing any items that did not correlate above $|.30|$ with many of the other items. Based on the inspection, the item "I can easily skip any non-playable content (e.g., videos, story scenes) that does not capture my interest." did not have adequate intercorrelations with any of the other items. Consequently, this item was removed from further analyses.

The Kaiser-Meyer-Olkin (KMO) and Bartlett's test of sphericity were also used to determine whether the data in this study supports factor analysis. The KMO is a measure of sampling adequacy for the R-matrix, and a minimum value of .60 was required for a good factor analysis (Tabachnick \& Fidell, 2007), and a value above .90 was regarded as "superb" (Hutcheson \& Sofroniou, 1999). The KMO for the 99 remaining items was 0.93, which indicates results obtained from a factor analysis should generate distinct and reliable factors (Field, 2009). The Bartlett's test of sphericity assesses whether the correlation matrix resemble an identity matrix, and a significant $\chi^{2}$ statistic is desirable. The Bartlett's test of sphericity revealed that the correlational matrix is significantly different from an identity matrix, $\chi^{2}(4851)=$ $32,138.92, p<.001$. This suggests that intercorrelations among the items are due to common variance share between the items (Zygmon \& Smith, 2014).

Finally, the anti-image correlation matrix, communalities, and factor loadings were examined to evaluate scale factorability. Field (2009) suggests that all of the diagonal elements of the anti-correlation matrix be greater than .50 , and to consider removing one of the items in 
a variable pair that does not exceed this cut-off value. None of the items were removed from the study at this point because all of the diagonal elements were .75 or above. Initial data explorations also revealed that many items had communalities in the .50 range with each factor containing at least three items with factor loadings above |.50|. Taking into account the sample size of over 600 , these results contribute to the overall confidence that conducting a factor analysis is appropriate (MacCallum, Wildaman, Zhang, \& Hong, 1999; Russell, 2002; Worthington \& Whittaker, 2006).

Factor Extraction. The degree of non-normality of the data was taken into consideration when deciding the appropriate extraction method. While many EFA studies tended to select maximum likelihood as the main extraction method, researchers have cautioned against using it when data is not normally distributed (Costello \& Osborne, 2005; Fabrigar, Wegener, MacCallum, \& Strahan, 1999; Treiblmaier \& Filzmoser, 2010; Zygmon \& Smith, 2014). Instead, principal axis factoring (PAF) is recommended in SPSS for when data "severely violated" the normality assumptions (Costello \& Osborne, 2005; Fabrigar et al., 1999).

In terms of rotation method, researchers tend to agree that oblique rotations yield more accurate results than orthogonal rotations, especially when factors are thought to be correlated (Costello \& Osborne, 2005; Fabrigar et al., 1999; Treiblmaier \& Filzmoser, 2010; Worthington \& Whittaker, 2006). Additionally, oblique rotations are deemed to reflect the true nature of social science data in which some correlations are expected among the factors. Other researchers maintain that the best way to determine the appropriate rotation method is to first perform an oblique rotation on the data and see if there are inter-factor correlations (Fabrigar et al., 1999; Henson \& Roberts, 2006; Tabachnick \& Fidell, 2007). 
Tabachnick and Fidell (2007) suggest that researchers have adequate ground to proceed with an oblique rotation when the factor correlation matrix contains correlations around .32 and above. Regarding the type of oblique rotation to perform, researchers have recommended that promax rotation be used since it starts out with an orthogonally rotated (i.e., varimax) solution and then relaxed the constraint so that factors are allowed to correlate with each other (Fabrigar et al., 1999; Matsunaga, 2010; Russell, 2002). Following the recommendations, an initial EFA with the selected PAF extraction method and promax rotation $(k a p p a=4)$ was conducted. The results revealed that there were some inter-factor correlations at .32 or above. Given that there are adequate correlations among some of the factors, the decision was made to keep the oblique rotation.

Multiple factor-retention strategies were adopted for determining the number of factors to retain. According to Kaiser-Guttman criterion, all factors with eigenvalue greater than 1.0 should be retained. Another strategy is to perform Cattell's scree test and visually examine the scree plot for a substantial break in the eigenvalues or the position of the elbow on the plot. Both of these strategies led to two different results. The results from an unrotated factor solution generated by the PAF extraction method suggest that there were 22 factors that met the Kaiser-Guttman criterion (see Table 33). Visual inspection of the scree plot suggested that there are six underlying factors (see Figure 12).

Research has shown that the two strategies are not the most accurate strategies for deciding the number of factors to retain. Specifically, the Kaiser-Guttman criterion tended to underestimate and overestimate the number of latent factors and the examining scree plot method has been criticized for poor reliability (Cliff, 1998; Fabrigar et al., 1999; Henson \& 
Roberts, 2006; Matsunaga, 2010; Russell, 2002; Zygmon \& Smith, 2014). Out of all of the factor extraction methods, parallel analysis proposed by Horn (1965) is often regarded as one of the best methods for determining the correct factor solution (Franklin, Gibson, Robertson, Pohlmann, \& Fralish, 1995; Henson \& Roberts, 2006; Matsunaga, 2010; Russell, 2002; Zygmon \& Smith, 2014).

Parallel analysis is an iterative procedure that takes sampling error into account by creating a new set of data with the same number of variables and cases called "parallel data". Factor analysis is then performed on this data to generate eigenvalue for each factor. These steps are usually repeated several hundreds of times before all of the eigenvalues per data set are averaged. The averaged eigenvalues are then compared with the original data's eigenvalues, and each factor from the original's data is retained if its eigenvalue exceeds the parallel factor's averaged eigenvalues.

Consequently, a parallel analysis was conducted using the SPSS syntax developed by O'connor (2000). The syntax was set to run 1000 parallel data sets with the distribution and random data eigenvalues' percentile at $95 \%$. Additionally, the syntax was specified to run principal components analysis based on permutations of the original data set. Permutations of the original data set was recommended by the author when data does not meet the normality assumptions. Results revealed that there were 9 underlying factors (see Table 34). 


\section{TABLE 33}

\section{INITIAL EIGENVALUE OUTPUT}

\begin{tabular}{ccc}
\hline Factor \# & Eigenvalue & \% Variance \\
\hline 1 & 22.28 & 22.51 \\
2 & 5.44 & 5.49 \\
3 & 4.18 & 4.22 \\
4 & 3.49 & 3.53 \\
5 & 3.16 & 3.20 \\
6 & 2.48 & 2.51 \\
7 & 2.11 & 2.13 \\
8 & 1.97 & 1.99 \\
9 & 1.66 & 1.67 \\
10 & 1.62 & 1.64 \\
11 & 1.48 & 1.50 \\
12 & 1.45 & 1.46 \\
13 & 1.40 & 1.42 \\
14 & 1.25 & 1.27 \\
15 & 1.23 & 1.24 \\
16 & 1.21 & 1.22 \\
17 & 1.20 & 1.22 \\
18 & 1.16 & 1.17 \\
19 & 1.08 & 1.09 \\
20 & 1.07 & 1.08 \\
21 & 1.04 & 1.05 \\
22 & 1.00 & 1.01 \\
\hline
\end{tabular}




\section{Scree Plot}

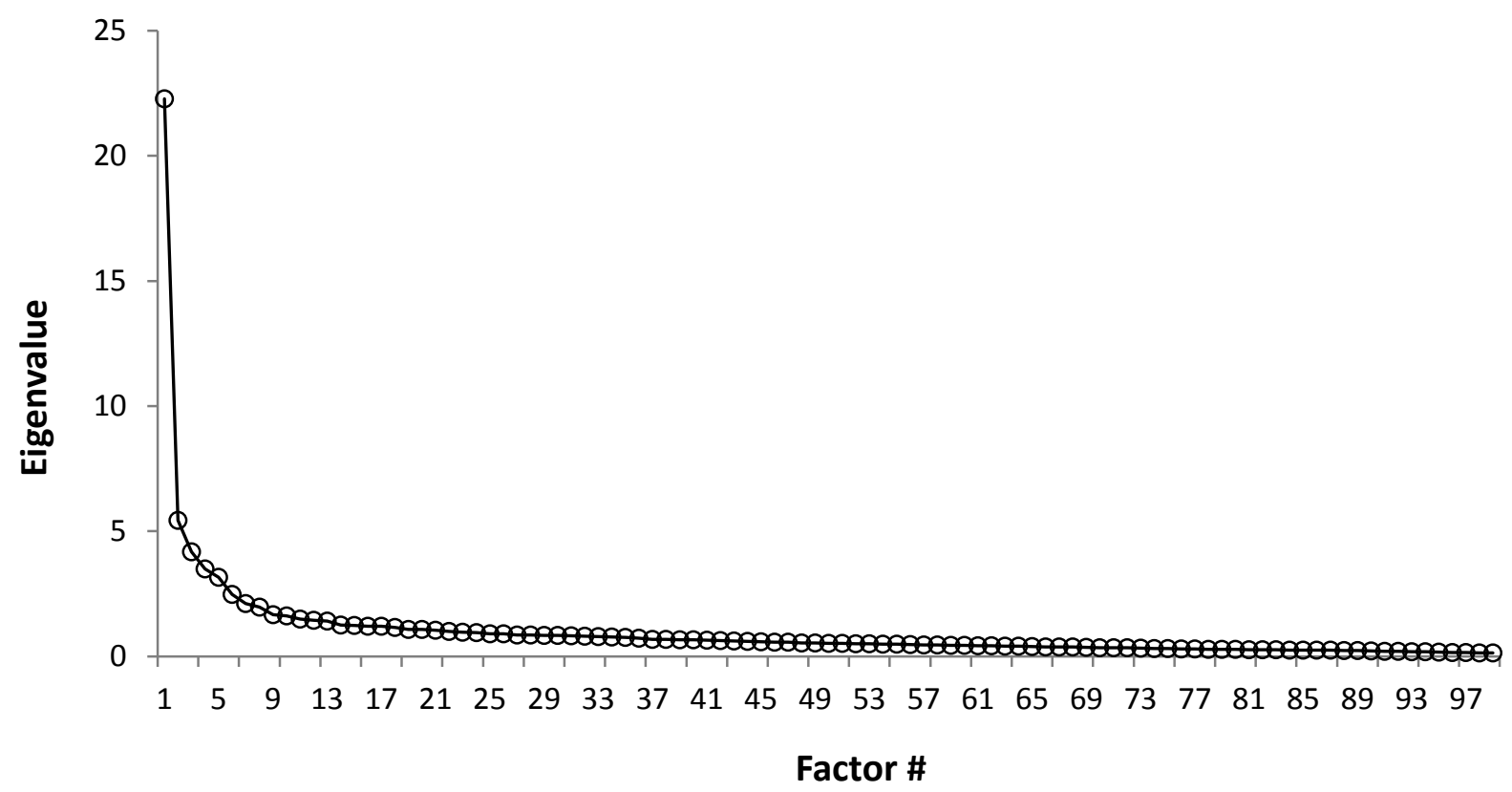

Figure 12. Scree plot for an unrotated factor solution.

TABLE 34

PARALLEL ANALYSIS RESULTS

\begin{tabular}{ccc}
\hline Factor \# & $\begin{array}{c}\text { Original Data's } \\
\text { Eigenvalue }\end{array}$ & $\begin{array}{c}\text { Parallel Factors' } \\
\text { Eigenvalue }\end{array}$ \\
\hline 1 & 22.28 & 1.96 \\
2 & 5.44 & 1.89 \\
3 & 4.18 & 1.84 \\
4 & 3.49 & 1.80 \\
5 & 3.16 & 1.76 \\
6 & 2.48 & 1.73 \\
7 & 2.11 & 1.70 \\
8 & 1.97 & 1.67 \\
9 & 1.66 & 1.64 \\
\hline
\end{tabular}

In addition to Kaiser-Guttman criterion, Cattell's scree test, and Horns' parallel analysis, other criteria were used to guide the process of factor retention. Specifically, factors with fewer 
than three items would be rejected. Researchers recommend that each factor contains at least three variables since factors that do not contain the minimum variables are likely weak and unstable (Costello \& Osborne, 2005; Hinkin, 1995; Russell, 2002). Finally, good factors typically have simple structure and are easy to explain. Thus, factors that could not be interpreted meaningfully would not be retained.

Ultimately, the primary goal of factor analysis is to uncover a parsimonious structure solution by being able to explain the data with the fewest number of factors as possible. Keeping this goal in mind, the strategy adopted in this research is to avoid retaining more than 10 factors. As a result, the 22-factor solution resulted from the Kaiser-Guttman criterion would not be considered. Instead, results obtained from examining the scree plot and parallel analysis would be used as the boundaries for possible factor solutions.

Several EFAs were conducted with PAF extraction method and promax rotation for a 6-, 7-, 8-, and 9-factor solution. In the process of factor interpretation, both the pattern matrix and structure matrix were examined. However, the primary focus of analysis was on the pattern matrix. Most researchers suggest that pattern matrix be the focus of factor interpretation when factors are correlated (Costello \& Osborne, 2005; Field, 2009; Hair, Black, Babin, Anderson, \& Tatham, 2006; Russell, 2002; Tabachnick \& Fidell, 2007). This is because pattern matrix is deemed to be more meaningful in determining which item load uniquely on which factor. In terms of the cutoff value for item loading, the $|0.40|$ value was selected. This value equates to approximately $16 \%$ overlapping variance between variable and factor. It was selected because it is the most common cutoff value, and it falls in the range of recommend cutoff values from 
$|0.32|$ to $|0.70|$ (Hinkin, 1995; 1998; Field, 2009; Matsunaga, 2010; Nunnally, 1978; Tabachnick \& Fidell, 2007).

Item Removal. Initial inspections revealed the 7-factor solution had the most interpretable structure with the clearest variable loadings. The 7-factor solution also had the highest conceptual relevance. However, it was difficult to confirm that the 7-factor solution is the best solution when there were weak variables that appeared to interfere with the other factor structure solutions. In order to improve the clarity of the data structure, a procedure of item removal was implemented at this stage.

Several criteria were taken into consideration for deleting an item. In general, items that are candidates for deletion consist of items that: have a communality coefficient below .30, contain factor loadings below $|.40|$, crossload on two or more factors with loading values greater than $|.32|$, make little or no contribution to the internal consistency of the scale scores, have low conceptual relevance to a factor, and/or are not conceptually consistent with other items loaded on the same factor (Costello \& Osborne, 2005; Worthington \& Whittaker, 2006; Tabachnick \& Fidell, 2007). Importantly, an EFA and internal reliability analysis (Cronbach's $\alpha$ ) were run each time an item is deleted to ensure that the deleted item would not have a major effect on the factor structure as well as the internal consistency of the scale.

Based on the established criteria, 44 items were removed from further analyses at this stage. In addition to the first item ("I can easily skip any non-playable content (e.g., videos, story scenes) that does not capture my interest.") that was removed at the beginning of the study, a total of 45 items were eliminated from the EFA study. Appendix X presents a list of all the items that were excluded from the study. The Cronbach's $\alpha$ for the remaining 55 items was 
0.93 , which exceeds the 0.70 acceptable threshold and indicates "excellent" internal consistency of the items on the scale (George \& Mallery, 2003; Hinkin, 1995; Nunnally, 1978).

9-Factor Solution. After problematic items were removed from the study, the 9-factor solution was revealed to be the most parsimonious and conceptually relevant solution. The 9factor solution also aligned with the parallel analysis results. Together, all nine factors explained approximately $49.3 \%$ of the total variance (see Table 35). The Cronbach's alpha for each of the factor or subscale surpasses the 0.70 acceptable threshold, with seven of the subscales containing alpha in the "good" range (George \& Mallery, 2003; Hinkin, 1995; Nunnally, 1978).

The nine factors are named: Usability/Playability, Narratives, Play Engrossment, Enjoyment, Creative Freedom, Audio Aesthetics, Personal Gratification, Social Connectivity, and Visual Aesthetics. The Usability/Playability factor covered 11 items and accounted for $7.4 \%$ of the variance (see Table 36). The Narratives factor consisted of 7 items and accounted for $6.9 \%$ of the variance (see Table 37). The Play Engrossment factor included 8 items and accounted for $6.7 \%$ of the variance (see Table 38). The Enjoyment factor contained 5 items and accounted for $5.5 \%$ of the variance (see Table 39). The Creative Freedom factor comprised 7 items and accounted for $5.5 \%$ of the variance (see Table 40 ).

The Audio Aesthetics factor consisted of 4 items and accounted for $5.5 \%$ of the variance (see Table 41). The Personal Gratification factor covered 6 items and accounted for $4.9 \%$ of the variance (see Table 42). The Social Connectivity factor included 4 items and accounted for $4.5 \%$ of the variance (see Table 43). Finally, the Visual Aesthetics factor contained 3 items and accounted for $2.3 \%$ of the variance (see Table 44). Appendices $Y$ and $Z$ provide a complete look at the pattern matrix and structure matrix of the 9-factor solution, respectively. 
TABLE 35

9-FACTOR SOLUTION: SUMMARY OF EIGENVALUES AND CRONBACH'S ALPHAS

\begin{tabular}{lcccc}
\hline Factor Number & \# of Items & \multicolumn{2}{c}{ Varimax Rotation* } & Cronbach's $\alpha$ \\
\cline { 3 - 4 } & & Eigenvalues & \% of Variance & \\
\hline Factor 1: Usability/Playability & 11 & 4.06 & 7.4 & 0.84 \\
Factor 2: Narratives & 7 & 3.82 & 6.9 & 0.85 \\
Factor 3: Play Engrossment & 8 & 3.71 & 6.7 & 0.84 \\
Factor 4: Enjoyment & 5 & 3.04 & 5.5 & 0.81 \\
Factor 5: Creative Freedom & 7 & 3.03 & 5.5 & 0.85 \\
Factor 6: Audio Aesthetics & 4 & 3.02 & 5.5 & 0.88 \\
Factor 7: Personal Gratification & 6 & 2.69 & 4.9 & 0.77 \\
Factor 8: Social Connectivity & 4 & 2.50 & 4.5 & 0.83 \\
Factor 9: Visual Aesthetics & 3 & 1.26 & 2.3 & 0.75 \\
\hline
\end{tabular}

Note: Item "I feel bored while playing the game." was reversed coded for the $\alpha$ of "Factor 6: Enjoyment".

*For estimation purposes, eigenvalues based on the varimax rotation were used since SPSS cannot calculated eigenvalues when factors are correlated. 
TABLE 36

FACTOR 1 (USABILITY/PLAYABILITY): SUMMARY OF THE FACTOR'S ITEMS

\begin{tabular}{|c|c|c|c|c|c|}
\hline \multirow[b]{2}{*}{ Item } & \multirow[b]{2}{*}{ Mean } & \multirow[b]{2}{*}{ SD } & \multicolumn{2}{|c|}{ Factor Loadings } & \multirow[b]{2}{*}{$h^{2}$} \\
\hline & & & Pattern & Structure & \\
\hline I think it is easy to learn how to play the game. & 5.68 & 1.50 & 0.77 & 0.64 & 0.51 \\
\hline I find the controls of the game to be straightforward. & 6.13 & 1.12 & 0.69 & 0.67 & 0.48 \\
\hline $\begin{array}{l}\text { I always know how to achieve my goals/objectives in } \\
\text { the game. }\end{array}$ & 5.67 & 1.28 & 0.66 & 0.61 & 0.40 \\
\hline I find the game's interface to be easy to navigate. & 5.93 & 1.09 & 0.64 & 0.67 & 0.48 \\
\hline $\begin{array}{l}\text { I do not need to go through a lengthy tutorial or read } \\
\text { a manual to play the game. }\end{array}$ & 5.76 & 1.49 & 0.56 & 0.48 & 0.28 \\
\hline I find the game's menus to be user friendly. & 5.83 & 1.15 & 0.53 & 0.58 & 0.36 \\
\hline I feel the game trains me well in all of the controls. & 5.60 & 1.32 & 0.52 & 0.55 & 0.34 \\
\hline $\begin{array}{l}\text { I always know my next goal when I finish an event in } \\
\text { the game. }\end{array}$ & 5.46 & 1.40 & 0.47 & 0.48 & 0.30 \\
\hline $\begin{array}{l}\text { I feel the game provides me the necessary } \\
\text { information to accomplish a goal within the game. }\end{array}$ & 5.68 & 1.18 & 0.47 & 0.59 & 0.40 \\
\hline $\begin{array}{l}\text { I think the information provided in the game (e.g., } \\
\text { onscreen messages, help) is clear. }\end{array}$ & 5.88 & 1.05 & 0.43 & 0.56 & 0.38 \\
\hline I feel very confident while playing the game. & 5.56 & 1.18 & 0.41 & 0.54 & 0.42 \\
\hline
\end{tabular}

Note: Pattern $=$ Pattern Matrix, Structure $=$ Structure Matrix, and $h^{2}=$ communality coefficient. 
TABLE 37

FACTOR 2 (NARRATIVES): SUMMARY OF THE FACTOR'S ITEMS

\begin{tabular}{|c|c|c|c|c|c|}
\hline \multirow[b]{2}{*}{ Item } & \multirow[b]{2}{*}{ Mean } & \multirow[b]{2}{*}{ SD } & \multicolumn{2}{|c|}{ Factor Loadings } & \multirow[b]{2}{*}{$h^{2}$} \\
\hline & & & Pattern & Structure & \\
\hline $\begin{array}{l}\text { I think the characters in the game are well } \\
\text { developed. }\end{array}$ & 5.17 & 1.61 & 0.84 & 0.76 & 0.60 \\
\hline $\begin{array}{l}\text { I am captivated by the game's story from the } \\
\text { beginning. }\end{array}$ & 5.14 & 1.62 & 0.84 & 0.85 & 0.73 \\
\hline I enjoy the fantasy or story provided by the game. & 5.79 & 1.28 & 0.61 & 0.75 & 0.63 \\
\hline I can identify with the characters in the game. & 4.55 & 1.72 & 0.60 & 0.56 & 0.37 \\
\hline I am emotionally moved by the events in the game. & 4.15 & 1.82 & 0.58 & 0.65 & 0.50 \\
\hline $\begin{array}{l}\text { I am very interested in seeing how the events in the } \\
\text { game will progress. }\end{array}$ & 5.88 & 1.25 & 0.51 & 0.70 & 0.57 \\
\hline I can clearly understand the game's story. & 5.91 & 1.22 & 0.48 & 0.48 & 0.31 \\
\hline
\end{tabular}

Note: Pattern $=$ Pattern Matrix, Structure $=$ Structure Matrix, and $h^{2}=$ communality coefficient. 
TABLE 38

FACTOR 3 (PLAY ENGROSSMENT): SUMMARY OF THE FACTOR'S ITEMS

\begin{tabular}{|c|c|c|c|c|c|}
\hline \multirow[b]{2}{*}{ Item } & \multirow[b]{2}{*}{ Mean } & \multirow[b]{2}{*}{ SD } & \multicolumn{2}{|c|}{ Factor Loadings } & \multirow[b]{2}{*}{$h^{2}$} \\
\hline & & & Pattern & Structure & \\
\hline $\begin{array}{l}\text { I feel detached from the outside world while playing } \\
\text { the game. }\end{array}$ & 4.27 & 1.80 & 0.76 & 0.67 & 0.48 \\
\hline $\begin{array}{l}\text { I do not care to check events that are happening in } \\
\text { the real world during the game. }\end{array}$ & 4.07 & 1.82 & 0.75 & 0.61 & 0.44 \\
\hline $\begin{array}{l}\text { I cannot tell that I am getting tired while playing the } \\
\text { game. }\end{array}$ & 4.22 & 1.91 & 0.67 & 0.62 & 0.40 \\
\hline $\begin{array}{l}\text { Sometimes I lose track of time while playing the } \\
\text { game. }\end{array}$ & 5.67 & 1.46 & 0.61 & 0.68 & 0.51 \\
\hline $\begin{array}{l}\text { I temporarily forget about my everyday worries while } \\
\text { playing the game. }\end{array}$ & 5.32 & 1.47 & 0.56 & 0.64 & 0.43 \\
\hline $\begin{array}{l}\text { I tend to spend more time playing the game than I } \\
\text { have planned. }\end{array}$ & 5.28 & 1.60 & 0.52 & 0.58 & 0.38 \\
\hline $\begin{array}{l}\text { I can block out most other distractions when playing } \\
\text { the game. }\end{array}$ & 5.49 & 1.34 & 0.49 & 0.59 & 0.40 \\
\hline $\begin{array}{l}\text { Whenever I stopped playing the game I cannot wait } \\
\text { to start playing it again. }\end{array}$ & 4.78 & 1.50 & 0.49 & 0.64 & 0.46 \\
\hline
\end{tabular}

Note: Pattern = Pattern Matrix, Structure = Structure Matrix, and $h^{2}=$ communality coefficient.

TABLE 39

FACTOR 4 (ENJOYMENT): SUMMARY OF THE FACTOR'S ITEMS

\begin{tabular}{lcccccc}
\hline & & \multicolumn{3}{c}{ Factor Loadings } & \\
Item & Mean & SD & Pattern & Structure & $\boldsymbol{h}^{\mathbf{2}}$ \\
\hline I think the game is fun. & 6.50 & 0.81 & 0.88 & 0.86 & 0.75 \\
I enjoy playing the game. & 6.51 & 0.76 & 0.86 & 0.85 & 0.73 \\
I feel bored while playing the game. & 2.45 & 1.46 & -0.58 & -0.55 & 0.32 \\
I am likely to recommend this game to others. & 6.27 & 1.06 & 0.58 & 0.70 & 0.52 \\
If given the chance, I want to play this game again. & 6.31 & 1.02 & 0.55 & 0.68 & 0.54 \\
\hline
\end{tabular}

Note: Pattern $=$ Pattern Matrix, Structure $=$ Structure Matrix, and $h^{2}=$ communality coefficient. 
TABLE 40

FACTOR 5 (CREATIVE FREEDOM): SUMMARY OF THE FACTOR'S ITEMS

\begin{tabular}{lcccccc}
\hline & & & \multicolumn{3}{c}{ Factor Loadings } & \\
\cline { 5 - 6 } Item & Mean & SD & Pattern & Structure & $\boldsymbol{h}^{2}$ \\
\hline I feel the game allows me to be imaginative. & 5.38 & 1.54 & 0.90 & 0.76 & 0.61 \\
I feel creative while playing the game. & 4.91 & 1.60 & 0.86 & 0.76 & 0.60 \\
I feel the game gives me enough freedom to act how & 5.51 & 1.46 & 0.62 & 0.61 & 0.42 \\
I want. & & & & & \\
I feel the game allows me to express myself. & 4.62 & 1.64 & 0.61 & 0.68 & 0.52 \\
I feel I can explore things in the game. & 5.66 & 1.47 & 0.44 & 0.61 & 0.44 \\
I feel my curiosity is stimulated as the result of & 5.42 & 1.41 & 0.43 & 0.67 & 0.54 \\
playing the game. & & & & & \\
I think the game is unique or original. & 5.60 & 1.51 & 0.43 & 0.57 & 0.42 \\
\hline
\end{tabular}

Note: Pattern $=$ Pattern Matrix, Structure $=$ Structure Matrix, and $h^{2}=$ communality coefficient.

TABLE 41

FACTOR 6 (AUDIO AESTHETICS): SUMMARY OF THE FACTOR'S ITEMS

\begin{tabular}{|c|c|c|c|c|c|}
\hline \multirow[b]{2}{*}{ Item } & \multirow[b]{2}{*}{ Mean } & \multirow[b]{2}{*}{ SD } & \multicolumn{2}{|c|}{ Factor Loadings } & \multirow[b]{2}{*}{$h^{2}$} \\
\hline & & & Pattern & Structure & \\
\hline I enjoy the sound effects in the game. & 5.88 & 1.29 & 0.87 & 0.89 & 0.80 \\
\hline I enjoy the music in the game. & 5.68 & 1.53 & 0.76 & 0.80 & 0.66 \\
\hline $\begin{array}{l}\text { I feel the game's audio (e.g., sound effects, music) } \\
\text { enhances my gaming experience. }\end{array}$ & 5.92 & 1.43 & 0.76 & 0.78 & 0.63 \\
\hline $\begin{array}{l}\text { I think the game's audio fits the mood or style of the } \\
\text { game. }\end{array}$ & 6.17 & 1.04 & 0.63 & 0.73 & 0.58 \\
\hline
\end{tabular}

Note: Pattern = Pattern Matrix, Structure = Structure Matrix, and $h^{2}=$ communality coefficient. 
TABLE 42

FACTOR 7 (PERSONAL GRATIFICATION): SUMMARY OF THE FACTOR'S ITEMS

\begin{tabular}{|c|c|c|c|c|c|}
\hline \multirow[b]{2}{*}{ Item } & \multirow[b]{2}{*}{ Mean } & \multirow[b]{2}{*}{ SD } & \multicolumn{2}{|c|}{ Factor Loadings } & \multirow[b]{2}{*}{$h^{2}$} \\
\hline & & & Pattern & Structure & \\
\hline $\begin{array}{l}\text { I am in suspense about whether I will succeed in the } \\
\text { game. }\end{array}$ & 5.06 & 1.73 & 0.70 & 0.60 & 0.42 \\
\hline $\begin{array}{l}\text { I feel successful when I overcome the obstacles in } \\
\text { the game. }\end{array}$ & 6.19 & 0.92 & 0.66 & 0.68 & 0.48 \\
\hline I want to do as well as possible during the game. & 6.20 & 1.02 & 0.62 & 0.63 & 0.45 \\
\hline $\begin{array}{l}\text { I am very focused on my own performance while } \\
\text { playing the game. }\end{array}$ & 5.83 & 1.18 & 0.57 & 0.61 & 0.43 \\
\hline $\begin{array}{l}\text { I feel the game constantly motivates me to proceed } \\
\text { further to the next stage or level. }\end{array}$ & 5.81 & 1.24 & 0.57 & 0.67 & 0.51 \\
\hline $\begin{array}{l}\text { I find my skills gradually improve through the course } \\
\text { of overcoming the challenges in the game. }\end{array}$ & 6.23 & 1.00 & 0.48 & 0.55 & 0.36 \\
\hline
\end{tabular}

TABLE 43

FACTOR 8 (SOCIAL CONNECTIVITY): SUMMARY OF THE FACTOR'S ITEMS

\begin{tabular}{|c|c|c|c|c|c|}
\hline \multirow[b]{2}{*}{ Item } & \multirow[b]{2}{*}{ Mean } & \multirow[b]{2}{*}{ SD } & \multicolumn{2}{|c|}{ Factor Loadings } & \multirow[b]{2}{*}{$h^{2}$} \\
\hline & & & Pattern & Structure & \\
\hline $\begin{array}{l}\text { I find the game supports social interaction (e.g., chat) } \\
\text { between players. }\end{array}$ & 4.78 & 1.93 & 0.84 & 0.83 & 0.72 \\
\hline I like to play this game with other players. & 5.28 & 1.97 & 0.75 & 0.76 & 0.63 \\
\hline $\begin{array}{l}\text { I am able to play the game with other players if I } \\
\text { choose. }\end{array}$ & 5.61 & 1.89 & 0.71 & 0.72 & 0.54 \\
\hline I enjoy the social interaction within the game. & 4.86 & 1.58 & 0.64 & 0.65 & 0.54 \\
\hline
\end{tabular}

Note: Pattern = Pattern Matrix, Structure = Structure Matrix, and $h^{2}=$ communality coefficient. 
TABLE 44

FACTOR 9 (VISUAL AESTHETICS): SUMMARY OF THE FACTOR'S ITEMS

\begin{tabular}{lcccccc}
\hline & & & \multicolumn{3}{c}{ Factor Loadings } & \\
\cline { 5 - 6 } Item & Mean & SD & Pattern & Structure & $\boldsymbol{h}^{2}$ \\
\hline I enjoy the game's graphics. & 6.19 & 1.00 & 0.64 & 0.70 & 0.53 \\
$\begin{array}{l}\text { I think the graphics of the game fit the mood or style } \\
\text { of the game. }\end{array}$ & 6.27 & 0.89 & 0.63 & 0.68 & 0.51 \\
\begin{tabular}{l} 
I think the game is visually appealing. \\
\hline
\end{tabular} & 6.25 & 1.03 & 0.59 & 0.61 & 0.40 \\
\hline
\end{tabular}

Note: Pattern $=$ Pattern Matrix, Structure $=$ Structure Matrix, and $h^{2}=$ communality coefficient.

In order to develop a better understanding about the relationship among the factors, the average ratings of all the items per factor were calculated for each participant and multiple Pearson's product moment correlations were performed. Pearson's correlation tests were also conducted to assess the relationship between each of the nine factors and the overall assessment of game satisfaction. Results indicated that there is a significant positive relationship among all of the factors. Additionally, all of the factors have a significant positive relationship with overall satisfaction ratings. In order words, the overall satisfaction ratings tend to increase as the average ratings of each factor increase. Table 45 presents the correlation results between factors and between each factor and the overall ratings of game satisfaction. 
Factor Correlations and Correlations with Overall Game Satisfaction $(N=629, d f=627)$

Factor 1 Factor 2 Factor 3 Factor 4 Factor 5 Factor 6 Factor 7 Factor 8 Factor 9 Overall Satisfaction

\begin{tabular}{|c|c|c|c|c|c|c|c|c|c|c|}
\hline Factor 1: Usability/ Playability & 1.00 & & & & & & & & & \\
\hline Factor 2: Narratives & $0.29^{* *}$ & 1.00 & & & & & & & & \\
\hline Factor 3: Play Engrossment & $0.26^{* *}$ & $0.39^{* *}$ & 1.00 & & & & & & & \\
\hline Factor 4: Enjoyment & $0.36^{* *}$ & $0.47^{* *}$ & $0.41^{* *}$ & 1.00 & & & & & & \\
\hline Factor 5: Creative Freedom & $0.21^{* *}$ & $0.65^{* *}$ & $0.44^{* *}$ & $0.46^{* *}$ & 1.00 & & & & & \\
\hline Factor 6: Audio Aesthetics & $0.23^{* *}$ & $0.44^{* *}$ & $0.29^{* *}$ & $0.37^{* *}$ & $0.38^{* *}$ & 1.00 & & & & \\
\hline Factor 7: Personal Gratification & $0.31^{* *}$ & $0.39^{* *}$ & $0.45^{* *}$ & $0.47^{* *}$ & $0.38^{* *}$ & $0.38^{* *}$ & 1.00 & & & \\
\hline Factor 8: Social Connectivity & $0.15^{* *}$ & $0.09^{*}$ & $0.08^{*}$ & $0.15^{* *}$ & $0.18^{* *}$ & $0.18^{* *}$ & $0.27^{* *}$ & 1.00 & & \\
\hline Factor 9: Visual Aesthetics & $0.34^{* *}$ & $0.45^{* *}$ & $0.28^{* *}$ & $0.46^{* *}$ & $0.37^{* *}$ & $0.52^{* *}$ & $0.38^{* *}$ & $0.11^{* *}$ & 1.00 & \\
\hline Overall Satisfaction & $0.31^{* *}$ & $0.48^{* *}$ & $0.37^{* *}$ & $0.75^{* *}$ & $0.50^{* *}$ & $0.37^{* *}$ & $0.35^{* *}$ & $0.10^{*}$ & $0.43^{* *}$ & 1.00 \\
\hline
\end{tabular}




\section{Discussion.}

Results from the EFA study suggest the 9-factor solution is the most parsimonious and conceptual relevance model based on the observed data. The 9-factor model consist of the following underlying factors: Usability/Playability, Narratives, Play Engrossment, Enjoyment, Creative Freedom, Audio Aesthetics, Personal Gratification, Social Connectivity, and Visual Aesthetics. Usability/Playability involves the ease in which the game can be played with clear goals/objectives in mind, and with minimal cognitive interferences or obstructions from the user interfaces and controls. The Narratives factor concerns the story aspects of the game (e.g., events and characters) and their abilities to capture the player's interest and shape the player's emotions.

Play Engrossment generally refers the degree to which the game can hold the player's attention and interest. This factor contains the classic elements (e.g., intense concentration, distorted sense of time, and loss of self-consciousness) that are frequently discussed in the literature in relation to video game engagement (e.g., immersion, flow). Enjoyment involves the amount of pleasure and delight that was perceived by the player as a result of playing the game. Creative Freedom refers to the extent to which the game is able to foster the player's creativity and curiosity, and allows the player to freely express his or her individuality while playing the game.

Audio Aesthetics relates to the different auditory aspects of the game (e.g., sound effects) and how much they enrich the gaming experience. Personal Gratification concerns the motivational aspects of the game (e.g., challenge) that promote the player's sense of accomplishment, and the desire to succeed and continue playing the game. Social Connectivity 
involves the degree to which the game facilitates social connection between players through its tools and features. Finally, Visual Aesthetics refers to the game graphics and how attractive they appeared to the player.

Interestingly, out of all of the factor pairs the Narratives and Creative Freedom factors were found to have the highest correlation coefficient $(r=0.65)$. This suggests that there is a strong connection between the story aspects of the game and the abilities to stimulate one's creativity and curiosity, as well as enhance one's perception of autonomy within the game. Additionally, it is interesting to find that the Visual Aesthetics factor accounts only $2.3 \%$ of variance while the Audio Aesthetics factor accounts for $5.5 \%$ of variance. This implies that the auditory aspects of the game contribute more to a satisfying gaming experience than the graphics of the game. Furthermore, while Pearson's correlation tests show that Social Connectivity has statistically significant relationships with Narratives and Play Engrossment the correlation coefficients for both factor pairs are quite small $(r<0.10)$. Thus, it is likely that the new data sample collected for the CFA study might confirm that these two pair of factors do not have any relationship with each other.

In general, all of the nine factors were found to have a significant positive relationship with overall game satisfaction ratings, which lends further evidence to the construct validity of the scale. In particular, the correlation coefficients for eight of the factors with overall game satisfaction ratings can be considered to be in the medium to large range. However, the correlation coefficient between Social Connectivity and overall game satisfaction is small $(r=$ 0.10). This could be largely due to the majority games evaluated in this study are not strongly social oriented, which resulted in the weak relationship with overall game satisfaction. 
Specifically, the majority of the games evaluated can be played alone or in a single player mode, and very few games depend on the involvement of other players (e.g., Words With Friends).

Overall, Cronbach's alpha statistics indicate that each of the nine factors or subscales has adequate internal consistency, which suggests that the factors will remain stable in the CFA study. In addition to re-examining the reliability of the scale, the CFA study will mainly focus on evaluating the overall fit of the specified 9-factor model with the newly observed data using goodness-of-fit statistics. In order to increase the confidence that the specified model is the most appropriate solution, it will be compared against alternative models using goodness-of-fit statistics to see which model provides the best explanation of the data. Particularly, results from this study suggest two other plausible models (i.e., 8-factor and 7-factor), and thus, they will be compared to the specified 9-factor model. In the 8-factor model, the Audio and Visual Aesthetics are grouped as one factor. The 7-factor model not only grouped Audio and Visual Aesthetics together, but it also combined Narratives and Creative Freedom into a single factor. 


\section{CHAPTER 5}

\section{CONFIRMATORY FACTOR ANALYSIS (CFA)}

\section{Step 5: Confirmatory Factor Analysis (CFA)}

The primary goal of the CFA phase was to assess how well the 9-factor solution derived from the EFA phase fit a new sample of observed data. In order to further enhance the construct validity of the adjusted model, the hypothesized 9-factor model was also compared with other alternative models via goodness-of-fit statistics (Cabrera-Nguyen, 2010; Worthington \& Whittaker, 2006). Specifically, the hypothesized full model was evaluated against the following models: 9-uncorrelated-factor, 8-factor, 7-factor, and 1-factor.

\section{Method.}

A total of 1317 surveys were collected after the survey links were closed. However, during the screening and cleaning process $41.5 \%(n=546)$ of the surveys was identified as containing non-valid responses, and were removed from the final data set. In general, the surveys were removed due to similar reasons that were listed in the EFA study (e.g., incomplete surveys, multiple submissions by the same participant). Additionally, submitted surveys that did not meet the three pre-established criteria (i.e., completed less than 10 minutes, and game evaluated had not been played in the last three months or had less than 10 hours of play) were removed from the study. In order to ensure an independent sample was collected for this phase, any surveys that were identified to be from the same person who participated in the EFA study were also removed.

Participants. After the data was screened and cleaned, a total of 771 questionnaires were retained for the final analyses. Participants in this study ages ranged from 18 to 60 years 
old $(M=25.87, S D=7.97)$. These video game players hold various occupations such as students, store clerks, teachers, and engineers. Of the 771 respondents, about $37.4 \%$ were female gamers. Approximately 75.2\% identified themselves as either "Casual" or "Mid-core/Core" gamers.

About $71.4 \%$ of respondents reported to spend, on average, at least five hours per week playing video games. Many respondents also indicated that they frequently used multiple gaming devices (mainly console, computer, and mobile devices) to play video games, and tended to play games from different genres. The most popular genres reported being Action, Adventure, Role-Playing, and Strategy. Table 46 provides a summary of participants' demographics. Figures 13 and 14 present a visual illustration of the gaming devices and game genres participants indicated to frequently play, respectively. 
Table 46

Demographics of Participants in the CFA Study

\begin{tabular}{|c|c|}
\hline Variable & Value \\
\hline Total $(N)$ & 771 \\
\hline Mean Age in years $(S D)$ & $25.87(7.97)$ \\
\hline \multicolumn{2}{|l|}{ Gender } \\
\hline Male & $483(62.6 \%)$ \\
\hline Female & $288(37.4 \%)$ \\
\hline \multicolumn{2}{|l|}{ Ethnicity } \\
\hline American Indian/Alaskan Native & $21(2.7 \%)$ \\
\hline Asian/Pacific Islander & $89(11.5 \%)$ \\
\hline Black/African American & $25(3.2 \%)$ \\
\hline Hispanic/Latino & $45(5.8 \%)$ \\
\hline White (not of Hispanic origin) & $544(70.6 \%)$ \\
\hline Biracial/Multiracial/Mixed & $22(2.9 \%)$ \\
\hline I do not wish to answer. & $25(3.2 \%)$ \\
\hline \multicolumn{2}{|l|}{ Education Level } \\
\hline Some high school & $16(2.1 \%)$ \\
\hline High school graduate or GED & $77(10.0 \%)$ \\
\hline Some college & $356(46.2 \%)$ \\
\hline College graduate (2- and 4-year degree) & $261(33.9 \%)$ \\
\hline $\begin{array}{l}\text { Post-graduate degree (MA, PhD, Law, Medical, or } \\
\text { Professional school) }\end{array}$ & $61(7.9 \%)$ \\
\hline \multicolumn{2}{|l|}{ Type of Video Game Player* } \\
\hline Newbie/Novice & $45(5.8 \%)$ \\
\hline Casual & $280(36.3 \%)$ \\
\hline Mid-core/Core & $300(38.9 \%)$ \\
\hline Hardcore/Expert & $146(18.9 \%)$ \\
\hline \multicolumn{2}{|l|}{ Mean Hours Spent Playing Game per Week } \\
\hline Less than 1 hour & $46(6.0 \%)$ \\
\hline 1 to 4 hours & $174(22.6 \%)$ \\
\hline 5 to 9 hours & $183(23.7 \%)$ \\
\hline 10 to 19 hours & $184(23.9 \%)$ \\
\hline 20 to 29 hours & $114(14.8 \%)$ \\
\hline 30 to 39 hours & $28(3.6 \%)$ \\
\hline More than 40 hours & $42(5.4 \%)$ \\
\hline
\end{tabular}

*According to how the participants identified themselves. 


\section{CFA Study: Gaming Devices Frequently Use}

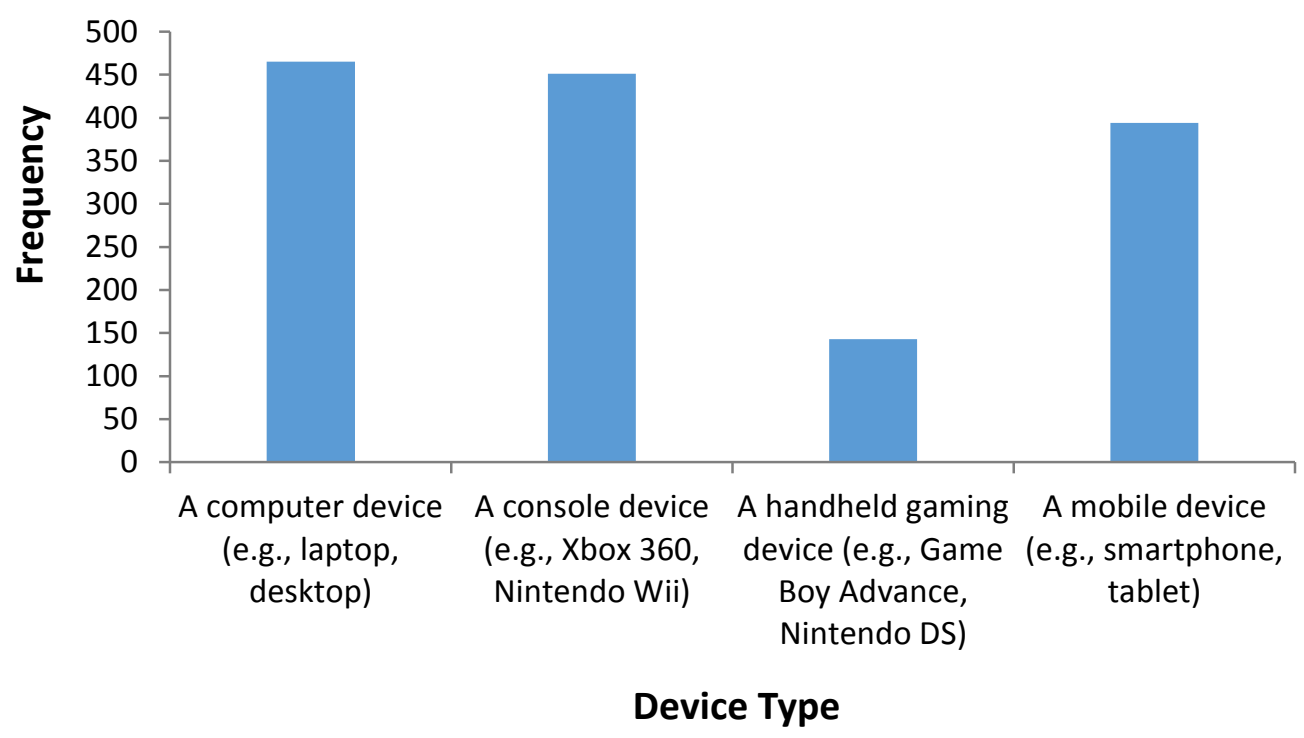

Figure 13. Gaming devices participants reported to frequently use to play video games.

Note: Participants were allowed to select more than one response.

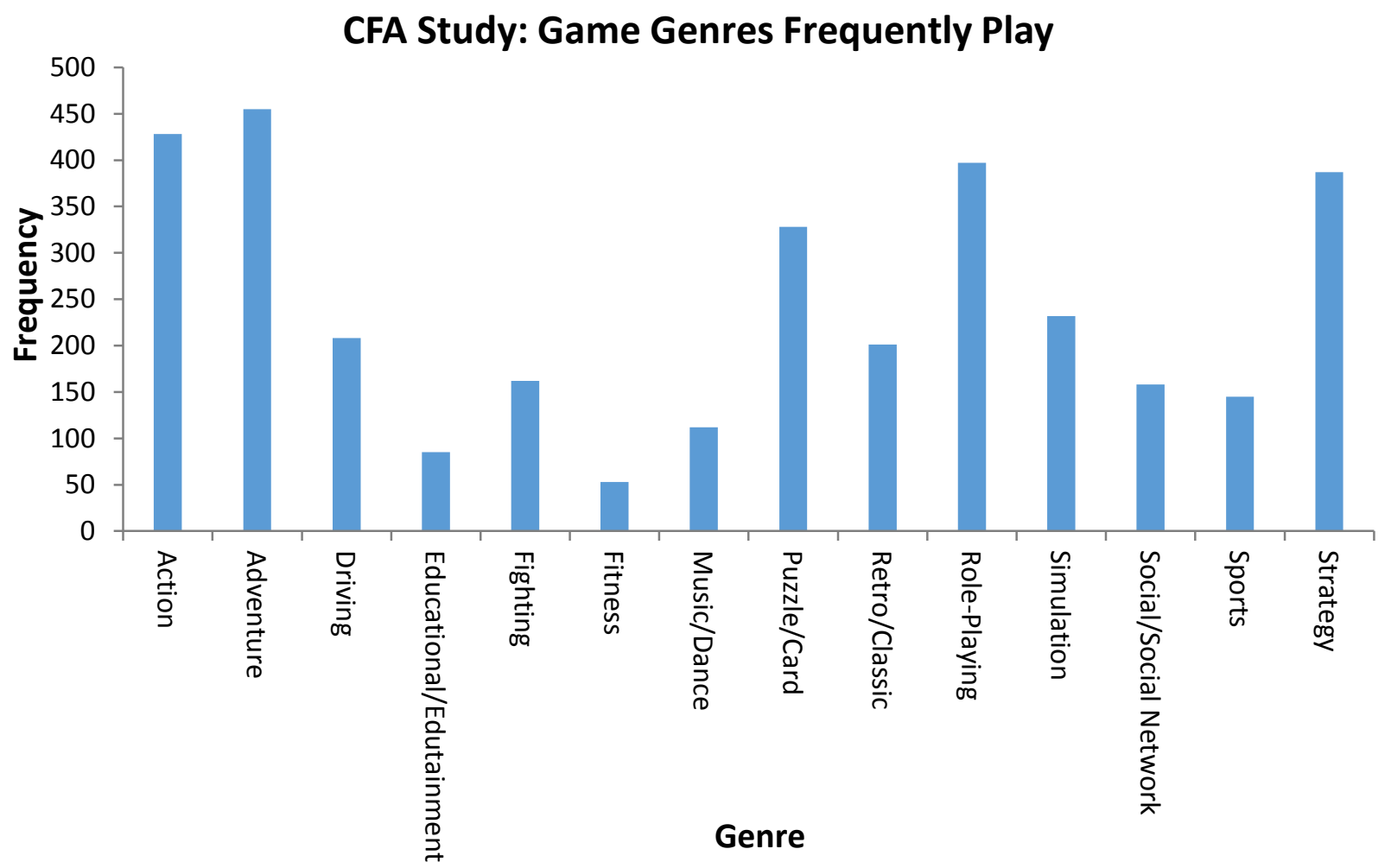

Figure 14. Game genres participants reported to frequently play.

Note: Participants were allowed to select more than one response. 
Video Games. Similar to the EFA study, the majority of the video games evaluated in this study were games that played within the last month (see Figure 15). Many participants also reported that they spent from 20 to 79 hours playing the game that they evaluated. Furthermore, the majority of the video games evaluated were reported to being played on a computer (e.g., laptop, desktop) or console device (e.g., Xbox 360, Nintendo Wii). Figures 16 and 17 provide a visual summary of the total time participants spent playing the game they evaluated and the type of gaming platform participants used to play the game, respectively.

\section{CFA Study: The Last Time Played the Game Under Evaluation}

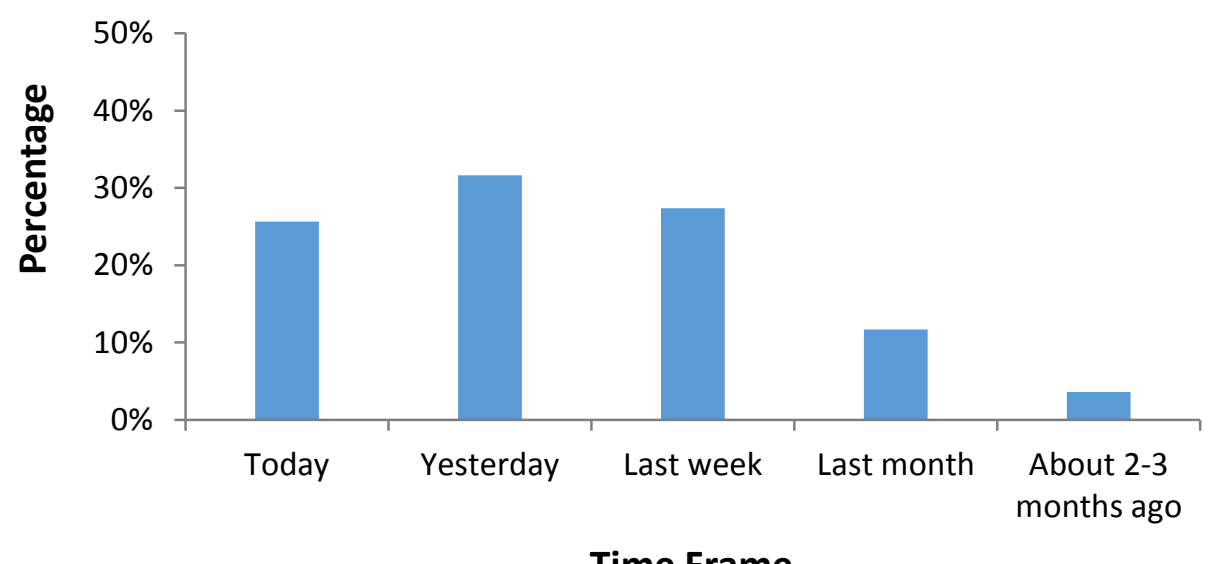

Time Frame

Figure 15. The last time participants reported to play the game they evaluated. 


\section{CFA Study: Total Time Spent Playing the Game Under Evaluation}

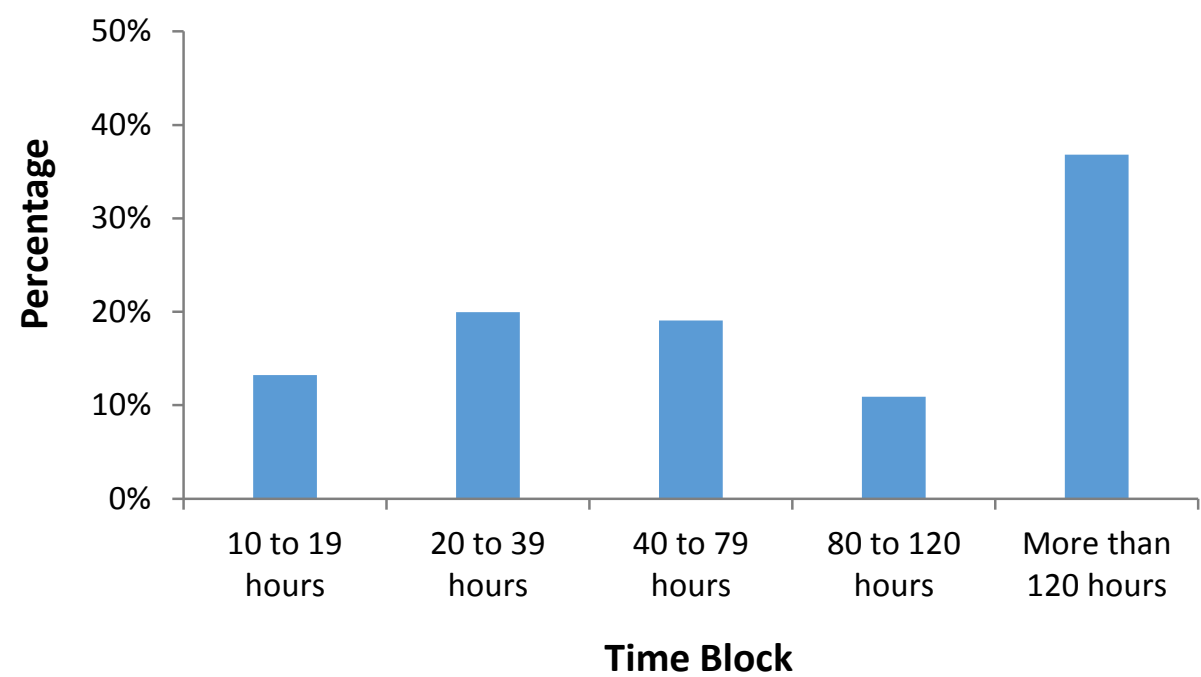

Figure 16. The total time participants spent playing the game they evaluated.

\section{CFA Study: Type of Gaming Device Used to Play the Game Under Evaluation}

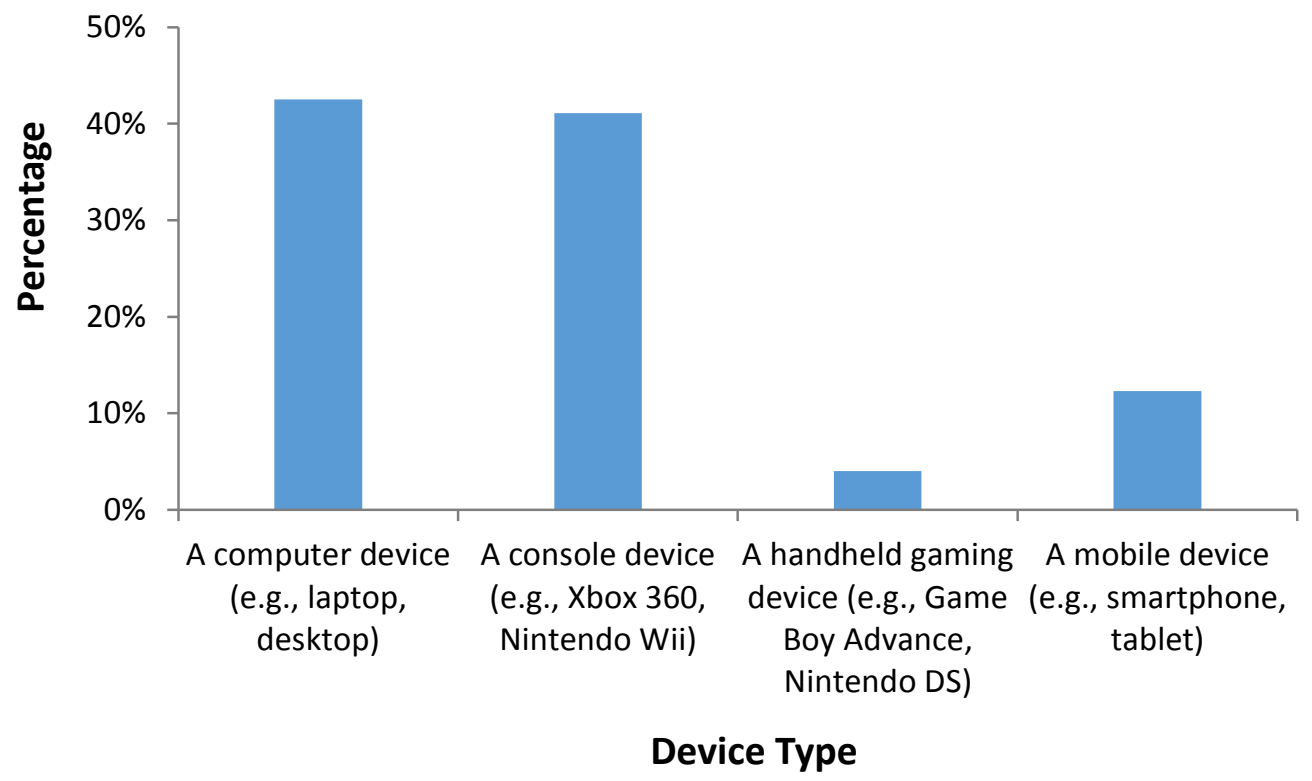

Figure 17. The total time participants spent playing the game they evaluated. 
Of the 771 video games evaluated in this study, 312 (40.5\%) were from unique video game titles. Additionally, of the 312 unique game titles evaluated in this study about $66.0 \%(n=$ 206) were new video games that have not been evaluated in the EFA study. Appendix AA provides a detailed list of all the video game titles along with the main genre and sub-genre they were classified under. Similar to the EFA study, the video games evaluated in this study covered a variety of popular genres. Specifically, many of the video games were classified to be either in the Action, RPG, Strategy, or Action Adventure genre. Unlike the EFA study, there were more video games from the Strategy genre in this study than in the EFA study. There were also video games from the Trivia/Game Show genre, which was not evaluated in the EFA study. Table 47 presents an overview of all of the video game genres represented in this study. 
TABLE 47

\section{OVERVIEW OF THE VIDEO GAME GENRES REPRESENTED IN THE CFA STUDY}

\begin{tabular}{|c|c|c|}
\hline Main Genre & $n$ & Percent \\
\hline $\begin{array}{l}\text { Action (e.g., Destiny, World of Tanks, Dynasty Warriors 6, New Super } \\
\text { Mario Bros. U) }\end{array}$ & 191 & $24.8 \%$ \\
\hline $\begin{array}{l}\text { Role-Playing (e.g., Dark Souls, World of Warcraft, The Elder Scrolls V: } \\
\text { Skyrim, Pokemon Alpha Sapphire) }\end{array}$ & 157 & $20.4 \%$ \\
\hline $\begin{array}{l}\text { Strategy (e.g., DotA 2, Hearthstone: Heroes of Warcraft, League of } \\
\text { Legends, This War of Mine) }\end{array}$ & 128 & $16.6 \%$ \\
\hline $\begin{array}{l}\text { Action Adventure (e.g., Minecraft, Grand Theft Auto V, Assassin's } \\
\text { Creed IV: Black Flag, The Last of Us) }\end{array}$ & 123 & $16.0 \%$ \\
\hline Sports (e.g., FIFA 15, NBA 2K15, Wii Sports, SSX) & 47 & $6.1 \%$ \\
\hline $\begin{array}{l}\text { Puzzle/Card/Board (e.g., Candy Crush Saga, Words With Friends, } \\
\text { Farm Heroes Saga, Full Deck Solitaire) }\end{array}$ & 36 & $4.7 \%$ \\
\hline $\begin{array}{l}\text { Simulation (e.g., The Sims 4, Space Engineers, Kerbal Space Program, } \\
\text { Shall We Date? Scarlet Fate+) }\end{array}$ & 32 & $4.2 \%$ \\
\hline $\begin{array}{l}\text { Driving/Racing (e.g., Mario Kart Wii, Need for Speed, Gran Turismo, } \\
\text { Starsky \& Hutch) }\end{array}$ & 25 & $3.2 \%$ \\
\hline Trivia/Game Show (e.g., Trivia Crack, QuizUp, You Don't Know Jack) & 15 & $1.9 \%$ \\
\hline $\begin{array}{l}\text { Fighting (e.g., Injustice: Gods Among Us, Super Smash Bros. Brawl, } \\
\text { Mortal Kombat, Brawlhalla) }\end{array}$ & 7 & $0.9 \%$ \\
\hline Music/Dance (e.g., Just Dance 2015, Guitar Hero 3, Band Stars) & 5 & $0.6 \%$ \\
\hline Other (e.g., Wii Party U, Mario Party, The Cat Lady, Clicker Heroes) & 5 & $0.6 \%$ \\
\hline
\end{tabular}

Note: Each video game title was categorized under one main genre. Various popular gaming websites (e.g., GameFaqs.com, Metacritic.com, and IGN.com) were consulted during the game genre classification process.

Finally, the majority of the video games evaluated in this study were games that participants "liked" rather than "disliked". At the end of the game evaluation, the majority of participants indicated that, overall, they felt "Extremely Satisfied" or "Satisfied" with the game that they had evaluated. Figure 18 shows a visual breakdown of respondents' overall level of satisfaction with the game they rated. 


\section{CFA Study: Overall Satisfaction Level with the Game Under Evaluation}

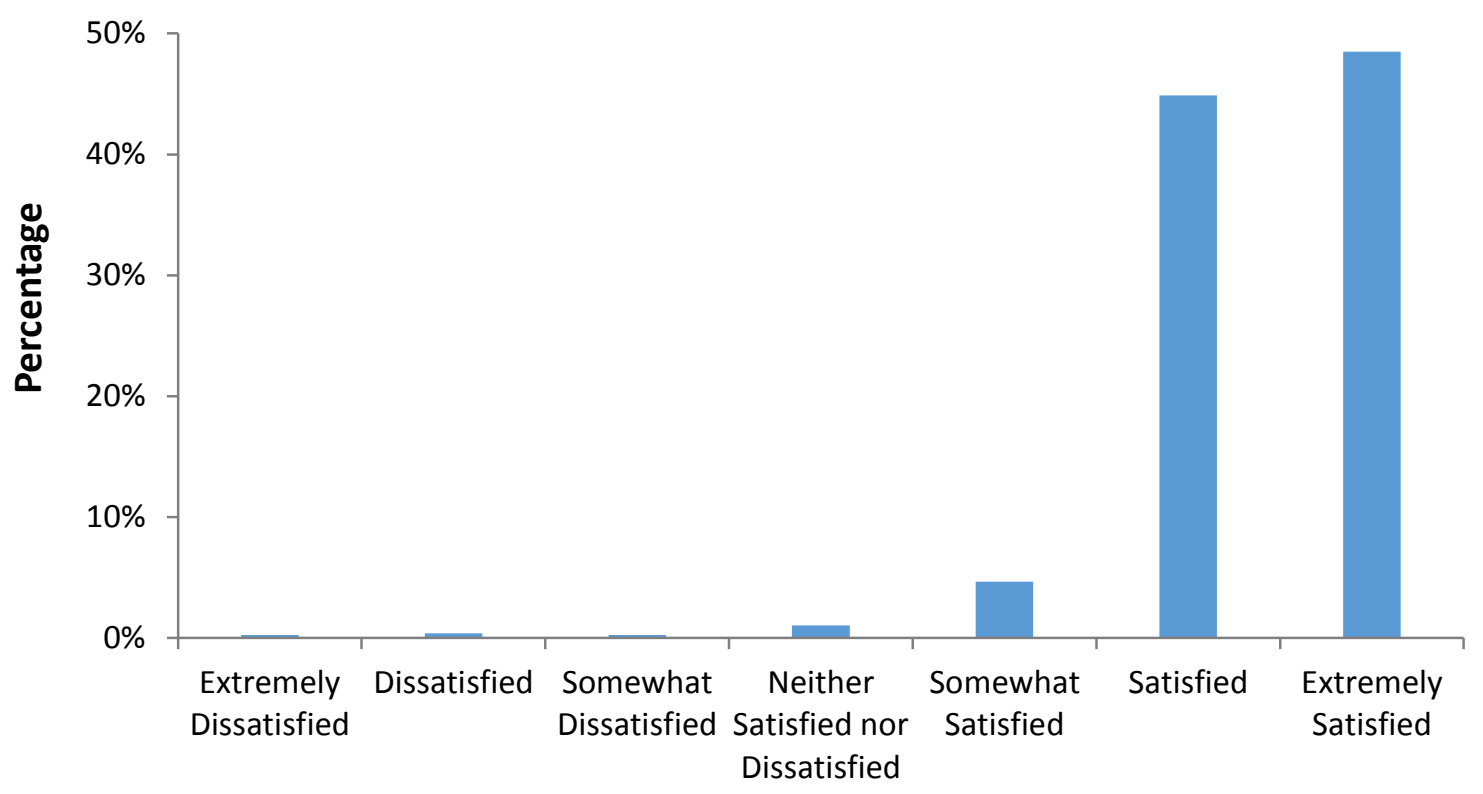

\section{Satisfaction Level}

Figure 18. Participants' overall level of satisfaction with the game they evaluated.

Materials. Qualtrics ${ }^{\circledR}$ Online Survey Software was again used to create the online questionnaire in this study. The questionnaire in this study was nearly identical to the one used in the EFA study, with the main difference being the number of statements or items in this study was nearly reduced in half from the 100 items presented in the EFA study. All of the major sections and structure of the questionnaire were kept the same as in the EFA study.

Particularly, the questionnaire comprised of the following sections: consent form (see Appendix BB), game title (see Appendix G), questions about the game (see Appendix H), game evaluation statements (see Appendix Y), overall satisfaction rating of the game (see Appendix J), and demographics of participants (see Appendix U). Similar to the EFA study, after completing the questionnaire participants were brought to a separate section where they can 
enter their contact information for a chance to win 1 of $20 \$ 50$ Amazon gift cards. Participants were also informed that their contact information will only be used for the purpose of selecting gift card winners.

Procedure. Information about the study and links to the survey were shared across multiple popular social networking and online websites (e.g., Facebook, Linkedln, Craiglist.com, and Reddit.com). The survey link was shared on various online gaming communities (e.g., Girl Tribe Gaming, Steam on Google+). An email invitation to participate in the study was sent to a sample of 1550 students and staff at WSU via Qualtrics Panels. Also, the study was made available on the WSU Sona System where students were offered the options of receiving 1 Sona credit or be entered in the gift card raffle for completing the survey.

The survey link was available for 40 days, from January 19, 2014 to February 27, 2015. After the data collection phase has ended, a random drawing was conducted to select the 20 gift card recipients. All participants who completed the survey and left their contact information were eligible to receive a $\$ 50$ Amazon gift card. Gift card winners were notified via email, and a $\$ 50$ gift card was delivered to participant's email address once it has been confirmed.

\section{Results.}

IBM SPSS Statistics 22, SPSS Amos 22, and Microsoft Excel 2013 were used to analyze the data.

Normality. Visual examination of the histograms and results of the Shapiro-Wilk tests revealed that each of the 55 items deviated significantly from a normal distribution. Similar to the EFA study, the majority of the items has a negatively skewed distribution, which is consistent with 
the high ratings of overall game satisfaction. In addition, the majority of the data can be considered as moderately skewed with four variables have skewness values greater than $|2|$ and/or kurtosis values greater than 7 (Finney \& DiStefano, 2013). Appendix CC provides a detailed report of the skewness and kurtosis values of all the items. Similar to the EFA phase, the decision was made to keep the data untransformed.

Missing Data. "N/A" responses were treated as missing values in this study. Similar to the EFA study, the total amount of missing data in this study was not considered as problematic with about $3.3 \%$ of the data missing. Results of Little's MCAR test, $\chi^{2}(10943, N=771)=$ $12,063.03, p<.05$, suggested that the data was not missing completely at random. Many variables and cases appeared to have missing values.

Approximately $96.4 \%$ of variables $(n=53)$ and $43.7 \%$ of cases $(n=337)$ contained at least one missing value. The percentage of missing values for each variable ranges from $0.1 \%$ to 16.9\%. Table 48 listed all of the variables that contained over $10 \%$ of missing values with their mean and standard deviation. Appendix DD offers a list of all of the variables with missing values. 
TABLE 48

CFA STUDY: VARIABLES WITH OVER 10\% OF MISSING VALUES

\begin{tabular}{|c|c|c|c|c|}
\hline \multirow[b]{2}{*}{ Item } & \multicolumn{2}{|c|}{ Missing Values } & \multirow[b]{2}{*}{ Mean } & \multirow[b]{2}{*}{ SD } \\
\hline & $n$ & Percent & & \\
\hline I enjoy the social interaction within the game. & 130 & $16.9 \%$ & 5.03 & 1.60 \\
\hline I can clearly understand the game's story. & 121 & $15.7 \%$ & 5.70 & 1.53 \\
\hline I can identify with the characters in the game. & 113 & $14.7 \%$ & 4.32 & 1.90 \\
\hline I am captivated by the game's story from the beginning. & 112 & $14.5 \%$ & 5.16 & 1.76 \\
\hline I like to play this game with other players. & 108 & $14.0 \%$ & 5.46 & 1.94 \\
\hline $\begin{array}{l}\text { I find the game supports social interaction (e.g., chat) } \\
\text { between players. }\end{array}$ & 107 & $13.9 \%$ & 4.88 & 2.01 \\
\hline I enjoy the fantasy or story provided by the game. & 95 & $12.3 \%$ & 5.67 & 1.47 \\
\hline I think the characters in the game are well developed. & 85 & $11.0 \%$ & 5.32 & 1.67 \\
\hline I am able to play the game with other players if I choose. & 77 & $10.0 \%$ & 5.69 & 1.98 \\
\hline
\end{tabular}

Estimation Method. Given that the data did not follow normal distributions, one potential estimation method to use would be the asymptotically distribution free (ADF; Browne, 1984) since it was developed for non-normal data. However, ADF estimator requires a very large sample size (over 1,000 ) and has been demonstrated to perform poorly with sample sizes less than 2,500 (Curran, West, \& Finch, 1996; Hu, Bentler, \& Kano, 1992; Muthén \& Kaplan, 1992). Another estimator appropriate for non-normal data is the unweighted least square (ULS), but it offers very limited number of goodness-of-fit indices on AMOS. In addition, the majority of the fit indices that ULS provides are not recommended by researchers for model fit evaluations.

The remaining estimator option is the maximum likelihood (ML). This estimator assumes that the data of the observed variables is normally distributed. There are three important considerations for using this estimator under non-normal conditions. First, inflated chi-square 
statistic, which potentially lead to the over-rejection of models (Benson \& Fleishman, 1994;

Brown, 2014; Curran et al., 1996; Hu et al., 1992; Kenny, 2014). Second, underestimation of some fit indices (e.g., GFI, CFI), which could cause plausible models being rejected (Brown, 2014; Finney \& DiStefano, 2013). Third, standard errors of parameter estimates would be underestimated (Benson \& Fleishman, 1994; Brown, 2014; Finney \& DiStefano, 2013; Russell, 2002).

Despite these issues, research has shown that there is very little negative effect on the quality of the parameter estimates under non-normal conditions (Brown, 2014; Enders, 2006; Fan, Wang, \& Thompson, 1997). In addition, many research studies have shown that the ML estimator can be robust in different situations (e.g., mild to moderate violations of normality; Chou, Bentler, \& Satorra, 1991; Fan, Thompson, \& Wang, 1999; Fan et al., 1997; Finney \& DiStefano, 2013; Matsunaga, 2010). Furthermore, Finney and DiStefano (2013) consider the ML estimator to be an appropriate estimation method when data is moderately skewed (skewness $<|2|$ and kurtosis $<7)$. Given that the majority of the data fit this assessment, the decision was made to proceed with the analysis using the ML estimator.

Method for Addressing Missing Data. In dealing with the missing data, AMOS' full information maximum likelihood (FIML) estimation was used as the primary missing data estimation method. In particular, FIML was used to produce the majority of the CFA results (e.g., parameter estimates, chi-square test, and RMSEA). Unlike the EM method, FIML does not impute any missing values and utilizes all the information available in the incomplete dataset to estimate parameters. FIML has been demonstrated to generate unbiased parameter estimates and standard errors, as well as valid model fit information when data is not missing completely 
at random (Dong \& Peng, 2013; Enders, 2001; Enders \& Bandalos, 2001; Hallgren \& Witkiewitz, 2013). Additionally, Enders (2001) reported that FIML is robust in providing unbiased parameter estimates across different situations (e.g., missing data rates, sample sizes, and normality conditions).

While FIML is one of the most pragmatic approaches in dealing with missing data, it does not generate a standardized residual covariance matrix, therefore, it does not allow for post-hoc model modifications. Also, some of the analyses (e.g., SRMR, internal reliability) are not possible via AMOS' FIML. As a result, the EM method via SPSS MVA add-on module was used to generate Cronbach's alpha, SRMR, and Pearson's r statistical test results. In general, research has shown that ML-based methods (e.g., EM, FIML) produces similar results (Dong \& Peng, 2013; Graham, Olchowski, \& Gilreath, 2007; Schafer \& Graham, 2002).

Overall Model Fit Assessment. In terms of evaluating a model fit, researchers suggest to report the chi-square test statistic, but not relying on it for the assessment of overall model fit (Byrne, 2010; Hu \& Bentler, 1999; Kline, 2005; Russell, 2002; Worthington \& Whittaker, 2006). The chi-square test has been widely criticized as being flawed with its unrealistic assumption that the model fits perfectly in the population, and sensitivity to sample size and non-normality. Specifically, large sample sizes (e.g., above 200) and non-normal distributions tend to inflate chi-square values, which increase the probability of a plausible model being rejected. Given the known issues with the chi-square test statistic, researchers recommend using two to three other fit indices (e.g., CFI, SRMR, and RMSEA) in determining overall model fit (Hu \& Bentler, 1999; Kline, 2005; Worthington \& Whittaker, 2006). 
In this study, three goodness-of-fit indices were mainly used to assess overall model fit. They are root mean square error of approximation (RMSEA; Steiger \& Lind, 1980), standardized root mean square residual (SRMR), and Hoelter's Critical N (CN; Hoelter, 1983). RMSEA is a fit index that takes model complexity and sample size into account. It assesses how well the model would fit the population covariance matrix, and is considered as "one of the most informative criteria in covariance structure modeling" (Byrne, 2010, p. 80). Generally, RMSEA values less than .05 indicates close approximate fit while values between .05 and .08 indicates adequate fit (Browne \& Cudeck, 1993; Fabrigar et al., 1999). However, Hu and Bentler (1999) recommend a more stringent cut-off of .06 or lower to indicate good fit.

SRMR measures the discrepancies between the covariance matrices of the observed data and the model. Similar to RMSEA, SRMR can be considered as a "badness of fit" index in that higher values suggest poorer fit. Generally, SRMR values less than .10 indicates adequate model fit (Kline, 2005; Worthington \& Whittaker, 2006). Nevertheless, Hu and Bentler (1999) propose a value of .08 or below as being indicative of good model fit. Additionally, Hoelter's CN focuses on the study's sample size and report the largest sample size to yield a non-significant chi-square value. Hoelter's $\mathrm{CN}$ is considered appropriate to interpret when the chi-square statistic is significant and $N$ is greater than 200 (Kenny, 2014). CN values over 200 signify the sample size and model fit are adequate while values below 75 signify unacceptable model fit and sample size (Byrne, 2010; Kenny, 2014).

Although the Comparative Fit Index (CFI; Bentler, 1990) is frequently used to determine overall model fit, with value above 0.95 indicates good fit (Hu \& Bentler, 1999). Kenny (2014) has advised against using this fit index due to the statistical fact that the CFI value tends to be 
very small when the RSMEA value of the null model is below 0.158 . The null model in this study has a RSMEA value of 0.121 with the lower and upper bound values of the $90 \%$ confident interval being 0.119 and 0.122 , respectively. Consequently, the CFI statistic was reported, but not evaluated in terms of overall model fit.

The three specified fit indices (i.e., RMSEA, SRMR, and Hoelter's CN) were also used to compare the hypothesized 9-factor model against alternative models. Specifically, the model with lower RMSEA and SRMR, and higher Hoelter's CN values would be deemed as the better model. Along with the three specified fit indices, the Expected Cross-Validation Index (ECVI; Browne \& Cudeck, 1989) fit index and the chi-square difference $\left(\Delta \chi^{2}\right)$ test statistic were used in the comparison of different models.

The ECVI is a predictive fit index which measures how well the model would fit other samples similar in size and from the same population (Browne \& Cudeck, 1989). The ECVI does not have a fix range of values and is most useful for comparing alternative models (Byrne, 2010; Fabrigar et al., 1999). Generally, the model with the smallest ECVI value has the highest chance of being replicated, and would be considered as the best model for replication purposes. Finally, the chi-square difference test was used to compare the fit between the hypothesized 9factor model against a reduced model (e.g., 8-factor model). A significant statistic $(p<.05)$ typically suggests that the full model is the better model. Table 49 provides a summary of the guidelines for assessing overall model fit and comparing the hypothesized models to alternative models. 
Table 49

Guidelines for Overall Model Fit Assessment and Model Comparison

\begin{tabular}{ll}
\hline Fit Statistic & Fit Recommendation(s) \\
\hline RMSEA & Adequate: .06 to .08 \\
& Good: $\leq .06$ \\
SRMR & Adequate: .08 to .10 \\
& Good: $\leq .08$ \\
Hoelter's CN & Adequate: $>200$ \\
& Unacceptable: $<75$ \\
ECVI & Preferred: The smallest value \\
$\Delta \chi^{2}$ & Preferred: $p<.05$ \\
\hline
\end{tabular}

Hypothesized 9-Factor Model Fit Assessment. The 9-factor solution derived from the EFA study was used in this study as the hypothesized full model. The full model consists of the following unobserved latent factors: Usability/Playability (11 items), Narratives (7 items), Play Engrossment (8 items), Enjoyment (5 items), Creative Freedom (7 items), Audio Aesthetics (4 items), Personal Gratification (6 items), Social Connectivity (4 items), and Visual Aesthetics (3 items). Each item is considered as an observed or measured variable in confirmatory factor analysis. All of the latent factors were allowed to covary with each other. Table 50 presents a list of all of the items in the CFA study. Figure 19 provides a simplified illustration of the hypothesized model, where ellipses represent latent variables and rectangles represent observed variables. 
TABLE 50

\section{OBSERVED VARIABLES IN THE CFA STUDY}

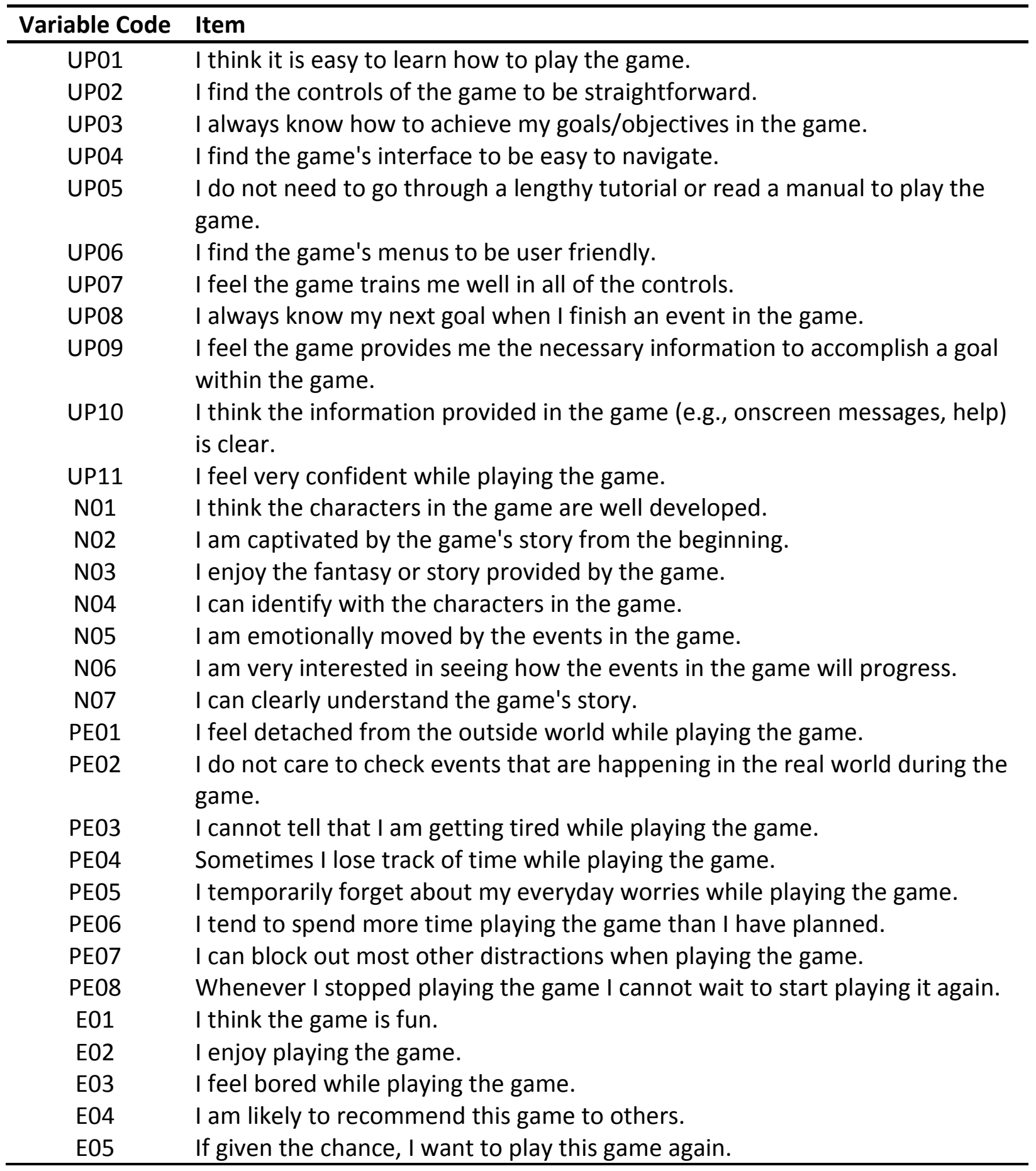


TABLE 50 (continued)

\section{OBSERVED VARIABLES IN THE CFA STUDY}

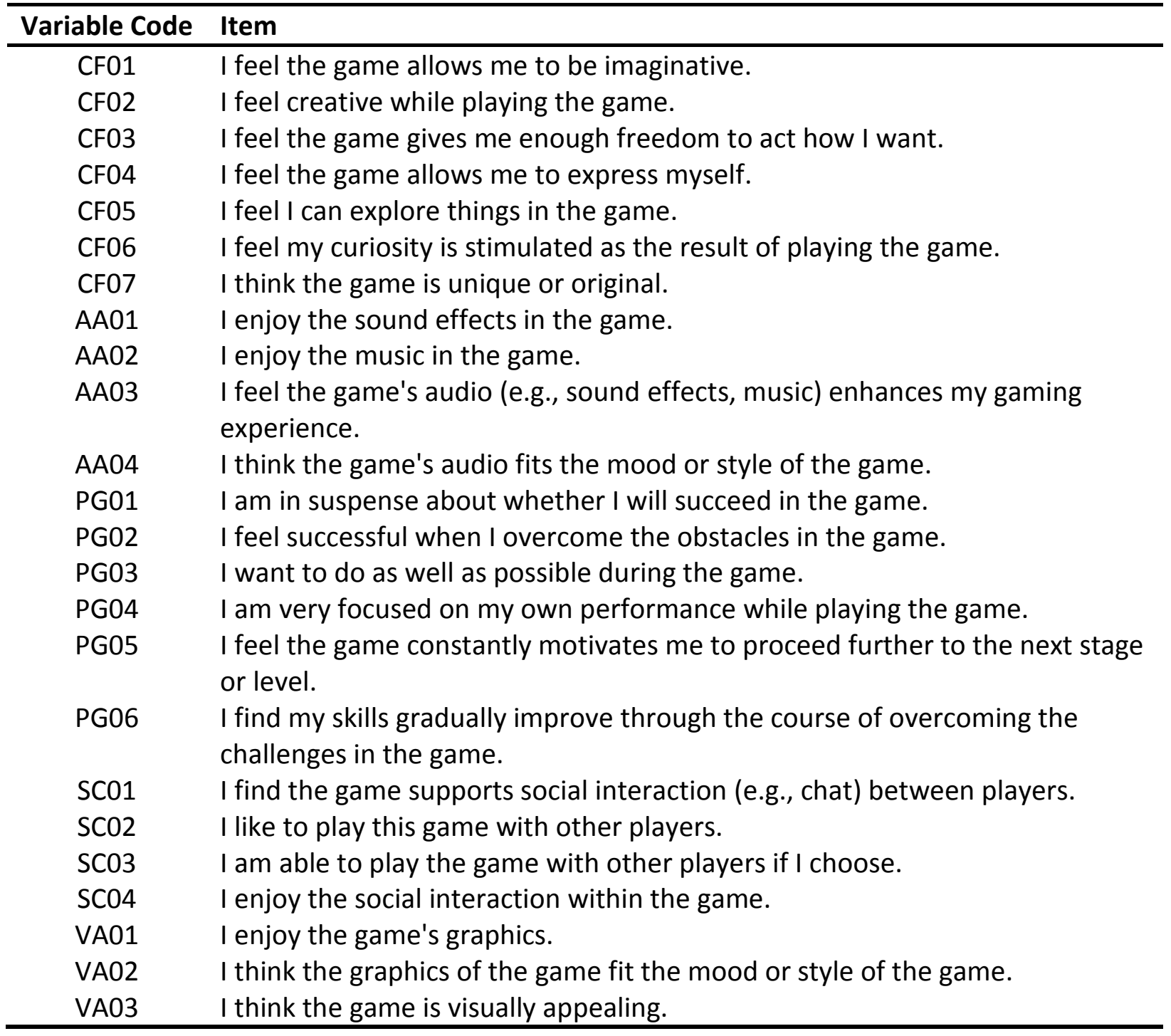




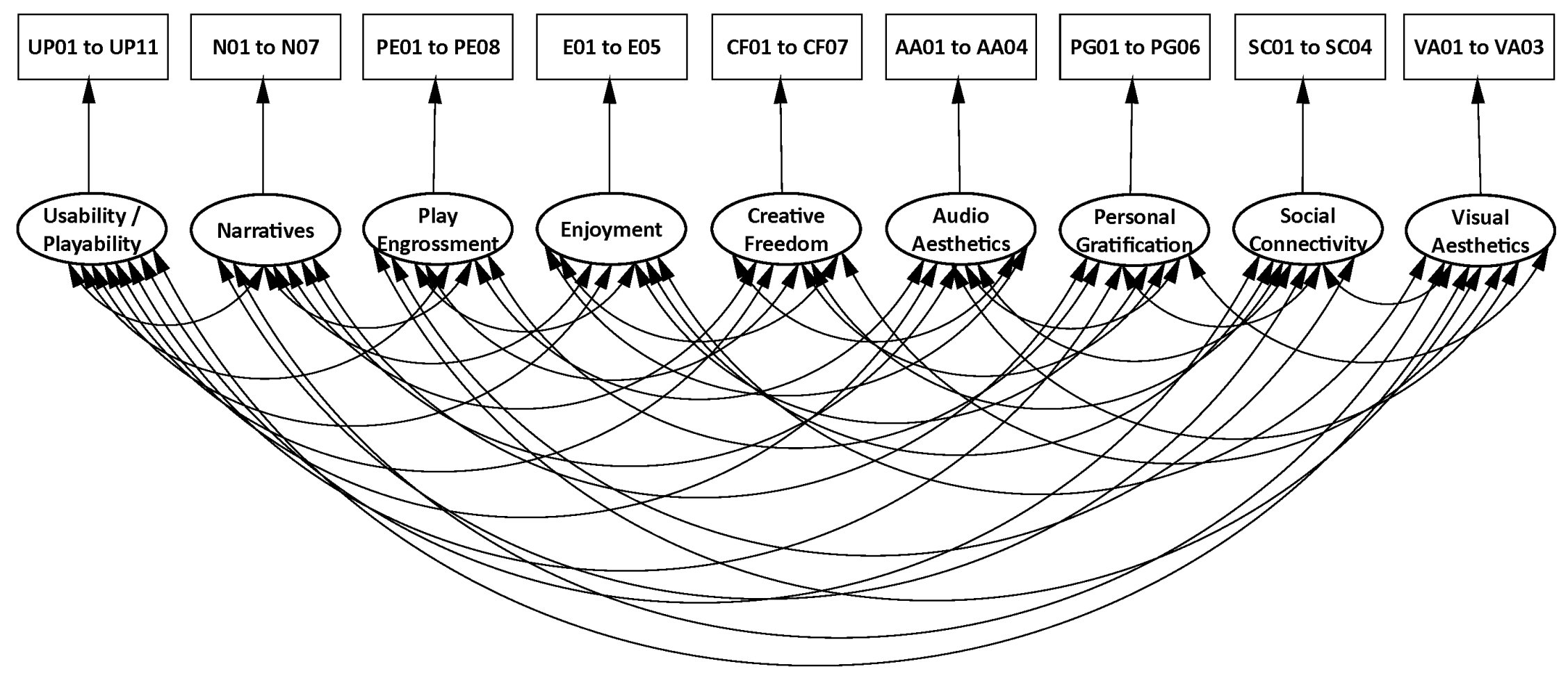

Figure 19. A visual representation of the hypothesized 9-factor model. 
Results revealed that the hypothesized 9-factor model has an overall good fit with the new data sample. As expected, the chi-square statistic, $\chi^{2}(1394, N=771)=4,428.63, p<.001$, was significant due to the large sample size $(N=771)$ and non-normal data. Additionally, the CFI value (0.82) was also very low due to the small RMSEA value (.121) of the null model stated earlier. However, the three primary goodness-of-fit indices (i.e., RMSEA, SRMR, and Hoelter's CN) all suggested that there is a good fit between the full 9-factor model and the observed data. Specifically, both the RMSEA and SRMR values were below Hu and Bentler's (1999) suggested values. Both of the Hoelter's .05 and $.01 \mathrm{CN}$ values also exceeded 200, which indicated that the sample size was adequate. Table 51 provides values of all of the fit indices.

TABLE 51

HYPOTHESIZED 9-FACTOR MODEL'S FIT STATISTICS ( $N=771)$

\begin{tabular}{ll}
\hline Fit Index & Value \\
\hline$\chi^{2}$ & $(1394)=4,428.63, p<.001$ \\
CFI & 0.82 \\
RMSEA $(90 \% \mathrm{CI})$ & $.053(.051, .055)$ \\
SRMR & 0.07 \\
Hoelter's .05; .01 & 258,265 \\
\hline
\end{tabular}

Note: Chi-square statistic and CFI were not used in the overall assessment of model fit due to the large sample size $(N=771)$ and the null model's RMSEA being below 0.158 .

Additionally, results suggested that all of the observed variables have adequate loading on the corresponding latent factor. Particularly, all of the unstandardized regression weights were significant and standardized regression weights above 0.40 . Table 52 presents the unstandardized and standardized regression weights, standard errors (SE), and squared multiple correlations (SMC) for each pair of observed variable and latent factor. The inter- 
relationship among all of the factors were also significant, with the exception of two pairs of factors (Social Connectivity and Narratives, and Social Connectivity and Play Engrossment). The correlation between the two pairs of latent variables was negligible $(r<0.05)$ in this study.

Table 53 presents the covariances and correlations between each pair of factors.

TABLE 52

UNSTANDARDIZED AND STANDARDIZED FACTOR LOADINGS

\begin{tabular}{lcccc}
\hline Pair & $\begin{array}{c}\text { Unstandardized } \\
\text { Estimate }\end{array}$ & SE & $\begin{array}{c}\text { Standardized } \\
\text { Estimate }\end{array}$ & $\begin{array}{c}\text { SMC } \\
\text { Estimate }\end{array}$ \\
\hline UP01 <-- Usability/Playability & 1.00 & N/A & 0.51 & 0.26 \\
UP02 <-- Usability/Playability & 0.87 & 0.07 & 0.61 & 0.37 \\
UP03 <-- Usability/Playability & 0.90 & 0.08 & 0.55 & 0.30 \\
UP04 <-- Usability/Playability & 0.92 & 0.07 & 0.66 & 0.43 \\
UP05 <-- Usability/Playability & 0.84 & 0.09 & 0.43 & 0.18 \\
UP06 <-- Usability/Playability & 0.89 & 0.08 & 0.61 & 0.37 \\
UP07 <-- Usability/Playability & 1.05 & 0.09 & 0.62 & 0.39 \\
UP08 <-- Usability/Playability & 0.95 & 0.09 & 0.52 & 0.27 \\
UP09 <-- Usability/Playability & 1.02 & 0.08 & 0.68 & 0.46 \\
UP10 <-- Usability/Playability & 0.74 & 0.07 & 0.54 & 0.29 \\
UP11 <-- Usability/Playability & 0.73 & 0.07 & 0.50 & 0.25 \\
N01 <-- Narratives & 1.00 & N/A & 0.68 & 0.46 \\
N02 <-- Narratives & 1.22 & 0.07 & 0.79 & 0.62 \\
N03 <-- Narratives & 1.01 & 0.06 & 0.78 & 0.61 \\
N04 <-- Narratives & 1.01 & 0.07 & 0.60 & 0.36 \\
N05 <-- Narratives & 0.86 & 0.07 & 0.52 & 0.27 \\
N06 <-- Narratives & 0.83 & 0.05 & 0.71 & 0.50 \\
N07 <-- Narratives & 0.85 & 0.06 & 0.63 & 0.40 \\
PE01 <-- Play Engrossment & 1.00 & N/A & 0.65 & 0.42 \\
PE02 <-- Play Engrossment & 1.00 & 0.07 & 0.61 & 0.37 \\
PE03 <-- Play Engrossment & 0.97 & 0.07 & 0.61 & 0.37 \\
PE04 <-- Play Engrossment & 0.63 & 0.05 & 0.52 & 0.27 \\
PE05 <-- Play Engrossment & 0.81 & 0.05 & 0.65 & 0.43 \\
PE06 <-- Play Engrossment & 0.61 & 0.06 & 0.44 & 0.19 \\
PE07 <-- Play Engrossment & 0.73 & 0.05 & 0.61 & 0.38 \\
PE08 <-- Play Engrossment & 0.93 & 0.06 & 0.65 & 0.42 \\
\hline
\end{tabular}


TABLE 52 (continued)

UNSTANDARDIZED AND STANDARDIZED FACTOR LOADINGS

\begin{tabular}{|c|c|c|c|c|}
\hline Pair & $\begin{array}{c}\text { Unstandardized } \\
\text { Estimate }\end{array}$ & SE & $\begin{array}{c}\text { Standardized } \\
\text { Estimate }\end{array}$ & $\begin{array}{c}\text { SMC } \\
\text { Estimate }\end{array}$ \\
\hline E01<-- Enjoyment & 1.00 & $\mathrm{~N} / \mathrm{A}$ & 0.81 & 0.65 \\
\hline E02<-- Enjoyment & 0.96 & 0.04 & 0.81 & 0.65 \\
\hline E03 <-- Enjoyment & -1.18 & 0.08 & -0.53 & 0.28 \\
\hline E04 <-- Enjoyment & 1.30 & 0.06 & 0.75 & 0.56 \\
\hline E05 <-- Enjoyment & 1.10 & 0.06 & 0.66 & 0.44 \\
\hline CF01 <-- Creative Freedom & 1.00 & $\mathrm{~N} / \mathrm{A}$ & 0.78 & 0.61 \\
\hline CF02 <-- Creative Freedom & 1.02 & 0.05 & 0.77 & 0.58 \\
\hline CF03 <-- Creative Freedom & 0.79 & 0.05 & 0.64 & 0.40 \\
\hline CF04 <-- Creative Freedom & 1.00 & 0.05 & 0.74 & 0.55 \\
\hline CF05 <-- Creative Freedom & 0.85 & 0.05 & 0.49 & 0.41 \\
\hline CF06 <-- Creative Freedom & 0.86 & 0.05 & 0.64 & 0.48 \\
\hline CF07 <-- Creative Freedom & 0.57 & 0.04 & 0.69 & 0.24 \\
\hline AA01 <--- Audio Aesthetics & 1.00 & $\mathrm{~N} / \mathrm{A}$ & 0.81 & 0.66 \\
\hline AA02 <--- Audio Aesthetics & 1.06 & 0.04 & 0.82 & 0.68 \\
\hline AA03 <--- Audio Aesthetics & 1.12 & 0.04 & 0.91 & 0.82 \\
\hline AA04 <--- Audio Aesthetics & 0.66 & 0.03 & 0.76 & 0.57 \\
\hline PG01 <-- Personal Gratification & 1.00 & $\mathrm{~N} / \mathrm{A}$ & 0.41 & 0.17 \\
\hline PG02 <-- Personal Gratification & 0.89 & 0.09 & 0.66 & 0.44 \\
\hline PG03 <-- Personal Gratification & 0.97 & 0.10 & 0.70 & 0.49 \\
\hline PG04 <-- Personal Gratification & 0.85 & 0.09 & 0.53 & 0.28 \\
\hline PG05 <-- Personal Gratification & 0.95 & 0.11 & 0.52 & 0.27 \\
\hline PG06 <-- Personal Gratification & 0.86 & 0.09 & 0.59 & 0.35 \\
\hline SC01 <-- Social Connectivity & 1.00 & $\mathrm{~N} / \mathrm{A}$ & 0.79 & 0.62 \\
\hline SC02 <-- Social Connectivity & 1.07 & 0.05 & 0.86 & 0.74 \\
\hline SC03 <-- Social Connectivity & 0.91 & 0.05 & 0.74 & 0.55 \\
\hline SC04 <-- Social Connectivity & 0.71 & 0.04 & 0.69 & 0.48 \\
\hline VA01<-- Visual Aesthetics & 1.00 & $\mathrm{~N} / \mathrm{A}$ & 0.80 & 0.64 \\
\hline VA02 <-- Visual Aesthetics & 0.70 & 0.04 & 0.67 & 0.45 \\
\hline VA03 <-- Visual Aesthetics & 0.97 & 0.05 & 0.77 & 0.59 \\
\hline
\end{tabular}

Note: $\mathrm{SE}=$ Standard error and SMC = squared multiple correlations. 
TABLE 53

COVARIANCES AND CORRELATIONS BETWEEN FACTORS

\begin{tabular}{|c|c|c|c|}
\hline Pair & Covariance & SE & Correlation \\
\hline Usability/Playability <--> Narratives & 0.40 & 0.05 & 0.42 \\
\hline Usability/Playability <--> Play Engrossment & 0.31 & 0.05 & 0.33 \\
\hline Usability/Playability <--> Enjoyment & 0.26 & 0.03 & 0.50 \\
\hline Usability/Playability <--> Creative Freedom & 0.33 & 0.05 & 0.32 \\
\hline Usability/Playability <--> Audio Aesthetics & 0.22 & 0.05 & 0.21 \\
\hline Usability/Playability <--> Personal & 0.28 & 0.04 & 0.45 \\
\hline \multicolumn{4}{|l|}{ Gratification } \\
\hline Usability/Playability <--> Social Connectivity & 0.18 & 0.06 & 0.14 \\
\hline Usability/Playability <--> Visual Aesthetics & 0.36 & 0.04 & 0.52 \\
\hline Narratives <--> Play Engrossment & 0.56 & 0.07 & 0.44 \\
\hline Narratives <--> Enjoyment & 0.39 & 0.04 & 0.55 \\
\hline Narratives <--> Creative Freedom & 0.99 & 0.09 & 0.70 \\
\hline Narratives <--> Audio Aesthetics & 0.78 & 0.08 & 0.53 \\
\hline Narratives <--> Personal Gratification & 0.37 & 0.05 & 0.44 \\
\hline Narratives <--> Social Connectivity* & -0.01 & 0.08 & -0.01 \\
\hline Narratives <--> Visual Aesthetics & 0.50 & 0.05 & 0.52 \\
\hline Play Engrossment <--> Enjoyment & 0.31 & 0.04 & 0.43 \\
\hline Play Engrossment <--> Creative Freedom & 0.65 & 0.07 & 0.46 \\
\hline Play Engrossment <--> Audio Aesthetics & 0.38 & 0.07 & 0.26 \\
\hline Play Engrossment <--> Personal Gratification & 0.47 & 0.06 & 0.56 \\
\hline Play Engrossment <--> Social Connectivity* & 0.03 & 0.08 & 0.02 \\
\hline Play Engrossment <--> Visual Aesthetics & 0.34 & 0.05 & 0.36 \\
\hline Enjoyment <--> Creative Freedom & 0.39 & 0.04 & 0.49 \\
\hline Enjoyment <--> Audio Aesthetics & 0.31 & 0.04 & 0.38 \\
\hline Enjoyment <--> Personal Gratification & 0.33 & 0.04 & 0.71 \\
\hline Enjoyment <--> Social Connectivity & 0.17 & 0.05 & 0.17 \\
\hline Enjoyment <--> Visual Aesthetics & 0.28 & 0.03 & 0.53 \\
\hline Creative Freedom <--> Audio Aesthetics & 0.66 & 0.08 & 0.41 \\
\hline Creative Freedom <--> Personal Gratification & 0.40 & 0.06 & 0.43 \\
\hline Creative Freedom <--> Social Connectivity & 0.32 & 0.09 & 0.16 \\
\hline Creative Freedom <--> Visual Aesthetics & 0.46 & 0.05 & 0.44 \\
\hline Audio Aesthetics <--> Personal Gratification & 0.32 & 0.05 & 0.33 \\
\hline Audio Aesthetics <--> Social Connectivity & 0.32 & 0.09 & 0.15 \\
\hline Audio Aesthetics <--> Visual Aesthetics & 0.59 & 0.06 & 0.54 \\
\hline Personal Gratification <--> Social Connectivity & 0.32 & 0.06 & 0.27 \\
\hline Personal Gratification <--> Visual Aesthetics & 0.31 & 0.04 & 0.49 \\
\hline Social Connectivity <--> Visual Aesthetics & 0.21 & 0.06 & 0.16 \\
\hline
\end{tabular}

Note: $\mathrm{SE}=$ Standard error.

*Covariance estimate was not statistically significant $(p>.05)$ for this pair of factors. 
Model Comparison. The hypothesized 9-factor model was compared against four alternative models in terms of overall model fit. All the models have the same number of cases $(N=771)$ and observed variables or items $(N=55)$. The first alternative model consisted of the same nine factors with the same corresponding measured variable. However, none of the factors in the model were allowed to covary with one another (see Figure 20). The 8- and 7models were based on the results derived from the EFA study, which suggested that there are two possible conceptually relevant factor solutions aside from the 9-factor solution.

In particular, the 8-factor solution combined the Visual and Audio Aesthetics factors into a single factor (see Figure 21). The 7-factor solution was similar to the 8-factor solution, but it further combined the Narratives and Creative Freedom factors into one factor (see Figure 22). Both the 8- and 7-factor models allowed all of the factors to covary with each other. Finally, the 1-factor model hypothesized that all of the observed variables loaded on the same factor (see Figure 23).

As expected, the large sample size and small RMSEA value of the null model resulted in statistically significant chi-square and substandard CFI values across all models (see Table 54). However, compare with other alternative models the hypothesized 9-factor model had the highest CFI value. In terms of the main fit statistics used to compare model fit, both the 8 - and 7-factor models had fairly good fit with RMSEA, SRMR, and Hoelter's CN in the adequate or good range. Conversely, both the 9-uncorrelated and the 1-factor models had poor fit with at least two of the main fit indices in the substandard range.

In comparison to the four alternative models, the specified 9-factor model had the lowest RMSEA and SRMR values, and highest Hoelter's CN values. Additionally, the specified 9- 
factor model had the best fit in terms of its $\mathrm{EVCl}$ values. Finally, the chi-square difference tests conducted resulted in statistically significant results between the hypothesized 9-factor model and each of the alternative models. This indicated that the hypothesized 9-factor model has a significantly better fit in comparison to the four alternative models. Overall, results from the goodness-of-fit statistics demonstrated that the specified 9-factor solution is the most appropriate model. Table 55 presents the results of all the main fit statistics across different models.

TABLE 54

CHI-SQUARE AND CFI FIT INDICES ACROSS MODELS $(N=771)$

\begin{tabular}{lcc}
\hline Model & $\chi^{2}$ & CFI \\
\hline 9 factors (correlated) & $\chi^{2}(1394)=4,428.63, p<.001$ & 0.82 \\
9 factors (uncorrelated) & $\chi^{2}(1430)=6,380.73, p<.001$ & 0.71 \\
8 factors (combined AA \& VA)* & $\chi^{2}(1402)=5,026.64, p<.001$ & 0.79 \\
7 factors (combined AA \& VA; N \& CF)* & $\chi^{2}(1409)=5,5502.14, p<.001$ & 0.76 \\
1 factor & $\chi^{2}(1430)=10,731.93, p<.001$ & 0.46 \\
\hline
\end{tabular}

Note: Chi-square statistic and CFI were not used in the overall assessment of model fit due to the large sample size $(N=771)$ and the null model's RMSEA being below 0.158 .

${ }^{*} \mathrm{AA}=$ Audio Aesthetics, $\mathrm{VA}=$ Visual Aesthetics, $\mathrm{N}=$ Narratives, and $\mathrm{CF}=$ Creative Freedom. 


\section{TABLE 55}

MAIN FIT INDICES ACROSS MODELS $(N=771)$

\begin{tabular}{|c|c|c|c|c|c|}
\hline Model & $\begin{array}{l}\text { RMSEA } \\
(90 \% \mathrm{Cl})\end{array}$ & SRMR & $\begin{array}{c}\text { Hoelter's } \\
.05 ; .01 \\
\end{array}$ & $\begin{array}{c}\text { EVCl } \\
(90 \% \mathrm{Cl})\end{array}$ & $\Delta \chi^{2}$ \\
\hline 9 factors (correlated) & $\begin{array}{c}.053 \\
(.051, .055)\end{array}$ & 0.07 & $258 ; 265$ & $\begin{array}{c}6.27 \\
(6.02,6.54)\end{array}$ & $\mathrm{N} / \mathrm{A}$ \\
\hline $\begin{array}{l}9 \text { factors } \\
\text { (uncorrelated) }\end{array}$ & $\begin{array}{c}.067 \\
(.065, .069)\end{array}$ & 0.19 & $184 ; 188$ & $\begin{array}{c}8.72 \\
(8.40,9.04)\end{array}$ & $\begin{aligned} \Delta \chi^{2}(36) & =1,952.10, \\
p & <.001\end{aligned}$ \\
\hline $\begin{array}{l}8 \text { factors (combined } \\
\text { AA \& VA) }\end{array}$ & $\begin{array}{c}.058 \\
(.056, .060)\end{array}$ & 0.08 & $229 ; 235$ & $\begin{array}{c}7.03 \\
(6.75,7.32)\end{array}$ & $\begin{array}{c}\Delta \chi^{2}(8)=599.01 \\
p<.001\end{array}$ \\
\hline $\begin{array}{l}7 \text { factors (combined } \\
\text { AA \& VA; N \& CF) }\end{array}$ & $\begin{array}{c}.061 \\
(.060, .063)\end{array}$ & 0.08 & $210 ; 215$ & $\begin{array}{c}7.63 \\
(7.34,7.93)\end{array}$ & $\begin{aligned} \Delta \chi^{2}(15) & =1,073.51, \\
p & <.001\end{aligned}$ \\
\hline 1 factor & $\begin{array}{c}.092 \\
(.090, .094)\end{array}$ & 0.10 & $109 ; 112$ & $\begin{array}{c}14.37 \\
(13.94,14.80)\end{array}$ & $\begin{aligned} \Delta \chi^{2}(36) & =6,303.31, \\
p & <.001\end{aligned}$ \\
\hline
\end{tabular}



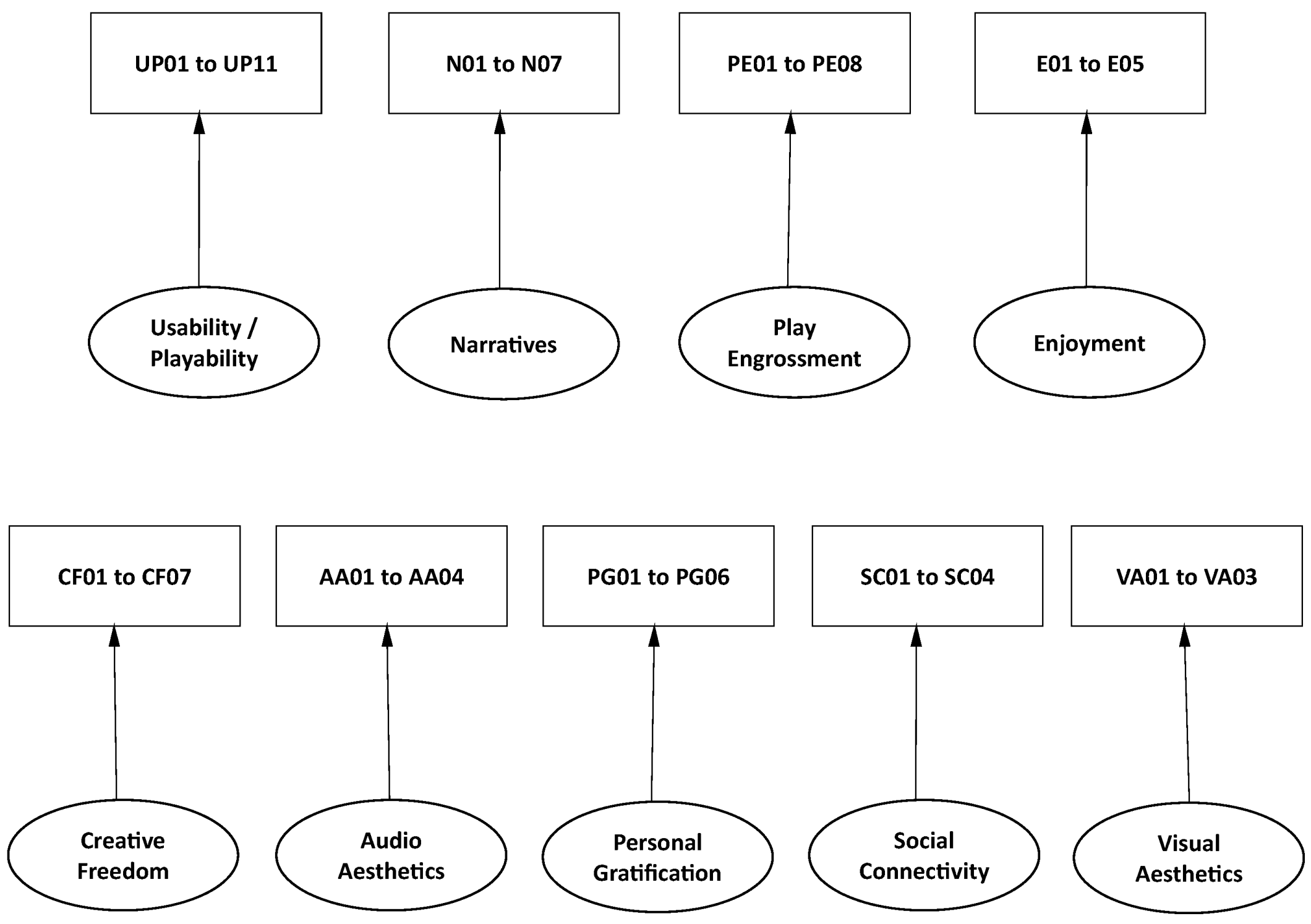

Figure 20. A visual representation of the 9-factor (uncorrelated) model. 


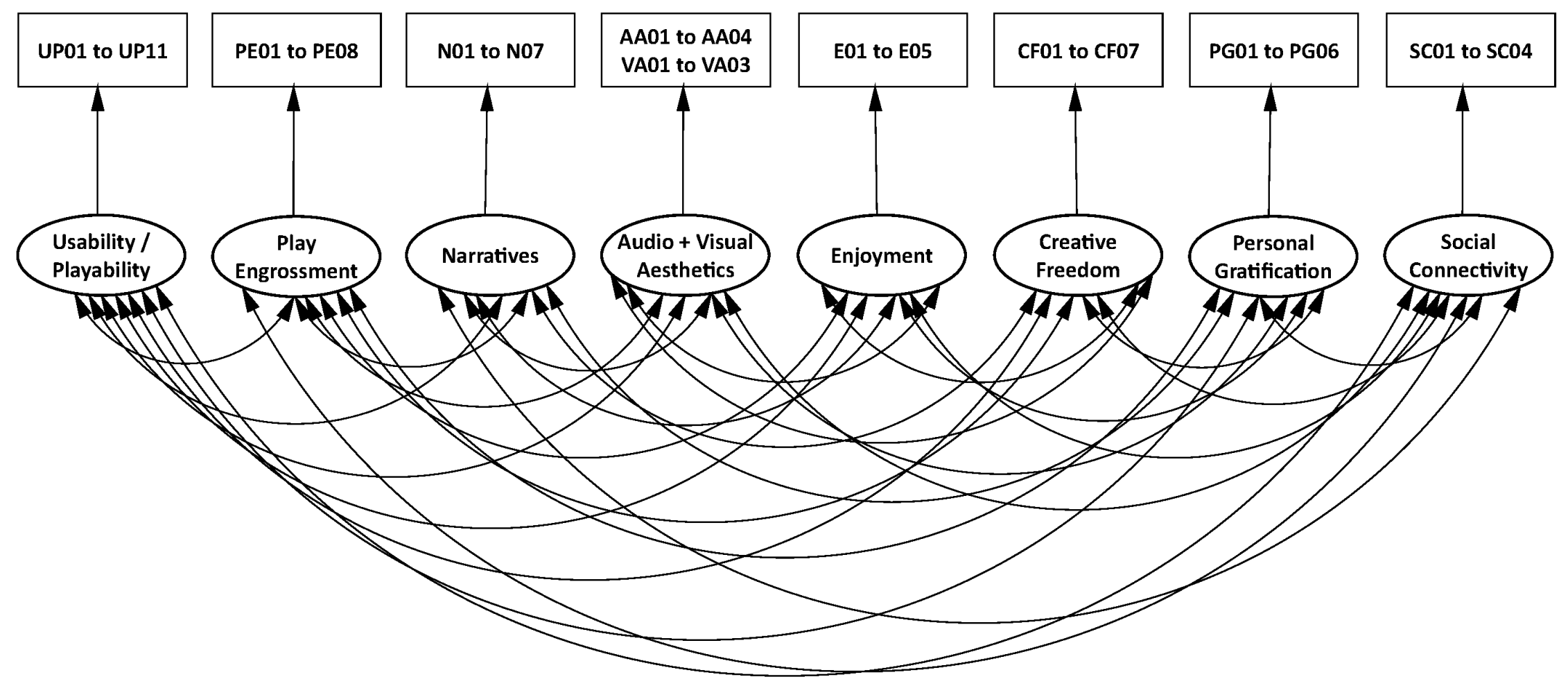

Figure 21. A visual representation of the 8-factor model. 


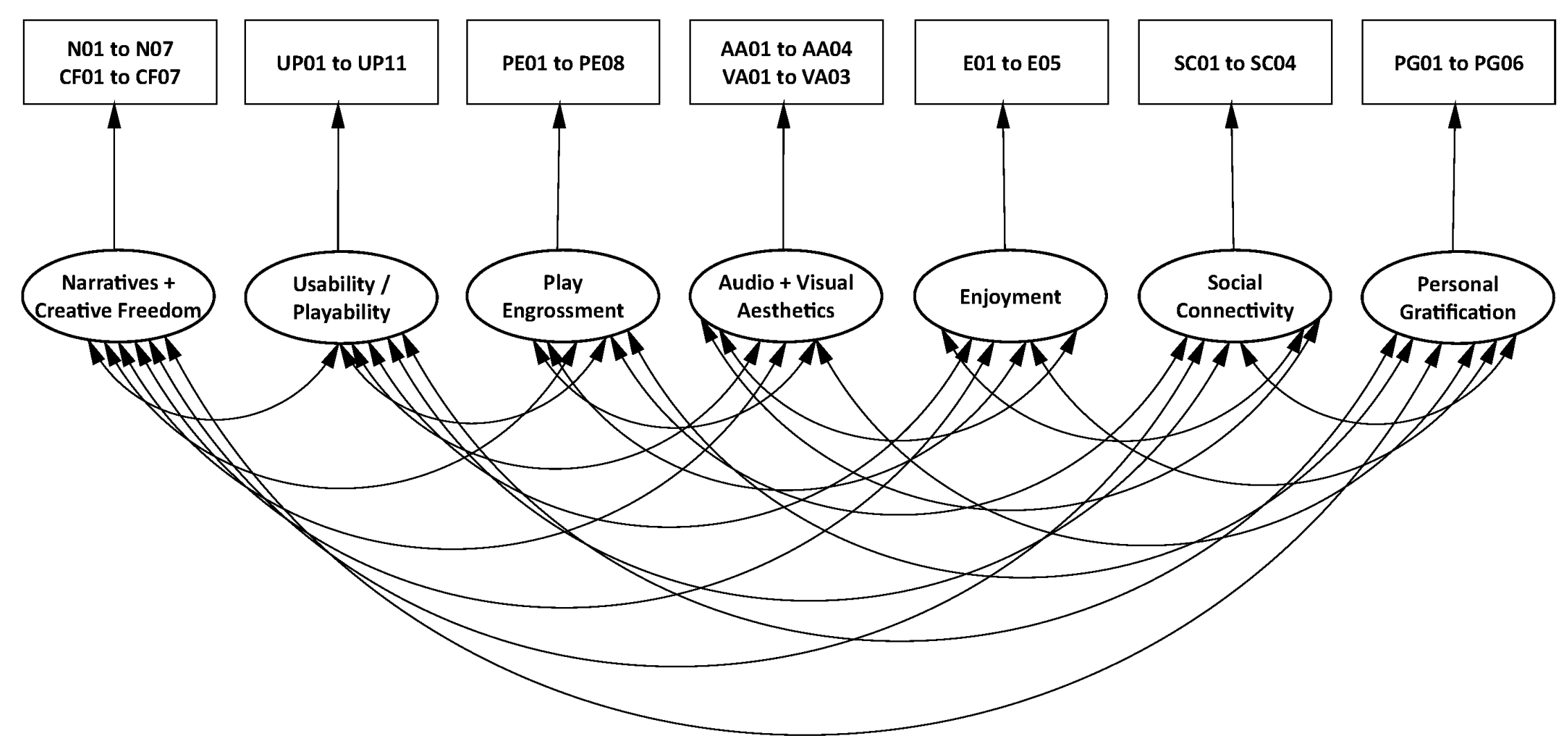

Figure 22. A visual representation of the 7-factor model. 


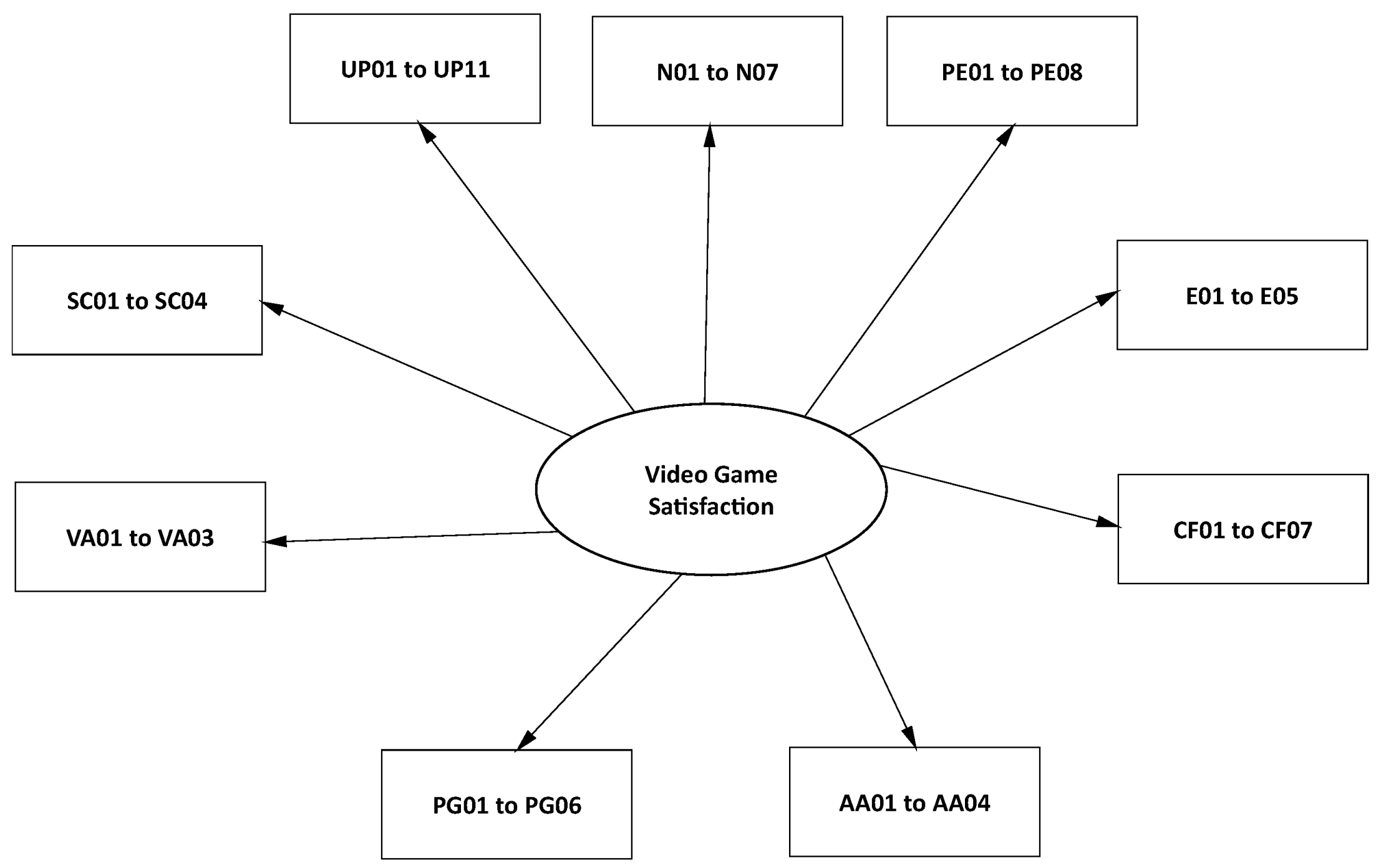

Figure 23. A visual representation of the 1-factor model. 


\section{Scale Reliability and Validity Assessment.}

After the assessment of model fit, it is important to re-examine the reliability of the scale and assess the convergent and discriminant validity of the scale based on parameter estimates (Cabrera-Nguyen, 2010). In order to compare the internal consistency of the hypothesized 9-factor solution across the EFA and CFA studies, Cronbach's alpha was calculated for all of the 55 variables and for each latent factor or subscale. Cronbach's $\alpha$ above 0.70 is considered as acceptable, 0.80 to 0.89 is considered as good, and 0.90 or above is considered as excellent (George \& Mallery, 2003; Hinkin, 1995; Nunnally, 1978).

Results revealed that the internal validity of the scale is consistent across the EFA and CFA studies. Although there was a small fluctuation in the Cronbach's $\alpha$ from the EFA study to the CFA study, the Cronbach's $\alpha$ for all factors or subscales stayed in the same acceptable or good range across the two studies. The overall Cronbach's $\alpha$ of the scale also remained in the excellent range in the CFA study as it did in the EFA study (see Table 56). Additionally, the relationships between overall game satisfaction and each of the factors was fairly stable across the two studies, with all relationships resulted in statistically significant Pearson's correlation coefficients. These results provided further evidence to the construct validity of the scale and its measuring video game satisfaction purposes. Table 57 provides the details of Pearson's $r$ results across the EFA and CFA studies. 
TABLE 56

CRONBACH'S ALPHAS ACROSS EFA $(N=629)$ AND CFA $(N=771)$ STUDIES

\begin{tabular}{lcc}
\hline Factor & $\begin{array}{c}\text { EFA Study } \\
\text { Cronbach's } \boldsymbol{\alpha}\end{array}$ & $\begin{array}{c}\text { CFA Study } \\
\text { Cronbach's } \boldsymbol{\alpha}\end{array}$ \\
\hline Factor 1: Usability/Playability & 0.84 & 0.83 \\
Factor 2: Narratives & 0.85 & 0.85 \\
Factor 3: Play Engrossment & 0.84 & 0.81 \\
Factor 4: Enjoyment & 0.81 & 0.80 \\
Factor 5: Creative Freedom & 0.85 & 0.86 \\
Factor 6: Audio Aesthetics & 0.88 & 0.89 \\
Factor 7: Personal Gratification & 0.77 & 0.72 \\
Factor 8: Social Connectivity & 0.83 & 0.86 \\
Factor 9: Visual Aesthetics & 0.75 & 0.79 \\
Entire Scale & 0.93 & 0.92 \\
\hline
\end{tabular}

TABLE 57

CORRELATIONS ACROSS EFA $(N=629, D F=627)$ AND CFA $(N=771, D F=769)$ STUDIES

\begin{tabular}{|c|c|c|c|c|c|c|c|c|c|}
\hline Factor & 1: UP & 2: N & 3: PE & 4: $E$ & 5: CF & 6: AA & 7: PG & 8: SC & 9: VA \\
\hline $\begin{array}{l}\text { EFA Overall } \\
\text { Satisfaction }\end{array}$ & $0.31^{* *}$ & $0.48^{* *}$ & $0.37^{* *}$ & $0.75^{* *}$ & $0.50^{* *}$ & $0.37^{* *}$ & $0.35^{* *}$ & $0.10^{*}$ & $0.43^{* *}$ \\
\hline $\begin{array}{l}\text { CFA Overall } \\
\text { Satisfaction }\end{array}$ & $0.32^{* *}$ & $0.43^{* *}$ & $0.34^{* *}$ & $0.69^{* *}$ & $0.41^{* *}$ & $0.35^{* *}$ & $0.45^{* *}$ & $0.11^{* *}$ & $.44^{* *}$ \\
\hline $\begin{array}{l}\text { Note. Overal } \\
\text { Extremely Sati } \\
\text { Narratives, } \\
\text { Aesthetics, }\end{array}$ & $\begin{array}{l}\text { ne sa } \\
d "(M \\
\text { or } 3= \\
\text { or } 7=\end{array}$ & $\begin{array}{l}\text { tion is } \\
5.33, \\
\text { Engro } \\
\text { onal }\end{array}$ & $\begin{array}{l}\text { en on a } \\
=0.85 ; \\
\text { nt, Fac } \\
\text { ication }\end{array}$ & $\begin{array}{l}\text { en-poi } \\
\text { A }=6.3 \\
=\text { Enj } \\
\text { tor } 8 \\
<.05 \text { ( }\end{array}$ & $\begin{array}{l}\text { kert sca } \\
\text { DCFA }=0 \\
\text { ent, Fac } \\
\text { iial Con } \\
\text { led). }\end{array}$ & $\begin{array}{l}\text { ith } 1 \\
\text { Factc } \\
5=\mathrm{C} \\
\text { ivity, }\end{array}$ & $\begin{array}{l}\text { Usab } \\
\text { Fre } \\
\text { acto }\end{array}$ & $\begin{array}{l}\text { Fact } \\
\text { isual }\end{array}$ & $\begin{array}{l}\text { and } 7= \\
\text { Factor } 2 \\
\text { Audio } \\
\text { etics. }\end{array}$ \\
\hline
\end{tabular}

Next, standardized factor loadings were examined to investigate convergent validity.

Researchers have suggested that factor loadings below 0.40 are weak and those above 0.70 are strong (Cabrera-Nguyen, 2010; Garson, 2010; Hair et al., 2006). All of the factor loadings were 
above 0.40 , with all but four loadings above 0.50 (see Table 58). In addition, correlations among the factor in the CFA study were examined to assess discriminant validity of the scale.

Researchers have recommended that factor correlations be below 0.80 or 0.85 to ensure good discriminant validity (Brown, 2014; Cabrera-Nguyen, 2010; Garson, 2010; Kline, 2005). All of the factor correlations were below the 0.80 benchmark, with the two strongest factor correlations were between Narratives and Creative Freedom $(r=0.70)$; Enjoyment and Personal Gratification $(r=0.71)$. Finally, an alternative, but less robust measure of discriminant validity is to compare the model fit between two similar models (e.g., 1-factor vs. 2-factor; Hair et al., 2006). As chi-square difference tests had revealed, the hypothesized 9-factor model provided a significantly better fit than the 8-factor and other models. Altogether, results demonstrated that the 9-factor solution has adequate convergent and discriminant validity.

TABLE 58

CFA STUDY: STANDARDIZED FACTOR LOADINGS BELOW 0.50

\begin{tabular}{|c|c|}
\hline Pair & $\begin{array}{l}\text { Standardized } \\
\text { Estimate }\end{array}$ \\
\hline UP05 <-- Usability/Playability & \\
\hline $\begin{array}{l}\text { UP05. I do not need to go through a lengthy tutorial or read a manual to play } \\
\text { the game. }\end{array}$ & 0.43 \\
\hline $\begin{array}{l}\text { PE06 <-- Play Engrossment } \\
\text { PE06. I am very interested in seeing how the events in the game will } \\
\text { progress. }\end{array}$ & 0.44 \\
\hline $\begin{array}{l}\text { CF05 <-- Creative Freedom } \\
\text { CF05. I feel I can explore things in the game. }\end{array}$ & 0.49 \\
\hline $\begin{array}{l}\text { PG01 <-- Personal Gratification } \\
\text { PG01. I am in suspense about whether I will succeed in the game. }\end{array}$ & 0.41 \\
\hline
\end{tabular}




\section{CHAPTER 6}

\section{GENERAL DISCUSSION}

\section{Summary of Research}

As video games continue to attract new fan base and the industry becomes increasingly competitive, more game companies will depend on some form of game evaluation methods (e.g., usability testing, playtesting) to improve a game's chance of commercial success. Of all the different methods to evaluate a video game, survey-based methods will generally be preferred by different game companies due to its cost-effectiveness. In general, surveys allow video game companies to collect a large number of feedback about a game directly from the players. Additionally, conducting a survey is ideal for small game companies with limited budget because it does not requires special equipment or software, and the players can complete the questionnaire in the comfort of their home. For game companies looking to collect detailed feedback, a survey is an inexpensive tool that can easily be incorporated with other game evaluation methods (i.e., usability testing).

Although there are a number of gaming questionnaires or scales exist in the literature, the majority of them are not suitable for game evaluation purposes in the industry. This is mainly due to the lack of comprehensiveness of existing gaming questionnaires, and that many of the scales were developed mainly for academic research purposes with applications in the industry settings as an afterthought. Importantly, the majority of the gaming scales were not developed and validated based on the current best practices of scale development and validation, which can severely threaten the reliability and validity of the scales. 
This dissertation attempted to address the need of the video game industry and fill the gap in the literature in terms of providing a psychometrically validated, comprehensive gaming scale measuring video game satisfaction. Specifically, a rigorous process of scale development and validation consisted of a five-step plan was adopted in the construction of the new gaming scale. First, numerous resources (e.g., existing game scales and heuristics) concerning video game enjoyment and satisfaction were gathered to generate an initial item pool for the new scale. The item pool went through multiple iterative phases of modification and refinement before they were being presented to a panel of experts for reviews.

After the item pool was revised according to the experts' suggestions, the scale was presented to four groups of game players who used it to assess a video game that they recently played. Following the pilot participants' suggestions, changes were made to the item pool to further improve the comprehension of the statements. The questionnaire was then distributed online to a large sample of gamers to complete. Exploratory factor analysis was conducted to uncover the underlying factors of the scale and the length of the scale was reduced by removing ineffective items. Finally, the revised scale was distributed again to a different sample of gamers to complete, and confirmatory factor analysis was performed to evaluate how well the hypothesized model derived from the EFA study fit the new sample of observed data.

\section{The New Instrument and Its Applications}

After the completion of the five-step plan, a new satisfaction scale for gaming called the Game User Experience Satisfaction Scale (GUESS) emerged. The GUESS consists of nine subscales and 55 items. The nine subscales are called Usability/Playability, Narratives, Play Engrossment, Enjoyment, Creative Freedom, Audio Aesthetics, Personal Gratification, Social 
Connectivity, and Visual Aesthetics. The GUESS was found to have strong psychometric properties. Particularly, the GUESS was deemed to have high content validity based on the expert review phase.

Both of the EFA and CFA studies demonstrated that the GUESS has good internal consistency. In addition, results obtained from the CFA study provided supporting evidence to the construct validity of the GUESS. Specifically, the GUESS was determined to have satisfactory convergent and discriminant validity. Overall, these results contribute to the overall confidence that the GUESS is a reliable and valid measure of video game satisfaction.

In terms of the applications of the GUESS, the GUESS can be administered to a wide range of video game players and be used to evaluate different types of video games. For instance, the GUESS have been developed based on the feedback of different types of gamers (e.g., Newbie/Novice, Hardcore/Expert) as well as ESL gamers. Thus, it contains simple language that can easily be understood by any video game players with some high school education. Also, the GUESS was developed and validated based on the assessments of over 450 unique video game titles across many popular genres (e.g., Role-Playing, Action Adventure). As a result, the new instrument can be applied across many types of video games in the industry. Furthermore, the GUESS is not lengthy, which makes it ideal to use in the industry settings. The entire scale generally takes around 5-10 minutes to complete.

Currently, the GUESS can be administered in the current format that is shown on Appendix EE. Although for best results, it is recommended that the items on the scale be randomized and separated into a set of five items per page. In terms of scoring the GUESS, it is recommended that the ratings of all the items per factor be averaged to obtain an average 
score of each subscale. Additionally, the average score of each subscale can be added together in order to obtain a composite score of video game satisfaction. During the scoring process, it is important to remember to reverse score the item about boredom (i.e., "I feel bored while playing the game.") to obtain accurate results.

Right now the scale has just been developed, and thus, there is little information on the scoring standard. Thus, it is currently recommend that the GUESS be used to compare different video games of the same genre, and the game with the highest score can be considered as more satisfying to play. Alternatively, the GUESS can be used to compare video games from the same series or from different versions to determine whether the latest series or version is an improved over the old ones. Finally, if there is a game being evaluated without any narratives or social components video game practitioners have the option of removing the Narratives or Social Connectivity subscales from the entire scale. However, it is generally recommended that the entire scale be kept intact for more accurate results.

\section{Future Research}

This research covered the first few essential steps to develop and validate a comprehensive gaming scale measuring video game satisfaction. Thus, more research is needed to further validate and extend the applicability of the GUESS to different types of game and gamer populations. This research only examined the scale's reliability, and content and construct validity. Future research needs to assess the scale in terms of criterion-related validity. For example, future studies can examine how well the score obtained from the GUESS can predict the player's performance within the game, the likelihood that the player will continue playing the game, as well as review scores from critics. Additionally, the GUESS has 
only been administered to video game players who are at least 18 years old with some high school education. Consequently, researchers interested in using the GUESS with younger populations with lower education levels need to evaluate using the GUESS in those contexts.

More research is also needed to generalize the GUESS to more game genres.

Specifically, the games evaluated in this research mostly consisted of commercial games that were designed purely to entertain. It is not known how much of the scale will be applicable in evaluating serious games (e.g., educational). Additionally, the majority of the games evaluated in this research were games that participants generally liked rather than disliked. Thus, future studies should consider using the GUESS to evaluate games that are not well-liked. Overall, future research should focus on using the GUESS to evaluate video games from one particular genre in order to assess how the scale might change from genre to genre. Finally, more research is needed to determine the appropriate scoring standard for video games from each genre.

\section{Conclusion}

At present, there is a need for a psychometrically validated and comprehensive gaming scale that is appropriate for playtesting and game evaluation purposes. The Game User Experience Satisfaction Scale (GUESS) was developed based on a rigorous system of scale development and validation to meet that need. The GUESS contains 55 items with nine subscales, and takes around 5-10 minutes to complete. The GUESS was administered to two large, independent samples of over 600 video game players who evaluated over 450 unique video games from a wide range of genres. 
Most importantly, the GUESS was developed based on the current best practices in the scale development literature. Specifically, the GUESS was found to be a reliable measure across the two diverse samples of video games evaluated in this research. Additionally, it was demonstrated to have satisfactory content and construct validity. The GUESS was designed to be applicable in the video game industry, and thus, it is suitable to use in any playtesting sessions and for general game evaluation purposes. In order to extend the generalizability of the GUESS future research should focus on examining the scale in the context of video games that people disliked as well as games that were designed with purposes other than entertainment (i.e., serious games). 


\section{REFERENCES}




\section{REFERENCES}

Abran, A., Khelifi, A., Suryn, W., \& Seffah, A. (2003). Usability meanings and interpretations in ISO standards. Software Quality Journal, 11(4), 325-338.

Agarwal, R., \& Karahanna, E. (2000). Time flies when you're having fun: Cognitive absorption and beliefs about information technology usage. MIS Quarterly, 24(4), 665-694.

Albert, W., \& Tullis, T. (2013). Measuring the user experience: Collecting, analyzing, and presenting usability metrics. Waltham, MA: Morgan Kaufmann.

Alexander, A. L., Brunyé, T., Sidman, J., \& Weil, S. A. (2005). From gaming to training: A review of studies on fidelity, immersion, presence, and buy-in and their effects on transfer in PC-based simulations and games. DARWARS Training Impact Group, 5, 1-14.

Anand, V. (2007). A study of time management: The correlation between video game usage and academic performance markers. CyberPsychology \& Behavior, 10(4), 552-559.

Anderson, C. A. (2004). An update on the effects of playing violent video games. Journal of Adolescence, 27(1), 113-122.

Anderson, C. A., \& Bushman, B. J. (2001). Effects of violent games on aggressive behavior, aggressive cognition, aggressive affect, physiological arousal, and prosocial behavior: $\mathrm{A}$ meta-analytic review of the scientific literature. Psychological Science, 12, 353-359.

Anguera, J. A., Boccanfuso, J., Rintoul, J. L., Al-Hashimi, O., Faraji, F., Janowich, J., . . Gazzaley, A. (2013). Video game training enhances cognitive control in older adults. Nature, 501(7465), 97-101.

Appleton, J. J., Christenson, S. L., Kim, D., \& Reschly, A. L. (2006). Measuring cognitive and psychological engagement: Validation of the Student Engagement Instrument. Journal of School Psychology, 44(5), 427-445.

Aycock, H. (1992). Principles of good game design. Business Source Premier, 14(1), 94-98.

Barwood, H., \& Falstein, N. (2006, March 26). The 400 project Rule List. Retrieved from http://www.finitearts.com/Pages/400page.html

Basak, C., Boot, W. R., Voss, M. W., \& Kramer, A. F. (2008). Can training in a real-time strategy video game attenuate cognitive decline in older adults? Psychology and Aging, 23(4), 765-777. 
Bavelier, D., Green, C. S., Pouget, A., \& Schrater, P. (2012). Brain plasticity through the life span: Learning to learn and action video games. Annual Review of Neuroscience, 35, 391-416.

Bekker, M. M., Baauw, E., \& Barendregt, W. (2008). A comparison of two analytical evaluation methods for educational computer games for young children. Cognition, Technology \& Work, 10(2), 129-140.

Bennett, D. A. (2001). How can I deal with missing data in my study? Australian and New Zealand Journal of Public Health, 25(5), 464-469.

Benson, J., \& Fleishman, J. A. (1994). The robustness of maximum likelihood and distributionfree estimators to non-normality in confirmatory factor analysis. Quality and Quantity, 28(2), 117-136.

Bentler, P. M. (1990). Comparative fit indexes in structural models. Psychological Bulletin, 107(2), 238-246.

Bevan, N. (2009, August). What is the difference between the purpose of usability and user experience evaluation methods. In Workshop User eXperience Evaluation Methods in Product Development (UXEM'09 Workshop at 12th Conference on Human-Computer Interaction, INTERACT 2009), (pp. 1-4). Uppsala, Sweden.

Blanca, M. J., Arnau, J., López-Montiel, D., Bono, R., \& Bendayan, R. (2013). Skewness and kurtosis in real data samples. Methodology: European Journal of Research Methods for the Behavioral and Social Sciences, 9(2), 78-84.

Boyle, E., Connolly, T. M., \& Hainey, T. (2011). The role of psychology in understanding the impact of computer games. Entertainment Computing, 2(2), 69-74.

Brockmyer, J. H., Fox, C. M., Curtiss, K. A., McBroom, E., Burkhart, K. M., \& Pidruzny, J. N. (2009). The development of the Game Engagement Questionnaire: A measure of engagement in video game-playing. Journal of Experimental Social Psychology, 45(4), 624634.

Brooke, J. (1996). SUS-A quick and dirty usability scale. In P.W. Jordan, B. Thomas, B. A. Weerdmeester, \& I.L. McClelland (Eds.), Usability evaluation in industry (pp. 189 - 194). London: Taylor \& Francis.

Brooks, K. (2003). There is nothing virtual about immersion: Narrative immersion for VR and other interface." Motorola Labs/Human Interface Labs, MIT Media Laboratory. Retrieved from http://alumni.media.mit.edu/ brooks/storybiz/immersiveNotVirtual.pdf 
Brown, T. A. (2014). Confirmatory factor analysis for applied research (2nd ed.). New York, NY: The Guilford Press.

Brown, E., \& Cairns, P. (2004, April). A grounded investigation of game immersion. In CHI'04 Extended Abstracts on Human Factors in Computing Systems (pp. 1297-1300). ACM.

Browne, M. W. (1984). Asymptotically distribution-free methods for the analysis of covariance structures. British Journal of Mathematical and Statistical Psychology, 37, 62-83.

Browne, M. W., \& Cudeck, R. (1989). Single sample cross-validation indices for covariance structures. Multivariate Behavioral Research, 24(4), 445-455.

Browne, M.W., \& Cudeck, R. (1993). Alternative ways of assessing model fit. In K. A. Bollen \& J. S. Long (Eds.), Testing structural equation models (pp. 136-162). Newbury Park, CA: Sage.

Byrne, B.M. (2010). Structural equation modeling with AMOS: Basic concepts, applications, and programming (2nd ed.). New York, NY: Taylor \& Francis Group.

Cabrera-Nguyen, P. (2010). Author guidelines for reporting scale development and validation results in the Journal of the Society for Social Work and Research. Journal of the Society for Social Work and Research, 1(2), 99-103.

Calvillo-Gámez, E. H., Cairns, P., \& Cox, A. L. (2010). Assessing the core elements of the gaming experience. In R. Bernhaupt (Ed.), Evaluating user experience in games (pp. 47-71). New York, NY: Springer.

Chalker, D. (2008, July 3). Reiner Knizia: “Creation of a successful game”. Critical Hits. Retrieved from http://www.critical-hits.com/blog/2008/07/03/reiner-knizia-creation-ofa-successful-game/

Chan, P. A., \& Rabinowitz, T. (2006). A cross-sectional analysis of video games and attention deficit hyperactivity disorder symptoms in adolescents. Annals of General Psychiatry, 5(1), 16.

Chen, J. (2007). Flow in games (and everything else). Communications of the ACM, 50(4), 31-34.

Chen, M., Kolko, B., Cuddihy, E., \& Medina, E. (2005). Modelling and measuring engagement in computer games. In Proceedings of the Conference for the Digital Games Research Association. 
Chen, M., Kolko, B. E., Cuddihy, E., \& Medina, E. (2011, June). Modeling but NOT measuring engagement in computer games. In Proceedings of the 7th International Conference on Games+ Learning+ Society Conference (pp. 55-63). ETC Press.

Chin, J. P., Diehl, V. A., \& Norman, K. L. (1988, May). Development of an instrument measuring user satisfaction of the human-computer interface. In Proceedings of the SIGCHI Conference on Human factors in Computing Systems (pp. 213-218). ACM.

Choi, D., \& Kim, J. (2004). Why people continue to play online games: In search of critical design factors to increase customer loyalty to online contents. CyberPsychology \& Behavior, 7(1), 11-24.

Chou, C. P., Bentler, P. M., \& Satorra, A. (1991). Scaled test statistics and robust standard errors for non-normal data in covariance structure analysis: a Monte Carlo study. British Journal of Mathematical and Statistical Psychology, 44(2), 347-357.

Clanton, C. (1998, April). An interpreted demonstration of computer game design. In CHI 98 Conference Summary on Human Factors in Computing Systems (pp. 1-2). ACM.

Cliff, N. (1988). The eigenvalues-greater-than-one rule and the reliability of components. Psychological Bulletin, 103(2), 276-279.

Collins, J. (1997, July 7). Conducting in-house play testing. Gamasutra. Retrieved from http://www.gamasutra.com/view/feature/3211/

Comrey, A. L., \& Lee, H. B. (1992). A first course in factor analysis (2nd ed.). Hilldsale, NJ: Lawrence Erlbaum Associates.

Coomans, M. K. D., \& Timmermans, H. J. P. (1997, August). Towards a taxonomy of virtual reality user interfaces. In Proceedings of the International Conference on Information Visualisation (IV 97). London, England.

Cornett, S. (2004, April). The usability of massively multiplayer online roleplaying games: designing for new users. In Proceedings of the SIGCHI Conference on Human Factors in Computing Systems (pp. 703-710). ACM.

Costello, A. B. \& Osborne, J. W. (2005). Best practices in exploratory factor analysis: Four recommendations for getting the most from your analysis. Practical Assessment, Research \& Evaluation, 10(7), 1-9.

Csikszentmihalyi, M. (1975). Beyond boredom and anxiety: The experience of play in work and games. San Francisco, CA: Jossey-Bass. 
Csikszentmihalyi, M. (1990). Flow: The psychology of optimal experience. New York, NY: Harper and Row.

Csikszentmihalyi, M. (1997). Finding flow: The psychology of engagement with everyday life. New York, NY: Basic Books.

Csikszentmihalyi, M., Abuhamdeh, S., \& Nakamura, J., (2005). Flow. In Elliot, A. J., \& Dweck, C. S. (Eds.), Handbook of competence and motivation (pp. 598-608). New York, NY: The Guilford Press.

Curran, P. J., West, S. G., \& Finch, J. F. (1996). The robustness of test statistics to nonnormality and specification error in confirmatory factor analysis. Psychological Methods, 1(1), 16.

Davis, J. P., Steury, K., \& Pagulayan, R. (2005). A survey method for assessing perceptions of a game: The consumer playtest in game design. Game Studies, 5(1).

Dawes, J. G. (2008). Do data characteristics change according to the number of scale points used? An experiment using 5 point, 7 point and 10 point scales. International Journal of Market Research, 51(1), 61-77.

Dempster, A. P., Laird, N. M., \& Rubin, D. B. (1977). Maximum likelihood from incomplete data via the EM algorithm. Journal of the Royal Statistical Society. Series B (Methodological), 38(1), 1-38.

Desurvire, H., Caplan, M., \& Toth, J. A. (2004, April). Using heuristics to evaluate the playability of games. In $\mathrm{CHI}$ 'O4 extended abstracts on Human factors in computing systems (pp. 1509-1512). ACM.

Desurvire, H., \& Wiberg, C. (2009). Game usability heuristics (play) for evaluating and designing better games: The next iteration. In A. A. Ozok \& P. Zaphiris (Eds.), Online communities and social computing (pp. 557-566). New York, NY: Springer.

Desurvire, H., \& Wiberg, C. (2010). User Experience Design for Inexperienced Gamers: GAPGame Approachability Principles. In Evaluating User Experience in Games (pp. 131-147). Springer London.

Dill, K. E., \& Dill, J. C. (1998).Video game violence: A review of the empirical literature. Aggression and Violent Behavior: A Review Journal, 3, 407-428.

Dong, Y., \& Peng, C. Y. J. (2013). Principled missing data methods for researchers. SpringerPlus, 2(1), 1-17. 
Douglas, Y., \& Hargadon, A. (2000, May). The pleasure principle: Immersion, engagement, flow. In Proceedings of the eleventh ACM on Hypertext and hypermedia (pp. 153-160). ACM.

Downs, J., Vetere, F., Howard, S., \& Loughnan, S. (2013, November). Measuring audience experience in social videogaming. In Proceedings of the 25th Australian ComputerHuman Interaction Conference: Augmentation, Application, Innovation, Collaboration (pp. 217-220). ACM.

Enders, C. K. (2001). The impact of non-normality on full information maximum-likelihood estimations for structural equation models with missing data. Psychological Methods, 6(4), 352-370.

Enders, C. K. (2003). Using the expectation maximization algorithm to estimate coefficient alpha for scales with item-level missing data. Psychological Methods, 8(3), 322-337.

Enders, C. K. (2006). Analyzing structural equation models with missing data. In G.R. Hancock \& R.O. Mueller (Eds.), Structural Equation Modeling: A Second Course (pp. 315-344). Greenwich, CT: Information Age Publishing, Inc.

Enders, C. K., \& Bandalos, D. L. (2001). The relative performance of full information maximum likelihood estimation for missing data in structural equation models. Structural Equation Modeling, 8(3), 430-457.

Entertainment Software Association (ESA, 2014). 2014 Sales demographic and usage data: Essential facts about the computer and video game industry. Retrieved from http://www.theesa.com/wp-content/uploads/2014/10/ESA_EF_2014.pdf

Ermi, L., \& Mäyrä, F. (2005). Fundamental components of the gameplay experience: Analysing immersion. In S. Castell \& J. Jenson, (Eds.), The Proceedings of the DiGRA Conference Changing Views: Worlds in Play (pp. 15-27).

Fabrigar, L. R., Wegener, D. T., MacCallum, R. C., \& Strahan, E. J. (1999). Evaluating the use of exploratory factor analysis in psychological research. Psychological Methods, 4(3), 272-299.

Fan, X., Thompson, B., \& Wang, L. (1999). Effects of sample size, estimation methods, and model specification on structural equation modeling fit indexes. Structural Equation Modeling: A Multidisciplinary Journal, 6(1), 56-83. 
Fan, X., Wang, L., \& Thompson, B. (1997, March). Effects of data nonnormality and other factors on fit indices and parameter estimates for true and misspecified SEM models. Paper presented at the American Educational Research Association Annual Meeting, Chicago, IL.

Fang, X., Zhang, J., \& Chan, S. S. (2013). Development of an instrument for studying flow in computer game play. International Journal of Human-Computer Interaction, 29(7), 456470.

Farnsworth, T. (2007). Issues in game development: The utility of heuristics versus current techniques (Master's thesis). Available from TomFarnsworth.com.

Febretti, A., \& Garzotto, F. (2009, April). Usability, playability, and long-term engagement in computer games. In CHI'09 Extended Abstracts on Human Factors in Computing Systems (pp. 4063-4068). ACM.

Federoff, M. A. (2002). Heuristics and usability guidelines for the creation and evaluation of fun in video games (Master's thesis). Available from CiteSeerX database.

Field, A. P. (2009). Discovering statistics using SPSS ( $3^{\text {rd }}$ ed.). Los Angeles, CA: Sage.

Finney, S. J., \& DiStefano, C. (2013). Nonnormal and categorical data in structural equation modeling. In G. R. Hancock \& R. O. Mueller (Eds.), Structural equation modeling: $A$ second course (2nd ed.) (pp. 269-314). Charlotte, NC: IAP.

Fisher, S. (1994). Identifying video game addiction in children and adolescents. Addictive Behaviors, 19(5), 545-553.

Fling, S., Smith, L., Rodriguez, T., Thornton, D., Atkins, E., \& Nixon, K. (1992). Videogames, aggression, and self-esteem: A survey. Social Behavior and Personality: An International Journal, 20(1), 39-45.

Fox-Wasylyshyn, S. M., \& El-Masri, M. M. (2005). Handling missing data in self-report measures. Research in Nursing \& Health, 28(6), 488-495.

Franceschini, S., Gori, S., Ruffino, M., Viola, S., Molteni, M., \& Facoetti, A. (2013). Action video games make dyslexic children read better. Current Biology, 23, 1-5.

Franklin, S. B., Gibson, D. J., Robertson, P. A., Pohlmann, J. T., \& Fralish, J. S. (1995). Parallel analysis: a method for determining significant principal components. Journal of Vegetation Science, 6(1), 99-106.

Fu, F. L., Su, R. C., \& Yu, S. C. (2009). EGameFlow: A scale to measure learners' enjoyment of elearning games. Computers \& Education, 52(1), 101-112. 
Fulton, B. (2002, March 21). Beyond psychological theory: Getting data that improves games. Gamasutra. Retrieved from http://www.gamasutra.com/view/feature/131412/

Gaggioli, A., Bassi, M., \& Fave, A. D. (2003). Quality of experience in virtual environments. Emerging Communication, 5, 121-136.

Gallagher, D. (2013, March 10). 7 health benefits of playing video games. The Week. Retrieved from http://theweek.com/article/index/241121/7-health-benefits-of-playingvideo-games

Garson, D. (2010). Statnotes: Topics in multivariate analysis: Factor Analysis. Retrieved from http://faculty.chass.ncsu.edu/garson/pa765/statnote.htm

Gartner (2013). Gartner says worldwide video game market to total \$93 billion in 2013. Retrieved from http://www.gartner.com/newsroom/id/2614915

George, D., \& Mallery, P. (2003). SPSS for Windows step by step: A simple guide and reference, 11.0 update $\left(4^{\text {th }}\right.$ ed.). Boston, MA: Allyn \& Bacon.

Ghani, J. A., \& Deshpande, S. P. (1994). Task characteristics and the experience of optimal flow in human-computer interaction. The Journal of Psychology, 128(4), 381-391.

Glicksohn, J., \& Avnon, M. (1997). Explorations in virtual reality: Absorption, cognition and altered state of consciousness. Imagination, Cognition, \& Personality, 17, 141-151.

Gold, M. S., \& Bentler, P. M. (2000). Treatments of missing data: A Monte Carlo comparison of RBHDI, iterative stochastic regression imputation, and expectationmaximization. Structural Equation Modeling, 7(3), 319-355.

Graham, J. W. (2009). Missing data analysis: Making it work in the real world. Annual Review of Psychology, 60, 549-576.

Graham, J. W., Olchowski, A. E., \& Gilreath, T. D. (2007). How many imputations are really needed? Some practical clarifications of multiple imputation theory. Prevention Science, 8(3), 206-213.

Green, C. S., \& D. Bavelier (2006). Enumeration versus object tracking: Insights from video game players. Cognition, 101, 217-245.

Green, C. S., Pouget, A., \& Bavelier, D. (2010). Improved probabilistic inference as a general learning mechanism with Action video games. Current Biology, 20(17), 1573-1579. 
Griffith, J. L., Voloschin, P., Gibb, G. D., \& Bailey, J. R. (1983). Differences in eye-hand motor coordination of video-game users and non-users. Perceptual and Motor Skills, 57, 155158.

Griffiths, M. (1999). Violent video games and aggression: A review of the literature. Aggression and Violent Behavior, 4, 203-212.

Grüsser, S. M., Thalemann, R., \& Griffiths, M. D. (2006). Excessive computer game playing: Evidence for addiction and aggression? CyberPsychology \& Behavior, 10(2), 290-292.

Guarini, D. (2013, November 7). 9 ways video games can actually be good for you. The Huffington Post. Retrieved from http://www.huffingtonpost.com/2013/11/07/videogames-good-for-us_n_4164723.html

Hair, J. F., Black, W. C., Babin, B. J., Anderson, R. E., \& Tatham, R. L. (2006). Multivariate data analysis ( $6^{\text {th }}$ ed.). Upper Saddle River, N.J.: Pearson Education Inc.

Hallgren, K. A., \& Witkiewitz, K. (2013). Missing data in alcohol clinical trials: A comparison of methods. Alcoholism: Clinical and Experimental Research, 37(12), 2152-2160.

Henson, R. K., \& Roberts, J. K. (2006). Use of exploratory factor analysis in published research common errors and some comment on improved practice. Educational and Psychological measurement, 66(3), 393-416.

Hinkin, T. R. (1995). A review of scale development practices in the study of organizations. Journal of Management, 21(5), 967-988.

Hinkin, T. R. (1998). A brief tutorial on the development of measures for use in survey questionnaires. Organizational Research Methods, 1(1), 104-121.

Hoelter, J. W. (1983). The analysis of covariance structures goodness-of-fit indices. Sociological Methods \& Research, 11(3), 325-344.

Hoffman, D. L., \& Novak, T. P. (1996). Marketing in hypermedia computer-mediated environments: Conceptual foundations. The Journal of Marketing, 60(3), 50-68.

Horn, J.L. (1965). A rational and test for the number of factors in factor analysis. Psychometrika, 30, 179-185.

Hornbæk, K. (2006). Current practice in measuring usability: Challenges to usability studies and research. International Journal of Human-Computer Studies, 64(2), 79-102.

Hu, L-T. \& Bentler, P.M., (1999). Cutoff criteria for fit indexes in covariance structure analysis: Conventional criteria versus new alternatives. Structural Equation Modeling, 6, 1-55. 
Hu, L. T., Bentler, P. M., \& Kano, Y. (1992). Can test statistics in covariance structure analysis be trusted? Psychological Bulletin, 112(2), 351-362.

Huang, M. H. (2003). Designing website attributes to induce experiential encounters. Computers in Human Behavior, 19(4), 425-442.

Hutcheson, G. D., \& Sofroniou, N. (1999). The multivariate social scientist. London, England: Sage.

International Game Developers Association (IGDA, 2004). Quality of life in the game industry: Challenges and best practices. Retrieved from http://c.ymcdn.com/sites/www.igda.org/resource/collection/9215B88F-2AA3-4471B44D-B5D58FF25DC7/2004_IGDA_QualityOfLife_WhitePaper.pdf

IJsselsteijn, W., de Kort, Y., Poels, K., Jurgelionis, A., \& Bellotti, F. (2007, June). Characterising and measuring user experiences in digital games. In International Conference on Advances in Computer Entertainment Technology (Vol. 2, pp. 27-31).

IJsselsteijn, W. A., Poels, K., \& de Kort, Y. A. W. (2008). Measuring player experiences in digital Games: Development of the Game Experience Questionnaire (GEQ). Manuscript in preparation.

ISO 9241 (1992). Ergonomic requirements for office work with visual display terminals (VDTs). Geneva, Switzerland: ISO/IEC.

ISO 9241 (2010). Ergonomics of human system interaction. Geneva, Switzerland: ISO/IEC.

ISO 9241-11 (1998). Ergonomic requirements for office work with visual display terminals (VDTs) - Part II guidance on usability. Geneva, Switzerland: ISO/IEC.

ISO/IEC 9126 (2001). Software product evaluation-Quality characteristics and guidelines for the user. Geneva, Switzerland: ISO/IEC.

ISO/IEC 25010 (2011). Systems and software engineering -- Systems and software quality requirements and evaluation (SQuaRE) -- System and software quality models. Geneva, Switzerland: ISO/IEC.

Jackson, L. A. (2012). The upside of videogame playing. Games for Health: Research, Development, and Clinical Applications, 1(6), 452-455.

Jennett, C., Cox, A. L., Cairns, P., Dhoparee, S., Epps, A., Tijs, T., \& Walton, A. (2008). Measuring and defining the experience of immersion in games. International Journal of HumanComputer Studies, 66(9), 641-661. 
Jensen, M. P. (2003). Questionnaire validation: A brief guide for readers of the research literature. The Clinical Journal of Pain, 19(6), 345-352.

Jones, M. G. (1998, February). Creating electronic learning environments: Games, flow, and the user interface. In Proceedings of Selected Research and Development Presentations at the National Convention of the Association for Educational Communications and Technology (AECT) (pp. 205-214). St. Louis, Missouri.

Jørgensen, A. H. (2004, October). Marrying HCl/Usability and computer games: A preliminary look. In Proceedings of the Third Nordic Conference on Human-Computer Interaction (pp. 393-396). ACM.

Kass, R. A., \& Tinsley, H. E. A. (1979). Factor analysis. Journal of Leisure Research, 11, 120-138.

Kenny, D. A (2014, October 6). Measuring model fit. Retrieved from http://davidakenny.net/cm/fit.htm

Kline, R. B. (2005). Principles and practice of structural equations modeling (2nd ed.). New York, NY: The Guilford Press.

Korhonen, H. (2011, November). The explanatory power of playability heuristics. In Proceedings of the 8th International Conference on Advances in Computer Entertainment Technology (pp. 40-48). ACM.

Korhonen, H., \& Koivisto, E. M. (2006, September). Playability heuristics for mobile games. In Proceedings of the 8th Conference on Human-Computer Interaction with Mobile Devices and Services (pp. 9-16). ACM.

Korhonen, H., \& Koivisto, E. M. (2007, September). Playability heuristics for mobile multi-player games. In Proceedings of the 2nd International Conference on Digital Interactive Media in Entertainment and Arts (pp. 28-35). ACM.

Koufaris, M. (2002). Applying the technology acceptance model and flow theory to online consumer behavior. Information Systems Research, 13(2), 205-223.

Kremen, A. M., \& Block, J. (2002). Absorption: Construct explication by Q-sort assessments of personality. Journal of Research in Personality, 36(3), 252-259.

Krosnick, J. A. (1999). Survey research. Annual Review of Psychology, 50(1), 537-567.

Lafferty, J. (2013, December 9). Top 25 Facebook apps: December 2013 - King rules. Inside Facebook. Retrieved from http://www.insidefacebook.com/2013/12/09/top-25-facebook-apps-december-2013king-rules/ 
Laitinen, S. (2005, June 23). Better games through usability evaluation and testing. Gamasutra. Retrieved from http://www.gamasutra.com/view/feature/130745/

Latham, A. J., Patston, L. L., \& Tippett, L. J. (2013). The virtual brain: 30 years of video-game play and cognitive abilities. Frontiers in Psychology, 4.

Lewis, J. R. (1982, October). Testing small system customer set-up. In Proceedings of the Human Factors and Ergonomics Society Annual Meeting (Vol. 26, No. 8, pp. 718-720). SAGE Publications.

Lewis, J. R. (1995). IBM computer usability satisfaction questionnaires: Psychometric evaluation and instructions for use. International Journal of Human-Computer Interaction, 7(1), 57-78.

Li, R., Polat, U., Makous, W., \& Bavelier, D. (2009). Enhancing the contrast sensitivity function through action video game training. Nature Neuroscience, 12(5), 549-551.

Li, R. W., Ngo, C., Nguyen, J., \& Levi, D. M. (2011). Video-game play induces plasticity in the visual system of adults with amblyopia. PLoS Biology, 9(8), 1-11.

Lietz, P. (2008) Questionnaire design in attitude and opinion research: Current state of an art. Technical report number: FOR 655, Jacobs University Bremen.

Lombard, M. \& Ditton, T. (1997). At the heart of it all: The concept of presence. Journal of Computer-Mediated Communication, 3(2). Retrieved from http://onlinelibrary.wiley.com/doi/10.1111/j.1083-6101.1997.tb00072.x/full

MacCallum, R. C., Wildaman, K. F., Zhang, S., \& Hong, S. (1999). Sample size in factor analysis. Psychological Methods, 4(1), 84-89.

Malone, T. W. (1982, March). Heuristics for designing enjoyable user interfaces: Lessons from computer games. In Proceedings of the 1982 Conference on Human Factors in Computing Systems (pp. 63-68). ACM.

Malhotra, N. K. (2006). Questionnaire design and scale development. In R. Grover \& M. Vriens (Eds.), The handbook of marketing research uses misuses and future advances (pp. 8394). Thousand Oaks, CA: Sage Publications.

Malgady, R. G. (2007). How skewed are psychological data? A standardized index of effect size. The Journal of General Psychology, 134(3), 355-359.

Matsunaga, M. (2010). How to factor-analyze your data right: Do's, don'ts, and howto's. International Journal of Psychological Research, 3(1), 97-110. 
Mayes, D. K., \& Cotton, J. E. (2001, October). Measuring engagement in video games: A questionnaire. In Proceedings of the Human Factors and Ergonomics Society Annual Meeting (Vol. 45, No. 7, pp. 692-696). SAGE Publications.

McAllister, G., \& White, G. R. (2010). Video game development and user experience. In R. Bernhaupt (Ed.), Evaluating user experience in games (pp. 107-128). New York, NY: Springer.

McMahan, A. (2003). Immersion, engagement and presence: A method for analyzing 3-D video games. In M. Wolf \& B. Perron (Eds.), The video game theory reader (pp. 67-86). New York: Routledge.

Microsoft (2013). Studios User Research. Retrieved from http://mgsuserresearch.com/bio.html

MobyGames (2015). MobyStats. Retrieved from http://www.mobygames.com/moby_stats

Moreno-Ger, P., Torrente, J., Hsieh, Y. G., \& Lester, W. T. (2012). Usability testing for serious games: Making informed design decisions with user data. Advances in Human-Computer Interaction, 2012, 1-13.

Musil, C. M., Warner, C. B., Yobas, P. K., \& Jones, S. L. (2002). A comparison of imputation techniques for handling missing data. Western Journal of Nursing Research, 24(7), 815-829.

Muthén, B., \& Kaplan, D. (1985). A comparison of some methodologies for the factor analysis of non-normal Likert variables. British Journal of Mathematical and Statistical Psychology, 38(2), 171-189.

Muthén, B., \& Kaplan, D. (1992). A comparison of some methodologies for the factor analysis of non-normal Likert variables: A note on the size of the model. British Journal of Mathematical and Statistical Psychology, 45(1), 19-30.

Nadon, R., Hoyt, I. P., Register, P. A., \& Kihlstrom, J. F. (1991). Absorption and hypnotizability: Context effects reexamined. Journal of Personality and Social Psychology, 60(1), 144.

Nakamura, J., \& Csikszentmihalyi, M. (2002). The concept of flow. In C. R. Snyder \& S. J. Lopez (Eds.), Handbook of positive psychology (pp. 89-105). New York, NY: Oxford University Press.

Newberry, R. (2013, September 3). Minecraft PC sales hit 12 million making it 33 million for the franchise - but it's a long way to the top. Pixel Enemy. Retrieved from http://pixelenemy.com/minecraft-pc-sales-hit-12-million-making-it-33-million-for-thefranchise-but-its-a-long-way-to-the-top/ 
Nielsen, J. (1994). Usability engineering. Cambridge, MA: Academic Press.

Nintendo (2011, June 1). Nintendo DS Lite suggested retail price drops to \$99.99 and Mario games go red. Retrieved from http://www.nintendo.com/whatsnew/detail/GpyiVGIEHeEsyyOhStzp4kEuzfnDTdFz

Norris, A. E., \& Aroian, K. J. (2004). To transform or not transform skewed data for psychometric analysis: That is the question! Nursing Research, 53(1), 67-71.

Nunnally, J. C (1978). Psychometric theory (2 ${ }^{\text {nd }}$ ed.). New York, NY: McGraw-Hill.

O'Brien, H. L., \& Toms, E. G. (2010). The development and evaluation of a survey to measure user engagement. Journal of the American Society for Information Science and Technology, 61(1), 50-69.

O'connor, B. P. (2000). SPSS and SAS programs for determining the number of components using parallel analysis and Velicer's MAP test. Behavior Research Methods, Instruments, \& Computers, 32(3), 396-402.

Omar, H., \& Jaafar, A. (2010, March). Heuristics evaluation in computer games. In International Conference on Information Retrieval \& Knowledge Management, (CAMP), (pp. 188-193). IEEE.

Oppenheim, A. N. (1992). Questionnaire design, interviewing and attitude measurement. New York, NY: Continuum International Publishing Group.

Paavilainen, J. (2010, May). Critical review on video game evaluation heuristics: Social games perspective. In Proceedings of the International Academic Conference on the Future of Game Design and Technology (pp. 56-65). ACM.

Pace, S. (2004). A grounded theory of the flow experiences of Web users. International Journal of Human-Computer Studies, 60(3), 327-363.

Pagulayan, R. J., Keeker, K., Wixon, D., Romero, R., \& Fuller, T. (2003). User-centered design in games. In J. Jacko \& A. Sears (Eds.), Handbook for human-computer interaction in interactive systems (pp. 883-906). Mahwah, NJ: Lawrence Erlbaum Associates, Inc.

Pagulayan, R. J., Steury, K. R., Fulton, B., \& Romero, R. L. (2005). Designing for fun: User-testing case studies. In M. A. Blythe, K. Overbeeke, A. F. Monk, \& P. C. Wright (Eds.), Funology: From usability to enjoyment (pp. 137-150). Boston, MA: Kluwer Academic Publishers.

Papaloukas, S., Patriarcheas, K., \& Xenos, M. (2009, September). Usability assessment heuristics in new genre videogames. In Proceedings of the 2009 13th Panhellenic Conference on Informatics (pp. 202-206). IEEE. 
Parnell, M. J. (2009). Playing with scales: Creating a measurement scale to assess the experience of video games. (Master's thesis). Available from http://www.ucl.ac.uk/uclic/

Pavlas, D., Jentsch, F., Salas, E., Fiore, S. M., \& Sims, V. (2012). The Play Experience Scale Development and Validation of a Measure of Play. Human Factors: The Journal of the Human Factors and Ergonomics Society, 54(2), 214-225.

Peng, C.-Y. J., Harwell, M., Liou, S.-M., \& Ehman, L. H. (2006). Advances in missing data methods and implications for educational research. In S. Sawilowsky (Ed.), Real data analysis (pp. 31-78). Greenwich, CT: Information Age.

Pinelle, D., Wong, N., \& Stach, T. (2008, April). Heuristic evaluation for games: Usability principles for video game design. In Proceedings of the SIGCHI Conference on Human Factors in Computing Systems (pp. 1453-1462). ACM.

Pinelle, D., Wong, N., Stach, T., \& Gutwin, C. (2009, May). Usability heuristics for networked multiplayer games. In Proceedings of the ACM 2009 International Conference on Supporting Group Work (pp. 169-178). ACM.

Preston, C. C., \& Colman, A. M. (2000). Optimal number of response categories in rating scales: Reliability, validity, discriminating power, and respondent preferences. Acta Psychologica, 104(1), 1-15.

Qin, H., Rau, P.-L. P., \& Salvendy, G. (2009). Measuring player immersion in the computer game narrative. International Journal of Human-Computer Interaction, 25(2), 107-133.

Rajanen, M., \& Marghescu, D. (2006). The impact of game usability to player attitude. In Proceedings of 29th Information Systems Research Seminar in Scandinavia (IRIS 29), (pp. 1-17). Helsingoer, Denmark.

Reilly, L. (2012, September 9). 5 reasons video games are actually good for you. IGN. Retrieved from http://www.ign.com/articles/2012/09/10/5-reasons-video-games-are-actuallygood-for-you

Roche, S. M., \& McConkey, K. M. (1990). Absorption: Nature, assessment, and correlates. Journal of Personality and Social Psychology, 59, 91-101.

Rodio, F., \& Bastien, J. C. (2013, September). Heuristics for Video Games Evaluation: How Players Rate Their Relevance for Different Game Genres According to Their Experience. In Proceedings of the 25 lème Conférence Francophone on I'Interaction HommeMachine, IHM'13.

Roth, P. L. (1994). Missing data: A conceptual review for applied psychologists. Personnel Psychology, 47(3), 537-560. 
Russell, D. W. (2002). In search of underlying dimensions: The use (and abuse) of factor analysis in Personality and Social Psychology Bulletin. Personality and Social Psychology Bulletin, 28(12), 1629-1646.

Ryan, R. M., Rigby, C. S., \& Przybylski, A. (2006). The motivational pull of video games: A selfdetermination theory approach. Motivation and Emotion, 30(4), 344-360.

Sánchez, J. L. G., Vela, F. L. G., Simarro, F. M., \& Padilla-Zea, N. (2012). Playability: Analysing user experience in video games. Behaviour \& Information Technology, 31(10), 10331054.

Sauro, J. (2010, August 25). Should you use 5 or 7 Point scales? Measuring Usability. Retrieved from http://www.measuringusability.com/blog/scale-points.php

Sauro, J. (2013, February 11). A brief history of usability. Measuring Usability. Retrieved from http://www.measuringu.com/blog/usability-history.php

Sauro, J., \& Lewis, J. R. (2011, May). When designing usability questionnaires, does it hurt to be positive? In Proceedings of the SIGCHI Conference on Human Factors in Computing Systems (pp. 2215-2224). ACM.

Schafer, J. L. (1999). Multiple imputation: A primer. Statistical Methods in Medical Research, 8(1), 3-15.

Schafer, J. L., \& Graham, J. W. (2002). Missing data: Our view of the state of the art. Psychological Methods, 7(2), 147-177.

Schaufeli, W. B., \& Bakker, A. B. (2004). Job demands, job resources, and their relationship with burnout and engagement: A multi-sample study. Journal of Organizational Behavior, 25(3), 293-315.

Schlomer, G. L., Bauman, S., \& Card, N. A. (2010). Best practices for missing data management in counseling psychology. Journal of Counseling Psychology, 57(1), 1-10.

Shapiro, J. (2013, November 27). 4 reasons video games are good for your health (according to American Psychological Association). Forbes. Retrieved from http://www.forbes.com/sites/jordanshapiro/2013/11/27/4-reasons-video-games-aregood-for-your-health-according-to-american-psychological-association/

Sherry, J. L. (2004). Flow and media enjoyment. Communication Theory, 14(4), 328-347.

Sinclair, B. (2010, February 4). The Sims turns 10, tops 125 million units. GameSpot. Retrieved from http://www.gamespot.com/articles/the-sims-turns-10-tops125-million-units/1100-6249485/ 
Schell, J. (2008). The art of game design: A book of lenses. Burlington, MA: Morgan Kaufmann Publishers.

Shelley, B. (2001, August 15). Guidelines for developing successful games. Gamasutra. Retrieved from http://www.gamasutra.com/view/feature/131450/

Slater, M. (1999). Measuring presence: A response to the Witmer and Singer presence questionnaire. Presence: Teleoperators and Virtual Environments, 8(5), 560-565.

Slater, M., \& Steed, A. (2000). A virtual presence counter. Presence, 9(5), 413-434.

Slater, M., Usoh, M., \& Steed, A. (1994). Depth of presence in virtual environments. Presence, $3(2), 130-144$.

Song, S., Lee, J., \& Hwang, I. (2007). A new framework of usability evaluation for massively multi-player online game: Case study of "World of Warcraft" game. In Human-Computer Interaction. $\mathrm{HCl}$ Applications and Services (pp. 341-350). Springer Berlin Heidelberg.

Spence, I., \& Feng, J. (2010). Video games and spatial cognition. Review of General Psychology, 14, 92-104.

Square Enix (2013, March 31). Businesses. Retrieved from http://www.hd.squareenix.com/eng/group/index.html\#game1

Stafford, S., Preisz, E., \& Greenwood-Ericksen, A. (2010, September 10). Usability breakthroughs: Four techniques to improve your game. Gamasutra. Retrieved from http://www.gamasutra.com/view/feature/134501/

Steiger, J. H., \& Lind, J. C. (1980, June). Statistically based tests for the number of common factors. Paper presented at the Psychometric Society annual meeting, lowa City, IA.

Sweetser, P., Johnson, D. M., \& Wyeth, P. (2012). Revisiting the GameFlow model with detailed heuristics. Journal: Creative Technologies, 2012(3).

Sweetser, P., \& Wyeth, P. (2005). GameFlow: A model for evaluating player enjoyment in games. Computers in Entertainment (CIE), 3(3), 1-24.

Tabachnick, B. G., \& Fidell, L. S. (2007). Using multivariate statistics (5 $5^{\text {th }}$ ed.). Boston, MA: Pearson.

Takatalo, J., Häkkinen, J., Komulainen, J., Särkelä, H., \& Nyman, G. (2006, October). Involvement and presence in digital gaming. In Proceedings of the 4th Nordic Conference on HumanComputer Interaction: Changing Roles (pp. 393-396). ACM. 
Tan, J. L., Goh, D. H. L., Ang, R. P., \& Huan, V. S. (2010, October). Usability and playability heuristics for evaluation of an instructional game. In World Conference on E-Learning in Corporate, Government, Healthcare, and Higher Education (Vol. 2010, No. 1, pp. 363373).

Taylor, L. N. (2002). Video games: Perspective, point-of-view, and immersion. (Master's thesis). Available from http://www.laurientaylor.org/research/taylor_l.pdf

TEDxTalks. (2012, November). Daphne Bavelier: Your brain on video games [Video file]. Retrieved from http://www.ted.com/talks/daphne_bavelier_your_brain_on_video_games.html

Tejeiro Salguero, R. A., \& Morán, R. M. B. (2002). Measuring problem video game playing in adolescents. Addiction, 97(12), 1601-1606.

Tellegen, A., \& Atkinson, G. (1974). Openness to absorbing and self-altering experiences ("absorption"), a trait related to hypnotic susceptibility. Journal of Abnormal Psychology, 83, 268-277.

Totilo, S. (2012, July 9). The difference between a good video game and a bad one. Kotaku. Retrieved from http://kotaku.com/5924387/the-difference-between-a-good-videogame-and-a-bad-one

Treiblmaier, H., \& Filzmoser, P. (2010). Exploratory factor analysis revisited: How robust methods support the detection of hidden multivariate data structures in IS research. Information \& Management, 47(4), 197-207.

Tsikriktsis, N. (2005). A review of techniques for treating missing data in OM survey research. Journal of Operations Management, 24(1), 53-62.

Vagias, W. M. (2006). Likert-type scale response anchors. Clemson International Institute for Tourism \& Research Development, Department of Parks, Recreation and Tourism Management. Clemson University.

Vandewater, E. A., Shim, M. S., \& Caplovitz, A. G. (2004). Linking obesity and activity level with children's television and video game use. Journal of Adolescence, 27(1), 71-85.

Virzi, R. A. (1990, October). Streamlining the design process: Running fewer subjects. In Proceedings of the Human Factors and Ergonomics Society Annual Meeting (Vol. 34, No. 4, pp. 291-294). SAGE Publications.

Virzi, R. A. (1992). Refining the test phase of usability evaluation: how many subjects is enough? Human Factors: The Journal of the Human Factors and Ergonomics Society, 34(4), 457-468. 
Wang, L., Fan, X., \& Willson, V. L. (1996). Effects of nonnormal data on parameter estimates and fit indices for a model with latent and manifest variables: An empirical study. Structural Equation Modeling: A Multidisciplinary Journal, 3(3), 228-247.

Webster, J., \& Ho, H. (1997). Audience engagement in multimedia presentations. ACM SIGMIS Database, 28(2), 63-77.

Webster, J., Trevino, L. K., \& Ryan, L. (1993). The dimensionality and correlates of flow in human-computer interactions. Computers in Human Behavior, 9(4), 411-426.

Weibel, D., Wissmath, B., Habegger, S., Steiner, Y., \& Groner, R. (2008). Playing online games against computer-vs. human-controlled opponents: Effects on presence, flow, and enjoyment. Computers in Human Behavior, 24(5), 2274-2291.

White, G. R., Mirza-Babaei, P., McAllister, G., \& Good, J. (2011, May). Weak inter-rater reliability in heuristic evaluation of video games. In CHI'11 Extended Abstracts on Human Factors in Computing Systems (pp. 1441-1446). ACM.

Wickens, C. D., Lee, J. D., Liu, Y., \& Gordon-Becker, S. (2003). Introduction to Human Factors Engineering ( $2^{\text {nd }}$ ed.). Newark, NJ: Prentice Hall.

Wiebe, E. N., Lamb, A., Hardy, M., \& Sharek, D. (2014). Measuring engagement in video gamebased environments: Investigation of the User Engagement Scale. Computers in Human Behavior, 32, 123-132.

Wirth, W., Hartmann, T., Böcking, S., Vorderer, P., Klimmt, C., Schramm, H., ... \& Jäncke, P. (2007). A process model of the formation of spatial presence experiences. Media Psychology, 9(3), 493-525.

Witmer, B. G., \& Singer, M. J. (1998). Measuring presence in virtual environments: A presence questionnaire. Presence: Teleoperators and Virtual Environments, 7(3), 225-240.

Wixom, B. H., \& Todd, P. A. (2005). A theoretical integration of user satisfaction and technology acceptance. Information Systems Research, 16(1), 85-102.

Worthington, R. L., \& Whittaker, T. A. (2006). Scale development research a content analysis and recommendations for best practices. The Counseling Psychologist, 34(6), 806-838.

Young, T. T. (2011). A usability analysis of video games: The development of assessment standards (Master's thesis). Available from TheQuantumQuill.com.

Yee, N. (2006). Motivations for play in online games. CyberPsychology \& Behavior, 9(6), 772775. 
Yuji, H. (1996). Computer games and information-processing skills. Perceptual \& Motor Skills, 83, 643-647.

Zahorik, P., \& Jenison, R. (1998). Presence as being-in-the-world. Presence, 7(1), 78-89.

Zygmon, C., \& Smith, M. R. (2014). Robust factor analysis in the presence of normality violations, missing data, and outliers: Empirical questions and possible solutions. The Quantitative Methods for Psychology, 10(1), 40-55. 
APPENDICES 


\section{APPENDIX A}

STRENGTHS AND WEAKNESSES OF EXISTING GAMING SCALES

\begin{tabular}{|c|c|c|c|c|}
\hline $\begin{array}{l}\text { Scale/Questionnaire } \\
\text { Name }\end{array}$ & $\begin{array}{c}\text { Number } \\
\text { of } \\
\text { Items }\end{array}$ & $\begin{array}{c}\text { Number } \\
\text { of } \\
\text { Subscales }\end{array}$ & Strengths & Weaknesses \\
\hline $\begin{array}{l}\text { Core Elements of the } \\
\text { Gaming Experience } \\
\text { Questionnaire } \\
\text { (CEGEQ) by Calvillo- } \\
\text { Gámez et al. (2010) }\end{array}$ & 38 & 5 & $\begin{array}{l}\text { The data of the framework were } \\
\text { mostly derived from } 80+\text { reviews and } \\
\text { 15+ interviews from two PC game } \\
\text { magazines, two console game } \\
\text { magazines, three game websites, and } \\
\text { five semi-structured interviews } \\
\text { CFA was used to validate the items } \\
\text { and the factors } \\
\text { Large sample ( } N=598 \text { ) was collected } \\
\text { for the CFA }\end{array}$ & $\begin{array}{l}\text { - EFA was not conducted prior to a } \\
\text { CFA } \\
\text { - Strictly focuses on the basic } \\
\text { elements of the gaming experience } \\
\text { - Questionnaire was developed for } \\
\text { the purpose of validating the CEGE } \\
\text { framework and not specifically for } \\
\text { game evaluation purposes }\end{array}$ \\
\hline $\begin{array}{l}\text { EGameFlow by Fu et } \\
\text { al. (2009) }\end{array}$ & 42 & 8 & $\begin{array}{l}\text { Comprehensively measures the level } \\
\text { of enjoyment in e-learning games } \\
\text { - Scale items are mostly based on an } \\
\text { existing set of game heuristics } \\
\text { - The scale development process } \\
\text { closely followed an established scale- } \\
\text { development theory }\end{array}$ & 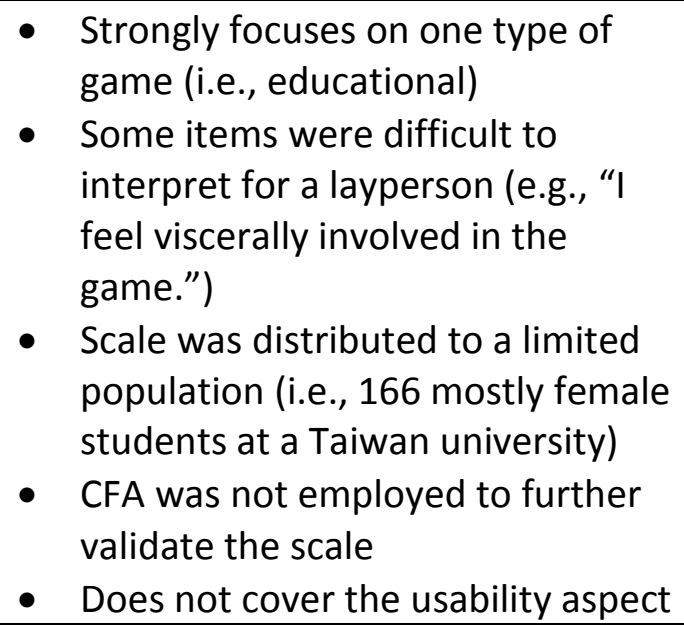 \\
\hline
\end{tabular}


APPENDIX A (continued)

STRENGTHS AND WEAKNESSES OF EXISTING GAMING SCALES

\begin{tabular}{|c|c|c|c|c|}
\hline $\begin{array}{l}\text { Scale/Questionnaire } \\
\text { Name }\end{array}$ & $\begin{array}{c}\text { Number } \\
\text { of } \\
\text { Items }\end{array}$ & $\begin{array}{c}\text { Number } \\
\text { of } \\
\text { Subscales }\end{array}$ & Strengths & Weaknesses \\
\hline $\begin{array}{l}\text { Flow Experience in } \\
\text { Computer Game Play } \\
\text { by Fang et al. (2013)* }\end{array}$ & 23 & 6 & $\begin{array}{l}\text { Based on strong theoretical } \\
\text { framework } \\
\text { - Measures all flow elements according } \\
\text { to the flow theory } \\
\text { - Scale development procedure was } \\
\text { based on an established card-sorting } \\
\text { procedure } \\
\text { - Factor analysis was conducted to } \\
\text { assess the scale construct validity with } \\
\text { adequate sample size }(N=260)\end{array}$ & $\begin{array}{l}\text { - Strongly focused on the flow } \\
\text { construct } \\
\text { - Sample size collected for factor } \\
\text { analysis was predominantly male } \\
\text { gamers ( } 82.6 \%) \\
\text { - No information was provided on } \\
\text { the type of game that was rated in } \\
\text { the study } \\
\text { - CFA was not employed to further } \\
\text { validate the scale } \\
\text { - Two of the factors have less than } 3 \\
\text { items per factor }\end{array}$ \\
\hline $\begin{array}{l}\text { Game Engagement } \\
\text { Questionnaire (GEQ) } \\
\text { by Brockmyer et al. } \\
\text { (2009) }\end{array}$ & 19 & $\mathrm{~N} / \mathrm{A}$ & $\begin{array}{l}\text { - Scale items are drawn from existing } \\
\text { literature regarding key factors in } \\
\text { game engagement } \\
\text { - Scale covers aspects of immersion, } \\
\text { presence, flow, psychological } \\
\text { absorption, and dissociation } \\
\text { - Scale was demonstrated to be a } \\
\text { psychometrically strong measure of } \\
\text { game engagement levels }\end{array}$ & $\begin{array}{l}\text { - Scale was designed to be used in } \\
\text { research to understand the } \\
\text { negative effects of violent video } \\
\text { games } \\
\text { - Scale only measures factors related } \\
\text { to game engagement } \\
\text { - Scale uses only three response } \\
\text { options (i.e., "Yes", "Maybe", "No") } \\
\text { - Scale were administered mostly to } \\
\text { middle school children and college- } \\
\text { aged, frequent male gamers }\end{array}$ \\
\hline
\end{tabular}


APPENDIX A (continued)

STRENGTHS AND WEAKNESSES OF EXISTING GAMING SCALES

\begin{tabular}{|c|c|c|c|c|}
\hline $\begin{array}{l}\text { Scale/Questionnaire } \\
\text { Name }\end{array}$ & $\begin{array}{c}\text { Number } \\
\text { of } \\
\text { Items }\end{array}$ & $\begin{array}{c}\text { Number } \\
\text { of } \\
\text { Subscales }\end{array}$ & Strengths & Weaknesses \\
\hline $\begin{array}{l}\text { Game Experience } \\
\text { Questionnaire (GEQ) } \\
\text { by IJsselsteijn et al. } \\
(2008)\end{array}$ & 33 & 7 & $\begin{array}{l}\text { Measures the gaming experience } \\
\text { through } 7 \text { dimensions (immersion, } \\
\text { tension, competence, flow, negative } \\
\text { affect, challenge, and positive affect) } \\
\text { - Available in Dutch, English, German, } \\
\text { Swedish, and Finnish } \\
\text { - Has been applied in a number of } \\
\text { research studies that investigate } \\
\text { implicit and objective measures of the } \\
\text { gaming experience }\end{array}$ & $\begin{array}{l}\text { - } \quad \text { Does not cover the usability aspect } \\
\text { - Some items are too generic, and } \\
\text { thus, difficult to interpret (e.g., "It } \\
\text { felt like a rich experience." and "I } \\
\text { found it impressive.") } \\
\text { - Has not been officially published in a } \\
\text { journal, and thus, little is known } \\
\text { behind the methodology used to } \\
\text { derive and validate the } \\
\text { questionnaire }\end{array}$ \\
\hline $\begin{array}{l}\text { Gameplay Scale by } \\
\text { Parnell (2009) }\end{array}$ & 26 & 4 & $\begin{array}{l}\text { - Measures game's initial } \\
\text { appeal/quality } \\
\text { Best practices of scale design were } \\
\text { taken into considerations during the } \\
\text { scale development } \\
\text { - Scale was shown to has some } \\
\text { predictive power in differentiating } \\
\text { between below- and above-average } \\
\text { review scores (metascores) }\end{array}$ & $\begin{array}{l}\text { - Cluster analysis was performed on a } \\
\text { small, restricted sample size (i.e., } 94 \\
\text { participants which mostly consisted } \\
\text { of young male, "core" gamers) } \\
\text { - Scale focuses on the first 1-2 hours } \\
\text { of play } \\
\text { - Results were limited to a small set of } \\
\text { games (i.e., PixelJunk Eden, } \\
\text { Prototype, Hulk) }\end{array}$ \\
\hline
\end{tabular}


APPENDIX A (continued)

STRENGTHS AND WEAKNESSES OF EXISTING GAMING SCALES

\begin{tabular}{|c|c|c|c|c|}
\hline $\begin{array}{l}\text { Scale/Questionnaire } \\
\text { Name }\end{array}$ & $\begin{array}{c}\text { Number } \\
\text { of } \\
\text { Items }\end{array}$ & $\begin{array}{c}\text { Number } \\
\text { of } \\
\text { Subscales }\end{array}$ & Strengths & Weaknesses \\
\hline $\begin{array}{l}\text { Gameplay Experience } \\
\text { Questionnaire by } \\
\text { Ermi \& Mäyrä (2005) }\end{array}$ & 18 & 3 & $\begin{array}{l}\text { - Measures the three key dimensions of } \\
\text { immersion that contribute to the } \\
\text { gameplay experience } \\
\text { - Games chosen in the evaluation of } \\
\text { the questionnaire covered multiple } \\
\text { genres (e.g., FPS, Sports, Simulation) } \\
\text { - EFA was used to reduce the number } \\
\text { of items on the questionnaire }\end{array}$ & $\begin{array}{l}\text { - The questionnaire was primarily } \\
\text { designed to validate the SCI model } \\
\text { - Questionnaire respondents were } \\
\text { mostly young Finnish males } \\
\text { - Some items on the questionnaire } \\
\text { did not translate well from Finnish } \\
\text { to English (e.g., "I handled also my } \\
\text { own emotions through the game.") } \\
\text { CFA was not employed to further } \\
\text { validate the scale }\end{array}$ \\
\hline $\begin{array}{l}\text { Gaming Engagement } \\
\text { Questionnaire (GEQ) } \\
\text { by Chen et al. (2005) }\end{array}$ & 25 & $\mathrm{~N} / \mathrm{A}$ & $\begin{array}{l}\text { - Measures the player's level of } \\
\text { involvement in a game in relation to } \\
\text { the flow construct }\end{array}$ & $\begin{array}{l}\text { - Little is known about the scale } \\
\text { development methodology since } \\
\text { the scale is not officially published } \\
\text { - Items on the scale are mostly aimed } \\
\text { - } \quad \text { at measuring a flow-like state } \\
\text { - Scale has not been validated }\end{array}$ \\
\hline
\end{tabular}


APPENDIX A (continued)

STRENGTHS AND WEAKNESSES OF EXISTING GAMING SCALES

\begin{tabular}{|c|c|c|c|c|}
\hline $\begin{array}{l}\text { Scale/Questionnaire } \\
\text { Name }\end{array}$ & $\begin{array}{c}\text { Number } \\
\text { of } \\
\text { Items }\end{array}$ & $\begin{array}{c}\text { Number } \\
\text { of } \\
\text { Subscales }\end{array}$ & Strengths & Weaknesses \\
\hline $\begin{array}{l}\text { Immersion } \\
\text { Questionnaire by } \\
\text { Jennett et al. (2008) }\end{array}$ & 32 & 5 & $\begin{array}{l}\text { - Questionnaire items were based on } \\
\text { previous research findings relating to } \\
\text { flow, cognitive absorption, and } \\
\text { presence } \\
\text { - Questionnaire has been shown to } \\
\text { correlate with objective measures } \\
\text { (e.g., task completion time, and eye } \\
\text { movements) }\end{array}$ & $\begin{array}{l}\text { - Questionnaire mainly focuses on } \\
\text { important aspects relating to the } \\
\text { immersion construct } \\
\text { - The questionnaire was } \\
\text { administered to a limited } \\
\text { population (i.e., mostly male } \\
\text { gamers) } \\
\text { - Only Principal Components Analysis } \\
\text { (PCA) was conducted to validate } \\
\text { the scale } \\
\text { Details on how each item fit under } \\
\text { the five identified factors are not } \\
\text { formally published }\end{array}$ \\
\hline $\begin{array}{l}\text { Online Game } \\
\text { Experience } \\
\text { Questionnaire by } \\
\text { Choi \& Kim (2004)* }\end{array}$ & 20 & 4 & $\begin{array}{l}\text { - Measures the key factors influencing } \\
\text { - } \text { Qustomer loyalty for online games } \\
\text { large sample size }(N=1,993) \text { in Korea } \\
\text { - CFA was ran to validate the model } \\
\text { structure }\end{array}$ & $\begin{array}{l}\text { - Data collected from the } \\
\text { questionnaire was restricted to } 16 \\
\text { popular online games } \\
\text { - Some questionnaire items were } \\
\text { difficult to interpret } \\
\text { - Questionnaire was developed for } \\
\text { the purpose of validating the } \\
\text { researchers' theoretical model and } \\
\text { not for game evaluation purposes } \\
\text { - Lack of usability items } \\
\text { - No EFA was conducted prior to CFA }\end{array}$ \\
\hline
\end{tabular}


APPENDIX A (continued)

STRENGTHS AND WEAKNESSES OF EXISTING GAMING SCALES

\begin{tabular}{|c|c|c|c|c|}
\hline $\begin{array}{l}\text { Scale/Questionnaire } \\
\text { Name }\end{array}$ & $\begin{array}{c}\text { Number } \\
\text { of } \\
\text { Items }\end{array}$ & $\begin{array}{c}\text { Number } \\
\text { of } \\
\text { Subscales }\end{array}$ & Strengths & Weaknesses \\
\hline $\begin{array}{l}\text { Play Experience Scale } \\
\text { (PES) by Pavlas et al. } \\
(2012)\end{array}$ & 16 & 4 & $\begin{array}{l}\text { - Measures play experience in video } \\
\text { games } \\
\text { - Has a strong focus on motivational } \\
\text { factors that are largely not addressed } \\
\text { in other game scales/questionnaires } \\
\text { - Factor analyses were conducted to } \\
\text { refine and validate the scale in the } \\
\text { first validation study }\end{array}$ & $\begin{array}{l}\text { - Strongly focuses on flow and } \\
\text { motivational aspects } \\
\text { - Only four games were used during } \\
\text { the validation process (i.e., Tetris, } \\
\text { flOW, custom-designed letter } \\
\text { search task, InnerCell) } \\
\text { - Both validation studies employed a } \\
\text { small }(N=77) \text { to moderate sample } \\
(N=203) \text { size of young college } \\
\text { students }\end{array}$ \\
\hline $\begin{array}{l}\text { Player Experience of } \\
\text { Need Satisfaction } \\
\text { (PENS) by Ryan et al. } \\
\text { (2006) }\end{array}$ & 22 & 4 & $\begin{array}{l}\text { Measures motivation for computer } \\
\text { game play in relation to enjoyment } \\
\text { Based on existing theory of human } \\
\text { motivation (i.e., self-determination } \\
\text { theory) } \\
\text { - PENS model has been demonstrated } \\
\text { to predict fun, value, and sustained } \\
\text { engagement in some video games }\end{array}$ & $\begin{array}{l}\text { - Mostly focuses on motives for } \\
\text { game play in terms of competence, } \\
\text { autonomy, and relatedness factors } \\
\text { - Factor analysis was not employed } \\
\text { to validate the scale } \\
\text { - Proprietary information and cost } \\
\text { money to use for game companies }\end{array}$ \\
\hline
\end{tabular}


APPENDIX A (continued)

STRENGTHS AND WEAKNESSES OF EXISTING GAMING SCALES

\begin{tabular}{|c|c|c|c|c|}
\hline $\begin{array}{l}\text { Scale/Questionnaire } \\
\text { Name }\end{array}$ & $\begin{array}{c}\text { Number } \\
\text { of } \\
\text { Items } \\
\end{array}$ & $\begin{array}{c}\text { Number } \\
\text { of } \\
\text { Subscales }\end{array}$ & Strengths & Weaknesses \\
\hline $\begin{array}{l}\text { Player Immersion in } \\
\text { Computer Game } \\
\text { Narrative } \\
\text { Questionnaire by Qin } \\
\text { et al. (2009) }\end{array}$ & 27 & 7 & $\begin{array}{l}\text { - Measures the level of immersion in a } \\
\text { game story/narrative } \\
\text { EFA and CFA were performed to } \\
\text { validate the questionnaire } \\
\text { - The data used to validate the } \\
\text { questionnaire was drawn from a } \\
\text { moderate sample size ( } \mathrm{N}_{\mathrm{EFA}}=309 \text {; } \\
\mathrm{N}_{\mathrm{CFA}}=325 \text { ) }\end{array}$ & $\begin{array}{l}\text { - Data were mostly collected from } \\
\text { college-aged gamers who lived in } \\
\text { China } \\
\text { - Questionnaire focuses specifically } \\
\text { on game narrative in relation to } \\
\text { immersion } \\
\text { - Some items on the questionnaire } \\
\text { are difficult to interpret (e.g., "I am } \\
\text { familiar with the cultural } \\
\text { background.") }\end{array}$ \\
\hline $\begin{array}{l}\text { Social Presence in } \\
\text { Gaming } \\
\text { Questionnaire } \\
\text { (SPGQ) by de Kort et } \\
\text { al. (2007) }\end{array}$ & 21 & 3 & $\begin{array}{l}\text { - The only gaming questionnaire that } \\
\text { measures social presence } \\
\text { - Data collected in the process of } \\
\text { validating the questionnaire were } \\
\text { from a variety of game genres (e.g., } \\
\text { FPS, RPG, Action, Sports) } \\
\text { - EFA was used to determine the } \\
\text { number of subscales and items }\end{array}$ & $\begin{array}{l}\text { - } \quad \text { Only measures one aspect of } \\
\text { - } \quad \text { Questionning (i.e., social presence) } \\
\text { mostly young male gamers } \\
\text { - Many of the items on the } \\
\text { questionnaire were difficult to be } \\
\text { used in game evaluations (e.g., "I } \\
\text { felt malicious delight.") } \\
\text { - CFA was not employed to further } \\
\text { validate the scale }\end{array}$ \\
\hline
\end{tabular}


APPENDIX A (continued)

STRENGTHS AND WEAKNESSES OF EXISTING GAMING SCALES

\begin{tabular}{|c|c|c|c|c|}
\hline $\begin{array}{l}\text { Scale/Questionnaire } \\
\text { Name }\end{array}$ & $\begin{array}{c}\text { Number } \\
\text { of } \\
\text { Items }\end{array}$ & $\begin{array}{c}\text { Number } \\
\text { of } \\
\text { Subscales }\end{array}$ & Strengths & Weaknesses \\
\hline $\begin{array}{l}\text { Revised User } \\
\text { Engagement Scale } \\
\text { (UESz) by Wiebe et } \\
\text { al. (2014) }\end{array}$ & 28 & 4 & $\begin{array}{l}\text { The scale was a revised version of an } \\
\text { established scale redesigned } \\
\text { specifically for video game-based } \\
\text { environments } \\
\text { - } \text { EFA was conducted on a large sample } \\
\text { size }(N=413) \\
\text { - The revised scale was more predictive } \\
\text { of game performance than the Flow } \\
\text { State Scale }\end{array}$ & $\begin{array}{l}\text { - Only one game was evaluated for } \\
\text { the EFA (i.e., Block Walk) } \\
\text { - The game under evaluation was } \\
\text { played for a short duration (i.e., } \\
\text { from } 10-90 \text { minutes) on a website } \\
\text { - Many of the items on the scale } \\
\text { referred to a specific website which } \\
\text { contain the game instead of the } \\
\text { game itself } \\
\text { - The scale did not contain other } \\
\text { important gaming aspects (e.g., } \\
\text { narratives, social interaction) }\end{array}$ \\
\hline
\end{tabular}

*The questionnaire was not formally named. Thus, for the sake of identification a generic name was chosen.

Note: Typically, the number of factors identified in a scale/questionnaire after the validation process will be considered as the number of subscales. "N/A" will be used in cases where little information is known about the key factors measured by a scale/questionnaire or due to the author(s) not clearly indicating that the scale/questionnaire contains subscales. 
CHEN AND COLLEAGUES' (2011) PARADIGM OF ENGAGEMENT

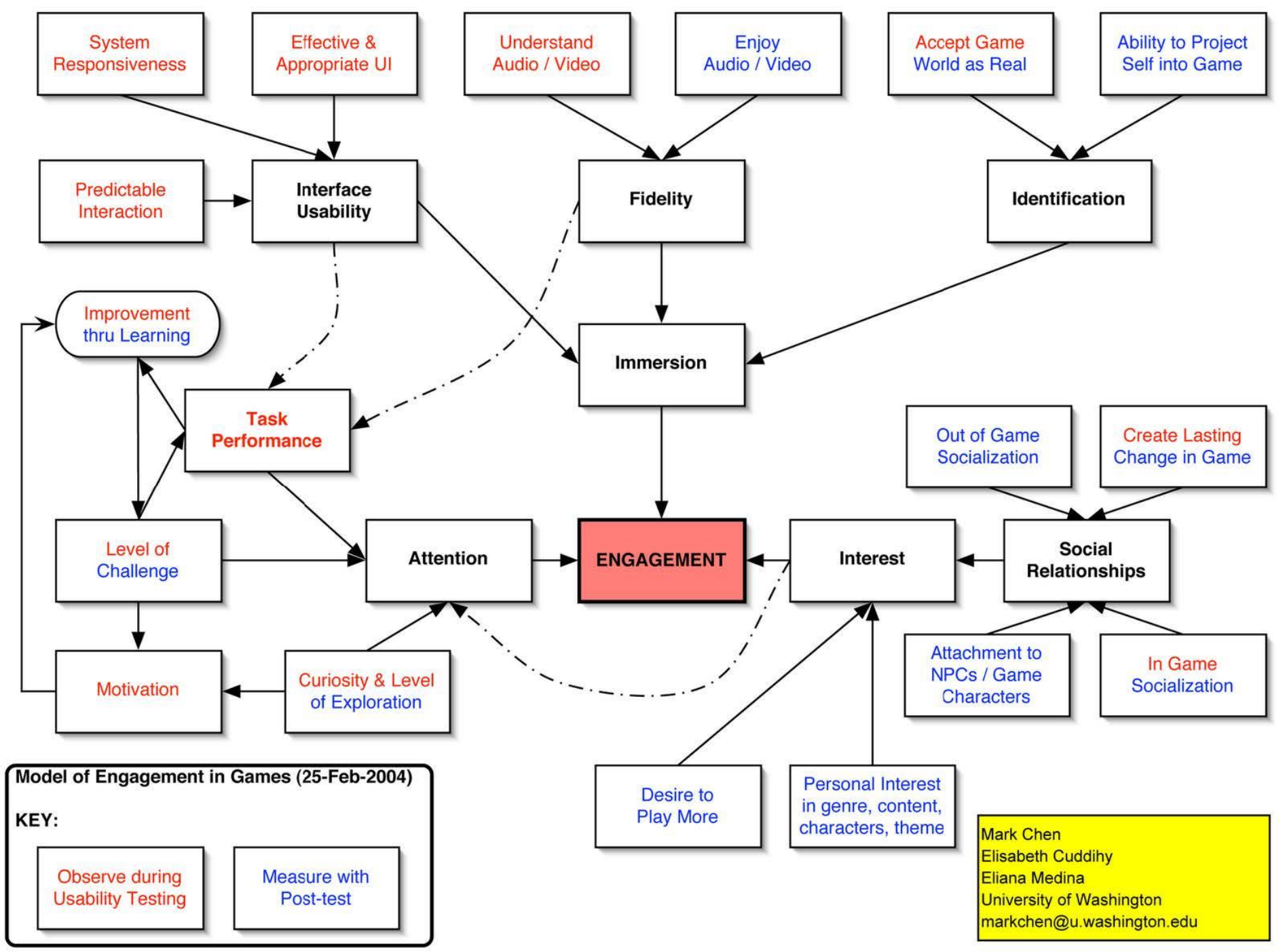


APPENDIX C

ERMI AND MÄYRÄ (2005) SCI PARADIGM

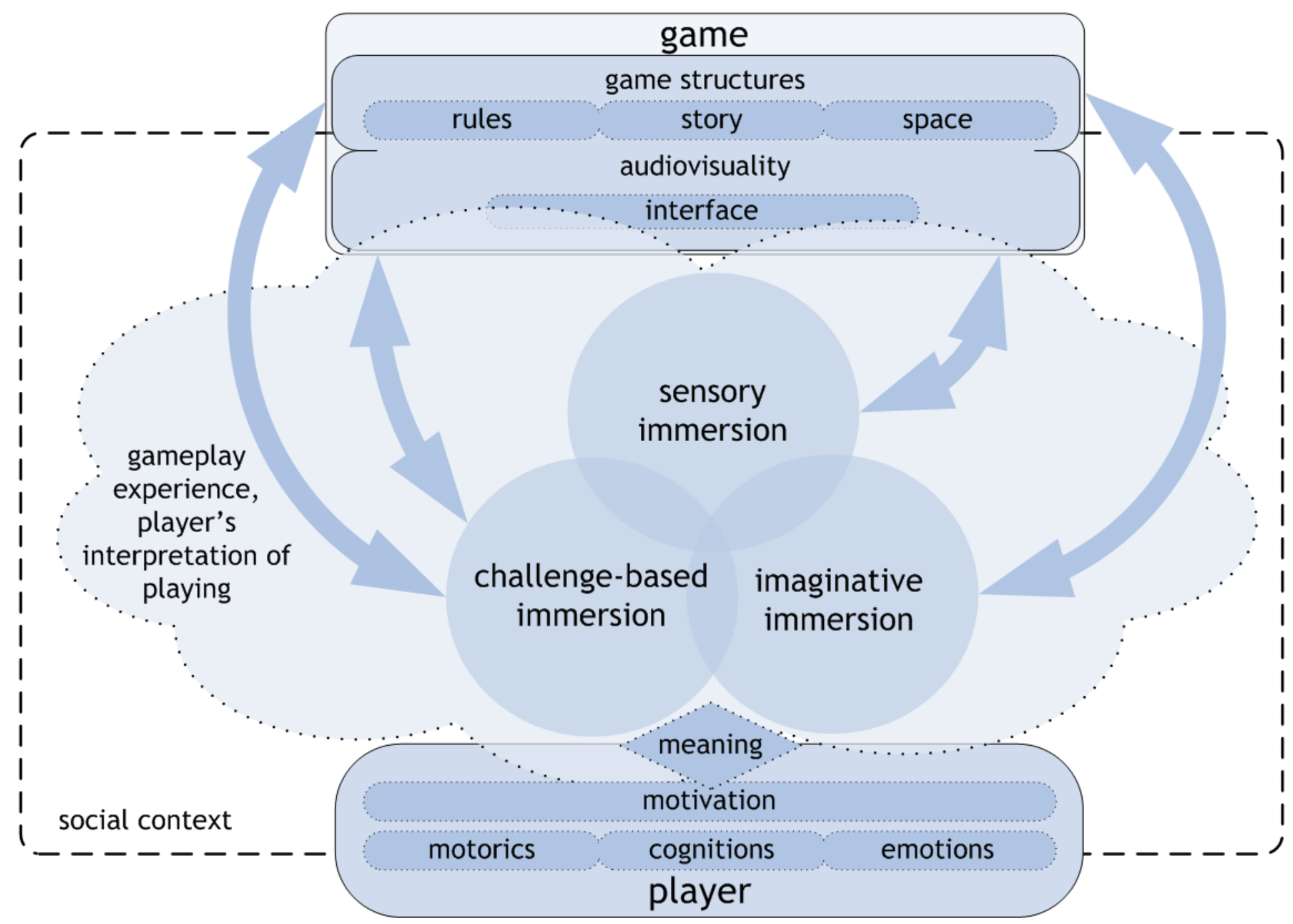


APPENDIX D

EXISTING QUESTIONNAIRES' KEY DIMENSIONS

\begin{tabular}{|c|c|c|c|}
\hline Source & Target Measure & Dimension & Description \\
\hline \multirow{5}{*}{$\begin{array}{l}\text { Agarwal \& Karahanna } \\
\text { (2000) - Cognitive } \\
\text { Absorption Scale }\end{array}$} & $\begin{array}{l}\text { Cognitive } \\
\text { Absorption }\end{array}$ & $\begin{array}{r}\text { Temporal } \\
\text { Dissociation }\end{array}$ & $\begin{array}{l}\text { The inability to judge how much time has passed as a result of the } \\
\text { interaction with the software. }\end{array}$ \\
\hline & & $\begin{array}{r}\text { Focused } \\
\text { Immersion }\end{array}$ & $\begin{array}{l}\text { The ability to solely focus one's attention toward the software in } \\
\text { spite of distractions. }\end{array}$ \\
\hline & & $\begin{array}{r}\text { Heightened } \\
\text { Enjoyment }\end{array}$ & The general pleasurable aspects of interacting with the software. \\
\hline & & Control & $\begin{array}{l}\text { The sense of control the user perceived to have over his/her } \\
\text { interaction with the software. }\end{array}$ \\
\hline & & Curiosity & $\begin{array}{l}\text { The degree to which interacting with the software stimulates } \\
\text { cognitive curiosity. }\end{array}$ \\
\hline $\begin{array}{l}\text { Brockmyer et al. } \\
(2009)-\text { GEQ }\end{array}$ & Engagement & $\mathrm{N} / \mathrm{A}$ & $\begin{array}{l}\text { The player's level of involvement in a game which include } \\
\text { immersion, presence, flow, psychological absorption, and } \\
\text { dissociation properties. }\end{array}$ \\
\hline
\end{tabular}


APPENDIX D (continued)

\section{EXISTING QUESTIONNAIRES' KEY DIMENSIONS}

\begin{tabular}{|c|c|c|c|}
\hline Source & Target Measure & Dimension & Description \\
\hline \multirow[t]{5}{*}{$\begin{array}{l}\text { Calvillo-Gámez et al. } \\
\text { (2010)-CEGEQ }\end{array}$} & $\begin{array}{l}\text { Core Gaming } \\
\text { Experience }\end{array}$ & Control & $\begin{array}{l}\text { Part of the game core called "Puppetry", it involves the player } \\
\text { obtaining knowledge and resources from a game in order to } \\
\text { manipulate it. The process of acquiring game control is comprised } \\
\text { of six elements: small actions, controllers, memory, point-of-view, } \\
\text { goal, and something-to-do. }\end{array}$ \\
\hline & & Ownership & $\begin{array}{l}\text { Part of the game core called "Puppetry", it concerns the player } \\
\text { accepting responsibility for his actions in the game. The process of } \\
\text { gaining ownership is influenced by four elements: big actions, } \\
\text { personal goals, you-but-not-you, and rewards. }\end{array}$ \\
\hline & & Facilitators & $\begin{array}{l}\text { Part of the game core called "Puppetry", facilitators involves three } \\
\text { elements (i.e., time, aesthetic value, and previous experience) that } \\
\text { mediate between the levels of ownership and control. }\end{array}$ \\
\hline & & Game-Play & $\begin{array}{l}\text { Part of the game core called "Video-Game", it is deemed as the } \\
\text { "soul" of a game and consists of rules and scenarios within a game. }\end{array}$ \\
\hline & & Environment & $\begin{array}{l}\text { Part of the game core called "Video-Game", it is referred to as the } \\
\text { "body" of a game and consists of game graphics and sound. }\end{array}$ \\
\hline
\end{tabular}


APPENDIX D (continued)

\section{EXISTING QUESTIONNAIRES' KEY DIMENSIONS}

\begin{tabular}{|c|c|c|c|}
\hline Source & Target Measure & Dimension & Description \\
\hline $\begin{array}{l}\text { Chen et al. (2004) - } \\
\text { GEQ }\end{array}$ & Engagement & N/A & $\begin{array}{l}\text { The player's level of involvement in a game with a strong focus on } \\
\text { the flow properties. }\end{array}$ \\
\hline \multirow{4}{*}{$\begin{array}{l}\text { Choi \& Kim (2004) - } \\
\text { Online Game } \\
\text { Experience } \\
\text { Questionnaire* }\end{array}$} & \multirow[t]{4}{*}{$\begin{array}{l}\text { Optimal Gaming } \\
\text { Experience }\end{array}$} & $\begin{array}{l}\text { Customer } \\
\text { Loyalty }\end{array}$ & $\begin{array}{l}\text { The degree to which the player would return to play the same } \\
\text { game. }\end{array}$ \\
\hline & & Flow & $\begin{array}{l}\text { The different gaming aspects (e.g., fun, control, absorption) that } \\
\text { lead to an optimal level of the play experience. }\end{array}$ \\
\hline & & $\begin{array}{r}\text { Personal } \\
\text { Interaction }\end{array}$ & $\begin{array}{l}\text { Relates to the interaction between the player and the game, which } \\
\text { involves three elements: goal, operator, and feedback. }\end{array}$ \\
\hline & & $\begin{array}{r}\text { Social } \\
\text { Interaction }\end{array}$ & $\begin{array}{l}\text { Relates to the interaction among a group of players, which involves } \\
\text { two elements: communication place and communication tool. }\end{array}$ \\
\hline $\begin{array}{l}\text { Ermi \& Mäyrä (2005) } \\
\text { - Gameplay }\end{array}$ & Immersion & $\begin{array}{r}\text { Sensory } \\
\text { Immersion }\end{array}$ & $\begin{array}{l}\text { The degree to which the sound and visual in a game captured the } \\
\text { player's senses and attention. }\end{array}$ \\
\hline Experience & & Challenge-Based & The level of immersion that the player experienced in relation to \\
\hline Questionnaire & & Immersion & the player's skills and the challenges presented in a game. \\
\hline & & $\begin{array}{l}\text { Imaginative } \\
\text { Immersion }\end{array}$ & $\begin{array}{l}\text { The extent in which the player was emotionally involved in game } \\
\text { narrative and emotionally connected to the game characters. }\end{array}$ \\
\hline
\end{tabular}


APPENDIX D (continued)

\section{EXISTING QUESTIONNAIRES' KEY DIMENSIONS}

\begin{tabular}{|c|c|c|c|}
\hline Source & Target Measure & Dimension & Description \\
\hline \multirow[t]{8}{*}{$\begin{array}{l}\text { Fu et al. (2009)- } \\
\text { EGameFlow }\end{array}$} & \multirow[t]{8}{*}{ Enjoyment } & Concentration & $\begin{array}{l}\text { Different aspects of a game that can promote the player's being } \\
\text { fully concentrated on playing a game (e.g., non-distractive tasks, } \\
\text { low workload tasks). }\end{array}$ \\
\hline & & Goal Clarity & $\begin{array}{l}\text { Mainly involves overall and intermediate goals of a game being } \\
\text { clearly presented to the player. }\end{array}$ \\
\hline & & Feedback & $\begin{array}{l}\text { Involves adequate feedback being provided to the player related to } \\
\text { the progress, outcomes, actions, tasks, and events in a game. }\end{array}$ \\
\hline & & Challenge & $\begin{array}{l}\text { Concerns a balance in challenge level and skills being presented in } \\
\text { a game and that a game fully equipped the player with appropriate } \\
\text { skills and tools to conquer the challenges. }\end{array}$ \\
\hline & & Autonomy & The player's sense of ownership and control over a game. \\
\hline & & Immersion & $\begin{array}{l}\text { The level of involvement the player experienced while playing from } \\
\text { emotional connections to a lost sense of time and space. }\end{array}$ \\
\hline & & $\begin{array}{r}\text { Social } \\
\text { Interaction }\end{array}$ & $\begin{array}{l}\text { Mainly involves a game providing useful tools and resources to aid } \\
\text { social interactions and collaborations between players. }\end{array}$ \\
\hline & & $\begin{array}{l}\text { Knowledge } \\
\text { Improvement }\end{array}$ & $\begin{array}{l}\text { Relates to the knowledge being taught in a game, and how } \\
\text { conducive it is to the player's own learning. }\end{array}$ \\
\hline
\end{tabular}


APPENDIX D (continued)

\section{EXISTING QUESTIONNAIRES' KEY DIMENSIONS}

\begin{tabular}{|c|c|c|c|}
\hline Source & Target Measure & Dimension & Description \\
\hline \multirow[t]{7}{*}{$\begin{array}{l}\text { IJsselsteijn et al. } \\
\text { (2008- GEQ }\end{array}$} & Play Experience & Competence & $\begin{array}{l}\text { The player's sense of competency with the game he or she was } \\
\text { playing. }\end{array}$ \\
\hline & & Immersion & $\begin{array}{l}\text { Relating to the two aspects of immersion (i.e., sensory and } \\
\text { imaginative) in Ermi and Mäyrä's (2005) SCl-model of immersion, } \\
\text { which involve a game being able to bring the player a rich game } \\
\text { experience. }\end{array}$ \\
\hline & & Flow & The player's level of focus in a game when playing it. \\
\hline & & Tension & $\begin{array}{l}\text { The amount of annoyance the player experienced when playing a } \\
\text { game. }\end{array}$ \\
\hline & & Challenge & $\begin{array}{l}\text { Relating to the level of difficulty of a game and how much effort } \\
\text { the player put in a game. }\end{array}$ \\
\hline & & Negative Affect & $\begin{array}{l}\text { The player's negative feelings (e.g., boredom, tiredness) about the } \\
\text { game he or she was playing. }\end{array}$ \\
\hline & & Positive Affect & $\begin{array}{l}\text { The player's positive feelings (e.g., fun, enjoyment) about the game } \\
\text { he or she was playing. }\end{array}$ \\
\hline
\end{tabular}


APPENDIX D (continued)

\section{EXISTING QUESTIONNAIRES' KEY DIMENSIONS}

\begin{tabular}{|c|c|c|c|}
\hline Source & Target Measure & Dimension & Description \\
\hline $\begin{array}{l}\text { Jennett et al. (2008) } \\
\text { - Immersion } \\
\text { Questionnaire }\end{array}$ & Immersion & $\begin{array}{r}\text { Cognitive } \\
\text { Involvement } \\
\text { Real World } \\
\text { Dissociation } \\
\text { Challenge } \\
\text { Emotional } \\
\text { Involvement } \\
\text { Control }\end{array}$ & $\begin{array}{l}\text { Considered to be a personal factor, it mainly involves the level of } \\
\text { focus and attention the player invested in a game. } \\
\text { Considered to be a personal factor, it refers to the extent in which } \\
\text { the player experienced a separation between the game } \\
\text { environment and the real-world environment. } \\
\text { Considered to be a game factor, it relates to the level of difficulty } \\
\text { and the player's motivation and performance in a game. } \\
\text { Considered to be a personal and an influential factor in the player's } \\
\text { motivation to complete game-related tasks, it involves the } \\
\text { emotional degree to which the player invested in a game. } \\
\text { Considered to be a game factor, it mainly entails the player's sense } \\
\text { of control over a game. }\end{array}$ \\
\hline $\begin{array}{l}\text { Parnell (2009) - } \\
\text { Gameplay Scale }\end{array}$ & $\begin{array}{c}\text { Game } \\
\text { Quality/Appeal }\end{array}$ & $\begin{array}{r}\text { Affective } \\
\text { Experience } \\
\text { Focus } \\
\text { Playability } \\
\text { Barriers } \\
\text { Usability Barriers }\end{array}$ & $\begin{array}{l}\text { General feelings and attitudes toward a game that concern certain } \\
\text { game-related aspects such as aesthetics, enjoyment, and } \\
\text { incentives. } \\
\text { Mainly entails cognitive absorption and the involvement of } \\
\text { challenge, empathy, camera view, and game mechanics. } \\
\text { Game issues that mostly related to how a game operates } \\
\text { specifically in terms of objectives, rules, and navigation. } \\
\text { Game issues that mostly related to the user-friendliness of game } \\
\text { interface (e.g., menu, settings) and controls. }\end{array}$ \\
\hline
\end{tabular}


APPENDIX D (continued)

\section{EXISTING QUESTIONNAIRES' KEY DIMENSIONS}

\begin{tabular}{|c|c|c|c|}
\hline Source & Target Measure & Dimension & Description \\
\hline \multirow{4}{*}{$\begin{array}{l}\text { Pavlas et al. (2012) - } \\
\text { PES }\end{array}$} & Play Experience & Freedom & The player's perceived control over a game. \\
\hline & & No Extrinsic & $\begin{array}{l}\text { The degree to which the player experienced pressure to perform } \\
\text { well from external sources. }\end{array}$ \\
\hline & & Play-Direct & $\begin{array}{l}\text { The extent in which the player believed that he or she was } \\
\text { "playing" a game. }\end{array}$ \\
\hline & & Autotelic-Focus & $\begin{array}{l}\text { A combination of the player's own intrinsic motivation to engage in } \\
\text { a game and the player's state of focus while playing. }\end{array}$ \\
\hline \multirow{7}{*}{$\begin{array}{l}\text { Qin et al. (2009) - } \\
\text { Player Immersion in } \\
\text { Computer Game } \\
\text { Narrative } \\
\text { Questionnaire }\end{array}$} & $\begin{array}{l}\text { Narrative } \\
\text { Immersion }\end{array}$ & Curiosity & $\begin{array}{l}\text { Concerning the sense to explore a game in relation to the degree to } \\
\text { which the player is intrigued by game narrative. }\end{array}$ \\
\hline & & Comprehension & $\begin{array}{l}\text { The ability to understand the storyline of a game, story structure, } \\
\text { and content. }\end{array}$ \\
\hline & & $\begin{array}{r}\text { Challenge and } \\
\text { Skills }\end{array}$ & $\begin{array}{l}\text { The level of task difficulty in a game in relation to game narrative } \\
\text { and the player's skills. }\end{array}$ \\
\hline & & Empathy & $\begin{array}{l}\text { The degree to which the player was emotionally involved in the } \\
\text { game world during the course of playing. }\end{array}$ \\
\hline & & Concentration & $\begin{array}{l}\text { The extent in which the player can focus on game narrative and } \\
\text { environment. }\end{array}$ \\
\hline & & Control & $\begin{array}{l}\text { The extent in which the player can have control over game } \\
\text { narrative-specifically, in terms of characters and interface within a } \\
\text { game. }\end{array}$ \\
\hline & & Familiarity & The degree of familiarity with the story and events in a game. \\
\hline
\end{tabular}


APPENDIX D (continued)

\section{EXISTING QUESTIONNAIRES' KEY DIMENSIONS}

\begin{tabular}{|c|c|c|c|}
\hline Source & Target Measure & Dimension & Description \\
\hline \multirow[t]{3}{*}{$\begin{array}{l}\text { Witmer \& Singer } \\
(1998)-P Q\end{array}$} & Presence & Involved/Control & $\begin{array}{l}\text { Relating to the general presence construct, it encompasses user } \\
\text { perceived control over events and actions in the virtual } \\
\text { environment (VE), and the degree of involvement the user } \\
\text { experiences while in the VE. }\end{array}$ \\
\hline & & Natural & $\begin{array}{l}\text { Relating to the general presence construct, it measures how } \\
\text { natural the interactions between the user and the VE were } \\
\text { perceived and how well are the experiences in the VE mapped with } \\
\text { real-world experiences. }\end{array}$ \\
\hline & & Interface Quality & $\begin{array}{l}\text { Relating to the general presence construct, it involves the user } \\
\text { being able to concentrate on the tasks within the VE with minimal } \\
\text { disruptions from the control devices and user interfaces. }\end{array}$ \\
\hline
\end{tabular}

*The questionnaire was not formally named. Thus, for the sake of identification a generic name was chosen. 


\section{APPENDIX E}

ITEM POOL USED IN THE EXPERT REVIEW PHASE

\begin{tabular}{|c|c|c|c|}
\hline Item \# & Item & Dimension/Category & Source \\
\hline \multirow[t]{5}{*}{1} & \multirow{5}{*}{$\begin{array}{l}\text { I thought it was easy to learn how to play the } \\
\text { game. }\end{array}$} & System Usefulness & Lewis (1995) \\
\hline & & Game Play & Federoff (2002) \\
\hline & & Game Play & Desurvire et al. (2004) \\
\hline & & Player Skills & Sweetser et al. (2005) \\
\hline & & Game Play & Desurvire \& Wiberg (2009) \\
\hline 2 & $\begin{array}{l}\text { I was able to see on the screen everything I } \\
\text { needed during the game. }\end{array}$ & Control & Calvillo-Gámez et al. (2010) \\
\hline 3 & $\begin{array}{l}\text { I kept looking forward to what will happen next in } \\
\text { the game. }\end{array}$ & $N / A$ & $\mathrm{~N} / \mathrm{A}$ \\
\hline \multirow[t]{2}{*}{4} & \multirow[t]{2}{*}{ I felt the game allowed me to express myself. } & $N / A$ & Korhonen \& Koivisto (2006) \\
\hline & & $\mathrm{N} / \mathrm{A}$ & Paavilainen (2010) \\
\hline 5 & $\begin{array}{l}\text { I thought the game provided me adequate hints } \\
\text { to overcome the challenges in the game. }\end{array}$ & Challenge & Fu et al. (2009) \\
\hline \multirow[t]{2}{*}{6} & \multirow[t]{2}{*}{ I had many ways to win the game. } & Game Play & Desurvire et al. (2004) \\
\hline & & Game Play & Desurvire \& Wiberg (2009) \\
\hline 7 & $\begin{array}{l}\text { I thought it was easy to skip non-playable content } \\
\text { (e.g., video sequences). }\end{array}$ & N/A & Pinelle et al. (2008) \\
\hline 8 & $\begin{array}{l}\text { I found my skills gradually improve through the } \\
\text { course of overcoming the challenge in the game. }\end{array}$ & Challenge & Fu et al. (2009) \\
\hline 9 & I felt spaced out when I'm playing the game. & $\mathrm{N} / \mathrm{A}$ & Brockmyer et al. (2009) \\
\hline \multirow[t]{2}{*}{10} & I felt the game did not put unnecessary burden on & Concentration & Sweetser et al. (2005) \\
\hline & me. & Usability \& Game Mechanics & Desurvire \& Wiberg (2009) \\
\hline \multirow[t]{4}{*}{11} & I thought the game was visually appealing. & $\mathrm{N} / \mathrm{A}$ & Korhonen \& Koivisto (2006) \\
\hline & & Screen Layout & Desurvire \& Wiberg (2009) \\
\hline & & Captivate Interest & Tan et al. (2010) \\
\hline & & Immersion & Sweetser et al. (2012) \\
\hline
\end{tabular}


ITEM POOL USED IN THE EXPERT REVIEW PHASE

\begin{tabular}{|c|c|c|c|}
\hline Item \# & Item & Dimension/Category & Source \\
\hline \multirow[t]{2}{*}{12} & I thought the information (e.g., onscreen & Screen & Chin, Diehl, \& Norman (1988) \\
\hline & messages, help) provided in the game was clear. & Information Quality & Lewis (1995) \\
\hline \multirow[t]{2}{*}{13} & I found my attention was immediately captured & Gameplay & Korhonen \& Koivisto (2006) \\
\hline & by the game when I first played it. & Game Play & Desurvire \& Wiberg (2009) \\
\hline 14 & $\begin{array}{l}\text { I thought the level of difficulty in the game was } \\
\text { right for me. }\end{array}$ & Focus & Parnell (2009) \\
\hline 15 & I felt emotionally involved in the game. & Immersion & Fu et al. (2009) \\
\hline \multirow[t]{2}{*}{16} & I was able to recover when I made a fatal mistake & Information Quality & Lewis (1995) \\
\hline & in the game. & Build Player's Confidence & Tan et al. (2010) \\
\hline 17 & $\begin{array}{l}\text { I felt time went by very quickly when I'm playing } \\
\text { the game. }\end{array}$ & Temporal Dissociation & Agarwal \& Karahanna (2000) \\
\hline 18 & $\begin{array}{l}\text { I wanted to do as well as possible when I was } \\
\text { playing the game. }\end{array}$ & Autotelic-Focus & Pavlas et al. (2012) \\
\hline 19 & $\begin{array}{l}\text { I didn't feel the urge to stop playing the game at } \\
\text { any point and check my surroundings. }\end{array}$ & $N / A$ & Jennett et al. (2008) \\
\hline \multirow[t]{3}{*}{20} & I didn't need to read a manual or documentation & Game Interface & Federoff (2002) \\
\hline & to play the game. & Usability & Desurvire et al. (2004) \\
\hline & & Usability \& Game Mechanics & Desurvire \& Wiberg (2009) \\
\hline 21 & $\begin{array}{l}\text { I thought it was easy for me to maintain my } \\
\text { attention in the game while playing it. }\end{array}$ & Focused Immersion & Agarwal \& Karahanna (2000) \\
\hline \multirow[t]{3}{*}{22} & I felt curious while playing the game. & Curiosity & Agarwal \& Karahanna (2000) \\
\hline & & $\mathrm{N} / \mathrm{A}$ & Paavilainen (2010) \\
\hline & & Captivate Interest & Tan et al. (2010) \\
\hline 23 & I always knew how I was progressing in the game. & Challenge-Based Immersion & Ermi \& Mäyrä (2005) \\
\hline 24 & $\begin{array}{l}\text { I thought the game was helpful in preventing me } \\
\text { from making irreversible errors in the game. }\end{array}$ & Game Usability & Korhonen \& Koivisto (2006) \\
\hline
\end{tabular}




\begin{tabular}{|c|c|c|c|}
\hline Item \# & Item & Dimension/Category & Source \\
\hline 25 & $\begin{array}{l}\text { I felt the game gave me enough freedom to act } \\
\text { how I wanted. }\end{array}$ & Freedom & Pavlas et al. (2012) \\
\hline 26 & $\begin{array}{l}\text { I was deeply concentrated in the game when I } \\
\text { was playing it. }\end{array}$ & Flow & IJsselsteijn et al. (2008) \\
\hline 27 & $\begin{array}{l}\text { I felt successful when I overcame the obstacles in } \\
\text { the game. }\end{array}$ & Challenge & Qin et al. (2009) \\
\hline 28 & $\begin{array}{l}\text { It was difficult for me to return to the real world } \\
\text { mentally after I stopped playing the game. }\end{array}$ & Empathy & Qin et al. (2009) \\
\hline 29 & $\begin{array}{l}\text { I always knew my next goal after I finished an } \\
\text { event in the game. }\end{array}$ & Concentration & Qin et al. (2009) \\
\hline 30 & $\begin{array}{l}\text { I thought the rewards in the game were given in a } \\
\text { timely manner. }\end{array}$ & Personal Interaction & Choi \& Kim (2004) \\
\hline 31 & $\begin{array}{l}\text { I was very concerned about whether I would win } \\
\text { or lose the game. }\end{array}$ & N/A & Jennett et al. (2008) \\
\hline 32 & $\begin{array}{l}\text { I always knew how to achieve my goal(s) in the } \\
\text { game. }\end{array}$ & Playability Barriers & Parnell (2009) \\
\hline \multirow[t]{3}{*}{33} & I felt the audio (e.g., sound effects, music) of the & Game Play & Federoff (2002) \\
\hline & game enhanced my gaming experience. & $\mathrm{N} / \mathrm{A}$ & Korhonen \& Koivisto (2006) \\
\hline & & Usability \& Game Mechanics & Desurvire \& Wiberg (2009) \\
\hline 34 & I think most people will enjoy playing this game. & $\mathrm{N} / \mathrm{A}$ & $\mathrm{N} / \mathrm{A}$ \\
\hline 35 & $\begin{array}{l}\text { I felt detached from the outside world while } \\
\text { playing the game. }\end{array}$ & N/A & Jennett et al. (2008) \\
\hline \multirow[t]{2}{*}{36} & I was completely involved in the task that I am & Involved/Control & Witmer \& Singer (1998) \\
\hline & performing while playing the game. & $\mathrm{N} / \mathrm{A}$ & Chen et al. (2005) \\
\hline 37 & $\begin{array}{l}\text { I couldn't tell that I'm getting tired when I'm } \\
\text { playing the game. }\end{array}$ & $\mathrm{N} / \mathrm{A}$ & Brockmyer et al. (2009) \\
\hline
\end{tabular}


ITEM POOL USED IN THE EXPERT REVIEW PHASE

\begin{tabular}{|c|c|c|c|}
\hline Item \# & Item & Dimension/Category & Source \\
\hline 38 & $\begin{array}{l}\text { I thought the game provided me adequate } \\
\text { support to overcome the challenges in the game. }\end{array}$ & Challenge & Fu et al. (2009) \\
\hline 39 & $\begin{array}{l}\text { I thought the game had unique features that kept } \\
\text { me interested. }\end{array}$ & Challenge & Sweetser et al. (2012) \\
\hline 40 & $\begin{array}{l}\text { I felt the events in the game were happening to } \\
\text { me. }\end{array}$ & Imaginative Immersion & Ermi \& Mäyrä (2005) \\
\hline \multirow[t]{3}{*}{41} & I thought the game taught me skills that were & Game Play & Federoff (2002) \\
\hline & useful in the game. & Game Play & Desurvire et al. (2004) \\
\hline & & Game Play & Desurvire \& Wiberg (2009) \\
\hline \multirow[t]{5}{*}{42} & If given the chance, I would replay this game & Game Play & Federoff (2002) \\
\hline & again. & N/A & Chen et al. (2005) \\
\hline & & Game Play & Desurvire et al. (2004) \\
\hline & & $\mathrm{N} / \mathrm{A}$ & Papaloukas et al. (2009) \\
\hline & & Enjoyment & Calvillo-Gámez et al. (2010) \\
\hline 43 & $\begin{array}{l}\text { I thought the game supported different playing } \\
\text { styles. }\end{array}$ & Gameplay & Korhonen \& Koivisto (2006) \\
\hline 44 & I thought the game was unique/original. & $\mathrm{N} / \mathrm{A}$ & $\mathrm{N} / \mathrm{A}$ \\
\hline 45 & I felt energized while playing the game. & $N / A$ & $N / A$ \\
\hline 46 & $\begin{array}{l}\text { I found that the game supported social interaction } \\
\text { (e.g., chat) between players. }\end{array}$ & Social Interaction & Fu et al. (2009) \\
\hline 47 & $\begin{array}{l}\text { I was in suspense about whether I would win or } \\
\text { lose the game. }\end{array}$ & N/A & Jennett et al. (2008) \\
\hline 48 & I found many events in the game to be novel. & Familiarity & Qin et al. (2009) \\
\hline \multirow[t]{2}{*}{49} & I was able to predict what would happen next in & Involved/Control & Witmer \& Singer (1998) \\
\hline & response to my actions in the game. & $\mathrm{N} / \mathrm{A}$ & Chen et al. (2005) \\
\hline 50 & I was moved by the events in the game. & Imaginative Immersion & Ermi \& Mäyrä (2005) \\
\hline
\end{tabular}


ITEM POOL USED IN THE EXPERT REVIEW PHASE

\begin{tabular}{|c|c|c|c|}
\hline Item \# & Item & Dimension/Category & Source \\
\hline \multirow[t]{4}{*}{51} & \multirow[t]{4}{*}{ I felt a sense of control over the game. } & Game Play & Desurvire et al. (2004) \\
\hline & & Control & Sweetser et al. (2005) \\
\hline & & Game Play & Desurvire \& Wiberg (2009) \\
\hline & & Autonomy & Fu et al. (2009) \\
\hline \multirow[t]{4}{*}{52} & \multirow{4}{*}{$\begin{array}{l}\text { Sometimes I lost track of time when I played the } \\
\text { game. }\end{array}$} & Temporal Dissociation & Agarwal \& Karahanna (2000) \\
\hline & & $\mathrm{N} / \mathrm{A}$ & Chen et al. (2005) \\
\hline & & Flow & IJsselsteijn et al. (2008) \\
\hline & & $\mathrm{N} / \mathrm{A}$ & Brockmyer et al. (2009) \\
\hline \multirow[t]{3}{*}{53} & \multirow{3}{*}{$\begin{array}{l}\text { I thought it was easy to save the game in different } \\
\text { states. }\end{array}$} & Game Interface & Federoff (2002) \\
\hline & & Usability & Desurvire et al. (2004) \\
\hline & & Usability \& Game Mechanics & Desurvire \& Wiberg (2009) \\
\hline 54 & I like to spend a lot of time playing this game. & Facilitators & Calvillo-Gámez et al. (2010) \\
\hline 55 & $\begin{array}{l}\text { I found the controls of the game to be } \\
\text { straightforward. }\end{array}$ & Player Skills & Sweetser et al. (2012) \\
\hline 56 & I felt annoyed while playing the game. & Tension/Annoyance & IJsselsteijn et al. (2008) \\
\hline 57 & $\begin{array}{l}\text { I found the game interface was easy to navigate } \\
\text { through. }\end{array}$ & Build Player's Confidence & Tan et al. (2010) \\
\hline \multirow[t]{2}{*}{58} & \multirow{2}{*}{$\begin{array}{l}\text { I forgot about my surroundings while playing the } \\
\text { game. }\end{array}$} & Flow & IJsselsteijn et al. (2008) \\
\hline & & Focus & Parnell (2009) \\
\hline 59 & $\begin{array}{l}\text { I temporarily forgot about my everyday worries } \\
\text { while playing the game. }\end{array}$ & Immersion & Fu et al. (2009) \\
\hline \multirow[t]{2}{*}{60} & \multirow{2}{*}{$\begin{array}{l}\text { I thought the sound effects of the game were } \\
\text { appropriate. }\end{array}$} & $N / A$ & Desurvire \& Wiberg (2009) \\
\hline & & Environment & Calvillo-Gámez et al. (2010) \\
\hline \multirow[t]{4}{*}{61} & \multirow{4}{*}{$\begin{array}{l}\text { I thought it was easy for me to identify my } \\
\text { score/status in the game. }\end{array}$} & Game Interface & Federoff (2002) \\
\hline & & Mechanics & Desurvire et al. (2004) \\
\hline & & Feedback & Sweetser et al. (2005) \\
\hline & & Usability \& Game Mechanics & Desurvire \& Wiberg (2009) \\
\hline
\end{tabular}


ITEM POOL USED IN THE EXPERT REVIEW PHASE

\begin{tabular}{|c|c|c|c|}
\hline Item \# & Item & Dimension/Category & Source \\
\hline 62 & I had fun interacting with the game. & Heightened Enjoyment & Agarwal \& Karahanna (2000) \\
\hline \multirow[t]{3}{*}{63} & I thought the characters in the game were well & Game Story & Desurvire et al. (2004) \\
\hline & developed. & Imaginative Immersion & Ermi \& Mäyrä (2005) \\
\hline & & Immersion & Sweetser et al. (2012) \\
\hline 64 & $\begin{array}{l}\text { I thought it was easy to know where I am in the } \\
\text { game. }\end{array}$ & $\mathrm{N} / \mathrm{A}$ & $\mathrm{N} / \mathrm{A}$ \\
\hline \multirow[t]{2}{*}{65} & I thought the graphics and audio of the game & $N / A$ & Chen et al. (2005) \\
\hline & were related. & Environment & Calvillo-Gámez et al. (2010) \\
\hline \multirow[t]{2}{*}{66} & I was able to easily customize important features & $\mathrm{N} / \mathrm{A}$ & Pinelle et al. (2008) \\
\hline & (e.g., audio settings) in the game. & $N / A$ & Papaloukas et al. (2009) \\
\hline \multirow[t]{3}{*}{67} & I found the game's menus to be user friendly. & Usability & Desurvire et al. (2004) \\
\hline & & Usability Barriers & Parnell (2009) \\
\hline & & Player Skills & Sweetser et al. (2012) \\
\hline 68 & $\begin{array}{l}\text { I sometimes found myself wanting to speak to the } \\
\text { game directly while playing it. }\end{array}$ & $N / A$ & Jennett et al. (2008) \\
\hline \multirow[t]{4}{*}{69} & I thought the rewards given in the game were & Personal Interaction & Choi \& Kim (2004) \\
\hline & effective in motivating me to progress further in & Game Play & Desurvire et al. (2004) \\
\hline & the game. & Gameplay & Korhonen \& Koivisto (2006) \\
\hline & & Game Play & Desurvire \& Wiberg (2009) \\
\hline 70 & I felt happy while playing the game. & Positive Affect & IJsselsteijn et al. (2008) \\
\hline \multirow[t]{3}{*}{71} & I felt bored while playing the game. & Heightened Enjoyment & Agarwal \& Karahanna (2000) \\
\hline & & Negative Affect & IJsselsteijn et al. (2008) \\
\hline & & Facilitators & Calvillo-Gámez et al. (2010) \\
\hline \multirow[t]{2}{*}{72} & I could clearly understand the game story. & Game Story & Desurvire et al. (2004) \\
\hline & & Comprehension & Qin et al. (2009) \\
\hline 73 & $\begin{array}{l}\text { I was very focused on my own performance while } \\
\text { playing the game. }\end{array}$ & Challenge-Based Immersion & Ermi \& Mäyrä (2005) \\
\hline
\end{tabular}


ITEM POOL USED IN THE EXPERT REVIEW PHASE

\begin{tabular}{|c|c|c|c|}
\hline Item \# & Item & Dimension/Category & Source \\
\hline 74 & $\begin{array}{l}\text { I thought the graphics were related to the } \\
\text { scenarios in the game. }\end{array}$ & Environment & Calvillo-Gámez et al. (2010) \\
\hline 75 & $\begin{array}{l}\text { I thought the graphics were appropriate for this } \\
\text { type of game. }\end{array}$ & Environment & Calvillo-Gámez et al. (2010) \\
\hline 76 & $\begin{array}{l}\text { I found this game to be the type of game that I } \\
\text { often played. }\end{array}$ & Facilitators & Calvillo-Gámez et al. (2010) \\
\hline 77 & $\begin{array}{l}\text { I felt this game reminded me of my favorite } \\
\text { games in the past. }\end{array}$ & Facilitators & Calvillo-Gámez et al. (2010) \\
\hline 78 & $\begin{array}{l}\text { I thought the game environment was responsive } \\
\text { to the actions that I performed in the game. }\end{array}$ & Involved/Control & Witmer \& Singer (1998) \\
\hline \multirow[t]{2}{*}{79} & I felt that I could explore things in the game. & $N / A$ & Clanton (1998) \\
\hline & & Sensory \& Imaginative Immersion & IJsselsteijn et al. (2008) \\
\hline 80 & $\begin{array}{l}\text { Whenever I stopped playing the game I can't wait } \\
\text { to start playing it again. }\end{array}$ & Assess Achievement & Tan et al. (2010) \\
\hline 81 & I usually found my way in the game world. & Playability Barriers & Parnell (2009) \\
\hline \multirow[t]{2}{*}{82} & I felt the game was real. & Sensory Immersion & Ermi \& Mäyrä (2005) \\
\hline & & $\mathrm{N} / \mathrm{A}$ & Brockmyer et al. (2009) \\
\hline 83 & $\begin{array}{l}\text { I was focused on the task at hand when I was } \\
\text { playing the game. }\end{array}$ & Focus & Pavlas et al. (2012) \\
\hline \multirow[t]{6}{*}{84} & I thought the game was fun. & Flow & Choi \& Kim (2004) \\
\hline & & Game Play & Desurvire et al. (2004) \\
\hline & & Positive Affect & IJsselsteijn et al. (2008) \\
\hline & & N/A & Jennett et al. (2008) \\
\hline & & Game Play & Desurvire \& Wiberg (2009) \\
\hline & & Affective Experience & Parnell (2009) \\
\hline 85 & $\begin{array}{l}\text { I thought it was easy to return to where I left off } \\
\text { in the game. }\end{array}$ & N/A & $\mathrm{N} / \mathrm{A}$ \\
\hline
\end{tabular}




\begin{tabular}{|c|c|c|c|}
\hline Item \# & Item & Dimension/Category & Source \\
\hline 86 & I enjoyed the graphics and imagery of the game. & $\mathrm{N} / \mathrm{A}$ & Jennett et al. (2008) \\
\hline \multirow[t]{2}{*}{87} & I felt the game constantly motivating me to keep & Affective Experience & Parnell (2009) \\
\hline & playing. & Ownership & Calvillo-Gámez et al. (2010) \\
\hline \multirow[t]{2}{*}{88} & I felt playing the game aroused my imagination. & Curiosity & Agarwal \& Karahanna (2000) \\
\hline & & Sensory \& Imaginative Immersion & IJsselsteijn et al. (2008) \\
\hline \multirow[t]{2}{*}{89} & I was very interested in seeing how the events in & Game Story & Desurvire et al. (2004) \\
\hline & the game would progress. & N/A & Jennett et al. (2008) \\
\hline 90 & $\begin{array}{l}\text { I felt all of my senses were completely engaged } \\
\text { while playing the game. }\end{array}$ & Involved/Control & Witmer \& Singer (1998) \\
\hline 91 & I always knew the next step in the game. & Autonomy & Fu et al. (2009) \\
\hline \multirow[t]{2}{*}{92} & I was very absorbed in what I was doing while & Focused Immersion & Agarwal \& Karahanna (2000) \\
\hline & playing the game. & Flow & Choi \& Kim (2004) \\
\hline \multirow[t]{2}{*}{93} & I enjoyed the music in the game. & Environment & Calvillo-Gámez et al. (2010) \\
\hline & & Captivate Interest & Tan et al. (2010) \\
\hline \multirow[t]{6}{*}{94} & I enjoyed playing the game. & Heightened Enjoyment & Agarwal \& Karahanna (2000) \\
\hline & & Game Play & Desurvire et al. (2004) \\
\hline & & Positive Affect & IJsselsteijn et al. (2008) \\
\hline & & $\mathrm{N} / \mathrm{A}$ & Jennett et al. (2008) \\
\hline & & Affective Experience & Parnell (2009) \\
\hline & & Enjoyment & Calvillo-Gámez et al. (2010) \\
\hline 95 & $\begin{array}{l}\text { I found that the game supports communities } \\
\text { within the game. }\end{array}$ & Social Interaction & Fu et al. (2009) \\
\hline 96 & I understood the rules of the game. & Game Play & Calvillo-Gámez et al. (2010) \\
\hline 97 & $\begin{array}{l}\text { I thought that I could play the game at my own } \\
\text { pace. }\end{array}$ & Educational/Pedagogical & Omar \& Jaafar (2010) \\
\hline 98 & I found the game to have delightful surprises. & $\mathrm{N} / \mathrm{A}$ & $\mathrm{N} / \mathrm{A}$ \\
\hline
\end{tabular}


ITEM POOL USED IN THE EXPERT REVIEW PHASE

\begin{tabular}{|c|c|c|c|}
\hline Item \# & Item & Dimension/Category & Source \\
\hline 99 & $\begin{array}{l}\text { I knew what I was supposed to do to win the } \\
\text { game. }\end{array}$ & Control & Calvillo-Gámez et al. (2010) \\
\hline 100 & I could identify with the characters in the game. & Focus & Parnell (2009) \\
\hline 101 & $\begin{array}{l}\text { I challenged myself even if the game did not } \\
\text { require it. }\end{array}$ & Ownership & Calvillo-Gámez et al. (2010) \\
\hline \multirow[t]{3}{*}{102} & I felt playing the game stimulated my curiosity. & Curiosity & Agarwal \& Karahanna (2000) \\
\hline & & $\mathrm{N} / \mathrm{A}$ & Paavilainen (2010) \\
\hline & & Captivate Interest & Tan et al. (2010) \\
\hline 103 & $\begin{array}{l}\text { I would recommend this game to other game } \\
\text { players. }\end{array}$ & N/A & N/A \\
\hline \multirow[t]{3}{*}{104} & I thought the outcomes in the game were fair. & Game Play & Federoff (2002) \\
\hline & & Game Story & Desurvire et al. (2004) \\
\hline & & Game-Play & Calvillo-Gámez et al. (2010) \\
\hline 105 & $\begin{array}{l}\text { I found the game's user interface interfered with } \\
\text { my ability to play the game. }\end{array}$ & N/A & Chen et al. (2005) \\
\hline 106 & I felt very confident while playing the game. & $\mathrm{N} / \mathrm{A}$ & Brooke (1996) \\
\hline 107 & $\begin{array}{l}\text { I enjoyed the fantasy or story provided by the } \\
\text { game. }\end{array}$ & Imaginative Immersion & Ermi \& Mäyrä (2005) \\
\hline 108 & $\begin{array}{l}\text { I was quickly captured by the game story at the } \\
\text { beginning. }\end{array}$ & Curiosity & Qin et al. (2009) \\
\hline 109 & $\begin{array}{l}\text { I usually ended up spending more time playing } \\
\text { the game than I had planned. }\end{array}$ & Temporal Dissociation & Agarwal \& Karahanna (2000) \\
\hline \multirow[t]{2}{*}{110} & I felt the visual representations (e.g., icons, & $\mathrm{N} / \mathrm{A}$ & Pinelle et al. (2008) \\
\hline & $\begin{array}{l}\text { avatars, map) in the game enhanced my gaming } \\
\text { experience. }\end{array}$ & N/A & Papaloukas et al. (2009) \\
\hline \multirow[t]{2}{*}{111} & I thought it was easy to customize the difficulty & $N / A$ & Pinelle et al. (2008) \\
\hline & level of the game. & Usability \& Game Mechanics & Desurvire \& Wiberg (2009) \\
\hline
\end{tabular}


APPENDIX E (continued)

ITEM POOL USED IN THE EXPERT REVIEW PHASE

\begin{tabular}{|c|c|c|c|}
\hline Item \# & Item & Dimension/Category & Source \\
\hline 112 & I felt creative while playing the game. & $\mathrm{N} / \mathrm{A}$ & $\mathrm{N} / \mathrm{A}$ \\
\hline 113 & $\begin{array}{l}\text { I was able to block out most other distractions } \\
\text { while playing the game. }\end{array}$ & Focused Immersion & Agarwal \& Karahanna (2000) \\
\hline 114 & $\begin{array}{l}\text { I received adequate feedback on my progress in } \\
\text { the game. }\end{array}$ & $\begin{array}{l}\text { Feedback } \\
\text { Feedback }\end{array}$ & $\begin{array}{l}\text { Sweetser et al. (2005) } \\
\text { Fu et al. (2009) }\end{array}$ \\
\hline 115 & I felt the game trained me in all of the controls. & Usability Barriers & Parnell (2009) \\
\hline 116 & $\begin{array}{l}\text { I thought the game provided all necessary } \\
\text { information to accomplish a goal within the game. }\end{array}$ & Personal Interaction & Choi \& Kim (2004) \\
\hline
\end{tabular}

Note: "N/A" under the Dimension/Category column is used in cases where the information is not known or clearly specified by the original source(s).

Additionally, new items that were created outside of the 13 game-related experience questionnaires, 15 list of heuristics, and 3 satisfaction questionnaires

have "N/A" under their source. 
APPENDIX F

EXPERT REVIEW: CONSENT FORM

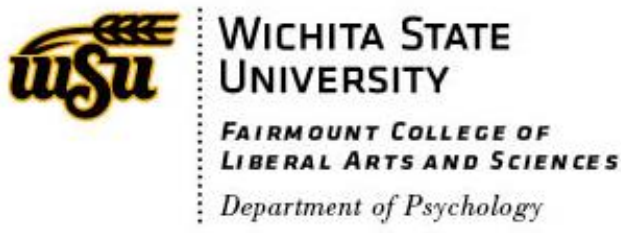

Consent Form

Purpose: Since you are 18 years of age or older, you are invited to participate in a study investigating video game satisfaction. We hope to gather your feedback about the design of the survey so that we can improve the survey for future studies.

Participant Selection: You were selected as a possible participant in this study because you fit the criteria of the population we are interested in studying, namely that you are over the age of 18 and you are knowledgeable about the field of video games and/or scale/questionnaire development area. You are one of at least 6 participants in this study.

Explanation of Procedures: If you decide to participate, you will be asked to complete an online survey to evaluate a video game you currently or recently played through a series of statements (e.g., I thought the game was visually appealing.) on a 7-point scale ( 1 = Strongly Disagree; 7 = Strongly Agree). Then you will be ask to scrutinize every statement on the survey, identify any problematic statements that are not effective in capturing video game satisfaction, and offer suggestions for improvement. Additionally, you will be asked to answer other questions related to the game you're evaluating (e.g., the device platform that you used to play the game), and general demographics questions (e.g., age, gender). It is expected that the survey will take approximately 60-90 minutes to complete.

Discomfort/Risks: There are no expected risks or discomforts. However, you may take a break at any time, and you may skip any questions that make you feel uncomfortable.

Benefits: Your participation in this study will be beneficial in helping researchers build a better instrument to measure video game satisfaction. 
APPENDIX F (continued)

\section{EXPERT REVIEW: CONSENT FORM}

Confidentiality: Every effort will be made to keep your study-related information confidential. However, in order to make sure the study is done properly and safely there may be circumstances where this information must be released. By signing this form, you are giving the research team permission to share information about you with the following groups:

- Office for Human Research Protections or other federal, state, or international regulatory agencies;

- The Wichita State University Institutional Review Board;

- The sponsor or agency supporting the study.

The researchers may publish the results of the study. If they do, they will only discuss group results. Your name will not be used in any publication or presentation about the study. We will work to make sure that no one sees your survey responses without approval. But, because we are using the Internet, there is a chance that someone could access your online responses without permission. In some cases, this information could be used to identify you. Your data will be protected with a code to reduce the risk that other people can view the responses.

Compensation: For your participation, you will receive a $\$ 30$ Amazon gift card.

Refusal/Withdrawal: Participation in this study is entirely voluntary. Your decision whether or not to participate will not affect your future relations with Wichita State University. If you agree to participate in this study, you are free to withdraw from the study at any time without penalty.

Contact: If you have any questions about this research, you may contact Mikki Phan at mhphan@wichita.edu or you can contact Dr. Barbara Chaparro at 316-978-3683 or via e-mail at barbara.chaparro@wichita.edu. If you have questions pertaining to your rights as a research subject, or about research-related injury, you can contact the Office of Research and Technology Transfer at Wichita State University, 1845 Fairmount Street, Wichita, KS 672600007, telephone (316) 978-3285.

You are under no obligation to participate in this study. By selecting the "Next >>" button below, you are indicating that:

- You have read (or someone has read to you) the information provided above,

- You are aware that this is a research study,

- You have voluntarily decided to participate. 


\section{APPENDIX G \\ INSTRUCTIONS FOR THE SELECTION OF A VIDEO GAME TO EVALUATE}

Please think of a video game that you currently play or recently played and type the game title in the text field below.

The game you choose can either be a game that you LIKE or DISLIKE. However, avoid choosing any games that you have little experience in playing (e.g., a game you just started to play) OR that you have stopped playing more than 3 months ago.

Please type the entire name of the game (e.g., Grand Theft Auto V) and DO NOT abbreviate the official game title.

Name of the video game: 


\section{APPENDIX H \\ QUESTIONS ABOUT THE GAME UNDER EVALUATION}

Before you begin the evaluation process, please provide us with a bit of information regarding the game that you plan to evaluate.

When was the last time you played this game?

o Today

o Yesterday

o Last week

0 Last month

o About 2-3 months ago

o About 4-6 months ago

o About 7-12 months ago

o More than a year ago

In TOTAL, approximately how many hours have you spent playing this game?

o Less than 5 hours

o 5 to 9 hours

o 10 to 19 hours

o 20 to 39 hours

0 40 to 79 hours

o 80 to 120 hours

o More than 120 hours

What type of device platform do you MAINLY use to play this game?

O A computer device (e.g., laptop, desktop)

- A console device (e.g., Xbox 360, Playstation 4, Nintendo Wii)

o A handheld gaming device (e.g., Game Boy Advance, Nintendo DS)

o A mobile device (e.g., smartphone, tablet, e-Reader)

o Other, please specify 


\section{APPENDIX I \\ EXPERT REVIEW: A SCREENSHOT OF AN EVALUATION PAGE}

\section{Game Evaluation}

Based on your experience playing this game, please rate the following statements on a scale from Strongly Disagree to Strongly Agree. If there is a statement that does not apply to the game that you are evaluating, then select the option "N/A".

\begin{tabular}{|c|c|c|c|c|c|c|c|c|}
\hline & $\begin{array}{l}\text { Strongly } \\
\text { Disagree }\end{array}$ & Disagree & $\begin{array}{l}\text { Somewhat } \\
\text { Disagree }\end{array}$ & $\begin{array}{l}\text { Neither } \\
\text { Agree } \\
\text { nor } \\
\text { Disagree }\end{array}$ & $\begin{array}{c}\text { Somewhat } \\
\text { Agree }\end{array}$ & Agree & $\begin{array}{l}\text { Strongly } \\
\text { Agree }\end{array}$ & $\mathrm{N} / \mathrm{A}$ \\
\hline $\begin{array}{l}\text { I felt emotionally } \\
\text { involved in the } \\
\text { game. }\end{array}$ & 0 & 0 & 0 & 0 & 0 & 0 & 0 & 0 \\
\hline $\begin{array}{l}\text { I thought the } \\
\text { game was visually } \\
\text { appealing. }\end{array}$ & 0 & 0 & 0 & 0 & 0 & 0 & 0 & 0 \\
\hline $\begin{array}{l}\text { I thought the } \\
\text { information (e.g., } \\
\text { onscreen } \\
\text { messages, help) } \\
\text { provided in the } \\
\text { game was clear. }\end{array}$ & $\bigcirc$ & 0 & 0 & 0 & 0 & 0 & 0 & 0 \\
\hline $\begin{array}{l}\text { I thought the level } \\
\text { of difficulty in the } \\
\text { game was right for } \\
\text { me. }\end{array}$ & 0 & 0 & 0 & 0 & 0 & 0 & 0 & 0 \\
\hline $\begin{array}{l}\text { I found my } \\
\text { attention was } \\
\text { immediately } \\
\text { captured by the } \\
\text { game when I first } \\
\text { played it. }\end{array}$ & 0 & 0 & 0 & 0 & 0 & 0 & 0 & 0 \\
\hline
\end{tabular}

Concerning video game satisfaction, please type your comments/thoughts about any of the statements listed above (e.g., inappropriate statements, unclear statements, etc.). You can skip this field, if you do not have any comments/thoughts to add. 


\section{APPENDIX J \\ Overall Game Satisfaction Rating}

Overall, how would you rate your level of satisfaction with the game you are evaluating?

o Extremely satisfied

o Satisfied

o Somewhat satisfied

o Neither satisfied no dissatisfied

o Somewhat dissatisfied

o Dissatisfied

o Extremely dissatisfied 


\section{APPENDIX K \\ EXPERT REVIEW: GENERAL QUESTIONS}

\section{Other Comments/Feedback}

Are there any other items or content areas that you feel is important in measuring video game satisfaction, but were not included in the questionnaire? Please briefly discuss about these items or content areas.

If you do not have other items or content areas to add to the questionnaire then write "None."

Do you have other general thoughts/comments about the questionnaire or the items on the questionnaire that you feel you didn't get a chance to discuss on the previous sections? Please briefly discuss about these thoughts/comments.

If you do not have other items or content areas to add to the questionnaire then write "None." 


\section{APPENDIX L \\ EXPERT REVIEW: DEMOGRAPHICS QUESTIONS}

\section{Demographics Info}

You are almost done! Please tell us a bit about yourself.

Age:

Gender:

o Male

o Female

Ethnicity:

o American Indian/Alaskan Native

o White (not of Hispanic origin)

o Black/African American

o Asian/Pacific Islander

o Hispanic/Latino

o Biracial/Multiracial/Mixed

o I do not wish to answer.

Occupation:

Do you have any experience working in the video game industry?

o Yes

o No

(If answered "Yes")

Please briefly describe this work experience (e.g., your role) and state approximately how long you have been working in the video game industry. 


\section{APPENDIX L (continued) \\ EXPERT REVIEW: DEMOGRAPHICS QUESTIONS}

Do you have any experience in developing questionnaire or scale?

o Yes

o No

(If answered "Yes")

On a 7-point scale (1 = Novice; 7 = Expert), how would you rate your experience level with questionnaire/scale development?

\begin{tabular}{|c|c|c|c|c|c|c|}
\hline 1 (Novice) & $\mathbf{2}$ & $\mathbf{3}$ & $\begin{array}{c}4 \\
\text { (Intermediate) }\end{array}$ & $\mathbf{5}$ & $\mathbf{6}$ & $\mathbf{7}$ (Expert) \\
\hline
\end{tabular}

What type of video game player do you consider yourself?

o Newbie/Novice

o Casual

o Mid-core/Core

o Hardcore/Expert

On average, how many hours do you spend playing video games per week?

o Less than 1 hour

o 1 to 4 hours

O 5 to 9 hours

o 10 to 19 hours

o 20 to 29 hours

o 30 to 39 hours

o More than 40 hours 


\section{APPENDIX L (continued) \\ EXPERT REVIEW: DEMOGRAPHICS QUESTIONS}

Which of the following devices do you FREQUENTLY use to play video games? Check all that apply.

A computer device (e.g., laptop, desktop)

A console device (e.g., Xbox 360, Playstation 4, Nintendo Wii)

A handheld gaming device (e.g., Game Boy Advance, Nintendo DS)

A mobile device (e.g., smartphone, tablet)

Which of the following video game genres do you FREQUENTLY play? Check all that apply.

Action (e.g., Halo, Call of Duty)

$\square$ Adventure (e.g., Resident Evil, Grand Theft Auto)

$\square$ Driving (e.g., Forza, Mario Kart)

$\square$ Educational/Edutainment (e.g., Math Blaster, Professor Layton Series)

$\square$ Fighting (e.g., Soul Caliber, Mortal Kombat)

$\square$ Fitness (e.g., Wii Fit, Your Shape: Fitness Evolved)

$\square$ Music/Dance (e.g., Guitar Hero, Just Dance)
Puzzle/Card (e.g., Tetris, Solitaire)

Retro/Classic (e.g., Pacman, The Original Donkey Kong)

Role Playing (e.g., Elder Scroll, World of Warcraft)

Simulation (e.g., The Sims, Spore)

Social/Social Network (e.g., Farmville, Candy Crush)

Sports (e.g., Madden NFL, FIFA)

Strategy (e.g., Civilization, Starcraft) 
REVISED ITEM POOL AFTER EXPERT REVIEW

\begin{tabular}{|c|c|c|}
\hline Item \# & Item Before Expert Review & Revised Item After Expert Review \\
\hline 1 & $\begin{array}{l}\text { I found my attention was immediately captured by the } \\
\text { game when I first played it. }\end{array}$ & I find the game captures my attention from the get-go. \\
\hline 2 & I thought the game was visually appealing. & I think the game is visually appealing. \\
\hline 3 & $\begin{array}{l}\text { I felt the audio (e.g., sound effects, music) of the game } \\
\text { enhanced my gaming experience. }\end{array}$ & $\begin{array}{l}\text { I feel the game's audio (e.g., sound effects, music) enhances } \\
\text { my gaming experience. }\end{array}$ \\
\hline 4 & I could identify with the characters in the game. & I can identify with the characters in the game. \\
\hline 5 & I felt energized while playing the game. & I feel energized while playing the game. \\
\hline 6 & $\begin{array}{l}\text { I thought it was easy for me to maintain my attention in } \\
\text { the game while playing it. }\end{array}$ & $\begin{array}{l}\text { I can easily maintain my attention on the game during game } \\
\text { play. }\end{array}$ \\
\hline 7 & $\begin{array}{l}\text { I found my skills gradually improve through the course } \\
\text { of overcoming the challenge in the game. }\end{array}$ & $\begin{array}{l}\text { I find my skills gradually improve through the course of } \\
\text { overcoming the challenges in the game. }\end{array}$ \\
\hline 8 & I felt playing the game aroused my imagination. & I feel the game allows me to be imaginative. \\
\hline 9 & I found the controls of the game to be straightforward. & I find the controls of the game to be straightforward. \\
\hline 10 & I understood the rules of the game. & I understand the rules of the game. \\
\hline 11 & $\begin{array}{l}\text { I found that the game supported social interaction (e.g., } \\
\text { chat) between players. }\end{array}$ & $\begin{array}{l}\text { I find the game supports social interaction (e.g., chat) } \\
\text { between players. }\end{array}$ \\
\hline 12 & I think most people will enjoy playing this game. & I think most people will enjoy playing this game. \\
\hline 13 & $\begin{array}{l}\text { I felt the visual representations (e.g., icons, avatars, } \\
\text { map) in the game enhanced my gaming experience. }\end{array}$ & $\begin{array}{l}\text { I feel the visual representations (e.g., icons, avatars, map) in } \\
\text { the game enhance my gaming experience. }\end{array}$ \\
\hline 14 & $\begin{array}{l}\text { I thought the sound effects of the game were } \\
\text { appropriate. }\end{array}$ & I enjoy the sound effects in the game. \\
\hline 15 & $\begin{array}{l}\text { I thought the characters in the game were well } \\
\text { developed. }\end{array}$ & I think the characters in the game are well developed. \\
\hline 16 & I was moved by the events in the game. & I am emotionally moved by the events in the game. \\
\hline 17 & $\begin{array}{l}\text { I didn't feel the urge to stop playing the game at any } \\
\text { point and check my surroundings. }\end{array}$ & $\begin{array}{l}\text { I do not care to check my real-world surroundings while } \\
\text { playing the game. }\end{array}$ \\
\hline
\end{tabular}




\section{REVISED ITEM POOL AFTER EXPERT REVIEW}

\begin{tabular}{|c|c|c|}
\hline Item \# & Item Before Expert Review & Revised Item After Expert Review \\
\hline 18 & $\begin{array}{l}\text { I thought the level of difficulty in the game was right for } \\
\text { me. }\end{array}$ & I think the game's level of difficulty is right for me. \\
\hline 19 & I felt the game allowed me to express myself. & I feel the game allows me to express myself. \\
\hline 20 & $\begin{array}{l}\text { I felt the game gave me enough freedom to act how I } \\
\text { wanted. }\end{array}$ & I feel the game gives me enough freedom to act how I want. \\
\hline 21 & $\begin{array}{l}\text { I was very interested in seeing how the events in the } \\
\text { game would progress. }\end{array}$ & $\begin{array}{l}\text { I am very interested in seeing how the events in the game } \\
\text { will progress. }\end{array}$ \\
\hline 22 & I thought it was easy to learn how to play the game. & I think it is easy to learn how to play the game. \\
\hline 23 & $\begin{array}{l}\text { I thought it was easy to skip non-playable content (e.g., } \\
\text { video sequences). }\end{array}$ & $\begin{array}{l}\text { I can easily skip any non-playable content (e.g., video } \\
\text { sequences) that does not capture my interest. }\end{array}$ \\
\hline 24 & I always knew how to achieve my goal(s) in the game. & I always know how to achieve my goal(s) in the game. \\
\hline 25 & $\begin{array}{l}\text { I found that the game supports communities within the } \\
\text { game. }\end{array}$ & I am able to play the game with other players if I choose. \\
\hline 26 & I would recommend this game to other game players. & I am likely to recommend this game to others. \\
\hline 27 & I could clearly understand the game story. & I can clearly understand the story presents in the game. \\
\hline 28 & $\begin{array}{l}\text { I sometimes found myself wanting to speak to the game } \\
\text { directly while playing it. }\end{array}$ & $\begin{array}{l}\text { Sometimes I find myself wanting to speak directly to the } \\
\text { game while playing it. }\end{array}$ \\
\hline 29 & $\begin{array}{l}\text { I felt detached from the outside world while playing the } \\
\text { game. }\end{array}$ & $\begin{array}{l}\text { I feel detached from the outside world while playing the } \\
\text { game. }\end{array}$ \\
\hline 30 & $\begin{array}{l}\text { I thought it was easy to customize the difficulty level of } \\
\text { the game. }\end{array}$ & $\begin{array}{l}\text { I find it is easy to customize the overall difficulty level of the } \\
\text { game. }\end{array}$ \\
\hline 31 & I challenged myself even if the game did not require it. & I challenge myself even when the game does not require it. \\
\hline 32 & $\begin{array}{l}\text { I didn't need to read a manual or documentation to play } \\
\text { the game. }\end{array}$ & $\begin{array}{l}\text { I do not need to go through a lengthy tutorial or read a } \\
\text { manual to play the game. }\end{array}$ \\
\hline
\end{tabular}




\section{REVISED ITEM POOL AFTER EXPERT REVIEW}

\begin{tabular}{|c|c|c|}
\hline Item \# & Item Before Expert Review & Revised Item After Expert Review \\
\hline 33 & $\begin{array}{l}\text { I was able to see on the screen everything I needed } \\
\text { during the game. }\end{array}$ & $\begin{array}{l}\text { I can see everything that I need to see on the screen during } \\
\text { the game. }\end{array}$ \\
\hline 34 & I thought the outcomes in the game were fair. & I think the outcomes in the game are fair. \\
\hline 35 & $\begin{array}{l}\text { Whenever I stopped playing the game I can't wait to } \\
\text { start playing it again. }\end{array}$ & $\begin{array}{l}\text { Whenever I stopped playing the game I cannot wait to start } \\
\text { playing it again. }\end{array}$ \\
\hline 36 & I felt happy while playing the game. & I feel happy while playing the game. \\
\hline 37 & I felt playing the game stimulated my curiosity. & $\begin{array}{l}\text { I feel my curiosity are stimulated as the result of playing the } \\
\text { game. }\end{array}$ \\
\hline 38 & $\begin{array}{l}\text { I was able to block out most other distractions while } \\
\text { playing the game. }\end{array}$ & $\begin{array}{l}\text { I can block out most other distractions when playing the } \\
\text { game. }\end{array}$ \\
\hline 39 & $\begin{array}{l}\text { I couldn't tell that I'm getting tired when I'm playing the } \\
\text { game. }\end{array}$ & I cannot tell that I am getting tired while playing the game. \\
\hline 40 & I felt a sense of control over the game. & I feel a sense of control over the game. \\
\hline 41 & $\begin{array}{l}\text { I wanted to do as well as possible when I was playing the } \\
\text { game. }\end{array}$ & I want to do as well as possible during the game. \\
\hline 42 & $\begin{array}{l}\text { I found the game interface was easy to navigate } \\
\text { through. }\end{array}$ & I find the game's interface to be easy to navigate. \\
\hline 43 & $\begin{array}{l}\text { I always knew my next goal after I finished an event in } \\
\text { the game. }\end{array}$ & $\begin{array}{l}\text { I always know my next goal when I finish an event in the } \\
\text { game. }\end{array}$ \\
\hline 44 & Sometimes I lost track of time when I played the game. & Sometimes I lose track of time while playing the game. \\
\hline 45 & $\begin{array}{l}\text { I felt all of my senses were completely engaged while } \\
\text { playing the game. }\end{array}$ & $\begin{array}{l}\text { I feel all of my senses are completely engaged during the } \\
\text { game. }\end{array}$ \\
\hline 46 & I felt annoyed while playing the game. & I feel annoyed with the game while playing it. \\
\hline 47 & $\begin{array}{l}\text { I was deeply concentrated in the game when I was } \\
\text { playing it. }\end{array}$ & I am in deep concentration when playing the game. \\
\hline
\end{tabular}




\section{REVISED ITEM POOL AFTER EXPERT REVIEW}

\begin{tabular}{|c|c|c|}
\hline Item \# & Item Before Expert Review & Revised Item After Expert Review \\
\hline 48 & $\begin{array}{l}\text { I was in suspense about whether I would win or lose the } \\
\text { game. }\end{array}$ & I am in suspense about whether I will succeed in the game. \\
\hline 49 & If given the chance, I would replay this game again. & If given the chance, I want to play this game again. \\
\hline 50 & I enjoyed the graphics and imagery of the game. & I enjoy the game's graphics. \\
\hline 51 & $\begin{array}{l}\text { I felt the game constantly motivating me to keep } \\
\text { playing. }\end{array}$ & $\begin{array}{l}\text { I feel the game constantly motivates me to proceed further } \\
\text { to the next stage or level. }\end{array}$ \\
\hline 52 & I found the game to have delightful surprises. & $\begin{array}{l}\text { I find the game to have delightful surprises (e.g., special } \\
\text { rewards, unique characters, hidden stories). }\end{array}$ \\
\hline 53 & $\begin{array}{l}\text { I felt successful when I overcame the obstacles in the } \\
\text { game. }\end{array}$ & I feel successful when I overcome the obstacles in the game. \\
\hline 54 & I thought that I could play the game at my own pace. & I am able to play the game at my own pace. \\
\hline 55 & I felt the events in the game were happening to me. & I feel the events in the game are happening to me. \\
\hline 56 & $\begin{array}{l}\text { I thought it was easy for me to identify my score/status } \\
\text { in the game. }\end{array}$ & I can easily identify my score or status in the game. \\
\hline 57 & I thought the game was unique/original. & I think the game is unique or original. \\
\hline 58 & $\begin{array}{l}\text { I was able to recover when I made a fatal mistake in the } \\
\text { game. }\end{array}$ & $\begin{array}{l}\text { I can recover when I make a big mistake in the game (e.g., } \\
\text { exit without saving). }\end{array}$ \\
\hline 59 & $\begin{array}{l}\text { I usually ended up spending more time playing the game } \\
\text { than I had planned. }\end{array}$ & $\begin{array}{l}\text { I tend to spend more time playing the game than I have } \\
\text { planned. }\end{array}$ \\
\hline 60 & I had many ways to win the game. & I have many ways to succeed in the game. \\
\hline 61 & I usually found my way in the game world. & I usually find my way around in the game world. \\
\hline 62 & $\begin{array}{l}\text { I was focused on the task at hand when I was playing the } \\
\text { game. }\end{array}$ & I am focused on the task(s) at hand during the game. \\
\hline 63 & I thought the game was fun. & I think the game is fun. \\
\hline 64 & I enjoyed the fantasy or story provided by the game. & I enjoy the fantasy or story provided by the game. \\
\hline 65 & I enjoyed the music in the game. & I enjoy the music in the game. \\
\hline
\end{tabular}




\section{REVISED ITEM POOL AFTER EXPERT REVIEW}

\begin{tabular}{|c|c|c|}
\hline Item \# & Item Before Expert Review & Revised Item After Expert Review \\
\hline 66 & $\begin{array}{l}\text { I thought it was easy to return to where I left off in the } \\
\text { game. }\end{array}$ & I find it is easy to return to where I left off in the game. \\
\hline 67 & I found many events in the game to be novel. & I find many events in the game to be novel or unique. \\
\hline 68 & $\begin{array}{l}\text { I thought the rewards in the game were given in a timely } \\
\text { manner. }\end{array}$ & $\begin{array}{l}\text { I think the rewards (e.g., points, special items, special } \\
\text { abilities) in the game are given in a timely manner. }\end{array}$ \\
\hline 69 & I felt that I could explore things in the game. & I feel I can explore things in the game. \\
\hline 70 & I enjoyed playing the game. & I enjoy playing the game. \\
\hline 71 & I felt the game trained me in all of the controls. & I feel the game trains me well in all of the controls. \\
\hline 72 & $\begin{array}{l}\text { I found this game to be the type of game that I often } \\
\text { played. }\end{array}$ & $\begin{array}{l}\text { I find this game to be the type of video game that I often } \\
\text { play. }\end{array}$ \\
\hline 73 & $\begin{array}{l}\text { I thought it was easy to save the game in different } \\
\text { states. }\end{array}$ & I think it is easy to save the game at different stages. \\
\hline 74 & $\begin{array}{l}\text { It was difficult for me to return to the real world } \\
\text { mentally after I stopped playing the game. }\end{array}$ & $\begin{array}{l}\text { I find it hard to return to the real world when I stop playing } \\
\text { the game. }\end{array}$ \\
\hline 75 & I thought the game supported different playing styles. & I think the game supports different styles of playing. \\
\hline 76 & I felt creative while playing the game. & I feel creative while playing the game. \\
\hline 77 & $\begin{array}{l}\text { I was very focused on my own performance while } \\
\text { playing the game. }\end{array}$ & $\begin{array}{l}\text { I am very focused on my own performance while playing the } \\
\text { game. }\end{array}$ \\
\hline 78 & $\begin{array}{l}\text { I thought the game had unique features that kept me } \\
\text { interested. }\end{array}$ & $\begin{array}{l}\text { I think the game has enough unique features to keep me } \\
\text { interested. }\end{array}$ \\
\hline 79 & I found the game's menus to be user friendly. & I find the game's menus to be user friendly. \\
\hline 80 & I felt bored while playing the game. & I feel bored while playing the game. \\
\hline 81 & $\begin{array}{l}\text { I was quickly captured by the game story at the } \\
\text { beginning. }\end{array}$ & I am captivated by the game's story from the beginning. \\
\hline
\end{tabular}




\section{REVISED ITEM POOL AFTER EXPERT REVIEW}

\begin{tabular}{|c|c|c|}
\hline Item \# & Item Before Expert Review & Revised Item After Expert Review \\
\hline 82 & $\begin{array}{l}\text { I received adequate feedback on my progress in the } \\
\text { game. }\end{array}$ & I receive adequate feedback on my progress in the game. \\
\hline 83 & I felt very confident while playing the game. & I feel very confident while playing the game. \\
\hline 84 & $\begin{array}{l}\text { I temporarily forgot about my everyday worries while } \\
\text { playing the game. }\end{array}$ & $\begin{array}{l}\text { I temporarily forget about my everyday worries while playing } \\
\text { the game. }\end{array}$ \\
\hline 85 & $\begin{array}{l}\text { I thought the information (e.g., onscreen messages, } \\
\text { help) provided in the game was clear. }\end{array}$ & $\begin{array}{l}\text { I think the information provided in the game (e.g., onscreen } \\
\text { messages, help) is clear. }\end{array}$ \\
\hline 86 & $\begin{array}{l}\text { I was able to easily customize important features (e.g., } \\
\text { audio settings) in the game. }\end{array}$ & I can easily customize settings (e.g., audio) in the game. \\
\hline 87 & $\begin{array}{l}\text { I was able to predict what would happen next in } \\
\text { response to my actions in the game. }\end{array}$ & $\begin{array}{l}\text { I can predict what will happen next in response to my actions } \\
\text { in the game. }\end{array}$ \\
\hline 88 & $\begin{array}{l}\text { I thought the rewards given in the game were effective } \\
\text { in motivating me to progress further in the game. }\end{array}$ & $\begin{array}{l}\text { I find the game's rewards are effective in motivating me to } \\
\text { progress further in the game. }\end{array}$ \\
\hline 89 & $\begin{array}{l}\text { I felt this game reminded me of my favorite games in the } \\
\text { past. }\end{array}$ & $\begin{array}{l}\text { I find this game to be similar to one of my past favorite } \\
\text { games. }\end{array}$ \\
\hline 90 & $\begin{array}{l}\text { I thought the game provided me adequate support to } \\
\text { overcome the challenges in the game. }\end{array}$ & $\begin{array}{l}\text { I receive adequate support (e.g., hints) from the game to } \\
\text { overcome its challenges. }\end{array}$ \\
\hline 91 & $\begin{array}{l}\text { I thought the game taught me skills that were useful in } \\
\text { the game. }\end{array}$ & $\begin{array}{l}\text { I think the game teaches me useful skills that I can use in the } \\
\text { game. }\end{array}$ \\
\hline 92 & I felt the game did not put unnecessary burden on me. & $\begin{array}{l}\text { I feel the game requires more mental effort to play than } \\
\text { necessary. }\end{array}$ \\
\hline 93 & $\begin{array}{l}\text { I thought the game provided all necessary information } \\
\text { to accomplish a goal within the game. }\end{array}$ & $\begin{array}{l}\text { I feel the game provides me the necessary information to } \\
\text { accomplish a goal within the game. }\end{array}$ \\
\hline 94 & $\begin{array}{l}\text { I thought the game environment was responsive to the } \\
\text { actions that I performed in the game. }\end{array}$ & $\begin{array}{l}\text { I find the game environment to be responsive to my actions } \\
\text { in the game. }\end{array}$ \\
\hline
\end{tabular}




\section{REVISED ITEM POOL AFTER EXPERT REVIEW}

\begin{tabular}{|c|c|c|}
\hline Item \# & Item Before Expert Review & Revised Item After Expert Review \\
\hline 95 & $\begin{array}{l}\text { I thought the game was helpful in preventing me from } \\
\text { making irreversible errors in the game. }\end{array}$ & $\begin{array}{l}\text { I find the game to be helpful in preventing me from making } \\
\text { irreversible errors (e.g., delete important items). }\end{array}$ \\
\hline 96 & $\begin{array}{l}\text { I thought the graphics were appropriate for this type of } \\
\text { game. }\end{array}$ & $\begin{array}{l}\text { I think the graphics of the game fit the mood or style of the } \\
\text { game. }\end{array}$ \\
\hline 97 & $\begin{array}{l}\text { I thought the graphics and audio of the game were } \\
\text { related. }\end{array}$ & I think the game's audio fits the mood or style of the game. \\
\hline 98 & New & I like to play this game with other players. \\
\hline 99 & New & $\begin{array}{l}\text { I find social communities to be supported outside of the } \\
\text { games (e.g., online forums). }\end{array}$ \\
\hline 100 & New & I enjoy the social interaction within the game. \\
\hline 101 & $\begin{array}{l}\text { I kept looking forward to what will happen next in the } \\
\text { game. }\end{array}$ & Removed \\
\hline 102 & $\begin{array}{l}\text { I thought the game provided me adequate hints to } \\
\text { overcome the challenges in the game. }\end{array}$ & Removed \\
\hline 103 & I felt spaced out when I'm playing the game. & Removed \\
\hline 104 & $\begin{array}{l}\text { I felt time went by very quickly when I'm playing the } \\
\text { game. }\end{array}$ & Removed \\
\hline 105 & I felt curious while playing the game. & Removed \\
\hline 106 & I always knew how I was progressing in the game. & Removed \\
\hline 107 & $\begin{array}{l}\text { I was very concerned about whether I would win or lose } \\
\text { the game. }\end{array}$ & Removed \\
\hline 108 & $\begin{array}{l}\text { I was completely involved in the task that I am } \\
\text { performing while playing the game. }\end{array}$ & Removed \\
\hline 109 & I felt emotionally involved in the game. & Removed \\
\hline 110 & I like to spend a lot of time playing this game. & Removed \\
\hline 111 & I forgot about my surroundings while playing the game. & Removed \\
\hline
\end{tabular}


APPENDIX M (continued)

REVISED ITEM POOL AFTER EXPERT REVIEW

\begin{tabular}{|c|c|c|}
\hline Item \# & Item Before Expert Review & Revised Item After Expert Review \\
\hline 112 & I had fun interacting with the game. & Removed \\
\hline 113 & I thought it was easy to know where I am in the game. & Removed \\
\hline 114 & I felt the game was real. & Removed \\
\hline 115 & I always knew the next step in the game. & Removed \\
\hline 116 & $\begin{array}{l}\text { I was very absorbed in what I was doing while playing } \\
\text { the game. }\end{array}$ & Removed \\
\hline 117 & I knew what I was supposed to do to win the game. & Removed \\
\hline 118 & $\begin{array}{l}\text { I found the game's user interface interfered with my } \\
\text { ability to play the game. }\end{array}$ & Removed \\
\hline 119 & $\begin{array}{l}\text { I thought the graphics were related to the scenarios in } \\
\text { the game. }\end{array}$ & Removed \\
\hline
\end{tabular}




\section{APPENDIX N \\ PILOT STUDY: SCREENING SURVEY}

Do you play video games on at least one of the following devices: cellphone/smartphone, tablet, console, desktop, laptop, and handheld device?

o Yes

o No (Skip to the "Non-Gamers" section)

At what age did you first begin playing video games? Please enter a whole number.

What type of video game player do you consider yourself?

o Newbie/Novice

o Casual

o Mid-core/Core

o Hardcore/Expert

What is/are your MAIN reason(s) for playing video games? Check all that apply.

To "let off" some steam

$\square$ To challenge my mind

$\square$ To waste time

$\square$ To immerse myself in another world

$\square$ To socialize with other people

$\square$ To compete with other people or computers

$\square$ For pure enjoyment

$\square$ Boredom

$\square$ To follow a storyline

$\square$ To live another life

$\square$ To improve my physical/mental skills

$\square$ To gain power

$\square$ Other, please specify 
APPENDIX N (continued)

\section{PILOT STUDY: SCREENING SURVEY}

On average, how many hours do you spend playing video games per week?

0 Less than 1 hour

o 1 to 4 hours

o 5 to 9 hours

o 10 to 19 hours

o 20 to 29 hours

o 30 to 39 hours

o More than 40 hours

When was the last time you played video games?

o Today

o Yesterday

o Last week

0 Last month

O About 2-3 months ago

o About 4-5 months ago

o About 6-11 months ago

- About a year ago

o More than a year ago

In general, please check the frequency circle that best describes the frequency in which you play video games on the following devices.

\begin{tabular}{|l|l|l|l|l|l|}
\hline & Never & Rarely & Sometimes & Often & $\begin{array}{c}\text { All of the } \\
\text { Time }\end{array}$ \\
\hline $\begin{array}{l}\text { A computer device (e.g., laptop, } \\
\text { desktop) }\end{array}$ & & & & & \\
\hline $\begin{array}{l}\text { A console device (e.g., Xbox 360, } \\
\text { Playstation 4, Nintendo Wii) }\end{array}$ & & & & & \\
\hline $\begin{array}{l}\text { A handheld gaming device (e.g., Game } \\
\text { Boy Advance, Nintendo DS) }\end{array}$ & & & & & \\
\hline $\begin{array}{l}\text { A mobile device (e.g., smartphone, } \\
\text { tablet) }\end{array}$ & & & & & \\
\hline
\end{tabular}


APPENDIX N (continued)

\section{PILOT STUDY: SCREENING SURVEY}

Rate your level of OVERALL knowledge about video games using the following scale.

\begin{tabular}{|c|c|c|c|c|c|c|}
\hline $\begin{array}{c}1 \\
\text { (Novice) }\end{array}$ & 2 & 3 & $\begin{array}{c}4 \\
\text { (Intermediate) }\end{array}$ & 5 & 6 & $\begin{array}{c}7 \\
\text { (Expert) }\end{array}$ \\
\hline
\end{tabular}

In general, please check the frequency circle that best describes the frequency in which you play the following game genres.

\begin{tabular}{|l|l|l|l|l|l|}
\hline & Never & Rarely & Sometimes & Often & $\begin{array}{c}\text { All of the } \\
\text { Time }\end{array}$ \\
\hline Action (e.g., Halo, Call of Duty) & & & & & \\
\hline Simulation (e.g., The Sims, Spore) & & & & & \\
\hline Driving (e.g., Forza, Mario Kart) & & & & & \\
\hline Puzzle/Card (e.g., Tetris, Solitaire) & & & & & \\
\hline $\begin{array}{l}\text { Role Playing (e.g., Elder Scroll, World of } \\
\text { Warcraft) }\end{array}$ & & & & & \\
\hline $\begin{array}{l}\text { Adventure (e.g., Resident Evil, Grand } \\
\text { Theft Auto) }\end{array}$ & & & & & \\
\hline Strategy (e.g., Civilization, Starcraft) & & & & & \\
\hline
\end{tabular}

In general, please check the frequency circle that best describes the frequency in which you play the following game genres.

\begin{tabular}{|l|l|l|l|l|l|}
\hline & Never & Rarely & Sometimes & $\begin{array}{c}\text { Often } \\
\text { Sports (e.g., Madden, FIFA) }\end{array}$ Time \\
\hline $\begin{array}{l}\text { Fighting (e.g., Soul Caliber, Mortal } \\
\text { Kombat) }\end{array}$ & & & & & \\
\hline $\begin{array}{l}\text { Music/Dance (e.g., Guitar Hero, Just } \\
\text { Dance) }\end{array}$ & & & & & \\
\hline $\begin{array}{l}\text { Educational/Edutainment (e.g., Math } \\
\text { Blaster, Professor Layton Series) }\end{array}$ & & & & & \\
\hline $\begin{array}{l}\text { Fitness (e.g., Wii Fit, Your Shape: Fitness } \\
\text { Evolved) }\end{array}$ & & & & & \\
\hline $\begin{array}{l}\text { Social/Social Network (e.g., Farmville, } \\
\text { Candy Crush) }\end{array}$ & & & & & \\
\hline $\begin{array}{l}\text { Retro/Classic (e.g., Pacman, The Original } \\
\text { Donkey Kong) }\end{array}$ & & & & & \\
\hline
\end{tabular}


APPENDIX N (continued)

\section{PILOT STUDY: SCREENING SURVEY}

Please list 1-5 video games that you have played in the past $\mathbf{3}$ months. Avoid abbreviating the name of the game, and write out the official name of the games.

Put "N/A" if you have not played any video games in the past 3 months.

On average, how many hours have you spent playing the games you listed above.

o Less than 5 hours

o 5 to 9 hours

o 10 to 19 hours

o 20 to 39 hours

o 40 to 79 hours

o 80 to 120 hours

o More than 120 hours

o I do not play any video games in the past 3 months.

\section{Non-Gamers}

Is there a particular reason that you do not play video games? Check all that apply.

It's expensive.

$\square$ I do not have time to play.

$\square \quad$ None of the people I hang out with play video games.

$\square$ It's too violent.

$\square$ I do not thing it would be entertaining.

$\square \quad$ I feel that I am too old for video games.

$\square \quad$ It's too difficult.

$\square$ I do not have enough technical know-how to play.

$\square$ It's boring/pointless.

$\square$ It's too masculine.

$\square$ It gives me motion sickness.

$\square$ Other, please specify 
APPENDIX N (continued)

PILOT STUDY: SCREENING SURVEY

\section{Demographics Info}

Age:

Gender:

o Male

o Female

\section{Occupation:}

\section{Ethnicity:}

o American Indian/Alaskan Native

o White (not of Hispanic origin)

o Black/African American

- Asian/Pacific Islander

o Hispanic/Latino

- Biracial/Multiracial/Mixed

o I do not wish to answer.

Highest level of education completed:

o Middle school or less

- Some high school

- High school graduate or GED

o Some college

- College graduate (2- and 4-year degree)

o Post-graduate degree (MA, PhD, Law, Medical, or Professional school)

Is English your native/first language?

o Yes

o No

(If answered "No")

What is your native/first language? 
APPENDIX N (continued)

\section{PILOT STUDY: SCREENING SURVEY}

\section{(If answered "No")}

How long have you been using English to communicate with other people?
0 Less than 1 year
01 to 2 years
03 to 4 years
o 5 to 6 years
0 7 to 9 years
o 10 to 14 years
o 15 to 19 years
0 More than 20 years 
APPENDIX O

PILOT STUDY: CONSENT FORM

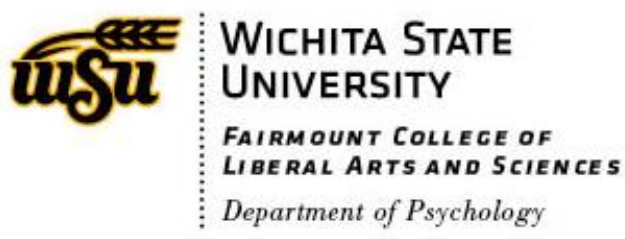

Consent Form

Purpose: Since you are 18 years of age or older, you are invited to participate in a study investigating video game satisfaction. We hope to gather your feedback about the design of the survey so that we can improve the survey for future studies.

Participant Selection: You were selected as a possible participant in this study because you fit the criteria of the population we are interested in studying, namely that you are at least the age of 18 and you have recently played a video game. You are one of 16 participants in this study.

Explanation of Procedures: If you decide to participate, you will first be asked to complete an online survey in this room to evaluate a video game you recently played through a series of statements (e.g., I think the game is fun.) on a 7-point scale ( 1 = Strongly Disagree; 7 = Strongly Agree) while speaking your thoughts aloud whenever you encountered a statement in which it is difficult for you to rate and/or interpret. After you have completed the survey, you will be presented with a paper copy of the survey in which you will be asked to revisit the problematic statements and clarify why they were problematic and offer suggestions to improve them. The whole one-on-one interview session will take approximately 30-45 minutes.

Discomfort/Risks: There are no expected risks or discomforts. However, you may take a break at any time, and you may skip any questions that make you feel uncomfortable.

Benefits: Your participation in this study will be beneficial in helping researchers build a better instrument to measure video game satisfaction.

Confidentiality: Every effort will be made to keep your study-related information confidential. However, in order to make sure the study is done properly and safely there may be circumstances where this information must be released. By signing this form, you are giving the research team permission to share information about you with the following groups: 


\section{APPENDIX O (continued)}

\section{PILOT STUDY: CONSENT FORM}

- Office for Human Research Protections or other federal, state, or international regulatory agencies;

- The Wichita State University Institutional Review Board;

- The sponsor or agency supporting the study.

The researchers may publish the results of the study. If they do, they will only discuss group results. Your name will not be used in any publication or presentation about the study. We will work to make sure that no one sees your survey responses without approval. But, because we are using the Internet, there is a chance that someone could access your online responses without permission. In some cases, this information could be used to identify you. Your data will be protected with a code to reduce the risk that other people can view the responses.

Compensation: For your participation, you will be awarded with 3 SONA credits.

Refusal/Withdrawal: Participation in this study is entirely voluntary. Your decision whether or not to participate will not affect your future relations with Wichita State University. If you agree to participate in this study, you are free to withdraw from the study at any time without penalty.

Contact: If you have any questions about this research, you may contact Mikki Phan at mhphan@wichita.edu or you can contact Dr. Barbara Chaparro at 316-978-3683 or via e-mail at barbara.chaparro@wichita.edu. If you have questions pertaining to your rights as a research subject, or about research-related injury, you can contact the Office of Research and Technology Transfer at Wichita State University, 1845 Fairmount Street, Wichita, KS 672600007, telephone (316) 978-3285.

You are under no obligation to participate in this study. By selecting the "Next >>" button below, you are indicating that:

- You have read (or someone has read to you) the information provided above,

- You are aware that this is a research study,

- You have voluntarily decided to participate. 


\section{APPENDIX P \\ PILOT STUDY: INSTRUCTION SCRIPT}

\section{At the beginning of each pilot session the following instructions were read to participants:}

Thank you for taking the time to participate in this study. Today, you will be asked to use an online survey to evaluate a video game that you have played within the last three months. As you are completing the survey please pay careful attention to the wordings on the survey. If at any point you encountered words or statements on the survey that is difficult to understand or interpret please speak aloud the issue so that I can note it on my computer.

Once the survey is completed we will revisit the issues that you encountered while taking the survey, and you will be asked to clarify these issues. Your feedback in today's session will help to refine the survey before it goes out to a large sample of video game players. So, please feel free to be candid with your comments - as they will not hurt my feelings. Do you have any questions before we begin?

If you do not have any questions, please begin the survey once you are ready. 


\section{APPENDIX Q \\ A SCREENSHOT OF ONE OF THE GAME EVALUATION PAGES}

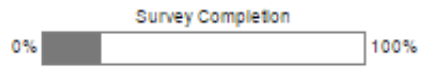

\section{Game Evaluation}

Based on your experience playing this game, please rate the following statements on a scale from Strongly Disagree to Strongly Agree.

It is possible that the game you are evaluating does not have the specific feature that is mentioned in a particular statement (e.g., story, characters, tutorials). If you feel the missing feature should

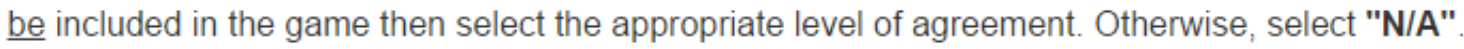

\begin{tabular}{|c|c|c|c|c|c|c|c|}
\hline & $\begin{array}{l}\text { Strongly } \\
\text { Disagree }\end{array}$ & Disagree & $\begin{array}{l}\text { Somewhat } \\
\text { Disagree }\end{array}$ & $\begin{array}{c}\text { Neither } \\
\text { Agree } \\
\text { nor } \\
\text { Disagree }\end{array}$ & $\begin{array}{c}\text { Somewhat } \\
\text { Agree }\end{array}$ & Agree & $\begin{array}{c}\text { Strongly } \\
\text { Agree }\end{array}$ \\
\hline $\begin{array}{l}\text { I enjoy the fantasy } \\
\text { or story provided } \\
\text { by the game. }\end{array}$ & 0 & 0 & 0 & 0 & 0 & 0 & 0 \\
\hline $\begin{array}{l}\text { I find it is easy to } \\
\text { return to where I } \\
\text { left off in the } \\
\text { game. }\end{array}$ & 0 & 0 & 0 & 0 & 0 & 0 & 0 \\
\hline $\begin{array}{l}\text { I think the game is } \\
\text { fun. }\end{array}$ & 0 & 0 & 0 & 0 & 0 & 0 & 0 \\
\hline $\begin{array}{l}\text { I am focused on } \\
\text { the task(s) at } \\
\text { hand during the } \\
\text { game. }\end{array}$ & 0 & 0 & 0 & 0 & 0 & 0 & $\bigcirc$ \\
\hline $\begin{array}{l}\text { I enjoy the music } \\
\text { in the game. }\end{array}$ & 0 & 0 & 0 & 0 & 0 & 0 & 0 \\
\hline
\end{tabular}


APPENDIX R

REVISED ITEM POOL AFTER THE PILOT STUDY

\begin{tabular}{|c|c|c|}
\hline Item \# & Item Before the Pilot Study & Revised Item After the Pilot Study \\
\hline 1 & I find the game captures my attention from the get-go. & $\begin{array}{l}\text { I find the game captures my attention from the very } \\
\text { beginning. }\end{array}$ \\
\hline 2 & I think the game is visually appealing. & Same \\
\hline 3 & $\begin{array}{l}\text { I feel the game's audio (e.g., sound effects, music) } \\
\text { enhances my gaming experience. }\end{array}$ & Same \\
\hline 4 & I can identify with the characters in the game. & Same \\
\hline 5 & I feel energized while playing the game. & Same \\
\hline 6 & $\begin{array}{l}\text { I can easily maintain my attention on the game during } \\
\text { game play. }\end{array}$ & Same \\
\hline 7 & $\begin{array}{l}\text { I find my skills gradually improve through the course of } \\
\text { overcoming the challenges in the game. }\end{array}$ & Same \\
\hline 8 & I feel the game allows me to be imaginative. & Same \\
\hline 9 & I like to play this game with other players. & Same \\
\hline 10 & I find the controls of the game to be straightforward. & Same \\
\hline 11 & I understand the rules of the game. & Same \\
\hline 12 & $\begin{array}{l}\text { I find the game supports social interaction (e.g., chat) } \\
\text { between players. }\end{array}$ & Same \\
\hline 13 & I think most people will enjoy playing this game. & Same \\
\hline 14 & $\begin{array}{l}\text { I feel the visual representations (e.g., icons, avatars, } \\
\text { map) in the game enhance my gaming experience. }\end{array}$ & Same \\
\hline 15 & I enjoy the sound effects in the game. & Same \\
\hline 16 & I think the characters in the game are well developed. & Same \\
\hline 17 & I am emotionally moved by the events in the game. & Same \\
\hline 18 & $\begin{array}{l}\text { I do not care to check my real-world surroundings while } \\
\text { playing the game. }\end{array}$ & $\begin{array}{l}\text { I do not care to check events that are happening in the real } \\
\text { world during the game. }\end{array}$ \\
\hline 19 & I think the game's level of difficulty is right for me. & Same \\
\hline
\end{tabular}


APPENDIX R (continued)

REVISED ITEM POOL AFTER THE PILOT STUDY

\begin{tabular}{|c|c|c|}
\hline Item \# & Item Before the Pilot Study & Revised Item After the Pilot Study \\
\hline 20 & I feel the game allows me to express myself. & Same \\
\hline 21 & $\begin{array}{l}\text { I feel the game gives me enough freedom to act how I } \\
\text { want. }\end{array}$ & Same \\
\hline 22 & $\begin{array}{l}\text { I am very interested in seeing how the events in the } \\
\text { game will progress. }\end{array}$ & Same \\
\hline 23 & I think it is easy to learn how to play the game. & Same \\
\hline 24 & $\begin{array}{l}\text { I can easily skip any non-playable content (e.g., video } \\
\text { sequences) that does not capture my interest. }\end{array}$ & $\begin{array}{l}\text { I can easily skip any non-playable content (e.g., videos, story } \\
\text { scenes) that does not capture my interest. }\end{array}$ \\
\hline 25 & I always know how to achieve my goal(s) in the game. & $\begin{array}{l}\text { I always know how to achieve my goals/objectives in the } \\
\text { game. }\end{array}$ \\
\hline 26 & I am able to play the game with other players if I choose. & Same \\
\hline 27 & I am likely to recommend this game to others. & Same \\
\hline 28 & I can clearly understand the story presents in the game. & I can clearly understand the game's story. \\
\hline 29 & $\begin{array}{l}\text { Sometimes I find myself wanting to speak directly to the } \\
\text { game while playing it. }\end{array}$ & Same \\
\hline 30 & $\begin{array}{l}\text { I feel detached from the outside world while playing the } \\
\text { game. }\end{array}$ & Same \\
\hline 31 & $\begin{array}{l}\text { I find it is easy to customize the overall difficulty level of } \\
\text { the game. }\end{array}$ & Same \\
\hline 32 & $\begin{array}{l}\text { I challenge myself even when the game does not require } \\
\text { it. }\end{array}$ & Same \\
\hline 33 & $\begin{array}{l}\text { I do not need to go through a lengthy tutorial or read a } \\
\text { manual to play the game. }\end{array}$ & Same \\
\hline 34 & $\begin{array}{l}\text { I can see everything that I need to see on the screen } \\
\text { during the game. }\end{array}$ & Same \\
\hline
\end{tabular}


APPENDIX R (continued)

\section{REVISED ITEM POOL AFTER THE PILOT STUDY}

\begin{tabular}{|c|c|c|}
\hline Item \# & Item Before the Pilot Study & Revised Item After the Pilot Study \\
\hline 35 & I think the outcomes in the game are fair. & Same \\
\hline 36 & $\begin{array}{l}\text { Whenever I stopped playing the game I cannot wait to } \\
\text { start playing it again. }\end{array}$ & Same \\
\hline 37 & $\begin{array}{l}\text { I think the game's audio fits the mood or style of the } \\
\text { game. }\end{array}$ & Same \\
\hline 38 & I feel happy while playing the game. & Same \\
\hline 39 & $\begin{array}{l}\text { I feel my curiosity are stimulated as the result of playing } \\
\text { the game. }\end{array}$ & $\begin{array}{l}\text { I feel my curiosity is stimulated as the result of playing the } \\
\text { game. }\end{array}$ \\
\hline 40 & $\begin{array}{l}\text { I can block out most other distractions when playing the } \\
\text { game. }\end{array}$ & Same \\
\hline 41 & $\begin{array}{l}\text { I find social communities to be supported outside of the } \\
\text { games (e.g., online forums). }\end{array}$ & Same \\
\hline 42 & $\begin{array}{l}\text { I cannot tell that I am getting tired while playing the } \\
\text { game. }\end{array}$ & Same \\
\hline 43 & I feel a sense of control over the game. & Same \\
\hline 44 & I want to do as well as possible during the game. & Same \\
\hline 45 & I find the game's interface to be easy to navigate. & Same \\
\hline 46 & $\begin{array}{l}\text { I always know my next goal when I finish an event in the } \\
\text { game. }\end{array}$ & Same \\
\hline 47 & I enjoy the social interaction within the game. & Same \\
\hline 48 & Sometimes I lose track of time while playing the game. & Same \\
\hline 49 & $\begin{array}{l}\text { I feel all of my senses are completely engaged during the } \\
\text { game. }\end{array}$ & Same \\
\hline 50 & I feel annoyed with the game while playing it. & Same \\
\hline 51 & I am in deep concentration when playing the game. & Same \\
\hline
\end{tabular}


REVISED ITEM POOL AFTER THE PILOT STUDY

\begin{tabular}{|c|c|c|}
\hline Item \# & Item Before the Pilot Study & Revised Item After the Pilot Study \\
\hline 52 & $\begin{array}{l}\text { I am in suspense about whether I will succeed in the } \\
\text { game. }\end{array}$ & Same \\
\hline 53 & If given the chance, I want to play this game again. & Same \\
\hline 54 & I enjoy the game's graphics. & Same \\
\hline 55 & $\begin{array}{l}\text { I feel the game constantly motivates me to proceed } \\
\text { further to the next stage or level. }\end{array}$ & Same \\
\hline 56 & $\begin{array}{l}\text { I find the game to have delightful surprises (e.g., special } \\
\text { rewards, unique characters, hidden stories). }\end{array}$ & Same \\
\hline 57 & $\begin{array}{l}\text { I feel successful when I overcome the obstacles in the } \\
\text { game. }\end{array}$ & Same \\
\hline 58 & I am able to play the game at my own pace. & Same \\
\hline 59 & I feel the events in the game are happening to me. & Same \\
\hline 60 & I can easily identify my score or status in the game. & Same \\
\hline 61 & I think the game is unique or original. & Same \\
\hline 62 & $\begin{array}{l}\text { I can recover when I make a big mistake in the game } \\
\text { (e.g., exit without saving). }\end{array}$ & Same \\
\hline 63 & $\begin{array}{l}\text { I tend to spend more time playing the game than I have } \\
\text { planned. }\end{array}$ & Same \\
\hline 64 & I have many ways to succeed in the game. & Same \\
\hline 65 & I usually find my way around in the game world. & Same \\
\hline 66 & I am focused on the task(s) at hand during the game. & Same \\
\hline 67 & I think the game is fun. & Same \\
\hline 68 & I enjoy the fantasy or story provided by the game. & Same \\
\hline 69 & I enjoy the music in the game. & Same \\
\hline 70 & I find it is easy to return to where I left off in the game. & Same \\
\hline 71 & I find many events in the game to be novel or unique. & Same \\
\hline
\end{tabular}


REVISED ITEM POOL AFTER THE PILOT STUDY

\begin{tabular}{|c|c|c|}
\hline Item \# & Item Before the Pilot Study & Revised Item After the Pilot Study \\
\hline 72 & $\begin{array}{l}\text { I think the rewards (e.g., points, special items, special } \\
\text { abilities) in the game are given in a timely manner. }\end{array}$ & Same \\
\hline 73 & I feel I can explore things in the game. & Same \\
\hline 74 & I enjoy playing the game. & Same \\
\hline 75 & I feel the game trains me well in all of the controls. & Same \\
\hline 76 & $\begin{array}{l}\text { I find this game to be the type of video game that I often } \\
\text { play. }\end{array}$ & Same \\
\hline 77 & I think it is easy to save the game at different stages. & Same \\
\hline 78 & I think the game supports different styles of playing. & Same \\
\hline 79 & $\begin{array}{l}\text { I find it hard to return to the real world when I stop } \\
\text { playing the game. }\end{array}$ & Same \\
\hline 80 & I feel creative while playing the game. & Same \\
\hline 81 & $\begin{array}{l}\text { I am very focused on my own performance while playing } \\
\text { the game. }\end{array}$ & Same \\
\hline 82 & $\begin{array}{l}\text { I think the game has enough unique features to keep me } \\
\text { interested. }\end{array}$ & Same \\
\hline 83 & I find the game's menus to be user friendly. & Same \\
\hline 84 & $\begin{array}{l}\text { I think the graphics of the game fit the mood or style of } \\
\text { the game. }\end{array}$ & Same \\
\hline 85 & I feel bored while playing the game. & Same \\
\hline 86 & I am captivated by the game's story from the beginning. & Same \\
\hline 87 & $\begin{array}{l}\text { I receive adequate feedback on my progress in the } \\
\text { game. }\end{array}$ & Same \\
\hline 88 & I feel very confident while playing the game. & Same \\
\hline 89 & $\begin{array}{l}\text { I temporarily forget about my everyday worries while } \\
\text { playing the game. }\end{array}$ & Same \\
\hline
\end{tabular}


APPENDIX R (continued)

REVISED ITEM POOL AFTER THE PILOT STUDY

\begin{tabular}{|c|c|c|}
\hline Item \# & Item Before the Pilot Study & Revised Item After the Pilot Study \\
\hline 90 & $\begin{array}{l}\text { I think the information provided in the game (e.g., } \\
\text { onscreen messages, help) is clear. }\end{array}$ & Same \\
\hline 91 & I can easily customize settings (e.g., audio) in the game. & Same \\
\hline 92 & $\begin{array}{l}\text { I can predict what will happen next in response to my } \\
\text { actions in the game. }\end{array}$ & Same \\
\hline 93 & $\begin{array}{l}\text { I find the game's rewards are effective in motivating me } \\
\text { to progress further in the game. }\end{array}$ & Same \\
\hline 94 & $\begin{array}{l}\text { I find this game to be similar to one of my past favorite } \\
\text { games. }\end{array}$ & Same \\
\hline 95 & $\begin{array}{l}\text { I receive adequate support (e.g., hints) from the game to } \\
\text { overcome its challenges. }\end{array}$ & Same \\
\hline 96 & $\begin{array}{l}\text { I think the game teaches me useful skills that I can use in } \\
\text { the game. }\end{array}$ & Same \\
\hline 97 & $\begin{array}{l}\text { I feel the game requires more mental effort to play than } \\
\text { necessary. }\end{array}$ & Same \\
\hline 98 & $\begin{array}{l}\text { I feel the game provides me the necessary information } \\
\text { to accomplish a goal within the game. }\end{array}$ & Same \\
\hline 99 & $\begin{array}{l}\text { I find the game environment to be responsive to my } \\
\text { actions in the game. }\end{array}$ & Same \\
\hline 100 & $\begin{array}{l}\text { I find the game to be helpful in preventing me from } \\
\text { making irreversible errors (e.g., delete important items). }\end{array}$ & Same \\
\hline
\end{tabular}


APPENDIX S

EFA STUDY: UNIQUE VIDEO GAME TITLES EVALUATED

\begin{tabular}{|c|c|c|c|}
\hline Number & Game Title & $n$ & Main Genre (Sub-Genre) \\
\hline 1 & Alien Swarm & 1 & Action (TPS) \\
\hline 2 & Ancient Domains of Mystery & 1 & RPG \\
\hline 3 & Angband & 1 & RPG \\
\hline 4 & Angry Birds & 1 & Puzzle/Card/Board \\
\hline 5 & Animal Crossing: City Folk & 1 & Simulation (Virtual Life) \\
\hline 6 & Animal Crossing: New Leaf & 3 & Simulation (Virtual Life) \\
\hline 7 & ArmA III & 2 & Action (FPS) \\
\hline 8 & Assassin's Creed & 1 & Action Adventure (Stealth) \\
\hline 9 & Assassin's Creed II & 2 & Action Adventure (Stealth) \\
\hline 10 & Assassin's Creed IV: Black Flag & 1 & Action Adventure (Stealth) \\
\hline 11 & Assassin's Creed Rogue & 1 & Action Adventure (Stealth) \\
\hline 12 & Assassin's Creed Unity & 7 & Action Adventure (Stealth) \\
\hline 13 & Assassin's Creed III: Liberation & 1 & Action Adventure (Stealth) \\
\hline 14 & Audiosurf & 1 & Music/Dance \\
\hline 15 & Bakery Story & 1 & Strategy (Time Management) \\
\hline 16 & Batman: Arkham City & 2 & Action Adventure (Open-World) \\
\hline 17 & Batman: Arkham Origins & 1 & Action Adventure (Stealth) \\
\hline 18 & Batman: Arkham Origins Blackgate & 1 & Action Adventure (Stealth) \\
\hline 19 & Battlefield 4 & 3 & Action (FPS) \\
\hline 20 & Bayonetta & 1 & Action Adventure \\
\hline 21 & Big Farm & 1 & Strategy (Time Management) \\
\hline 22 & BioShock & 2 & Action (FPS) \\
\hline 23 & Blacklight: Retribution & 1 & Action (FPS) \\
\hline 24 & Blood Brothers & 1 & RPG (Massively Multiplayer) \\
\hline 25 & Borderlands 2 & 6 & Action (FPS) \\
\hline
\end{tabular}


APPENDIX S (continued)

EFA STUDY: UNIQUE VIDEO GAME TITLES EVALUATED

\begin{tabular}{|c|c|c|c|}
\hline Number & Game Title & $n$ & Main Genre (Sub-Genre) \\
\hline 26 & Borderlands: The Pre-Sequel & 5 & Action (FPS) \\
\hline 27 & BrainWars: Competitive Brain Training Game Brain Wars & 1 & Puzzle/Card/Board \\
\hline 28 & Bubble Shooter & 2 & Puzzle/Card/Board \\
\hline 29 & Bubble Witch Saga 2 & 1 & Puzzle/Card/Board \\
\hline 30 & Call of Duty & 6 & Action (FPS) \\
\hline 31 & Call of Duty: Advanced Warfare & 18 & Action (FPS) \\
\hline 32 & Call of Duty: Black Ops & 2 & Action (FPS) \\
\hline 33 & Call of Duty: Black Ops II & 6 & Action (FPS) \\
\hline 34 & Call of Duty: Ghosts & 7 & Action (FPS) \\
\hline 35 & Call of Duty: Modern Warfare 3 & 1 & Action (FPS) \\
\hline 36 & Candy Crush Saga & 11 & Puzzle/Card/Board \\
\hline 37 & Child of Light & 1 & $\mathrm{RPG}$ \\
\hline 38 & Circle & 1 & Puzzle/Card/Board \\
\hline 39 & Clash of Clans & 4 & Strategy (Real-Time) \\
\hline 40 & Combine (Mindjolt) & 1 & Puzzle/Card/Board \\
\hline 41 & Cooking Fever & 1 & Strategy (Time Management) \\
\hline 42 & Counter-Strike & 1 & Action (FPS) \\
\hline 43 & Counter-Strike: Global Offensive & 5 & Action (FPS) \\
\hline 44 & Crusader Kings II & 2 & Strategy (Real-Time) \\
\hline 45 & Dark Souls & 3 & RPG (Action RPG) \\
\hline 46 & Dark Souls 2 & 3 & RPG (Action RPG) \\
\hline 47 & Dayz & 1 & Action (FPS) \\
\hline 48 & Dead Island & 1 & Action Adventure (Survival/Horror) \\
\hline 49 & Dead Space 2 & 1 & Action (TPS) \\
\hline 50 & Dead Trigger 2 & 1 & Action (FPS) \\
\hline
\end{tabular}


EFA STUDY: UNIQUE VIDEO GAME TITLES EVALUATED

\begin{tabular}{|c|c|c|c|}
\hline Number & Game Title & $n$ & Main Genre (Sub-Genre) \\
\hline 51 & Defender's Quest: Valley of the Forgotten & 1 & Strategy (Real-Time) \\
\hline 52 & Defense of the Ancients (DotA) 2 & 8 & Strategy (Real-Time) \\
\hline 53 & Defiance & 1 & Action (TPS) \\
\hline 54 & Demon's Souls & 1 & RPG (Action RPG) \\
\hline 55 & Despicable Me: Minion Rush & 1 & Action (Platformer) \\
\hline 56 & Destiny & 27 & Action (FPS) \\
\hline 57 & Deus Ex & 1 & Action Adventure (Open-World) \\
\hline 58 & Diablo III & 2 & RPG (Action RPG) \\
\hline 59 & Diablo III: Reaper of Souls & 2 & RPG (Action RPG) \\
\hline 60 & Diner Dash & 1 & Strategy (Time Management) \\
\hline 61 & Dishonored & 1 & Action Adventure (Stealth) \\
\hline 62 & Dragon Age 2 & 1 & RPG (Action RPG) \\
\hline 63 & Dragon Age: Inquisition & 4 & RPG \\
\hline 64 & Dragon Age: Origins & 5 & RPG \\
\hline 65 & Dragon Nest & 1 & RPG (Massively Multiplayer) \\
\hline 66 & Dragon's Crown & 1 & Action (Beat-'Em-Up) \\
\hline 67 & Dungeon Hunter 4 & 1 & RPG (Action RPG) \\
\hline 68 & Slaves to Armok: God of Blood Chapter II: Dwarf Fortress & 1 & Simulation \\
\hline 69 & Dynasty Warriors 8 & 1 & Action (Beat-'Em-Up) \\
\hline 70 & Earthbound (MOTHER 2) & 1 & RPG \\
\hline 71 & Escape Plan & 1 & Puzzle/Card/Board \\
\hline 72 & Europa Universalis IV: El Dorado & 3 & Strategy (Real-Time) \\
\hline 73 & EverQuest & 1 & RPG (Massively Multiplayer) \\
\hline 74 & EverQuest II & 1 & RPG (Massively Multiplayer) \\
\hline 75 & Fable & 1 & RPG (Action RPG) \\
\hline
\end{tabular}


APPENDIX S (continued)

EFA STUDY: UNIQUE VIDEO GAME TITLES EVALUATED

\begin{tabular}{|c|c|c|c|}
\hline Number & Game Title & $n$ & Main Genre (Sub-Genre) \\
\hline 76 & Fable Anniversary & 1 & RPG (Action RPG) \\
\hline 77 & Fallout 3 & 4 & RPG \\
\hline 78 & Fallout: New Vegas & 3 & RPG \\
\hline 79 & Far Cry 3 & 2 & Action (FPS) \\
\hline 80 & Far Cry 4 & 4 & Action (FPS) \\
\hline 81 & Fez & 1 & Action (Platformer) \\
\hline 82 & FIFA 11 & 1 & Sports \\
\hline 83 & FIFA 14 & 6 & Sports \\
\hline 84 & FIFA 15 & 7 & Sports \\
\hline 85 & FIFA Soccer & 2 & Sports \\
\hline 86 & FIFA Soccer 12 & 1 & Sports \\
\hline 87 & Final Fantasy Tactics Advance & 1 & Strategy (Turn-Based) \\
\hline 88 & Final Fantasy X HD Remaster & 1 & RPG \\
\hline 89 & Final Fantasy XIV Online: A Realm Reborn & 3 & RPG (Massively Multiplayer) \\
\hline 90 & Forza Horizon 2 & 2 & Driving/Racing \\
\hline 91 & Freefall & 1 & Action \\
\hline 92 & Garry's Mod & 1 & Action Adventure (Sandbox) \\
\hline 93 & God of War & 1 & Action Adventure \\
\hline 94 & GODUS & 1 & Simulation \\
\hline 95 & Grand Theft Auto & 1 & Action Adventure (Open-World) \\
\hline 96 & Grand Theft Auto V & 29 & Action Adventure (Open-World) \\
\hline 97 & Guild Wars 2 & 2 & RPG (Massively Multiplayer) \\
\hline 98 & Guitar Hero & 2 & Music/Dance \\
\hline 99 & Guitar Hero 3 & 2 & Music/Dance \\
\hline 100 & Guitar Hero World Tour & 1 & Music/Dance \\
\hline
\end{tabular}




\begin{tabular}{|c|c|c|c|}
\hline Number & Game Title & $n$ & Main Genre (Sub-Genre) \\
\hline 101 & Half-Life 2 & 2 & Action (FPS) \\
\hline 102 & Halo 4 & 3 & Action (FPS) \\
\hline 103 & Halo 5: Guardians & 1 & Action (FPS) \\
\hline 104 & Halo Reach & 1 & Action (FPS) \\
\hline 105 & Halo Wars & 1 & Strategy (Real-Time) \\
\hline 106 & Halo: Combat Evolved & 3 & Action (FPS) \\
\hline 107 & Halo: The Master Chief Collection & 1 & Action (FPS) \\
\hline 108 & Harvest Moon: A New Beginning & 1 & Simulation (Virtual Life) \\
\hline 109 & Hatsune Miku Project Diva F & 1 & Music/Dance \\
\hline 110 & Hay Day & 3 & Strategy \\
\hline 111 & Hearthstone: Heroes of Warcraft & 2 & Strategy (Turn-Based) \\
\hline 112 & Heavy Rain & 2 & Action Adventure \\
\hline 113 & Heroes and Generals & 1 & Action (FPS) \\
\hline 114 & Heroes of the Storm & 1 & Strategy (MOBA) \\
\hline 115 & Hill Climb Racing & 1 & Driving/Racing \\
\hline 116 & House of Fun - Slots & 1 & Puzzle/Card/Board \\
\hline 117 & Infinity Blade III & 1 & RPG (Action RPG) \\
\hline 118 & iRacing & 1 & Driving/Racing \\
\hline 119 & James Bond 007: Blood Stone & 1 & Action (TPS) \\
\hline 120 & Jetpack Joyride & 2 & Simulation (Flight/Space) \\
\hline 121 & Just Cause 2 & 1 & Action Adventure (Open-World) \\
\hline 122 & Kerbal Space Program & 4 & Simulation (Flight/Space) \\
\hline 123 & Killing Floor & 1 & Action (FPS) \\
\hline 124 & Kim Kardashian: Hollywood & 2 & Simulation \\
\hline 125 & King of Dragon Pass & 1 & Strategy (Turn-Based) \\
\hline 126 & Kingdom Hearts & 1 & RPG (Action RPG) \\
\hline
\end{tabular}


APPENDIX S (continued)

EFA STUDY: UNIQUE VIDEO GAME TITLES EVALUATED

\begin{tabular}{|c|c|c|c|}
\hline Number & Game Title & $n$ & Main Genre (Sub-Genre) \\
\hline 127 & Kingdom Hearts HD 1.5 Remix & 1 & RPG (Action RPG) \\
\hline 128 & Kitchen Scramble & 1 & Strategy (Time Management) \\
\hline 129 & League of Legends & 25 & Strategy (MOBA) \\
\hline 130 & Legend of Zelda: Ocarina of Time & 1 & Action Adventure (Open-World) \\
\hline 131 & LEGO The Lord of the Rings & 1 & Action Adventure (Open-World) \\
\hline 132 & LittleBigPlanet & 2 & Action (Platformer) \\
\hline 133 & Luftrausers & 1 & Action (Shoot-'Em-Up) \\
\hline 134 & Luigi's Mansion & 1 & Action Adventure (Open-World) \\
\hline 135 & Luigi's Mansion: Dark Moon & 1 & Action Adventure (Open-World) \\
\hline 136 & Madden NFL 15 & 6 & Sports \\
\hline 137 & Madden NFL 25 & 2 & Sports \\
\hline 138 & MapleStory & 1 & RPG (Massively Multiplayer) \\
\hline 139 & Mario Kart Wii & 17 & Driving/Racing \\
\hline 140 & Mass Effect 3 & 4 & RPG (Action RPG) \\
\hline 141 & Metal Gear Solid V: Ground Zeroes & 1 & Action Adventure (Stealth) \\
\hline 142 & Metro 2033 & 1 & Action (FPS) \\
\hline 143 & Microsoft Solitaire & 1 & Puzzle/Card/Board \\
\hline 144 & Middle-earth: Shadow of Mordor & 3 & RPG (Action RPG) \\
\hline 145 & Minecraft & 15 & Action Adventure (Sandbox) \\
\hline 146 & Monster Hunter 3 Ultimate & 3 & RPG (Action RPG) \\
\hline 147 & Mortal Kombat & 1 & Fighting \\
\hline 148 & Mortal Kombat Komplete Edition & 1 & Fighting \\
\hline 149 & Mortal Kombat vs. DC Universe & 2 & Fighting \\
\hline 150 & Ms. Pac-Man & 1 & Action (Arcade) \\
\hline 151 & My Singing Monsters & 1 & Simulation \\
\hline
\end{tabular}


APPENDIX S (continued)

EFA STUDY: UNIQUE VIDEO GAME TITLES EVALUATED

\begin{tabular}{|c|c|c|c|}
\hline Number & Game Title & $n$ & Main Genre (Sub-Genre) \\
\hline 152 & MyVegas Slots & 2 & Puzzle/Card/Board \\
\hline 153 & Nancy Drew: Labyrinth of Lies & 1 & Adventure \\
\hline 154 & NBA 2 K12 & 1 & Sports \\
\hline 155 & NBA 2 K14 & 5 & Sports \\
\hline 156 & NBA 2 K15 & 8 & Sports \\
\hline 157 & NBA LIVE 2004 & 1 & Sports \\
\hline 158 & New Super Mario Bros. Wii & 7 & Action (Platformer) \\
\hline 159 & Pac-Man & 1 & Action (Arcade) \\
\hline 160 & Paper Mario: Sticker Star & 1 & RPG \\
\hline 161 & Parasite Eve & 1 & RPG \\
\hline 162 & Path of Exile & 2 & RPG (Action RPG) \\
\hline 163 & Payday 2 & 3 & Action (FPS) \\
\hline 164 & Peggle & 1 & Puzzle/Card/Board \\
\hline 165 & Perfect World International & 1 & RPG (Massively Multiplayer) \\
\hline 166 & Persona 4 Golden & 1 & RPG \\
\hline 167 & PlanetSide 2 & 1 & Action (FPS) \\
\hline 168 & Plants vs Zombies 2: It's About Time & 2 & Strategy (Real-Time) \\
\hline 169 & Plants vs. Zombies & 3 & Strategy (Real-Time) \\
\hline 170 & Pokemon Alpha Sapphire & 2 & RPG \\
\hline 171 & Pokemon Red Version & 1 & RPG \\
\hline 172 & Pokemon X & 4 & RPG \\
\hline 173 & Pokemon Y & 2 & RPG \\
\hline 174 & Portal & 1 & Action (FPS) \\
\hline 175 & Portal 2 & 1 & Action (FPS) \\
\hline 176 & Puzzle and Dragons & 1 & Puzzle/Card/Board \\
\hline
\end{tabular}


APPENDIX S (continued)

EFA STUDY: UNIQUE VIDEO GAME TITLES EVALUATED

\begin{tabular}{|c|c|c|c|}
\hline Number & Game Title & $n$ & Main Genre (Sub-Genre) \\
\hline 177 & Red Dead Redemption & 3 & Action Adventure \\
\hline 178 & Red Faction: Guerrilla & 1 & Action (TPS) \\
\hline 179 & Resident Evil & 1 & Action Adventure (Survival/Horror) \\
\hline 180 & Resident Evil 6 & 1 & Action Adventure (Survival/Horror) \\
\hline 181 & Rhythm Heaven & 1 & Music/Dance \\
\hline 182 & Risk of Rain & 1 & Action (Platformer) \\
\hline 183 & Rock Band & 1 & Music/Dance \\
\hline 184 & Rocksmith 2014 Edition & 1 & Music/Dance \\
\hline 185 & Ryse Son of Rome & 1 & Action (Beat-'Em-Up) \\
\hline 186 & Saints Row IV & 1 & Action Adventure (Open-World) \\
\hline 187 & Samurai Warriors 4 & 1 & Action (Beat-'Em-Up) \\
\hline 188 & Shadowrun Dragonfall: Director's Cut & 1 & RPG \\
\hline 189 & Sid Meier's Civilization V & 2 & Strategy (Turn-Based) \\
\hline 190 & Silent Hill 2 & 1 & Action Adventure (Survival/Horror) \\
\hline 191 & Silent Hill: Homecoming & 1 & Action Adventure (Survival/Horror) \\
\hline 192 & SimCity (2013) & 1 & Strategy (Management) \\
\hline 193 & Skate 2 & 1 & Sports \\
\hline 194 & Skullgirls & 1 & Fighting \\
\hline 195 & Snood & 1 & Puzzle/Card/Board \\
\hline 196 & SoulCalibur & 1 & Fighting \\
\hline 197 & South Park: The Stick of Truth & 1 & RPG \\
\hline 198 & Spelunky & 1 & Action (Platformer) \\
\hline 199 & Spider-Man Unlimited & 1 & Action Adventure \\
\hline 200 & Splinter Cell: Blacklist & 1 & Action Adventure (Stealth) \\
\hline 201 & SpongeBob SquarePants: Battle for Bikini Bottom & 1 & Action (Platformer) \\
\hline
\end{tabular}


APPENDIX S (continued)

EFA STUDY: UNIQUE VIDEO GAME TITLES EVALUATED

\begin{tabular}{|c|c|c|c|}
\hline Number & Game Title & $n$ & Main Genre (Sub-Genre) \\
\hline 202 & Star Wars: The Old Republic & 2 & RPG (Massively Multiplayer) \\
\hline 203 & Starcraft II & 1 & Strategy (Real-Time) \\
\hline 204 & Subway Surfer & 1 & Action \\
\hline 205 & Sunset Overdrive & 1 & Action (TPS) \\
\hline 206 & Super Mario 3D World & 1 & Action (Platformer) \\
\hline 207 & Super Mario Galaxy & 1 & Action (Platformer) \\
\hline 208 & Super Mario World & 1 & Action (Platformer) \\
\hline 209 & Super Monkey Ball & 1 & Action \\
\hline 210 & Super Smash Bros. for Nintendo 3DS & 3 & Fighting \\
\hline 211 & Super Smash Bros. for Wii U & 6 & Fighting \\
\hline 212 & Taiko Drum Master & 1 & Music/Dance \\
\hline 213 & Tales of Symphonia & 1 & RPG \\
\hline 214 & Team Fortress 2 & 2 & Action (FPS) \\
\hline 215 & TERA & 1 & RPG (Massively Multiplayer) \\
\hline 216 & Tetris & 2 & Puzzle/Card/Board \\
\hline 217 & The Binding of Isaac & 1 & Action Adventure (Survival/Horror) \\
\hline 218 & The Binding of Isaac: Rebirth & 4 & Action Adventure (Survival/Horror) \\
\hline 219 & The Elder Scrolls Online & 1 & RPG (Massively Multiplayer) \\
\hline 220 & The Elder Scrolls V: Skyrim & 19 & RPG \\
\hline 221 & The Elder Scrolls: Oblivion & 2 & RPG \\
\hline 222 & The Evil Within & 3 & Action Adventure (Survival/Horror) \\
\hline 223 & The Last of Us & 6 & Action Adventure (Survival/Horror) \\
\hline 224 & The Last of Us Remastered & 2 & Action Adventure (Survival/Horror) \\
\hline 225 & The Legend of Korra & 1 & Action (Beat-'Em-Up) \\
\hline 226 & The Legend of Zelda: A Link Between Worlds & 1 & Action Adventure (Open-World) \\
\hline
\end{tabular}


APPENDIX S (continued)

EFA STUDY: UNIQUE VIDEO GAME TITLES EVALUATED

\begin{tabular}{|c|c|c|c|}
\hline Number & Game Title & $n$ & Main Genre (Sub-Genre) \\
\hline 227 & The Legend of Zelda: The Wind Waker for Wii U & 1 & Action Adventure (Open-World) \\
\hline 228 & The Mana World & 1 & RPG (Massively Multiplayer) \\
\hline 229 & The Sims 2 & 3 & Simulation (Virtual Life) \\
\hline 230 & The Sims 3 & 10 & Simulation (Virtual Life) \\
\hline 231 & The Sims FreePlay & 1 & Simulation (Virtual Life) \\
\hline 232 & The Walking Dead: Season 2 & 1 & Adventure \\
\hline 233 & The Walking Dead: The Game & 1 & Adventure \\
\hline 234 & The Witcher 2: Assassins of Kings & 1 & RPG (Action RPG) \\
\hline 235 & The Witcher: Enhanced Edition & 1 & RPG (Action RPG) \\
\hline 236 & The Wolf Among Us & 1 & Action Adventure \\
\hline 237 & Titanfall & 1 & Action (FPS) \\
\hline 238 & Tomb Raider & 2 & Action Adventure \\
\hline 239 & Tropico 5 & 1 & Simulation \\
\hline 240 & TwoDots & 2 & Puzzle/Card/Board \\
\hline 241 & Victoria II & 2 & Strategy (Real-Time) \\
\hline 242 & Wartune & 1 & RPG (Massively Multiplayer) \\
\hline 243 & Watch Dogs & 1 & Action Adventure (Open World) \\
\hline 244 & Wheel of Fortune & 1 & Puzzle/Card/Board \\
\hline 245 & Wii Fit & 1 & Fitness \\
\hline 246 & Wolfenstein & 1 & Action (FPS) \\
\hline 247 & Wolfenstein: The New Order & 1 & Action (FPS) \\
\hline 248 & Words With Friends & 4 & Puzzle/Card/Board \\
\hline 249 & World of Tanks & 5 & Action (TPS) \\
\hline 250 & World of Warcraft & 21 & RPG (Massively Multiplayer) \\
\hline 251 & World of Warcraft: Warlords of Draenor & 1 & RPG (Massively Multiplayer) \\
\hline
\end{tabular}


APPENDIX S (continued)

EFA STUDY: UNIQUE VIDEO GAME TITLES EVALUATED

\begin{tabular}{rllc}
\hline Number & Game Title & $\boldsymbol{n}$ & Main Genre (Sub-Genre) \\
\hline 252 & WWE 2K15 & 1 & Sports \\
253 & XCOM: Enemy Within & 1 & Strategy (Turn-Based) \\
254 & Zone 4: Fight District & 1 & RPG (Massively Multiplayer) \\
\hline Note: Each video game title was categorized under one main genre. Various popular gaming websites (e.g., GameFaqs.com, Metacritic.com, and IGN.com)
\end{tabular}

Note: Each video game title was categorized under one main genre. Various popular gaming websites (e.g., GameFaqs.com, Metacritic.com, and IGN.com) were consulted during the game genre classification process. 


\section{APPENDIX T}

\section{EFA STUDY: CONSENT FORM}

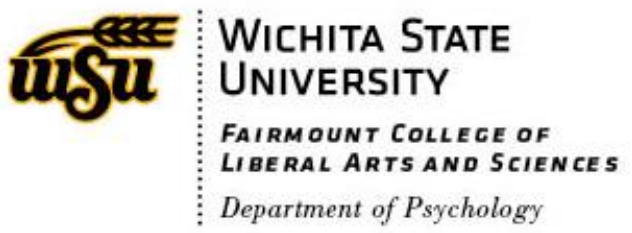

Consent Form

Purpose: Since you are 18 years of age or older, you are invited to participate in a study investigating video game satisfaction. We hope to learn more about how people rate different video games that they currently play or have recently played.

Participant Selection: You were selected as a possible participant in this study because you fit the criteria of the population we are interested in studying, namely that you are over the age of 18 and you have recently played a video game. You are one of at least 600 participants in this study.

Explanation of Procedures: If you decide to participate, you will be asked to complete an online survey to evaluate a video game you recently played through a series of statements (e.g., I would play this game again.) on a 7-point scale ( 1 = Strongly Disagree; 7 = Strongly Agree). Also, you will be asked to answer other questions related to the game you're evaluating (e.g., the device platform that you used to play the game), and general demographics questions (e.g., age, gender). The survey will take approximately 20-30 minutes to complete.

Discomfort/Risks: There are no expected risks or discomforts. However, you may take a break at any time, and you may skip any questions that make you feel uncomfortable.

Benefits: Your participation in this study will be beneficial in helping researchers better understand the key factors that contribute to video game satisfaction.

Confidentiality: Every effort will be made to keep your study-related information confidential. However, in order to make sure the study is done properly and safely there may be circumstances where this information must be released. By signing this form, you are giving the research team permission to share information about you with the following groups:

- Office for Human Research Protections or other federal, state, or international regulatory agencies;

- The Wichita State University Institutional Review Board;

- The sponsor or agency supporting the study. 


\section{APPENDIX T (continued)}

\section{EFA STUDY: CONSENT FORM}

The researchers may publish the results of the study. If they do, they will only discuss group results. Your name will not be used in any publication or presentation about the study. We will work to make sure that no one sees your survey responses without approval. But, because we are using the Internet, there is a chance that someone could access your online responses without permission. In some cases, this information could be used to identify you. Your data will be protected with a code to reduce the risk that other people can view the responses.

Compensation: For your participation, your name will be entered in a random drawing to win one of ten $\$ 50$ Amazon gift cards.

Refusal/Withdrawal: Participation in this study is entirely voluntary. Your decision whether or not to participate will not affect your future relations with Wichita State University. If you agree to participate in this study, you are free to withdraw from the study at any time without penalty.

Contact: If you have any questions about this research, you may contact Mikki Phan at mhphan@wichita.edu or you can contact Dr. Barbara Chaparro at 316-978-3683 or via e-mail at barbara.chaparro@wichita.edu. If you have questions pertaining to your rights as a research subject, or about research-related injury, you can contact the Office of Research and Technology Transfer at Wichita State University, 1845 Fairmount Street, Wichita, KS 672600007, telephone (316) 978-3285.

You are under no obligation to participate in this study. By selecting the "Next $>>$ " button below, you are indicating that:

- You have read (or someone has read to you) the information provided above,

- You are aware that this is a research study,

- You have voluntarily decided to participate. 
APPENDIX U

\section{EFA AND CFA STUDIES: DEMOGRAPHICS QUESTIONS}

\section{Demographics Info}

You are almost done! Please tell us a bit about yourself.

Age:

Gender:

o Male

o Female

\section{Ethnicity:}

o American Indian/Alaskan Native

o White (not of Hispanic origin)

o Black/African American

o Asian/Pacific Islander

o Hispanic/Latino

o Biracial/Multiracial/Mixed

o I do not wish to answer.

Highest level of education completed:

o Middle school or less

o Some high school

o High school graduate or GED

o Some college

o College graduate (2- and 4-year degree)

o Post-graduate degree (MA, PhD, Law, Medical, or Professional school)

\section{Occupation:}

\section{What type of video game player do you consider yourself?}

o Newbie/Novice

- Casual

o Mid-core/Core

o Hardcore/Expert 
APPENDIX U (continued)

EFA AND CFA STUDIES: DEMOGRAPHICS QUESTIONS

On average, how many hours do you spend playing video games per week?

o Less than 1 hour

o 1 to 4 hours

o 5 to 9 hours

o 10 to 19 hours

o 20 to 29 hours

o 30 to 39 hours

o More than 40 hours

Which of the following devices do you FREQUENTLY use to play video games? Check all that apply.

A computer device (e.g., laptop, desktop)

A console device (e.g., Xbox 360, Playstation 4, Nintendo Wii)

A handheld gaming device (e.g., Game Boy Advance, Nintendo DS)

A mobile device (e.g., smartphone, tablet)

Which of the following video game genres do you FREQUENTLY play? Check all that apply.

Action (e.g., Halo, Call of Duty)

$\square$ Adventure (e.g., Resident Evil, Grand Theft Auto)

$\square$ Driving (e.g., Forza, Mario Kart)

$\square$ Educational/Edutainment (e.g., Math Blaster, Professor Layton Series)

Fighting (e.g., Soul Caliber, Mortal Kombat)

Fitness (e.g., Wii Fit, Your Shape: Fitness Evolved)

$\square$ Music/Dance (e.g., Guitar Hero, Just Dance)
Puzzle/Card (e.g., Tetris, Solitaire)

Retro/Classic (e.g., Pacman, The Original Donkey Kong)

Role Playing (e.g., Elder Scroll, World of Warcraft)

Simulation (e.g., The Sims, Spore)

Social/Social Network (e.g., Farmville, Candy Crush)

Sports (e.g., Madden NFL, FIFA)

Strategy (e.g., Civilization, Starcraft) 
APPENDIX V

EFA STUDY: SKEWESS AND KURTOSIS VALUES OF ITEMS

\begin{tabular}{|c|c|c|c|c|c|c|c|}
\hline \multirow[t]{2}{*}{ Item } & \multirow[t]{2}{*}{$n$} & \multirow[t]{2}{*}{ Mean } & \multirow[t]{2}{*}{ SD } & \multicolumn{2}{|c|}{ Skewness } & \multicolumn{2}{|c|}{ Kurtosis } \\
\hline & & & & Value & Std. Error & Value & Std. Error \\
\hline $\begin{array}{l}\text { I find the game captures my attention from the } \\
\text { very beginning. }\end{array}$ & 626 & 6.20 & 1.13 & -2.02 & 0.10 & 5.00 & 0.20 \\
\hline I think the game is visually appealing. & 625 & 6.25 & 1.03 & -2.06 & 0.10 & 5.59 & 0.20 \\
\hline $\begin{array}{l}\text { I feel the game's audio (e.g., sound effects, } \\
\text { music) enhances my gaming experience. }\end{array}$ & 623 & 5.93 & 1.42 & -1.67 & 0.10 & 2.48 & 0.20 \\
\hline I can identify with the characters in the game. & 588 & 4.58 & 1.76 & -0.41 & 0.10 & -0.75 & 0.20 \\
\hline I feel energized while playing the game. & 625 & 5.64 & 1.31 & -1.13 & 0.10 & 1.17 & 0.20 \\
\hline $\begin{array}{l}\text { I can easily maintain my attention on the game } \\
\text { during game play. }\end{array}$ & 626 & 6.31 & 0.89 & -2.09 & 0.10 & 6.91 & 0.20 \\
\hline $\begin{array}{l}\text { I find my skills gradually improve through the } \\
\text { course of overcoming the challenges in the } \\
\text { game. }\end{array}$ & 625 & 6.23 & 1.00 & -1.92 & 0.10 & 5.35 & 0.20 \\
\hline I feel the game allows me to be imaginative. & 622 & 5.38 & 1.55 & -0.89 & 0.10 & 0.16 & 0.20 \\
\hline I like to play this game with other players. & 549 & 5.47 & 1.97 & -1.10 & 0.10 & -0.15 & 0.21 \\
\hline $\begin{array}{l}\text { I find the controls of the game to be } \\
\text { straightforward. }\end{array}$ & 628 & 6.13 & 1.13 & -2.00 & 0.10 & 5.09 & 0.19 \\
\hline I understand the rules of the game. & 622 & 6.56 & 0.69 & -1.85 & 0.10 & 4.33 & 0.20 \\
\hline $\begin{array}{l}\text { I find the game supports social interaction (e.g., } \\
\text { chat) between players. }\end{array}$ & 534 & 4.94 & 1.97 & -0.67 & 0.11 & -0.83 & 0.21 \\
\hline I think most people will enjoy playing this game. & 627 & 5.56 & 1.32 & -0.91 & 0.10 & 0.40 & 0.19 \\
\hline $\begin{array}{l}\text { I feel the visual representations (e.g., icons, } \\
\text { avatars, map) in the game enhance my gaming } \\
\text { experience. }\end{array}$ & 621 & 6.02 & 1.11 & -1.45 & 0.10 & 2.61 & 0.20 \\
\hline
\end{tabular}


APPENDIX V (continued)

EFA STUDY: SKEWESS AND KURTOSIS VALUES OF ITEMS

\begin{tabular}{|c|c|c|c|c|c|c|c|}
\hline \multirow[t]{2}{*}{ Item } & \multirow[t]{2}{*}{$n$} & \multirow[t]{2}{*}{ Mean } & \multirow[t]{2}{*}{ SD } & \multicolumn{2}{|c|}{ Skewness } & \multicolumn{2}{|c|}{ Kurtosis } \\
\hline & & & & Value & Std. Error & Value & Std. Error \\
\hline I enjoy the sound effects in the game. & 625 & 5.89 & 1.28 & -1.51 & 0.10 & 2.43 & 0.20 \\
\hline $\begin{array}{l}\text { I think the characters in the game are well } \\
\text { developed. }\end{array}$ & 562 & 5.22 & 1.65 & -0.86 & 0.10 & 0.04 & 0.21 \\
\hline $\begin{array}{l}\text { I am emotionally moved by the events in the } \\
\text { game. }\end{array}$ & 591 & 4.17 & 1.86 & -0.14 & 0.10 & -1.06 & 0.20 \\
\hline $\begin{array}{l}\text { I do not care to check events that are happening } \\
\text { in the real world during the game. }\end{array}$ & 622 & 4.07 & 1.83 & -0.04 & 0.10 & -1.10 & 0.20 \\
\hline $\begin{array}{l}\text { I think the game's level of difficulty is right for } \\
\text { me. }\end{array}$ & 621 & 5.87 & 1.15 & -1.38 & 0.10 & 2.31 & 0.20 \\
\hline I feel the game allows me to express myself. & 609 & 4.64 & 1.65 & -0.32 & 0.10 & -0.67 & 0.20 \\
\hline $\begin{array}{l}\text { I feel the game gives me enough freedom to act } \\
\text { how I want. }\end{array}$ & 614 & 5.54 & 1.46 & -1.01 & 0.10 & 0.43 & 0.20 \\
\hline $\begin{array}{l}\text { I am very interested in seeing how the events in } \\
\text { the game will progress. }\end{array}$ & 597 & 5.90 & 1.26 & -1.43 & 0.10 & 2.20 & 0.20 \\
\hline I think it is easy to learn how to play the game. & 629 & 5.68 & 1.50 & -1.39 & 0.10 & 1.29 & 0.19 \\
\hline $\begin{array}{l}\text { I can easily skip any non-playable content (e.g., } \\
\text { videos, story scenes) that does not capture my } \\
\text { interest. }\end{array}$ & 545 & 5.12 & 1.82 & -0.85 & 0.10 & -0.40 & 0.21 \\
\hline $\begin{array}{l}\text { I always know how to achieve my } \\
\text { goals/objectives in the game. }\end{array}$ & 629 & 5.67 & 1.28 & -1.13 & 0.10 & 1.08 & 0.19 \\
\hline $\begin{array}{l}\text { I am able to play the game with other players if I } \\
\text { choose. }\end{array}$ & 564 & 5.70 & 1.92 & -1.49 & 0.10 & 0.86 & 0.21 \\
\hline
\end{tabular}


APPENDIX V (continued)

EFA STUDY: SKEWESS AND KURTOSIS VALUES OF ITEMS

\begin{tabular}{|c|c|c|c|c|c|c|c|}
\hline \multirow[t]{2}{*}{ Item } & \multirow[t]{2}{*}{$n$} & \multirow[t]{2}{*}{ Mean } & \multirow[t]{2}{*}{ SD } & \multicolumn{2}{|c|}{ Skewness } & \multicolumn{2}{|c|}{ Kurtosis } \\
\hline & & & & Value & Std. Error & Value & Std. Error \\
\hline I am likely to recommend this game to others. & 625 & 6.26 & 1.06 & -1.98 & 0.10 & 4.76 & 0.20 \\
\hline I can clearly understand the game's story. & 555 & 5.95 & 1.24 & -1.53 & 0.10 & 2.38 & 0.21 \\
\hline $\begin{array}{l}\text { Sometimes I find myself wanting to speak } \\
\text { directly to the game while playing it. }\end{array}$ & 620 & 4.56 & 1.97 & -0.44 & 0.10 & -1.07 & 0.20 \\
\hline $\begin{array}{l}\text { I feel detached from the outside world while } \\
\text { playing the game. }\end{array}$ & 623 & 4.26 & 1.80 & -0.23 & 0.10 & -1.02 & 0.20 \\
\hline $\begin{array}{l}\text { I find it is easy to customize the overall difficulty } \\
\text { level of the game. }\end{array}$ & 585 & 5.19 & 1.81 & -0.90 & 0.10 & -0.24 & 0.20 \\
\hline $\begin{array}{l}\text { I challenge myself even when the game does } \\
\text { not require it. }\end{array}$ & 610 & 5.41 & 1.58 & -1.00 & 0.10 & 0.21 & 0.20 \\
\hline $\begin{array}{l}\text { I do not need to go through a lengthy tutorial or } \\
\text { read a manual to play the game. }\end{array}$ & 627 & 5.76 & 1.49 & -1.53 & 0.10 & 1.82 & 0.19 \\
\hline $\begin{array}{l}\text { I can see everything that I need to see on the } \\
\text { screen during the game. }\end{array}$ & 625 & 5.87 & 1.29 & -1.55 & 0.10 & 2.22 & 0.20 \\
\hline I think the outcomes in the game are fair. & 619 & 5.66 & 1.26 & -1.28 & 0.10 & 1.79 & 0.20 \\
\hline $\begin{array}{l}\text { Whenever I stopped playing the game I cannot } \\
\text { wait to start playing it again. }\end{array}$ & 628 & 4.78 & 1.50 & -0.38 & 0.10 & -0.59 & 0.19 \\
\hline $\begin{array}{l}\text { I think the game's audio fits the mood or style of } \\
\text { the game. }\end{array}$ & 621 & 6.18 & 1.04 & -1.84 & 0.10 & 4.82 & 0.20 \\
\hline I feel happy while playing the game. & 629 & 5.77 & 1.05 & -0.76 & 0.10 & 0.80 & 0.19 \\
\hline $\begin{array}{l}\text { I feel my curiosity is stimulated as the result of } \\
\text { playing the game. }\end{array}$ & 622 & 5.43 & 1.41 & -0.89 & 0.10 & 0.45 & 0.20 \\
\hline
\end{tabular}


APPENDIX V (continued)

EFA STUDY: SKEWESS AND KURTOSIS VALUES OF ITEMS

\begin{tabular}{|c|c|c|c|c|c|c|c|}
\hline \multirow[t]{2}{*}{ Item } & \multirow[t]{2}{*}{$n$} & \multirow[t]{2}{*}{ Mean } & \multirow[t]{2}{*}{ SD } & \multicolumn{2}{|c|}{ Skewness } & \multicolumn{2}{|c|}{ Kurtosis } \\
\hline & & & & Value & Std. Error & Value & Std. Error \\
\hline $\begin{array}{l}\text { I can block out most other distractions when } \\
\text { playing the game. }\end{array}$ & 628 & 5.49 & 1.34 & -0.95 & 0.10 & 0.68 & 0.19 \\
\hline $\begin{array}{l}\text { I find social communities to be supported } \\
\text { outside of the games (e.g., online forums). }\end{array}$ & 565 & 5.25 & 1.70 & -0.90 & 0.10 & -0.03 & 0.21 \\
\hline $\begin{array}{l}\text { I cannot tell that I am getting tired while playing } \\
\text { the game. }\end{array}$ & 625 & 4.22 & 1.92 & -0.05 & 0.10 & -1.33 & 0.20 \\
\hline I feel a sense of control over the game. & 625 & 5.60 & 1.24 & -1.14 & 0.10 & 1.50 & 0.20 \\
\hline I want to do as well as possible during the game. & 624 & 6.20 & 1.02 & -1.74 & 0.10 & 3.82 & 0.20 \\
\hline $\begin{array}{l}\text { I find the game's interface to be easy to } \\
\text { navigate. }\end{array}$ & 626 & 5.93 & 1.09 & -1.43 & 0.10 & 2.57 & 0.20 \\
\hline $\begin{array}{l}\text { I always know my next goal when I finish an } \\
\text { event in the game. }\end{array}$ & 614 & 5.47 & 1.41 & -1.03 & 0.10 & 0.51 & 0.20 \\
\hline I enjoy the social interaction within the game. & 515 & 5.04 & 1.60 & -0.71 & 0.11 & -0.22 & 0.21 \\
\hline $\begin{array}{l}\text { Sometimes I lose track of time while playing the } \\
\text { game. }\end{array}$ & 628 & 5.67 & 1.46 & -1.38 & 0.10 & 1.50 & 0.19 \\
\hline $\begin{array}{l}\text { I feel all of my senses are completely engaged } \\
\text { during the game. }\end{array}$ & 626 & 4.90 & 1.57 & -0.53 & 0.10 & -0.48 & 0.20 \\
\hline I feel annoyed with the game while playing it. & 627 & 3.68 & 1.73 & 0.13 & 0.10 & -1.04 & 0.19 \\
\hline $\begin{array}{l}\text { I am in deep concentration when playing the } \\
\text { game. }\end{array}$ & 629 & 5.54 & 1.38 & -1.09 & 0.10 & 0.94 & 0.19 \\
\hline $\begin{array}{l}\text { I am in suspense about whether I will succeed in } \\
\text { the game. }\end{array}$ & 620 & 5.07 & 1.74 & -0.70 & 0.10 & -0.54 & 0.20 \\
\hline $\begin{array}{l}\text { If given the chance, I want to play this game } \\
\text { again. }\end{array}$ & 626 & 6.31 & 1.01 & -2.10 & 0.10 & 5.76 & 0.20 \\
\hline
\end{tabular}


APPENDIX V (continued)

EFA STUDY: SKEWESS AND KURTOSIS VALUES OF ITEMS

\begin{tabular}{|c|c|c|c|c|c|c|c|}
\hline \multirow[t]{2}{*}{ Item } & \multirow[t]{2}{*}{$n$} & \multirow[t]{2}{*}{ Mean } & \multirow[t]{2}{*}{ SD } & \multicolumn{2}{|c|}{ Skewness } & \multicolumn{2}{|c|}{ Kurtosis } \\
\hline & & & & Value & Std. Error & Value & Std. Error \\
\hline I enjoy the game's graphics. & 629 & 6.19 & 1.00 & -1.67 & 0.10 & 3.57 & 0.19 \\
\hline $\begin{array}{l}\text { I feel the game constantly motivates me to } \\
\text { proceed further to the next stage or level. }\end{array}$ & 609 & 5.82 & 1.25 & -1.30 & 0.10 & 1.78 & 0.20 \\
\hline $\begin{array}{l}\text { I find the game to have delightful surprises (e.g., } \\
\text { special rewards, unique characters, hidden } \\
\text { stories). }\end{array}$ & 606 & 5.50 & 1.54 & -1.11 & 0.10 & 0.60 & 0.20 \\
\hline $\begin{array}{l}\text { I feel successful when I overcome the obstacles } \\
\text { in the game. }\end{array}$ & 621 & 6.19 & 0.92 & -1.38 & 0.10 & 2.32 & 0.20 \\
\hline I am able to play the game at my own pace. & 624 & 6.00 & 1.29 & -1.82 & 0.10 & 3.38 & 0.20 \\
\hline $\begin{array}{l}\text { I feel the events in the game are happening to } \\
\text { me. }\end{array}$ & 602 & 3.47 & 1.94 & 0.31 & 0.10 & -1.17 & 0.20 \\
\hline $\begin{array}{l}\text { I can easily identify my score or status in the } \\
\text { game. }\end{array}$ & 605 & 6.00 & 1.17 & -1.56 & 0.10 & 2.68 & 0.20 \\
\hline I think the game is unique or original. & 627 & 5.60 & 1.51 & -1.11 & 0.10 & 0.49 & 0.19 \\
\hline $\begin{array}{l}\text { I can recover when I make a big mistake in the } \\
\text { game (e.g., exit without saving). }\end{array}$ & 601 & 5.25 & 1.66 & -0.98 & 0.10 & 0.10 & 0.20 \\
\hline $\begin{array}{l}\text { I tend to spend more time playing the game } \\
\text { than I have planned. }\end{array}$ & 626 & 5.29 & 1.60 & -0.77 & 0.10 & -0.41 & 0.20 \\
\hline I have many ways to succeed in the game. & 618 & 5.66 & 1.33 & -1.20 & 0.10 & 1.30 & 0.20 \\
\hline I usually find my way around in the game world. & 579 & 6.03 & 1.11 & -1.54 & 0.10 & 2.91 & 0.20 \\
\hline $\begin{array}{l}\text { I am focused on the task(s) at hand during the } \\
\text { game. }\end{array}$ & 626 & 6.08 & 0.97 & -1.37 & 0.10 & 2.79 & 0.20 \\
\hline I think the game is fun. & 628 & 6.50 & 0.81 & -2.48 & 0.10 & 9.20 & 0.19 \\
\hline
\end{tabular}


APPENDIX V (continued)

EFA STUDY: SKEWESS AND KURTOSIS VALUES OF ITEMS

\begin{tabular}{|c|c|c|c|c|c|c|c|}
\hline \multirow[t]{2}{*}{ Item } & \multirow[t]{2}{*}{$n$} & \multirow[t]{2}{*}{ Mean } & \multirow[t]{2}{*}{ SD } & \multicolumn{2}{|c|}{ Skewness } & \multicolumn{2}{|c|}{ Kurtosis } \\
\hline & & & & Value & Std. Error & Value & Std. Error \\
\hline $\begin{array}{l}\text { I enjoy the fantasy or story provided by the } \\
\text { game. }\end{array}$ & 568 & 5.86 & 1.28 & -1.23 & 0.10 & 1.19 & 0.20 \\
\hline I enjoy the music in the game. & 616 & 5.71 & 1.50 & -1.32 & 0.10 & 1.24 & 0.20 \\
\hline $\begin{array}{l}\text { I find it is easy to return to where I left off in the } \\
\text { game. }\end{array}$ & 594 & 5.98 & 1.23 & -1.71 & 0.10 & 3.29 & 0.20 \\
\hline $\begin{array}{l}\text { I find many events in the game to be novel or } \\
\text { unique. }\end{array}$ & 602 & 5.45 & 1.42 & -0.93 & 0.10 & 0.40 & 0.20 \\
\hline $\begin{array}{l}\text { I think the rewards (e.g., points, special items, } \\
\text { special abilities) in the game are given in a } \\
\text { timely manner. }\end{array}$ & 596 & 5.57 & 1.36 & -1.13 & 0.10 & 0.93 & 0.20 \\
\hline I feel I can explore things in the game. & 591 & 5.70 & 1.48 & -1.19 & 0.10 & 0.77 & 0.20 \\
\hline I enjoy playing the game. & 628 & 6.51 & 0.76 & -2.48 & 0.10 & 10.06 & 0.19 \\
\hline $\begin{array}{l}\text { I feel the game trains me well in all of the } \\
\text { controls. }\end{array}$ & 616 & 5.60 & 1.32 & -1.16 & 0.10 & 1.23 & 0.20 \\
\hline $\begin{array}{l}\text { I find this game to be the type of video game } \\
\text { that I often play. }\end{array}$ & 627 & 5.78 & 1.38 & -1.40 & 0.10 & 1.62 & 0.19 \\
\hline $\begin{array}{l}\text { I think it is easy to save the game at different } \\
\text { stages. }\end{array}$ & 541 & 5.61 & 1.58 & -1.26 & 0.11 & 0.79 & 0.21 \\
\hline $\begin{array}{l}\text { I think the game supports different styles of } \\
\text { playing. }\end{array}$ & 622 & 5.45 & 1.56 & -1.05 & 0.10 & 0.28 & 0.20 \\
\hline $\begin{array}{l}\text { I find it hard to return to the real world when I } \\
\text { stop playing the game. }\end{array}$ & 623 & 2.71 & 1.75 & 0.97 & 0.10 & -0.07 & 0.20 \\
\hline I feel creative while playing the game. & 623 & 4.91 & 1.61 & -0.57 & 0.10 & -0.33 & 0.20 \\
\hline
\end{tabular}


APPENDIX V (continued)

EFA STUDY: SKEWESS AND KURTOSIS VALUES OF ITEMS

\begin{tabular}{|c|c|c|c|c|c|c|c|}
\hline \multirow[t]{2}{*}{ Item } & \multirow[t]{2}{*}{$n$} & \multirow[t]{2}{*}{ Mean } & \multirow[t]{2}{*}{ SD } & \multicolumn{2}{|c|}{ Skewness } & \multicolumn{2}{|c|}{ Kurtosis } \\
\hline & & & & Value & Std. Error & Value & Std. Error \\
\hline $\begin{array}{l}\text { I am very focused on my own performance } \\
\text { while playing the game. }\end{array}$ & 626 & 5.83 & 1.18 & -1.22 & 0.10 & 1.59 & 0.20 \\
\hline $\begin{array}{l}\text { I think the game has enough unique features to } \\
\text { keep me interested. }\end{array}$ & 626 & 5.98 & 1.09 & -1.43 & 0.10 & 2.66 & 0.20 \\
\hline I find the game's menus to be user friendly. & 626 & 5.83 & 1.15 & -1.47 & 0.10 & 2.96 & 0.20 \\
\hline $\begin{array}{l}\text { I think the graphics of the game fit the mood or } \\
\text { style of the game. }\end{array}$ & 625 & 6.28 & 0.89 & -1.68 & 0.10 & 4.16 & 0.20 \\
\hline I feel bored while playing the game. & 629 & 2.45 & 1.46 & 1.28 & 0.10 & 1.19 & 0.19 \\
\hline $\begin{array}{l}\text { I am captivated by the game's story from the } \\
\text { beginning. }\end{array}$ & 538 & 5.27 & 1.62 & -0.74 & 0.11 & -0.31 & 0.21 \\
\hline $\begin{array}{l}\text { I receive adequate feedback on my progress in } \\
\text { the game. }\end{array}$ & 600 & 5.54 & 1.26 & -1.11 & 0.10 & 1.23 & 0.20 \\
\hline I feel very confident while playing the game. & 626 & 5.56 & 1.18 & -0.82 & 0.10 & 0.57 & 0.20 \\
\hline $\begin{array}{l}\text { I temporarily forget about my everyday worries } \\
\text { while playing the game. }\end{array}$ & 627 & 5.32 & 1.47 & -1.02 & 0.10 & 0.62 & 0.19 \\
\hline $\begin{array}{l}\text { I think the information provided in the game } \\
\text { (e.g., onscreen messages, help) is clear. }\end{array}$ & 621 & 5.88 & 1.05 & -1.36 & 0.10 & 2.91 & 0.20 \\
\hline $\begin{array}{l}\text { I can easily customize settings (e.g., audio) in } \\
\text { the game. }\end{array}$ & 614 & 5.93 & 1.21 & -1.41 & 0.10 & 2.00 & 0.20 \\
\hline $\begin{array}{l}\text { I can predict what will happen next in response } \\
\text { to my actions in the game. }\end{array}$ & 607 & 5.29 & 1.40 & -0.93 & 0.10 & 0.60 & 0.20 \\
\hline $\begin{array}{l}\text { I find the game's rewards are effective in } \\
\text { motivating me to progress further in the game. }\end{array}$ & 606 & 5.66 & 1.23 & -1.06 & 0.10 & 0.95 & 0.20 \\
\hline
\end{tabular}


APPENDIX V (continued)

EFA STUDY: SKEWESS AND KURTOSIS VALUES OF ITEMS

\begin{tabular}{|c|c|c|c|c|c|c|c|}
\hline \multirow[t]{2}{*}{ Item } & \multirow[t]{2}{*}{$n$} & \multirow[t]{2}{*}{ Mean } & \multirow[t]{2}{*}{ SD } & \multicolumn{2}{|c|}{ Skewness } & \multicolumn{2}{|c|}{ Kurtosis } \\
\hline & & & & Value & Std. Error & Value & Std. Error \\
\hline $\begin{array}{l}\text { I find this game to be similar to one of my past } \\
\text { favorite games. }\end{array}$ & 613 & 5.15 & 1.79 & -0.90 & 0.10 & -0.23 & 0.20 \\
\hline $\begin{array}{l}\text { I receive adequate support (e.g., hints) from the } \\
\text { game to overcome its challenges. }\end{array}$ & 588 & 5.14 & 1.48 & -0.81 & 0.10 & 0.14 & 0.20 \\
\hline $\begin{array}{l}\text { I think the game teaches me useful skills that I } \\
\text { can use in the game. }\end{array}$ & 618 & 5.33 & 1.46 & -1.04 & 0.10 & 0.72 & 0.20 \\
\hline $\begin{array}{l}\text { I feel the game requires more mental effort to } \\
\text { play than necessary. }\end{array}$ & 625 & 3.55 & 1.78 & 0.41 & 0.10 & -0.94 & 0.20 \\
\hline $\begin{array}{l}\text { I feel the game provides me the necessary } \\
\text { information to accomplish a goal within the } \\
\text { game. }\end{array}$ & 619 & 5.68 & 1.18 & -1.31 & 0.10 & 2.21 & 0.20 \\
\hline $\begin{array}{l}\text { I find the game environment to be responsive to } \\
\text { my actions in the game. }\end{array}$ & 607 & 5.65 & 1.34 & -1.16 & 0.10 & 1.14 & 0.20 \\
\hline $\begin{array}{l}\text { I find the game to be helpful in preventing me } \\
\text { from making irreversible errors (e.g., delete } \\
\text { important items). }\end{array}$ & 577 & 4.99 & 1.66 & -0.66 & 0.10 & -0.32 & 0.20 \\
\hline
\end{tabular}




\section{APPENDIX W}

EFA STUDY: VARIABLES WITH MISSING VALUES

\begin{tabular}{|c|c|c|c|c|}
\hline \multirow[b]{2}{*}{ Item } & \multicolumn{2}{|c|}{ Missing Values } & \multirow[b]{2}{*}{ Mean } & \multirow[b]{2}{*}{ SD } \\
\hline & $n$ & Percent & & \\
\hline I enjoy the social interaction within the game. & 114 & $18.1 \%$ & 5.04 & 1.60 \\
\hline $\begin{array}{l}\text { I find the game supports social interaction (e.g., chat) } \\
\text { between players. }\end{array}$ & 95 & $15.1 \%$ & 4.94 & 1.97 \\
\hline I am captivated by the game's story from the beginning. & 91 & $14.5 \%$ & 5.27 & 1.62 \\
\hline I think it is easy to save the game at different stages. & 88 & $14.0 \%$ & 5.61 & 1.58 \\
\hline $\begin{array}{l}\text { I can easily skip any non-playable content (e.g., videos, story } \\
\text { scenes) that does not capture my interest. }\end{array}$ & 84 & $13.4 \%$ & 5.12 & 1.82 \\
\hline I like to play this game with other players. & 80 & $12.7 \%$ & 5.47 & 1.97 \\
\hline I can clearly understand the game's story. & 74 & $11.8 \%$ & 5.95 & 1.24 \\
\hline I think the characters in the game are well developed. & 67 & $10.7 \%$ & 5.22 & 1.65 \\
\hline I am able to play the game with other players if I choose. & 65 & $10.3 \%$ & 5.70 & 1.92 \\
\hline $\begin{array}{l}\text { I find social communities to be supported outside of the } \\
\text { games (e.g., online forums). }\end{array}$ & 64 & $10.2 \%$ & 5.25 & 1.70 \\
\hline I enjoy the fantasy or story provided by the game. & 61 & $9.7 \%$ & 5.86 & 1.28 \\
\hline $\begin{array}{l}\text { I find the game to be helpful in preventing me from making } \\
\text { irreversible errors (e.g., delete important items). }\end{array}$ & 52 & $8.3 \%$ & 4.99 & 1.66 \\
\hline I usually find my way around in the game world. & 50 & $7.9 \%$ & 6.03 & 1.11 \\
\hline $\begin{array}{l}\text { I find it is easy to customize the overall difficulty level of the } \\
\text { game. }\end{array}$ & 44 & $7.0 \%$ & 5.19 & 1.81 \\
\hline $\begin{array}{l}\text { I receive adequate support (e.g., hints) from the game to } \\
\text { overcome its challenges. }\end{array}$ & 41 & $6.5 \%$ & 5.14 & 1.48 \\
\hline I can identify with the characters in the game. & 41 & $6.5 \%$ & 4.58 & 1.76 \\
\hline I feel I can explore things in the game. & 38 & $6.0 \%$ & 5.70 & 1.48 \\
\hline I am emotionally moved by the events in the game. & 38 & $6.0 \%$ & 4.17 & 1.86 \\
\hline I find it is easy to return to where I left off in the game. & 35 & $5.6 \%$ & 5.98 & 1.23 \\
\hline $\begin{array}{l}\text { I think the rewards (e.g., points, special items, special } \\
\text { abilities) in the game are given in a timely manner. }\end{array}$ & 33 & $5.2 \%$ & 5.57 & 1.36 \\
\hline $\begin{array}{l}\text { I am very interested in seeing how the events in the game } \\
\text { will progress. }\end{array}$ & 32 & $5.1 \%$ & 5.90 & 1.26 \\
\hline I receive adequate feedback on my progress in the game. & 29 & $4.6 \%$ & 5.54 & 1.26 \\
\hline $\begin{array}{l}\text { I can recover when I make a big mistake in the game (e.g., } \\
\text { exit without saving). }\end{array}$ & 28 & $4.5 \%$ & 5.25 & 1.66 \\
\hline I find many events in the game to be novel or unique. & 27 & $4.3 \%$ & 5.45 & 1.42 \\
\hline I feel the events in the game are happening to me. & 27 & $4.3 \%$ & 3.47 & 1.94 \\
\hline I can easily identify my score or status in the game. & 24 & $3.8 \%$ & 6.00 & 1.17 \\
\hline $\begin{array}{l}\text { I find the game's rewards are effective in motivating me to } \\
\text { progress further in the game. }\end{array}$ & 23 & $3.7 \%$ & 5.66 & 1.23 \\
\hline
\end{tabular}




\section{APPENDIX W (continued)}

EFA STUDY: VARIABLES WITH MISSING VALUES

\begin{tabular}{|c|c|c|c|c|}
\hline \multirow[b]{2}{*}{ Item } & \multicolumn{2}{|c|}{ Missing Values } & \multirow[b]{2}{*}{ Mean } & \multirow[b]{2}{*}{ SD } \\
\hline & $n$ & Percent & & \\
\hline $\begin{array}{l}\text { I find the game to have delightful surprises (e.g., special } \\
\text { rewards, unique characters, hidden stories). }\end{array}$ & 23 & $3.7 \%$ & 5.50 & 1.54 \\
\hline $\begin{array}{l}\text { I find the game environment to be responsive to my actions } \\
\text { in the game. }\end{array}$ & 22 & $3.5 \%$ & 5.65 & 1.34 \\
\hline $\begin{array}{l}\text { I can predict what will happen next in response to my } \\
\text { actions in the game. }\end{array}$ & 22 & $3.5 \%$ & 5.29 & 1.40 \\
\hline $\begin{array}{l}\text { I feel the game constantly motivates me to proceed further } \\
\text { to the next stage or level. }\end{array}$ & 20 & $3.2 \%$ & 5.82 & 1.25 \\
\hline I feel the game allows me to express myself. & 20 & $3.2 \%$ & 4.64 & 1.65 \\
\hline I challenge myself even when the game does not require it. & 19 & $3.0 \%$ & 5.41 & 1.58 \\
\hline $\begin{array}{l}\text { I find this game to be similar to one of my past favorite } \\
\text { games. }\end{array}$ & 16 & $2.5 \%$ & 5.15 & 1.79 \\
\hline I can easily customize settings (e.g., audio) in the game. & 15 & $2.4 \%$ & 5.93 & 1.21 \\
\hline $\begin{array}{l}\text { I always know my next goal when I finish an event in the } \\
\text { game. }\end{array}$ & 15 & $2.4 \%$ & 5.47 & 1.41 \\
\hline I feel the game gives me enough freedom to act how I want. & 15 & $2.4 \%$ & 5.54 & 1.46 \\
\hline I feel the game trains me well in all of the controls. & 13 & $2.1 \%$ & 5.60 & 1.32 \\
\hline I enjoy the music in the game. & 13 & $2.1 \%$ & 5.71 & 1.50 \\
\hline $\begin{array}{l}\text { I think the game teaches me useful skills that I can use in } \\
\text { the game. }\end{array}$ & 11 & $1.7 \%$ & 5.33 & 1.46 \\
\hline I have many ways to succeed in the game. & 11 & $1.7 \%$ & 5.66 & 1.33 \\
\hline $\begin{array}{l}\text { I feel the game provides me the necessary information to } \\
\text { accomplish a goal within the game. }\end{array}$ & 10 & $1.6 \%$ & 5.68 & 1.18 \\
\hline I think the outcomes in the game are fair. & 10 & $1.6 \%$ & 5.66 & 1.26 \\
\hline I am in suspense about whether I will succeed in the game. & 9 & $1.4 \%$ & 5.07 & 1.74 \\
\hline $\begin{array}{l}\text { Sometimes I find myself wanting to speak directly to the } \\
\text { game while playing it. }\end{array}$ & 9 & $1.4 \%$ & 4.56 & 1.97 \\
\hline $\begin{array}{l}\text { I think the information provided in the game (e.g., onscreen } \\
\text { messages, help) is clear. }\end{array}$ & 8 & $1.3 \%$ & 5.88 & 1.05 \\
\hline I feel successful when I overcome the obstacles in the game. & 8 & $1.3 \%$ & 6.19 & 0.92 \\
\hline I think the game's audio fits the mood or style of the game. & 8 & $1.3 \%$ & 6.18 & 1.04 \\
\hline I think the game's level of difficulty is right for me. & 8 & $1.3 \%$ & 5.87 & 1.15 \\
\hline $\begin{array}{l}\text { I feel the visual representations (e.g., icons, avatars, map) in } \\
\text { the game enhance my gaming experience. }\end{array}$ & 8 & $1.3 \%$ & 6.02 & 1.11 \\
\hline I think the game supports different styles of playing. & 7 & $1.1 \%$ & 5.45 & 1.56 \\
\hline $\begin{array}{l}\text { I feel my curiosity is stimulated as the result of playing the } \\
\text { game. }\end{array}$ & 7 & $1.1 \%$ & 5.43 & 1.41 \\
\hline
\end{tabular}




\section{APPENDIX W (continued)}

EFA STUDY: VARIABLES WITH MISSING VALUES

\begin{tabular}{|c|c|c|c|c|}
\hline \multirow[b]{2}{*}{ Item } & \multicolumn{2}{|c|}{ Missing Values } & \multirow[b]{2}{*}{ Mean } & \multirow[b]{2}{*}{ SD } \\
\hline & $n$ & Percent & & \\
\hline $\begin{array}{l}\text { I do not care to check events that are happening in the real } \\
\text { world during the game. }\end{array}$ & 7 & $1.1 \%$ & 4.07 & 1.83 \\
\hline I understand the rules of the game. & 7 & $1.1 \%$ & 6.56 & 0.69 \\
\hline I feel the game allows me to be imaginative. & 7 & $1.1 \%$ & 5.38 & 1.55 \\
\hline I feel creative while playing the game. & 6 & $1.0 \%$ & 4.91 & 1.61 \\
\hline $\begin{array}{l}\text { I find it hard to return to the real world when I stop playing } \\
\text { the game. }\end{array}$ & 6 & $1.0 \%$ & 2.71 & 1.75 \\
\hline $\begin{array}{l}\text { I feel detached from the outside world while playing the } \\
\text { game. }\end{array}$ & 6 & $1.0 \%$ & 4.26 & 1.80 \\
\hline $\begin{array}{l}\text { I feel the game's audio (e.g., sound effects, music) enhances } \\
\text { my gaming experience. }\end{array}$ & 6 & $1.0 \%$ & 5.93 & 1.42 \\
\hline I am able to play the game at my own pace. & 5 & $0.8 \%$ & 6.00 & 1.29 \\
\hline I want to do as well as possible during the game. & 5 & $0.8 \%$ & 6.20 & 1.02 \\
\hline $\begin{array}{l}\text { I feel the game requires more mental effort to play than } \\
\text { necessary. }\end{array}$ & 4 & $0.6 \%$ & 3.55 & 1.78 \\
\hline $\begin{array}{l}\text { I think the graphics of the game fit the mood or style of the } \\
\text { game. }\end{array}$ & 4 & $0.6 \%$ & 6.28 & 0.89 \\
\hline I feel a sense of control over the game. & 4 & $0.6 \%$ & 5.60 & 1.24 \\
\hline I cannot tell that I am getting tired while playing the game. & 4 & $0.6 \%$ & 4.22 & 1.92 \\
\hline $\begin{array}{l}\text { I can see everything that I need to see on the screen during } \\
\text { the game. }\end{array}$ & 4 & $0.6 \%$ & 5.87 & 1.29 \\
\hline I am likely to recommend this game to others. & 4 & $0.6 \%$ & 6.26 & 1.06 \\
\hline I enjoy the sound effects in the game. & 4 & $0.6 \%$ & 5.89 & 1.28 \\
\hline $\begin{array}{l}\text { I find my skills gradually improve through the course of } \\
\text { overcoming the challenges in the game. }\end{array}$ & 4 & $0.6 \%$ & 6.23 & 1.00 \\
\hline I feel energized while playing the game. & 4 & $0.6 \%$ & 5.64 & 1.31 \\
\hline I think the game is visually appealing. & 4 & $0.6 \%$ & 6.25 & 1.03 \\
\hline I feel very confident while playing the game. & 3 & $0.5 \%$ & 5.56 & 1.18 \\
\hline I find the game's menus to be user friendly. & 3 & $0.5 \%$ & 5.83 & 1.15 \\
\hline $\begin{array}{l}\text { I think the game has enough unique features to keep me } \\
\text { interested. }\end{array}$ & 3 & $0.5 \%$ & 5.98 & 1.09 \\
\hline $\begin{array}{l}\text { I am very focused on my own performance while playing } \\
\text { the game. }\end{array}$ & 3 & $0.5 \%$ & 5.83 & 1.18 \\
\hline I am focused on the task(s) at hand during the game. & 3 & $0.5 \%$ & 6.08 & 0.97 \\
\hline $\begin{array}{l}\text { I tend to spend more time playing the game than I have } \\
\text { planned. }\end{array}$ & 3 & $0.5 \%$ & 5.29 & 1.60 \\
\hline
\end{tabular}


APPENDIX W (continued)

EFA STUDY: VARIABLES WITH MISSING VALUES

\begin{tabular}{|c|c|c|c|c|}
\hline \multirow[b]{2}{*}{ Item } & \multicolumn{2}{|c|}{ Missing Values } & \multirow[b]{2}{*}{ Mean } & \multirow[b]{2}{*}{ SD } \\
\hline & $n$ & Percent & & \\
\hline If given the chance, I want to play this game again. & 3 & $0.5 \%$ & 6.31 & 1.01 \\
\hline $\begin{array}{l}\text { I feel all of my senses are completely engaged during the } \\
\text { game. }\end{array}$ & 3 & $0.5 \%$ & 4.90 & 1.57 \\
\hline I find the game's interface to be easy to navigate. & 3 & $0.5 \%$ & 5.93 & 1.09 \\
\hline $\begin{array}{l}\text { I can easily maintain my attention on the game during game } \\
\text { play. }\end{array}$ & 3 & $0.5 \%$ & 6.31 & 0.89 \\
\hline $\begin{array}{l}\text { I find the game captures my attention from the very } \\
\text { beginning. }\end{array}$ & 3 & $0.5 \%$ & 6.20 & 1.13 \\
\hline $\begin{array}{l}\text { I temporarily forget about my everyday worries while } \\
\text { playing the game. }\end{array}$ & 2 & $0.3 \%$ & 5.32 & 1.47 \\
\hline $\begin{array}{l}\text { I find this game to be the type of video game that I often } \\
\text { play. }\end{array}$ & 2 & $0.3 \%$ & 5.78 & 1.38 \\
\hline I think the game is unique or original. & 2 & $0.3 \%$ & 5.60 & 1.51 \\
\hline I feel annoyed with the game while playing it. & 2 & $0.3 \%$ & 3.68 & 1.73 \\
\hline $\begin{array}{l}\text { I do not need to go through a lengthy tutorial or read a } \\
\text { manual to play the game. }\end{array}$ & 2 & $0.3 \%$ & 5.76 & 1.49 \\
\hline I think most people will enjoy playing this game. & 2 & $0.3 \%$ & 5.56 & 1.32 \\
\hline I enjoy playing the game. & 1 & $0.2 \%$ & 6.51 & 0.76 \\
\hline I think the game is fun. & 1 & $0.2 \%$ & 6.50 & 0.81 \\
\hline Sometimes I lose track of time while playing the game. & 1 & $0.2 \%$ & 5.67 & 1.46 \\
\hline $\begin{array}{l}\text { I can block out most other distractions when playing the } \\
\text { game. }\end{array}$ & 1 & $0.2 \%$ & 5.49 & 1.34 \\
\hline $\begin{array}{l}\text { Whenever I stopped playing the game I cannot wait to start } \\
\text { playing it again. }\end{array}$ & 1 & $0.2 \%$ & 4.78 & 1.50 \\
\hline I find the controls of the game to be straightforward. & 1 & $0.2 \%$ & 6.13 & 1.13 \\
\hline
\end{tabular}




\section{APPENDIX X}

EFA STUDY: ITEM THAT WERE REMOVED

\section{Item \# Item}

1 I can easily skip any non-playable content (e.g., videos, story scenes) that does not capture my interest.

2 I can easily customize settings (e.g., audio) in the game.

3 I challenge myself even when the game does not require it.

$4 \quad$ I usually find my way around in the game world.

5 I feel the visual representations (e.g., icons, avatars, map) in the game enhance my gaming experience.

6 I find this game to be the type of video game that I often play.

7 I think the rewards (e.g., points, special items, special abilities) in the game are given in a timely manner.

8 I think the outcomes in the game are fair.

9 I find the game environment to be responsive to my actions in the game.

10 I have many ways to succeed in the game.

11 I find the game captures my attention from the very beginning.

12 I think the game's level of difficulty is right for me.

13 Sometimes I find myself wanting to speak directly to the game while playing it.

14 I feel energized while playing the game.

15 I am focused on the task(s) at hand during the game.

16 I receive adequate feedback on my progress in the game.

17 I find this game to be similar to one of my past favorite games.

18 I think the game teaches me useful skills that I can use in the game.

19 I find social communities to be supported outside of the games (e.g., online forums).

20 I am in deep concentration when playing the game.

21 I find the game's rewards are effective in motivating me to progress further in the game.

22 I feel a sense of control over the game.

23 I can see everything that I need to see on the screen during the game.

24 I feel happy while playing the game. 


\section{APPENDIX X (continued)}

\section{EFA STUDY: ITEM THAT WERE REMOVED}

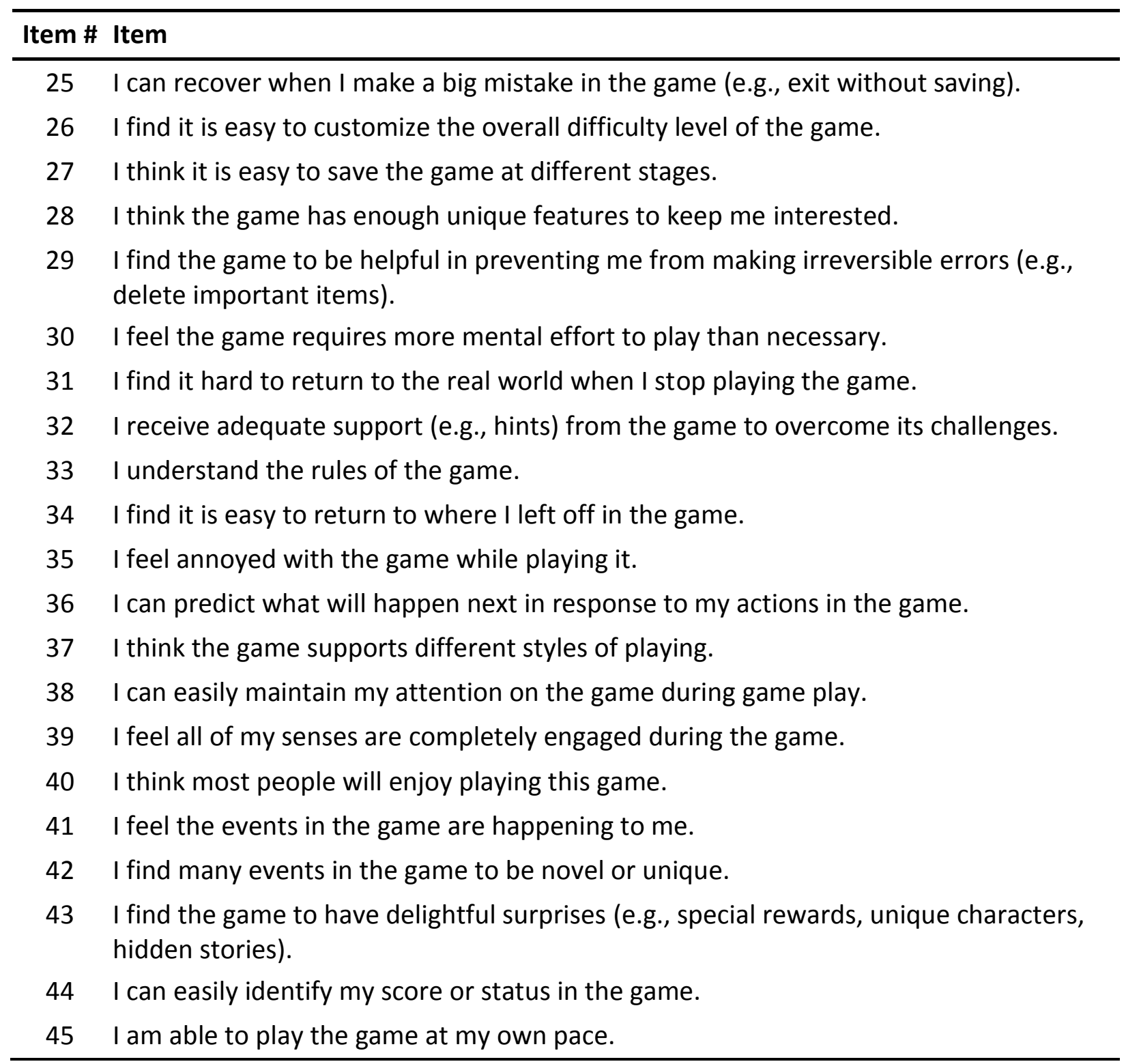


APPENDIX Y

EFA STUDY: PATTERN MATRIX LOADINGS FOR THE 9-FACTOR SOLUTION $(N=629)$

\begin{tabular}{|c|c|c|c|c|c|c|c|c|c|}
\hline \multirow[t]{2}{*}{ Item } & \multicolumn{9}{|c|}{ Factor Loadings for Promax Rotation } \\
\hline & Factor 1 & Factor 2 & Factor 3 & Factor 4 & Factor 5 & Factor 6 & Factor 7 & Factor 8 & Factor 9 \\
\hline I think it is easy to learn how to play the game. & 0.77 & 0.07 & -0.04 & -0.11 & 0.02 & -0.01 & -0.23 & -0.12 & -0.03 \\
\hline $\begin{array}{l}\text { I find the controls of the game to be } \\
\text { straightforward. }\end{array}$ & 0.69 & -0.13 & -0.07 & 0.19 & 0.07 & 0.04 & -0.03 & -0.05 & -0.10 \\
\hline $\begin{array}{l}\text { I always know how to achieve my } \\
\text { goals/objectives in the game. }\end{array}$ & 0.66 & -0.10 & 0.01 & -0.07 & 0.01 & 0.01 & -0.02 & 0.07 & -0.02 \\
\hline I find the game's interface to be easy to navigate. & 0.64 & -0.04 & 0.00 & 0.08 & -0.02 & 0.05 & 0.15 & -0.01 & -0.10 \\
\hline $\begin{array}{l}\text { I do not need to go through a lengthy tutorial or } \\
\text { read a manual to play the game. }\end{array}$ & 0.56 & 0.07 & 0.04 & 0.02 & -0.18 & -0.01 & -0.11 & -0.04 & -0.08 \\
\hline I find the game's menus to be user friendly. & 0.53 & 0.10 & -0.07 & 0.03 & -0.10 & 0.04 & 0.12 & 0.05 & -0.01 \\
\hline $\begin{array}{l}\text { I feel the game trains me well in all of the } \\
\text { controls. }\end{array}$ & 0.52 & 0.11 & -0.05 & -0.04 & 0.11 & 0.03 & 0.02 & -0.05 & 0.01 \\
\hline $\begin{array}{l}\text { I feel the game provides me the necessary } \\
\text { information to accomplish a goal within the } \\
\text { game. }\end{array}$ & 0.47 & 0.08 & 0.03 & 0.10 & -0.03 & -0.02 & -0.05 & 0.02 & 0.17 \\
\hline $\begin{array}{l}\text { I always know my next goal when I finish an } \\
\text { event in the game. }\end{array}$ & 0.47 & -0.06 & 0.14 & -0.21 & -0.02 & -0.03 & 0.19 & 0.07 & 0.00 \\
\hline $\begin{array}{l}\text { I think the information provided in the game } \\
\text { (e.g., onscreen messages, help) is clear. }\end{array}$ & 0.43 & 0.08 & -0.07 & 0.18 & -0.01 & 0.00 & 0.02 & 0.07 & 0.10 \\
\hline I feel very confident while playing the game. & 0.41 & 0.05 & 0.16 & -0.08 & 0.15 & -0.04 & 0.09 & 0.03 & 0.10 \\
\hline $\begin{array}{l}\text { I think the characters in the game are well } \\
\text { developed. }\end{array}$ & 0.00 & 0.84 & -0.13 & -0.05 & -0.07 & -0.01 & 0.10 & 0.09 & 0.01 \\
\hline
\end{tabular}


APPENDIX Y (continued)

EFA STUDY: PATTERN MATRIX LOADINGS FOR THE 9-FACTOR SOLUTION ( $\mathrm{N}=629)$

\begin{tabular}{|c|c|c|c|c|c|c|c|c|c|}
\hline \multirow[t]{2}{*}{ Item } & \multicolumn{9}{|c|}{ Factor Loadings for Promax Rotation } \\
\hline & Factor 1 & Factor 2 & Factor 3 & Factor 4 & Factor 5 & Factor 6 & Factor 7 & Factor 8 & Factor 9 \\
\hline $\begin{array}{l}\text { I am captivated by the game's story from the } \\
\text { beginning. }\end{array}$ & 0.06 & 0.84 & -0.02 & 0.06 & -0.03 & -0.01 & 0.05 & -0.08 & -0.05 \\
\hline $\begin{array}{l}\text { I enjoy the fantasy or story provided by the } \\
\text { game. }\end{array}$ & -0.08 & 0.61 & 0.01 & 0.16 & 0.04 & 0.02 & -0.09 & -0.11 & 0.16 \\
\hline I can identify with the characters in the game. & 0.07 & 0.60 & 0.10 & -0.13 & 0.01 & -0.04 & -0.12 & 0.17 & 0.06 \\
\hline $\begin{array}{l}\text { I am emotionally moved by the events in the } \\
\text { game. }\end{array}$ & -0.08 & 0.58 & 0.25 & -0.08 & 0.03 & 0.10 & 0.05 & -0.02 & -0.10 \\
\hline $\begin{array}{l}\text { I am very interested in seeing how the events in } \\
\text { the game will progress. }\end{array}$ & -0.09 & 0.51 & -0.02 & 0.16 & 0.04 & 0.04 & 0.22 & -0.04 & 0.04 \\
\hline I can clearly understand the game's story. & 0.20 & 0.48 & -0.06 & 0.05 & -0.04 & -0.07 & -0.14 & 0.01 & 0.15 \\
\hline $\begin{array}{l}\text { I feel detached from the outside world while } \\
\text { playing the game. }\end{array}$ & -0.04 & 0.07 & 0.76 & 0.01 & -0.07 & 0.05 & -0.06 & 0.01 & -0.16 \\
\hline $\begin{array}{l}\text { I do not care to check events that are happening } \\
\text { in the real world during the game. }\end{array}$ & -0.09 & 0.17 & 0.75 & 0.08 & -0.22 & 0.04 & -0.09 & 0.03 & -0.18 \\
\hline $\begin{array}{l}\text { I cannot tell that I am getting tired while playing } \\
\text { the game. }\end{array}$ & -0.01 & -0.01 & 0.67 & 0.03 & -0.05 & 0.01 & 0.01 & -0.06 & -0.06 \\
\hline $\begin{array}{l}\text { Sometimes I lose track of time while playing the } \\
\text { game. }\end{array}$ & -0.06 & -0.14 & 0.61 & 0.09 & 0.03 & -0.01 & 0.02 & -0.01 & 0.21 \\
\hline $\begin{array}{l}\text { I temporarily forget about my everyday worries } \\
\text { while playing the game. }\end{array}$ & 0.05 & -0.08 & 0.56 & 0.05 & 0.07 & -0.01 & 0.05 & -0.06 & 0.07 \\
\hline $\begin{array}{l}\text { I tend to spend more time playing the game than } \\
\text { I have planned. }\end{array}$ & 0.01 & -0.12 & 0.52 & -0.06 & 0.07 & -0.05 & 0.05 & 0.00 & 0.21 \\
\hline
\end{tabular}


APPENDIX Y (continued)

EFA STUDY: PATTERN MATRIX LOADINGS FOR THE 9-FACTOR SOLUTION ( $\mathrm{N}=629$ )

\begin{tabular}{|c|c|c|c|c|c|c|c|c|c|}
\hline \multirow[t]{2}{*}{ Item } & \multicolumn{9}{|c|}{ Factor Loadings for Promax Rotation } \\
\hline & Factor 1 & Factor 2 & Factor 3 & Factor 4 & Factor 5 & Factor 6 & Factor 7 & Factor 8 & Factor 9 \\
\hline $\begin{array}{l}\text { I can block out most other distractions when } \\
\text { playing the game. }\end{array}$ & 0.14 & -0.06 & 0.49 & 0.09 & 0.03 & 0.06 & 0.14 & 0.00 & -0.12 \\
\hline $\begin{array}{l}\text { Whenever I stopped playing the game I cannot } \\
\text { wait to start playing it again. }\end{array}$ & 0.08 & 0.05 & 0.49 & -0.02 & 0.15 & -0.07 & 0.12 & -0.05 & 0.02 \\
\hline I think the game is fun. & 0.02 & -0.04 & 0.07 & 0.88 & 0.06 & 0.01 & -0.11 & 0.07 & -0.03 \\
\hline I enjoy playing the game. & 0.01 & -0.01 & 0.02 & 0.86 & 0.06 & -0.07 & -0.03 & 0.02 & 0.01 \\
\hline I feel bored while playing the game. & 0.02 & 0.03 & -0.05 & -0.58 & 0.11 & -0.05 & -0.06 & 0.09 & 0.03 \\
\hline I am likely to recommend this game to others. & 0.11 & 0.18 & -0.01 & 0.58 & -0.04 & 0.00 & 0.04 & 0.04 & -0.02 \\
\hline $\begin{array}{l}\text { If given the chance, I want to play this game } \\
\text { again. }\end{array}$ & -0.06 & -0.01 & 0.13 & 0.55 & 0.05 & -0.15 & 0.10 & 0.12 & 0.14 \\
\hline I feel the game allows me to be imaginative. & -0.06 & -0.08 & -0.13 & 0.03 & 0.90 & -0.01 & 0.04 & -0.02 & -0.06 \\
\hline I feel creative while playing the game. & 0.05 & 0.00 & -0.09 & -0.09 & 0.86 & -0.03 & 0.09 & -0.01 & -0.08 \\
\hline $\begin{array}{l}\text { I feel the game gives me enough freedom to act } \\
\text { how I want. }\end{array}$ & -0.03 & -0.11 & 0.06 & 0.18 & 0.62 & 0.06 & -0.22 & 0.10 & 0.00 \\
\hline I feel the game allows me to express myself. & -0.03 & 0.16 & 0.13 & -0.13 & 0.61 & -0.05 & -0.14 & 0.16 & 0.05 \\
\hline I feel I can explore things in the game. & -0.03 & 0.17 & 0.05 & 0.03 & 0.44 & 0.09 & -0.15 & -0.05 & 0.15 \\
\hline $\begin{array}{l}\text { I feel my curiosity is stimulated as the result of } \\
\text { playing the game. }\end{array}$ & -0.06 & 0.21 & 0.11 & -0.08 & 0.43 & 0.04 & 0.20 & -0.12 & 0.02 \\
\hline I think the game is unique or original. & 0.04 & 0.12 & -0.07 & 0.19 & 0.43 & 0.09 & 0.16 & -0.12 & -0.21 \\
\hline I enjoy the sound effects in the game. & 0.01 & -0.02 & 0.01 & 0.01 & 0.04 & 0.87 & 0.01 & 0.06 & -0.01 \\
\hline
\end{tabular}


APPENDIX Y (continued)

EFA STUDY: PATTERN MATRIX LOADINGS FOR THE 9-FACTOR SOLUTION ( $\mathrm{N}=629)$

\begin{tabular}{|c|c|c|c|c|c|c|c|c|c|}
\hline \multirow[t]{2}{*}{ Item } & \multicolumn{9}{|c|}{ Factor Loadings for Promax Rotation } \\
\hline & Factor 1 & Factor 2 & Factor 3 & Factor 4 & Factor 5 & Factor 6 & Factor 7 & Factor 8 & Factor 9 \\
\hline I enjoy the music in the game. & 0.05 & 0.05 & 0.06 & -0.01 & 0.02 & 0.76 & -0.09 & -0.04 & 0.07 \\
\hline $\begin{array}{l}\text { I feel the game's audio (e.g., sound effects, } \\
\text { music) enhances my gaming experience. }\end{array}$ & -0.02 & -0.02 & 0.00 & -0.10 & 0.02 & 0.76 & -0.01 & 0.06 & 0.14 \\
\hline $\begin{array}{l}\text { I think the game's audio fits the mood or style of } \\
\text { the game. }\end{array}$ & 0.04 & -0.02 & 0.00 & 0.04 & -0.05 & 0.63 & 0.05 & 0.00 & 0.18 \\
\hline $\begin{array}{l}\text { I am in suspense about whether I will succeed in } \\
\text { the game. }\end{array}$ & -0.10 & 0.11 & 0.04 & -0.08 & -0.02 & 0.02 & 0.70 & 0.04 & -0.20 \\
\hline $\begin{array}{l}\text { I feel successful when I overcome the obstacles } \\
\text { in the game. }\end{array}$ & -0.07 & 0.01 & -0.04 & 0.08 & 0.02 & -0.11 & 0.66 & -0.02 & 0.13 \\
\hline I want to do as well as possible during the game. & 0.05 & -0.04 & 0.04 & -0.03 & -0.16 & -0.04 & 0.62 & 0.09 & 0.15 \\
\hline $\begin{array}{l}\text { I am very focused on my own performance while } \\
\text { playing the game. }\end{array}$ & 0.11 & -0.14 & 0.12 & -0.08 & -0.04 & 0.02 & 0.57 & 0.07 & 0.08 \\
\hline $\begin{array}{l}\text { I feel the game constantly motivates me to } \\
\text { proceed further to the next stage or level. }\end{array}$ & 0.04 & 0.18 & -0.01 & 0.02 & 0.05 & -0.05 & 0.57 & -0.08 & 0.06 \\
\hline $\begin{array}{l}\text { I find my skills gradually improve through the } \\
\text { course of overcoming the challenges in the } \\
\text { game. }\end{array}$ & -0.03 & -0.11 & -0.09 & 0.18 & 0.08 & 0.14 & 0.48 & 0.05 & -0.05 \\
\hline $\begin{array}{l}\text { I find the game supports social interaction (e.g., } \\
\text { chat) between players. }\end{array}$ & -0.03 & 0.12 & -0.02 & -0.02 & 0.14 & -0.08 & -0.06 & 0.84 & 0.00 \\
\hline I like to play this game with other players. & -0.05 & -0.18 & -0.06 & 0.07 & -0.04 & 0.09 & 0.12 & 0.75 & -0.03 \\
\hline $\begin{array}{l}\text { I am able to play the game with other players if I } \\
\text { choose. }\end{array}$ & 0.03 & -0.06 & 0.00 & 0.05 & -0.08 & 0.06 & 0.06 & 0.71 & -0.03 \\
\hline
\end{tabular}


APPENDIX Y (continued)

EFA STUDY: PATTERN MATRIX LOADINGS FOR THE 9-FACTOR SOLUTION ( $\mathrm{N}=629)$

\begin{tabular}{|c|c|c|c|c|c|c|c|c|c|}
\hline \multirow[t]{2}{*}{ Item } & \multicolumn{9}{|c|}{ Factor Loadings for Promax Rotation } \\
\hline & Factor 1 & Factor 2 & Factor 3 & Factor 4 & Factor 5 & Factor 6 & Factor 7 & Factor 8 & Factor 9 \\
\hline I enjoy the social interaction within the game. & 0.02 & 0.31 & -0.02 & -0.02 & 0.06 & 0.02 & 0.04 & 0.64 & -0.06 \\
\hline I enjoy the game's graphics. & -0.07 & 0.17 & -0.07 & 0.02 & -0.06 & 0.10 & 0.05 & -0.03 & 0.64 \\
\hline $\begin{array}{l}\text { I think the graphics of the game fit the mood or } \\
\text { style of the game. }\end{array}$ & -0.05 & 0.01 & -0.05 & 0.09 & -0.10 & 0.13 & 0.10 & -0.10 & 0.63 \\
\hline I think the game is visually appealing. & 0.01 & 0.03 & -0.05 & -0.08 & 0.01 & 0.18 & -0.06 & 0.03 & 0.59 \\
\hline
\end{tabular}

Note: Factor loadings of |.40| or above are bolded. 
APPENDIX Z

EFA STUDY: STRUCTURE MATRIX LOADINGS FOR THE 9-FACTOR SOLUTION $(N=629)$

\begin{tabular}{|c|c|c|c|c|c|c|c|c|c|}
\hline \multirow[t]{2}{*}{ Item } & \multicolumn{9}{|c|}{ Factor Loadings for Promax Rotation } \\
\hline & Factor 1 & Factor 2 & Factor 3 & Factor 4 & Factor 5 & Factor 6 & Factor 7 & Factor 8 & Factor 9 \\
\hline $\begin{array}{l}\text { I find the controls of the game to be } \\
\text { straightforward. }\end{array}$ & 0.67 & 0.11 & 0.12 & 0.33 & 0.14 & 0.12 & 0.21 & 0.07 & 0.27 \\
\hline I find the game's interface to be easy to navigate. & 0.67 & 0.18 & 0.22 & 0.33 & 0.17 & 0.19 & 0.36 & 0.11 & 0.31 \\
\hline I think it is easy to learn how to play the game. & 0.64 & 0.10 & 0.02 & 0.06 & 0.03 & -0.01 & -0.05 & -0.06 & 0.17 \\
\hline $\begin{array}{l}\text { I always know how to achieve my } \\
\text { goals/objectives in the game. }\end{array}$ & 0.61 & 0.02 & 0.11 & 0.12 & 0.06 & 0.05 & 0.15 & 0.17 & 0.22 \\
\hline $\begin{array}{l}\text { I feel the game provides me the necessary } \\
\text { information to accomplish a goal within the } \\
\text { game. }\end{array}$ & 0.59 & 0.28 & 0.24 & 0.37 & 0.24 & 0.19 & 0.27 & 0.12 & 0.45 \\
\hline I find the game's menus to be user friendly. & 0.58 & 0.21 & 0.14 & 0.27 & 0.13 & 0.18 & 0.30 & 0.14 & 0.31 \\
\hline $\begin{array}{l}\text { I think the information provided in the game } \\
\text { (e.g., onscreen messages, help) is clear. }\end{array}$ & 0.56 & 0.29 & 0.19 & 0.41 & 0.26 & 0.22 & 0.32 & 0.16 & 0.43 \\
\hline $\begin{array}{l}\text { I feel the game trains me well in all of the } \\
\text { controls. }\end{array}$ & 0.55 & 0.30 & 0.19 & 0.27 & 0.27 & 0.18 & 0.25 & 0.05 & 0.33 \\
\hline I feel very confident while playing the game. & 0.54 & 0.34 & 0.41 & 0.32 & 0.39 & 0.20 & 0.39 & 0.16 & 0.43 \\
\hline $\begin{array}{l}\text { I always know my next goal when I finish an } \\
\text { event in the game. }\end{array}$ & 0.48 & 0.06 & 0.25 & 0.07 & 0.10 & 0.06 & 0.29 & 0.17 & 0.21 \\
\hline $\begin{array}{l}\text { I do not need to go through a lengthy tutorial or } \\
\text { read a manual to play the game. }\end{array}$ & 0.48 & 0.03 & 0.04 & 0.08 & -0.07 & -0.01 & 0.02 & -0.01 & 0.11 \\
\hline $\begin{array}{l}\text { I am captivated by the game's story from the } \\
\text { beginning. }\end{array}$ & 0.25 & 0.85 & 0.33 & 0.46 & 0.55 & 0.36 & 0.37 & -0.07 & 0.37 \\
\hline
\end{tabular}


APPENDIX Z (continued)

EFA STUDY: STRUCTURE MATRIX LOADINGS FOR THE 9-FACTOR SOLUTION ( $\mathrm{N}=629$ )

\begin{tabular}{|c|c|c|c|c|c|c|c|c|c|}
\hline \multirow[t]{2}{*}{ Item } & \multicolumn{9}{|c|}{ Factor Loadings for Promax Rotation } \\
\hline & Factor 1 & Factor 2 & Factor 3 & Factor 4 & Factor 5 & Factor 6 & Factor 7 & Factor 8 & Factor 9 \\
\hline $\begin{array}{l}\text { I think the characters in the game are well } \\
\text { developed. }\end{array}$ & 0.18 & 0.76 & 0.20 & 0.34 & 0.46 & 0.32 & 0.33 & 0.09 & 0.33 \\
\hline $\begin{array}{l}\text { I enjoy the fantasy or story provided by the } \\
\text { game. }\end{array}$ & 0.18 & 0.75 & 0.33 & 0.51 & 0.55 & 0.38 & 0.30 & -0.09 & 0.47 \\
\hline $\begin{array}{l}\text { I am very interested in seeing how the events in } \\
\text { the game will progress. }\end{array}$ & 0.19 & 0.70 & 0.36 & 0.53 & 0.55 & 0.41 & 0.50 & 0.02 & 0.43 \\
\hline $\begin{array}{l}\text { I am emotionally moved by the events in the } \\
\text { game. }\end{array}$ & 0.08 & 0.65 & 0.45 & 0.29 & 0.49 & 0.35 & 0.33 & -0.01 & 0.25 \\
\hline I can identify with the characters in the game. & 0.20 & 0.56 & 0.28 & 0.20 & 0.41 & 0.20 & 0.18 & 0.15 & 0.29 \\
\hline I can clearly understand the game's story. & 0.33 & 0.48 & 0.15 & 0.30 & 0.30 & 0.17 & 0.14 & 0.02 & 0.35 \\
\hline $\begin{array}{l}\text { Sometimes I lose track of time while playing the } \\
\text { game. }\end{array}$ & 0.21 & 0.25 & 0.68 & 0.37 & 0.38 & 0.23 & 0.40 & 0.08 & 0.43 \\
\hline $\begin{array}{l}\text { I feel detached from the outside world while } \\
\text { playing the game. }\end{array}$ & 0.08 & 0.25 & 0.67 & 0.19 & 0.28 & 0.16 & 0.26 & 0.03 & 0.12 \\
\hline $\begin{array}{l}\text { Whenever I stopped playing the game I cannot } \\
\text { wait to start playing it again. }\end{array}$ & 0.27 & 0.38 & 0.64 & 0.33 & 0.47 & 0.20 & 0.44 & 0.04 & 0.34 \\
\hline $\begin{array}{l}\text { I temporarily forget about my everyday worries } \\
\text { while playing the game. }\end{array}$ & 0.25 & 0.27 & 0.64 & 0.33 & 0.38 & 0.20 & 0.39 & 0.03 & 0.35 \\
\hline $\begin{array}{l}\text { I cannot tell that I am getting tired while playing } \\
\text { the game. }\end{array}$ & 0.13 & 0.21 & 0.62 & 0.22 & 0.26 & 0.15 & 0.29 & -0.02 & 0.18 \\
\hline $\begin{array}{l}\text { I do not care to check events that are happening } \\
\text { in the real world during the game. }\end{array}$ & 0.02 & 0.23 & 0.61 & 0.17 & 0.19 & 0.14 & 0.20 & 0.00 & 0.07 \\
\hline
\end{tabular}


APPENDIX Z (continued)

EFA STUDY: STRUCTURE MATRIX LOADINGS FOR THE 9-FACTOR SOLUTION ( $N=629)$

\begin{tabular}{|c|c|c|c|c|c|c|c|c|c|}
\hline \multirow[t]{2}{*}{ Item } & \multicolumn{9}{|c|}{ Factor Loadings for Promax Rotation } \\
\hline & Factor 1 & Factor 2 & Factor 3 & Factor 4 & Factor 5 & Factor 6 & Factor 7 & Factor 8 & Factor 9 \\
\hline $\begin{array}{l}\text { I can block out most other distractions when } \\
\text { playing the game. }\end{array}$ & 0.29 & 0.26 & 0.59 & 0.34 & 0.34 & 0.24 & 0.44 & 0.10 & 0.26 \\
\hline $\begin{array}{l}\text { I tend to spend more time playing the game than } \\
\text { I have planned. }\end{array}$ & 0.22 & 0.20 & 0.58 & 0.24 & 0.32 & 0.15 & 0.34 & 0.09 & 0.36 \\
\hline I think the game is fun. & 0.32 & 0.41 & 0.36 & 0.86 & 0.47 & 0.33 & 0.40 & 0.13 & 0.46 \\
\hline I enjoy playing the game. & 0.32 & 0.42 & 0.34 & 0.85 & 0.46 & 0.29 & 0.43 & 0.09 & 0.47 \\
\hline I am likely to recommend this game to others. & 0.37 & 0.47 & 0.31 & 0.70 & 0.41 & 0.32 & 0.43 & 0.11 & 0.44 \\
\hline $\begin{array}{l}\text { If given the chance, I want to play this game } \\
\text { again. }\end{array}$ & 0.28 & 0.37 & 0.42 & 0.68 & 0.45 & 0.23 & 0.48 & 0.20 & 0.49 \\
\hline I feel bored while playing the game. & -0.18 & -0.23 & -0.22 & -0.55 & -0.20 & -0.24 & -0.31 & 0.04 & -0.27 \\
\hline I feel creative while playing the game. & 0.16 & 0.49 & 0.32 & 0.31 & 0.76 & 0.22 & 0.34 & 0.13 & 0.27 \\
\hline I feel the game allows me to be imaginative. & 0.08 & 0.46 & 0.28 & 0.36 & 0.76 & 0.23 & 0.30 & 0.11 & 0.26 \\
\hline I feel the game allows me to express myself. & 0.12 & 0.49 & 0.39 & 0.24 & 0.68 & 0.19 & 0.21 & 0.22 & 0.30 \\
\hline $\begin{array}{l}\text { I feel my curiosity is stimulated as the result of } \\
\text { playing the game. }\end{array}$ & 0.15 & 0.60 & 0.47 & 0.38 & 0.67 & 0.35 & 0.46 & -0.01 & 0.37 \\
\hline I feel I can explore things in the game. & 0.16 & 0.54 & 0.34 & 0.38 & 0.61 & 0.34 & 0.23 & 0.02 & 0.41 \\
\hline $\begin{array}{l}\text { I feel the game gives me enough freedom to act } \\
\text { how I want. }\end{array}$ & 0.11 & 0.36 & 0.31 & 0.38 & 0.61 & 0.24 & 0.17 & 0.17 & 0.29 \\
\hline I think the game is unique or original. & 0.16 & 0.49 & 0.28 & 0.45 & 0.57 & 0.32 & 0.39 & -0.02 & 0.23 \\
\hline I enjoy the sound effects in the game. & 0.17 & 0.39 & 0.26 & 0.37 & 0.35 & 0.89 & 0.39 & 0.16 & 0.41 \\
\hline
\end{tabular}


APPENDIX Z (continued)

EFA STUDY: STRUCTURE MATRIX LOADINGS FOR THE 9-FACTOR SOLUTION ( $\mathrm{N}=629$ )

\begin{tabular}{|c|c|c|c|c|c|c|c|c|c|}
\hline \multirow[t]{2}{*}{ Item } & \multicolumn{9}{|c|}{ Factor Loadings for Promax Rotation } \\
\hline & Factor 1 & Factor 2 & Factor 3 & Factor 4 & Factor 5 & Factor 6 & Factor 7 & Factor 8 & Factor 9 \\
\hline I enjoy the music in the game. & 0.20 & 0.42 & 0.28 & 0.36 & 0.34 & 0.80 & 0.31 & 0.05 & 0.43 \\
\hline $\begin{array}{l}\text { I feel the game's audio (e.g., sound effects, } \\
\text { music) enhances my gaming experience. }\end{array}$ & 0.15 & 0.33 & 0.22 & 0.27 & 0.29 & 0.78 & 0.32 & 0.15 & 0.42 \\
\hline $\begin{array}{l}\text { I think the game's audio fits the mood or style of } \\
\text { the game. }\end{array}$ & 0.25 & 0.35 & 0.26 & 0.40 & 0.30 & 0.73 & 0.40 & 0.11 & 0.50 \\
\hline $\begin{array}{l}\text { I feel successful when I overcome the obstacles } \\
\text { in the game. }\end{array}$ & 0.22 & 0.31 & 0.33 & 0.42 & 0.34 & 0.24 & 0.68 & 0.13 & 0.39 \\
\hline $\begin{array}{l}\text { I feel the game constantly motivates me to } \\
\text { proceed further to the next stage or level. }\end{array}$ & 0.30 & 0.46 & 0.39 & 0.44 & 0.43 & 0.31 & 0.67 & 0.07 & 0.42 \\
\hline I want to do as well as possible during the game. & 0.30 & 0.17 & 0.31 & 0.30 & 0.17 & 0.22 & 0.63 & 0.23 & 0.37 \\
\hline $\begin{array}{l}\text { I am very focused on my own performance while } \\
\text { playing the game. }\end{array}$ & 0.32 & 0.14 & 0.37 & 0.27 & 0.22 & 0.24 & 0.61 & 0.22 & 0.34 \\
\hline $\begin{array}{l}\text { I am in suspense about whether I will succeed in } \\
\text { the game. }\end{array}$ & 0.06 & 0.25 & 0.30 & 0.21 & 0.25 & 0.23 & 0.60 & 0.14 & 0.11 \\
\hline $\begin{array}{l}\text { I find my skills gradually improve through the } \\
\text { course of overcoming the challenges in the } \\
\text { game. }\end{array}$ & 0.18 & 0.22 & 0.23 & 0.41 & 0.29 & 0.35 & 0.55 & 0.18 & 0.28 \\
\hline $\begin{array}{l}\text { I find the game supports social interaction (e.g., } \\
\text { chat) between players. }\end{array}$ & 0.11 & 0.13 & 0.10 & 0.10 & 0.27 & 0.07 & 0.17 & 0.83 & 0.15 \\
\hline I like to play this game with other players. & 0.07 & -0.13 & 0.00 & 0.07 & 0.03 & 0.12 & 0.21 & 0.76 & 0.08 \\
\hline $\begin{array}{l}\text { I am able to play the game with other players if I } \\
\text { choose. }\end{array}$ & 0.15 & -0.05 & 0.06 & 0.09 & 0.06 & 0.13 & 0.21 & 0.72 & 0.12 \\
\hline
\end{tabular}


APPENDIX Z (continued)

EFA STUDY: STRUCTURE MATRIX LOADINGS FOR THE 9-FACTOR SOLUTION ( $N=629)$

\begin{tabular}{|c|c|c|c|c|c|c|c|c|c|}
\hline \multirow[t]{2}{*}{ Item } & \multicolumn{9}{|c|}{ Factor Loadings for Promax Rotation } \\
\hline & Factor 1 & Factor 2 & Factor 3 & Factor 4 & Factor 5 & Factor 6 & Factor 7 & Factor 8 & Factor 9 \\
\hline I enjoy the social interaction within the game. & 0.19 & 0.33 & 0.19 & 0.22 & 0.36 & 0.23 & 0.30 & 0.65 & 0.23 \\
\hline I enjoy the game's graphics. & 0.28 & 0.44 & 0.25 & 0.44 & 0.35 & 0.43 & 0.37 & 0.07 & 0.70 \\
\hline $\begin{array}{l}\text { I think the graphics of the game fit the mood or } \\
\text { style of the game. }\end{array}$ & 0.29 & 0.34 & 0.25 & 0.45 & 0.28 & 0.42 & 0.39 & 0.01 & 0.68 \\
\hline I think the game is visually appealing. & 0.28 & 0.31 & 0.19 & 0.30 & 0.28 & 0.40 & 0.26 & 0.12 & 0.61 \\
\hline
\end{tabular}

Note: Factor loadings of |.40| or above are bolded. 
CFA STUDY: UNIQUE VIDEO GAME TITLES EVALUATED

\begin{tabular}{|c|c|c|c|}
\hline Number & Game Title & $n$ & Main Genre (Sub-Genre) \\
\hline 1 & 18 wheels of steel & 1 & Driving/Racing \\
\hline 2 & 8 Ball Pool & 1 & Sports \\
\hline 3 & Age of Empires II: The Age of Kings & 1 & Strategy (Real-Time) \\
\hline 4 & Age of Empires III & 1 & Strategy (Real-Time) \\
\hline 5 & Alan Wake & 1 & Action Adventure (Survival/Horror) \\
\hline 6 & Alien: Isolation & 1 & Action Adventure (Survival/Horror) \\
\hline 7 & Angry Birds Epic & 1 & RPG \\
\hline 8 & Angry Birds Space & 1 & Puzzle/Card/Board \\
\hline 9 & Animal Crossing: New Leaf & 2 & Simulation (Virtual Life) \\
\hline 10 & ArmA III & 1 & Action (FPS) \\
\hline 11 & Assassin's Creed III: Liberation & 1 & Action Adventure (Stealth) \\
\hline 12 & Assassin's Creed IV: Black Flag & 5 & Action Adventure (Stealth) \\
\hline 13 & Assassin's Creed Revelations & 1 & Action Adventure (Stealth) \\
\hline 14 & Assassin's Creed Unity & 2 & Action Adventure (Stealth) \\
\hline 15 & Awesomenauts & 1 & Strategy (MOBA) \\
\hline 16 & Band Stars & 1 & Music/Dance \\
\hline 17 & Banished & 2 & Strategy (Management) \\
\hline 18 & Batman: Arkham Asylum & 1 & Action Adventure (Stealth) \\
\hline 19 & Battleblock Theater & 1 & Action (Platformer) \\
\hline 20 & Battlefield 4 & 6 & Action (FPS) \\
\hline 21 & Battlefield Hardline & 1 & Action (FPS) \\
\hline 22 & Battletoads & 1 & Action (Beat-'Em-Up) \\
\hline 23 & Bejewelled & 1 & Puzzle/Card/Board \\
\hline 24 & Beyond Two Souls & 1 & Action Adventure \\
\hline 25 & BioShock Infinite & 1 & Action (FPS) \\
\hline
\end{tabular}


APPENDIX AA (continued)

CFA STUDY: UNIQUE VIDEO GAME TITLES EVALUATED

\begin{tabular}{|c|c|c|c|}
\hline Number & Game Title & $n$ & Main Genre (Sub-Genre) \\
\hline 26 & Borderlands & 2 & Action (FPS) \\
\hline 27 & Borderlands 2 & 1 & Action (FPS) \\
\hline 28 & Borderlands: The Pre-Sequel & 2 & Action (FPS) \\
\hline 29 & Brawlhalla & 1 & Fighting \\
\hline 30 & Brothers in Arms 3: Sons of War & 1 & Action (TPS) \\
\hline 31 & Call of Duty & 5 & Action (FPS) \\
\hline 32 & Call of Duty: Advanced Warfare & 11 & Action (FPS) \\
\hline 33 & Call of Duty: Black Ops & 6 & Action (FPS) \\
\hline 34 & Call of Duty: Black Ops II & 4 & Action (FPS) \\
\hline 35 & Call of Duty: Ghosts & 3 & Action (FPS) \\
\hline 36 & Call of Duty: Modern Warfare 2 & 1 & Action (FPS) \\
\hline 37 & Call of Duty: Modern Warfare 3 & 2 & Action (FPS) \\
\hline 38 & Call of Duty: Zombies & 1 & Action (FPS) \\
\hline 39 & Candy Blast Mania & 1 & Puzzle/Card/Board \\
\hline 40 & Candy Crush Saga & 12 & Puzzle/Card/Board \\
\hline 41 & Clash of Clans & 11 & Strategy (Real-Time) \\
\hline 42 & Clicker Heroes & 1 & Adventure \\
\hline 43 & Cooking Fever & 1 & Strategy (Time Management) \\
\hline 44 & Costume Quest 2 & 1 & RPG (Action RPG) \\
\hline 45 & Counter-Strike & 2 & Action (FPS) \\
\hline 46 & Counter-Strike 1.6 & 1 & Action (FPS) \\
\hline 47 & Counter-Strike: Global Offensive & 10 & Action (FPS) \\
\hline 48 & Counter-Strike: Source & 1 & Action (FPS) \\
\hline 49 & Crash Bandicoot: The Wrath of Cortex & 1 & Action (Platformer) \\
\hline 50 & Crash Bandicoot: Warped & 1 & Action (Platformer) \\
\hline
\end{tabular}


APPENDIX AA (continued)

CFA STUDY: UNIQUE VIDEO GAME TITLES EVALUATED

\begin{tabular}{|c|c|c|c|}
\hline Number & Game Title & $n$ & Main Genre (Sub-Genre) \\
\hline 51 & Criminal Case & 1 & Puzzle/Card/Board \\
\hline 52 & Crossy Road & 1 & Action (Arcade) \\
\hline 53 & Crusader Kings II & 1 & Strategy (Real-Time) \\
\hline 54 & Dante's Inferno & 1 & Action (Beat-'Em-Up) \\
\hline 55 & Dark Souls & 4 & RPG (Action RPG) \\
\hline 56 & Dark Souls 2 & 2 & RPG (Action RPG) \\
\hline 57 & DayZ & 1 & Action (FPS) \\
\hline 58 & DC Universe Online & 1 & RPG (Massively Multiplayer) \\
\hline 59 & Dead Island & 2 & Action Adventure (Survival/Horror) \\
\hline 60 & Defense of the Ancients (DotA) 2 & 13 & Strategy (Real-Time) \\
\hline 61 & Delicious - Emily's New Beginning & 1 & Strategy (Time Management) \\
\hline 62 & Democracy 3 & 1 & Strategy (Management) \\
\hline 63 & Destiny & 27 & Action (FPS) \\
\hline 64 & Diablo II & 3 & RPG (Action RPG) \\
\hline 65 & Diablo III & 2 & RPG (Action RPG) \\
\hline 66 & Diablo III: Reaper of Souls & 2 & RPG (Action RPG) \\
\hline 67 & Disco Bees & 1 & Puzzle/Card/Board \\
\hline 68 & Dishonored & 1 & Action Adventure (Stealth) \\
\hline 69 & Disney Infinity 1.0 & 1 & Action Adventure (Sandbox) \\
\hline 70 & Divinity: Original Sin & 2 & RPG (Action RPG) \\
\hline 71 & Don't Starve Together & 1 & Action Adventure (Survival/Horror) \\
\hline 72 & Dragon Age: Inquisition & 19 & RPG \\
\hline 73 & Dragon Age: Origins & 2 & RPG \\
\hline 74 & Dragon's Dogma: Dark Arisen & 1 & RPG (Action RPG) \\
\hline 75 & Drop7 & 1 & Puzzle/Card/Board \\
\hline
\end{tabular}


APPENDIX AA (continued)

UNIQUE VIDEO GAME TITLES EVALUATED IN THE CFA STUDY

\begin{tabular}{|c|c|c|c|}
\hline Number & Game Title & $n$ & Main Genre (Sub-Genre) \\
\hline 76 & Dungeon Hunter 4 & 1 & RPG (Action RPG) \\
\hline 77 & Dungeon Keeper Gold & 1 & Strategy (Real-Time) \\
\hline 78 & Dying Light & 3 & Action Adventure (Survival/Horror) \\
\hline 79 & Dynasty Warriors 6 & 2 & Action (Beat-'Em-Up) \\
\hline 80 & Dynasty Warriors 8 & 1 & Action (Beat-'Em-Up) \\
\hline 81 & Elite: Dangerous & 2 & Simulation (Flight/Space) \\
\hline 82 & Endless Legend & 1 & Strategy (Turn-Based) \\
\hline 83 & Europa Universalis III & 1 & Strategy \\
\hline 84 & Eve Online & 1 & RPG (Massively Multiplayer) \\
\hline 85 & Everquest & 1 & RPG (Massively Multiplayer) \\
\hline 86 & Evolve & 2 & Action (FPS) \\
\hline 87 & Fable III & 1 & RPG (Action RPG) \\
\hline 88 & Fallout 3 & 4 & RPG \\
\hline 89 & Fallout: New Vegas & 4 & RPG \\
\hline 90 & Family Guy: The Quest for Stuff & 2 & Strategy (Management) \\
\hline 91 & Fantasy Life & 2 & RPG \\
\hline 92 & Far Cry 3 & 2 & Action (FPS) \\
\hline 93 & Far Cry 4 & 10 & Action (FPS) \\
\hline 94 & Farm Heroes Saga & 2 & Puzzle/Card/Board \\
\hline 95 & FIFA 14 & 4 & Sports \\
\hline 96 & FIFA 15 & 14 & Sports \\
\hline 97 & Fight Night & 1 & Fighting \\
\hline 98 & Final Fantasy I & 1 & RPG \\
\hline 99 & Final Fantasy IX & 1 & RPG \\
\hline 100 & Final Fantasy $\mathrm{X}$ & 2 & RPG \\
\hline
\end{tabular}


APPENDIX AA (continued)

CFA STUDY: UNIQUE VIDEO GAME TITLES EVALUATED

\begin{tabular}{|c|c|c|c|}
\hline Number & Game Title & $n$ & Main Genre (Sub-Genre) \\
\hline 101 & Final Fantasy XII & 1 & RPG \\
\hline 102 & Final Fantasy XIV Online & 1 & RPG (Massively Multiplayer) \\
\hline 103 & Fire Emblem Awakening & 2 & Strategy (Turn-Based) \\
\hline 104 & Fire Emblem: Genealogy of the Holy War & 1 & Strategy (Turn-Based) \\
\hline 105 & Flappy Bird & 1 & Action (Arcade) \\
\hline 106 & Forza Horizon 2 & 1 & Driving/Racing \\
\hline 107 & Friday Night 3D Bowling & 1 & Sports \\
\hline 108 & FTL: Faster Than Light & 1 & Simulation (Flight/Space) \\
\hline 109 & Full Deck Solitaire & 1 & Puzzle/Card/Board \\
\hline 110 & Game of Thrones Ascent & 1 & Action \\
\hline 111 & Garry's Mod & 3 & Action Adventure (Sandbox) \\
\hline 112 & God of War & 1 & Action Adventure \\
\hline 113 & GoodGame Empire & 1 & Strategy (Real-Time) \\
\hline 114 & Gran Turismo & 1 & Driving/Racing \\
\hline 115 & Gran Turismo 6 & 1 & Driving/Racing \\
\hline 116 & Grand Theft Auto & 2 & Action Adventure (Open-World) \\
\hline 117 & Grand Theft Auto IV & 1 & Action Adventure (Open-World) \\
\hline 118 & Grand Theft Auto V & 29 & Action Adventure (Open-World) \\
\hline 119 & Grand Theft Auto: Chinatown Wars & 1 & Action Adventure (Open-World) \\
\hline 120 & Grand Theft Auto: San Andreas & 1 & Action Adventure (Open-World) \\
\hline 121 & Guild Wars 2 & 3 & RPG (Massively Multiplayer) \\
\hline 122 & Guitar Hero & 1 & Music/Dance \\
\hline 123 & Guitar Hero 3 & 1 & Music/Dance \\
\hline 124 & Halo 3 & 1 & Action (FPS) \\
\hline 125 & Halo 4 & 2 & Action (FPS) \\
\hline
\end{tabular}


APPENDIX AA (continued)

CFA STUDY: UNIQUE VIDEO GAME TITLES EVALUATED

\begin{tabular}{|c|c|c|c|}
\hline Number & Game Title & $n$ & Main Genre (Sub-Genre) \\
\hline 126 & Halo Reach & 1 & Action (FPS) \\
\hline 127 & Halo: Combat Evolved & 1 & Action (FPS) \\
\hline 128 & Harry Potter and the Deathly Hallows, Part 1 & 2 & Action Adventure \\
\hline 129 & Hay Day & 1 & Strategy \\
\hline 130 & Heads Up! & 1 & Puzzle/Card/Board \\
\hline 131 & Hearthstone: Heroes of Warcraft & 9 & Strategy (Turn-Based) \\
\hline 132 & Heroes of the Storm & 2 & Strategy (MOBA) \\
\hline 133 & Heroine's Quest: The Herald of Ragnarok & 1 & RPG \\
\hline 134 & Hungry Shark Evolution & 1 & Action (Arcade) \\
\hline 135 & Injustice: Gods Among Us & 2 & Fighting \\
\hline 136 & Jigsaw Puzzle & 1 & Puzzle/Card/Board \\
\hline 137 & Jojo's Fashion Show: World Tour & 1 & Strategy (Time Management) \\
\hline 138 & Just Dance 2015 & 2 & Music/Dance \\
\hline 139 & Just Get 10 & 1 & Puzzle/Card/Board \\
\hline 140 & Kerbal Space Program & 2 & Simulation (Flight/Space) \\
\hline 141 & Kim Kardashian: Hollywood & 1 & Simulation \\
\hline 142 & Kingdom Hearts & 2 & RPG (Action RPG) \\
\hline 143 & Kingdom Rush & 1 & Action \\
\hline 144 & Kingdoms of Amalur: Reckoning & 1 & RPG (Action RPG) \\
\hline 145 & Kolor Lines & 1 & Puzzle/Card/Board \\
\hline 146 & Kritika: The White Knights & 1 & RPG (Massively Multiplayer) \\
\hline 147 & League of Angels & 1 & RPG (Massively Multiplayer) \\
\hline 148 & League of Legends & 47 & Strategy (MOBA) \\
\hline 149 & Left 4 Dead 2 & 1 & Action (FPS) \\
\hline 150 & Lego Marvel Super Heroes & 2 & Action Adventure \\
\hline
\end{tabular}


APPENDIX AA (continued)

CFA STUDY: UNIQUE VIDEO GAME TITLES EVALUATED

\begin{tabular}{|c|c|c|c|}
\hline Number & Game Title & $n$ & Main Genre (Sub-Genre) \\
\hline 151 & LINE: Disney Tsum Tsum & 1 & Puzzle/Card/Board \\
\hline 152 & LittleBigPlanet & 2 & Action (Platformer) \\
\hline 153 & LittleBigPlanet 3 & 1 & Action (Platformer) \\
\hline 154 & Looney Tunes Dash! & 1 & Action \\
\hline 155 & Madden NFL 15 & 3 & Sports \\
\hline 156 & Mahjong Solitaire Epic & 1 & Puzzle/Card/Board \\
\hline 157 & MapleStory & 1 & RPG (Massively Multiplayer) \\
\hline 158 & Mario Kart 7 & 1 & Driving/Racing \\
\hline 159 & Mario Kart 8 & 4 & Driving/Racing \\
\hline 160 & Mario Kart Wii & 11 & Driving/Racing \\
\hline 161 & Mario Party & 1 & Party \\
\hline 162 & Mass Effect & 3 & RPG (Action RPG) \\
\hline 163 & Mass Effect 2 & 1 & RPG (Action RPG) \\
\hline 164 & Mass Effect 3 & 2 & RPG (Action RPG) \\
\hline 165 & Mechwarrior Online & 2 & Action (FPS) \\
\hline 166 & Medal of Honor & 1 & Action (FPS) \\
\hline 167 & Medieval II: Total War & 1 & Strategy (Turn-Based) \\
\hline 168 & Middle-earth: Shadow of Mordor & 2 & RPG (Action RPG) \\
\hline 169 & Minecraft & 27 & Action Adventure (Sandbox) \\
\hline 170 & Minecraft Pocket Edition & 1 & Action Adventure (Sandbox) \\
\hline 171 & Mini Ninjas & 1 & Action Adventure \\
\hline 172 & MLB 15: The Show & 1 & Sports \\
\hline 173 & Monopoly & 1 & Puzzle/Card/Board \\
\hline 174 & Monster Hunter 3 Ultimate & 1 & RPG (Action RPG) \\
\hline 175 & Monster Hunter 4 & 1 & RPG (Action RPG) \\
\hline
\end{tabular}


APPENDIX AA (continued)

CFA STUDY: UNIQUE VIDEO GAME TITLES EVALUATED

\begin{tabular}{|c|c|c|c|}
\hline Number & Game Title & $n$ & Main Genre (Sub-Genre) \\
\hline 176 & Mortal Kombat & 1 & Fighting \\
\hline 177 & Murdered: Soul Suspect & 1 & Action Adventure (Stealth) \\
\hline 178 & Natural Selection 2 & 1 & Action (FPS) \\
\hline 179 & NBA 2K14 & 1 & Sports \\
\hline 180 & NBA 2 K15 & 12 & Sports \\
\hline 181 & NCAA Football 14 & 1 & Sports \\
\hline 182 & Need for Speed & 2 & Driving/Racing \\
\hline 183 & Need for Speed: Hot Pursuit & 1 & Driving/Racing \\
\hline 184 & NetHack & 1 & RPG \\
\hline 185 & New Super Mario Bros. Wii & 2 & Action (Platformer) \\
\hline 186 & New Super Mario Bros. 2 & 4 & Action (Platformer) \\
\hline 187 & New Super Mario Bros. U & 5 & Action (Platformer) \\
\hline 188 & NHL 13 & 1 & Sports \\
\hline 189 & NHL 15 & 2 & Sports \\
\hline 190 & Ni no Kuni: Wrath of the White Witch & 1 & RPG \\
\hline 191 & Okami & 1 & Action Adventure \\
\hline 192 & Order Up! & 1 & Simulation \\
\hline 193 & Panda Pop & 1 & Puzzle/Card/Board \\
\hline 194 & Pandemic & 1 & Strategy \\
\hline 195 & Paperboy & 1 & Action \\
\hline 196 & Payday 2 & 2 & Action (FPS) \\
\hline 197 & Persona Q: Shadow of the Labyrinth & 3 & RPG \\
\hline 198 & Pokemon Alpha Sapphire & 5 & RPG \\
\hline 199 & Pokemon Omega Ruby & 4 & RPG \\
\hline 200 & Pokemon $\mathrm{X}$ & 2 & RPG \\
\hline
\end{tabular}


APPENDIX AA (continued)

CFA STUDY: UNIQUE VIDEO GAME TITLES EVALUATED

\begin{tabular}{|c|c|c|c|}
\hline Number & Game Title & $n$ & Main Genre (Sub-Genre) \\
\hline 201 & Portal & 2 & Action (FPS) \\
\hline 202 & Portal 2 & 4 & Action (FPS) \\
\hline 203 & QuizUp & 1 & Trivia/Game Show \\
\hline 204 & Ratchet \& Clank: Going Commando & 1 & Action (Platformer) \\
\hline 205 & Rayman Legends & 1 & Action (Platformer) \\
\hline 206 & Real Racing 3 & 1 & Driving/Racing \\
\hline 207 & Red Dead Redemption & 2 & Action Adventure \\
\hline 208 & Resident Evil & 1 & Action Adventure (Survival/Horror) \\
\hline 209 & Resogun & 1 & Action (Shoot-'Em-Up) \\
\hline 210 & Return to Castle Wolfenstein: Enemy Territory & 1 & Action (FPS) \\
\hline 211 & Rising Storm & 1 & Action (FPS) \\
\hline 212 & Robocraft & 1 & Action (TPS) \\
\hline 213 & Runescape & 1 & RPG (Massively Multiplayer) \\
\hline 214 & S.T.A.L.K.E.R.: Shadow of Chernobyl & 1 & Action (FPS) \\
\hline 215 & Saints Row IV & 2 & Action Adventure (Open-World) \\
\hline 216 & Saints Row: Gat out of Hell & 2 & Action Adventure (Open-World) \\
\hline 217 & Saints Row: The Third & 1 & Action Adventure (Open-World) \\
\hline 218 & Seabeard & 1 & Action (Arcade) \\
\hline 219 & Shadow Warrior & 2 & Action (FPS) \\
\hline 220 & Shall We Date? Scarlet Fate+ & 1 & Simulation (Dating) \\
\hline 221 & Sid Meier's Civilization V & 6 & Strategy (Turn-Based) \\
\hline 222 & Silent Hill: Homecoming & 1 & Action Adventure (Survival/Horror) \\
\hline 223 & SimCity & 2 & Strategy (Management) \\
\hline 224 & SimCity Buildlt & 1 & Strategy (Management) \\
\hline 225 & Skylanders Trap Team & 1 & Action (Platformer) \\
\hline
\end{tabular}


APPENDIX AA (continued)

CFA STUDY: UNIQUE VIDEO GAME TITLES EVALUATED

\begin{tabular}{|c|c|c|c|}
\hline Number & Game Title & $n$ & Main Genre (Sub-Genre) \\
\hline 226 & Slaves to Armok: God of Blood Chapter II: Dwarf Fortress & 1 & Simulation \\
\hline 227 & Sleeping Dogs & 2 & Action Adventure (Open-World) \\
\hline 228 & Sniper Elite III & 2 & Action (TPS) \\
\hline 229 & Sniper Team 2 & 1 & Action (TPS) \\
\hline 230 & Soccer Stars & 1 & Sports \\
\hline 231 & Solitaire & 1 & Puzzle/Card/Board \\
\hline 232 & Sonic Dash & 1 & Action (Platformer) \\
\hline 233 & Sonic Unleashed & 1 & Action (Platformer) \\
\hline 234 & South Park: The Stick of Truth & 2 & RPG \\
\hline 235 & Space Engineers & 2 & Simulation \\
\hline 236 & SSX & 1 & Sports \\
\hline 237 & Star Wars Galaxies & 1 & RPG (Massively Multiplayer) \\
\hline 238 & Star Wars: Commander & 1 & Strategy (Real-Time) \\
\hline 239 & Star Wars: Knights of the Old Republic & 2 & RPG \\
\hline 240 & Star Wars: The Old Republic & 3 & RPG (Massively Multiplayer) \\
\hline 241 & StarCraft II: Heart of the Swarm & 3 & Strategy (Real-Time) \\
\hline 242 & Starsky \& Hutch & 1 & Driving/Racing \\
\hline 243 & Subway Surfers & 1 & Action \\
\hline 244 & Super Mario Galaxy & 1 & Action (Platformer) \\
\hline 245 & Super Mario Galaxy 2 & 1 & Action (Platformer) \\
\hline 246 & Super Meat Boy & 1 & Action (Platformer) \\
\hline 247 & Super Smash Bros. Brawl & 1 & Fighting \\
\hline 248 & Super Smash Bros. Melee & 1 & Fighting \\
\hline 249 & Swordsman Online & 1 & RPG (Massively Multiplayer) \\
\hline 250 & Tales of Vesperia & 1 & RPG \\
\hline
\end{tabular}


APPENDIX AA (continued)

CFA STUDY: UNIQUE VIDEO GAME TITLES EVALUATED

\begin{tabular}{|c|c|c|c|}
\hline Number & Game Title & $n$ & Main Genre (Sub-Genre) \\
\hline 251 & Tap Titans & 1 & Action \\
\hline 252 & Team Fortress 2 & 3 & Action (FPS) \\
\hline 253 & Temple Run & 1 & Action \\
\hline 254 & Terra Battle & 1 & RPG \\
\hline 255 & Terraria & 2 & Action Adventure (Sandbox) \\
\hline 256 & The Binding of Isaac: Rebirth & 3 & Action Adventure (Survival/Horror) \\
\hline 257 & The Cat Lady & 1 & Adventure \\
\hline 258 & The Elder Scrolls III: Morrowind & 1 & RPG \\
\hline 259 & The Elder Scrolls V: Skyrim & 22 & RPG \\
\hline 260 & The Evil Within & 1 & Action Adventure (Survival/Horror) \\
\hline 261 & The Last of Us & 3 & Action Adventure (Survival/Horror) \\
\hline 262 & The Last of Us Remastered & 1 & Action Adventure (Survival/Horror) \\
\hline 263 & The Legend of Korra & 1 & Action (Beat-'Em-Up) \\
\hline 264 & The Legend of Zelda & 2 & Action Adventure (Open-World) \\
\hline 265 & The Legend of Zelda: A Link to the Past & 1 & Action Adventure (Open-World) \\
\hline 266 & The Legend of Zelda: Ocarina of Time & 1 & Action Adventure (Open-World) \\
\hline 267 & The Legend of Zelda: Twilight Princess & 1 & Action Adventure (Open-World) \\
\hline 268 & The Lion King & 1 & Action (Platformer) \\
\hline 269 & The Lord of the Rings Online & 1 & RPG (Massively Multiplayer) \\
\hline 270 & The Secret World & 1 & RPG (Massively Multiplayer) \\
\hline 271 & The Sims & 1 & Simulation (Virtual Life) \\
\hline 272 & The Sims 3 & 5 & Simulation (Virtual Life) \\
\hline 273 & The Sims 3: Into the Future & 1 & Simulation (Virtual Life) \\
\hline 274 & The Sims 4 & 6 & Simulation (Virtual Life) \\
\hline 275 & The Sims FreePlay & 2 & Simulation (Virtual Life) \\
\hline
\end{tabular}


APPENDIX AA (continued)

CFA STUDY: UNIQUE VIDEO GAME TITLES EVALUATED

\begin{tabular}{|c|c|c|c|}
\hline Number & Game Title & $n$ & Main Genre (Sub-Genre) \\
\hline 276 & The Unfinished Swan & 1 & Adventure \\
\hline 277 & The Witcher: Enhanced Edition & 1 & RPG (Action RPG) \\
\hline 278 & The Wolf Among Us & 1 & Action Adventure \\
\hline 279 & Thief & 1 & Action Adventure (Stealth) \\
\hline 280 & This War of Mine & 2 & Strategy \\
\hline 281 & Titanfall & 1 & Action (FPS) \\
\hline 282 & Tomodachi Life & 2 & Simulation (Virtual Life) \\
\hline 283 & Total War: Rome II & 2 & Strategy (Turn-Based) \\
\hline 284 & Trivia Crack & 13 & Trivia/Game Show \\
\hline 285 & TwoDots & 1 & Puzzle/Card/Board \\
\hline 286 & Unit 13 & 1 & Action (TPS) \\
\hline 287 & UNO \& Friends & 1 & Puzzle/Card/Board \\
\hline 288 & Valiant Hearts: The Great War & 1 & Action (Platformer) \\
\hline 289 & Valkyria Chronicles & 1 & Strategy (Turn-Based) \\
\hline 290 & Villagers and Heroes & 1 & RPG (Massively Multiplayer) \\
\hline 291 & War Thunder & 1 & Simulation (Flight/Space) \\
\hline 292 & Warcraft III & 1 & Strategy (Real-Time) \\
\hline 293 & Warcraft: Orcs \& Humans & 1 & Strategy (Real-Time) \\
\hline 294 & Warframe & 3 & Action (TPS) \\
\hline 295 & Wargame: AirLand Battle & 1 & Strategy (Real-Time) \\
\hline 296 & Wargame: Red Dragon & 1 & Strategy (Real-Time) \\
\hline 297 & Wario Land II & 2 & Action (Platformer) \\
\hline 298 & Watch Dogs & 1 & Action Adventure (Open-World) \\
\hline 299 & Wii Party U & 1 & Party \\
\hline 300 & Wii Sports & 3 & Sports \\
\hline
\end{tabular}


APPENDIX AA (continued)

CFA STUDY: UNIQUE VIDEO GAME TITLES EVALUATED

\begin{tabular}{rlcc}
\hline Number & Game Title & $\boldsymbol{n}$ & Main Genre (Sub-Genre) \\
\hline 301 & Wizard101 & 1 & RPG (Massively Multiplayer) \\
302 & Wolfenstein: The New Order & 1 & Action (FPS) \\
303 & Word Chums & 1 & Puzzle/Card/Board \\
304 & Wordfeud & 1 & Puzzle/Card/Board \\
305 & Words With Friends & 2 & Puzzle/Card/Board \\
306 & World of Tanks & 4 & Action (TPS) \\
307 & World of Warcraft & 20 & RPG (Massively Multiplayer) \\
308 & World of Warcraft: Warlords of Draenor & 1 & RPG (Massively Multiplayer) \\
309 & WWE 2K15 & 1 & Sports \\
310 & X3: Terran Conflict & 1 & Simulation (Flight/Space) \\
311 & XCOM: Enemy Unknown & Strategy (Turn-Based) \\
312 & You Don't Know Jack & 2 & Trivia/Game Show \\
\hline
\end{tabular}




\section{CFA STUDY: CONSENT FORM}

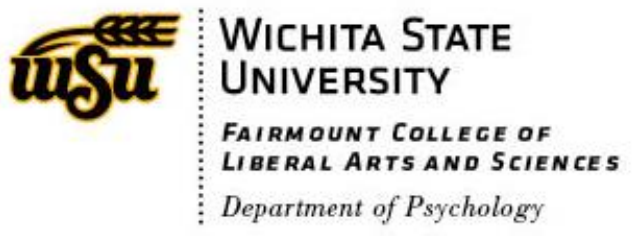

Consent Form

Purpose: Since you are 18 years of age or older, you are invited to participate in a study investigating video game satisfaction. We hope to learn more about how people rate different video games that they currently play or have recently played.

Participant Selection: You were selected as a possible participant in this study because you fit the criteria of the population we are interested in studying, namely that you are over the age of 18 and you have recently played a video game. You are one of at least 600 participants in this study.

Explanation of Procedures: If you decide to participate, you will be asked to complete an online survey to evaluate a video game you recently played through a series of statements (e.g., I enjoy playing the game.) on a 7-point scale ( 1 = Strongly Disagree; 7 = Strongly Agree). Also, you will be asked to answer other questions related to the game you're evaluating (e.g., the device platform that you used to play the game), and general demographics questions (e.g., age, gender). The survey will take approximately 10-20 minutes to complete.

Discomfort/Risks: There are no expected risks or discomforts. However, you may take a break at any time, and you have the option of discontinue filling out the survey if any of the questions make you feel uncomfortable.

Benefits: Your participation in this study will be beneficial in helping researchers better understand the key factors that contribute to video game satisfaction. 


\section{APPENDIX BB (continued)}

\section{CFA STUDY: CONSENT FORM}

Confidentiality: Every effort will be made to keep your study-related information confidential. However, in order to make sure the study is done properly and safely there may be circumstances where this information must be released. By signing this form, you are giving the research team permission to share information about you with the following groups:

- Office for Human Research Protections or other federal, state, or international regulatory agencies;

- The Wichita State University Institutional Review Board;

- The sponsor or agency supporting the study.

The researchers may publish the results of the study. If they do, they will only discuss group results. Your name will not be used in any publication or presentation about the study. We will work to make sure that no one sees your survey responses without approval. But, because we are using the Internet, there is a chance that someone could access your online responses without permission. In some cases, this information could be used to identify you. Your data will be protected with a code to reduce the risk that other people can view the responses.

Compensation: For your participation, your name will be entered in a random drawing to win 1 of $20 \$ 50$ Amazon gift cards.

Refusal/Withdrawal: Participation in this study is entirely voluntary. Your decision whether or not to participate will not affect your future relations with Wichita State University. If you agree to participate in this study, you are free to withdraw from the study at any time without penalty.

Contact: If you have any questions about this research, you may contact Mikki Phan at mhphan@wichita.edu or you can contact Dr. Barbara Chaparro at 316-978-3683 or via e-mail at barbara.chaparro@wichita.edu. If you have questions pertaining to your rights as a research subject, or about research-related injury, you can contact the Office of Research and Technology Transfer at Wichita State University, 1845 Fairmount Street, Wichita, KS 672600007, telephone (316) 978-3285.

You are under no obligation to participate in this study. By selecting the "Next $>>$ " button below, you are indicating that:

- You have read (or someone has read to you) the information provided above,

- You are aware that this is a research study,

- You have voluntarily decided to participate. 
APPENDIX CC

CFA STUDY: SKEWNESS AND KURTOSIS VALUES OF ITEMS

\begin{tabular}{|c|c|c|c|c|c|c|c|}
\hline \multirow[t]{2}{*}{ Item } & \multirow[t]{2}{*}{$n$} & \multirow[t]{2}{*}{ Mean } & \multirow[t]{2}{*}{ SD } & \multicolumn{2}{|c|}{ Skewness } & \multicolumn{2}{|c|}{ Kurtosis } \\
\hline & & & & Value & Std. Error & Value & Std. Error \\
\hline $\begin{array}{l}\text { Sometimes I lose track of time while playing the } \\
\text { game. }\end{array}$ & 766 & 5.92 & 1.37 & -1.60 & 0.09 & 2.35 & 0.18 \\
\hline I enjoy the sound effects in the game. & 760 & 5.54 & 1.60 & -1.27 & 0.09 & 0.96 & 0.18 \\
\hline $\begin{array}{l}\text { I am very focused on my own performance } \\
\text { while playing the game. }\end{array}$ & 770 & 6.02 & 1.19 & -1.48 & 0.09 & 2.20 & 0.18 \\
\hline $\begin{array}{l}\text { I tend to spend more time playing the game } \\
\text { than I have planned. }\end{array}$ & 766 & 5.45 & 1.59 & -1.04 & 0.09 & 0.22 & 0.18 \\
\hline I think it is easy to learn how to play the game. & 765 & 5.50 & 1.60 & -1.15 & 0.09 & 0.53 & 0.18 \\
\hline I enjoy playing the game. & 768 & 6.60 & 0.75 & -2.93 & 0.09 & 13.04 & 0.18 \\
\hline $\begin{array}{l}\text { I am in suspense about whether I will succeed in } \\
\text { the game. }\end{array}$ & 763 & 4.89 & 1.81 & -0.57 & 0.09 & -0.77 & 0.18 \\
\hline $\begin{array}{l}\text { I am able to play the game with other players if I } \\
\text { choose. }\end{array}$ & 694 & 5.69 & 1.98 & -1.46 & 0.09 & 0.68 & 0.19 \\
\hline $\begin{array}{l}\text { I think the information provided in the game } \\
\text { (e.g., onscreen messages, help) is clear. }\end{array}$ & 768 & 5.93 & 1.13 & -1.46 & 0.09 & 2.53 & 0.18 \\
\hline $\begin{array}{l}\text { I am captivated by the game's story from the } \\
\text { beginning. }\end{array}$ & 659 & 5.16 & 1.76 & -0.78 & 0.10 & -0.38 & 0.19 \\
\hline $\begin{array}{l}\text { I think the graphics of the game fit the mood or } \\
\text { style of the game. }\end{array}$ & 768 & 6.40 & 0.88 & -2.08 & 0.09 & 6.66 & 0.18 \\
\hline $\begin{array}{l}\text { I feel successful when I overcome the obstacles } \\
\text { in the game. }\end{array}$ & 766 & 6.25 & 1.00 & -1.85 & 0.09 & 4.45 & 0.18 \\
\hline $\begin{array}{l}\text { I always know my next goal when I finish an } \\
\text { event in the game. }\end{array}$ & 751 & 5.48 & 1.51 & -0.98 & 0.09 & 0.22 & 0.18 \\
\hline I think the game is unique or original. & 768 & 5.51 & 1.47 & -1.12 & 0.09 & 0.90 & 0.18 \\
\hline
\end{tabular}


APPENDIX CC (continued)

CFA STUDY: SKEWNESS AND KURTOSIS VALUES OF ITEMS

\begin{tabular}{|c|c|c|c|c|c|c|c|}
\hline \multirow[t]{2}{*}{ Item } & \multirow[t]{2}{*}{$n$} & \multirow[t]{2}{*}{ Mean } & \multirow[t]{2}{*}{ SD } & \multicolumn{2}{|c|}{ Skewness } & \multicolumn{2}{|c|}{ Kurtosis } \\
\hline & & & & Value & Std. Error & Value & Std. Error \\
\hline $\begin{array}{l}\text { I do not care to check events that are happening } \\
\text { in the real world during the game. }\end{array}$ & 766 & 4.07 & 1.87 & 0.06 & 0.09 & -1.22 & 0.18 \\
\hline I think the game is fun. & 771 & 6.52 & 0.77 & -2.15 & 0.09 & 6.18 & 0.18 \\
\hline $\begin{array}{l}\text { I always know how to achieve my } \\
\text { goals/objectives in the game. }\end{array}$ & 770 & 5.49 & 1.35 & -0.99 & 0.09 & 0.55 & 0.18 \\
\hline $\begin{array}{l}\text { I think the characters in the game are well } \\
\text { developed. }\end{array}$ & 686 & 5.32 & 1.67 & -0.99 & 0.09 & 0.10 & 0.19 \\
\hline $\begin{array}{l}\text { I find the controls of the game to be } \\
\text { straightforward. }\end{array}$ & 769 & 6.05 & 1.16 & -1.70 & 0.09 & 3.31 & 0.18 \\
\hline I enjoy the game's graphics. & 769 & 6.09 & 1.04 & -1.41 & 0.09 & 2.41 & 0.18 \\
\hline I want to do as well as possible during the game. & 769 & 6.22 & 1.03 & -1.61 & 0.09 & 2.97 & 0.18 \\
\hline $\begin{array}{l}\text { Whenever I stopped playing the game I cannot } \\
\text { wait to start playing it again. }\end{array}$ & 771 & 4.66 & 1.64 & -0.32 & 0.09 & -0.71 & 0.18 \\
\hline $\begin{array}{l}\text { I enjoy the fantasy or story provided by the } \\
\text { game. }\end{array}$ & 676 & 5.67 & 1.47 & -1.28 & 0.09 & 1.27 & 0.19 \\
\hline I feel very confident while playing the game. & 769 & 5.58 & 1.21 & -0.79 & 0.09 & 0.29 & 0.18 \\
\hline I am likely to recommend this game to others. & 768 & 6.25 & 1.09 & -2.07 & 0.09 & 5.13 & 0.18 \\
\hline $\begin{array}{l}\text { I temporarily forget about my everyday worries } \\
\text { while playing the game. }\end{array}$ & 770 & 5.59 & 1.40 & -1.14 & 0.09 & 1.02 & 0.18 \\
\hline I feel creative while playing the game. & 756 & 4.95 & 1.66 & -0.51 & 0.09 & -0.62 & 0.18 \\
\hline I can identify with the characters in the game. & 658 & 4.32 & 1.90 & -0.23 & 0.10 & -1.02 & 0.19 \\
\hline
\end{tabular}


APPENDIX CC (continued)

CFA STUDY: SKEWNESS AND KURTOSIS VALUES OF ITEMS

\begin{tabular}{|c|c|c|c|c|c|c|c|}
\hline \multirow[t]{2}{*}{ Item } & \multirow[t]{2}{*}{$n$} & \multirow[t]{2}{*}{ Mean } & \multirow[t]{2}{*}{ SD } & \multicolumn{2}{|c|}{ Skewness } & \multicolumn{2}{|c|}{ Kurtosis } \\
\hline & & & & Value & Std. Error & Value & Std. Error \\
\hline I feel the game allows me to be imaginative. & 748 & 5.07 & 1.60 & -0.64 & 0.09 & -0.32 & 0.18 \\
\hline $\begin{array}{l}\text { I feel the game provides me the necessary } \\
\text { information to accomplish a goal within the } \\
\text { game. }\end{array}$ & 758 & 5.77 & 1.24 & -1.31 & 0.09 & 1.80 & 0.18 \\
\hline $\begin{array}{l}\text { I think the game's audio fits the mood or style of } \\
\text { the game. }\end{array}$ & 753 & 6.07 & 1.12 & -1.70 & 0.09 & 3.58 & 0.18 \\
\hline I like to play this game with other players. & 663 & 5.46 & 1.94 & -1.16 & 0.09 & 0.06 & 0.19 \\
\hline $\begin{array}{l}\text { I do not need to go through a lengthy tutorial or } \\
\text { read a manual to play the game. }\end{array}$ & 768 & 5.55 & 1.61 & -1.22 & 0.09 & 0.73 & 0.18 \\
\hline I feel bored while playing the game. & 770 & 2.35 & 1.39 & 1.20 & 0.09 & 0.90 & 0.18 \\
\hline $\begin{array}{l}\text { I find the game supports social interaction (e.g., } \\
\text { chat) between players. }\end{array}$ & 664 & 4.88 & 2.01 & -0.66 & 0.09 & -0.84 & 0.19 \\
\hline $\begin{array}{l}\text { I feel the game constantly motivates me to } \\
\text { proceed further to the next stage or level. }\end{array}$ & 747 & 5.63 & 1.35 & -1.14 & 0.09 & 0.99 & 0.18 \\
\hline $\begin{array}{l}\text { I feel the game trains me well in all of the } \\
\text { controls. }\end{array}$ & 756 & 5.50 & 1.39 & -1.06 & 0.09 & 0.69 & 0.18 \\
\hline I feel the game allows me to express myself. & 736 & 4.68 & 1.68 & -0.36 & 0.09 & -0.67 & 0.18 \\
\hline I enjoy the music in the game. & 744 & 5.43 & 1.65 & -1.18 & 0.09 & 0.64 & 0.18 \\
\hline $\begin{array}{l}\text { I find my skills gradually improve through the } \\
\text { course of overcoming the challenges in the } \\
\text { game. }\end{array}$ & 767 & 6.04 & 1.08 & -1.64 & 0.09 & 3.87 & 0.18 \\
\hline I can clearly understand the game's story. & 650 & 5.70 & 1.53 & -1.41 & 0.10 & 1.44 & 0.19 \\
\hline I feel I can explore things in the game. & 734 & 5.52 & 1.66 & -1.08 & 0.09 & 0.16 & 0.18 \\
\hline
\end{tabular}


APPENDIX CC (continued)

CFA STUDY: SKEWNESS AND KURTOSIS VALUES OF ITEMS

\begin{tabular}{|c|c|c|c|c|c|c|c|}
\hline \multirow[t]{2}{*}{ Item } & \multirow[t]{2}{*}{$n$} & \multirow[t]{2}{*}{ Mean } & \multirow[t]{2}{*}{ SD } & \multicolumn{2}{|c|}{ Skewness } & \multicolumn{2}{|c|}{ Kurtosis } \\
\hline & & & & Value & Std. Error & Value & Std. Error \\
\hline $\begin{array}{l}\text { I cannot tell that I am getting tired while playing } \\
\text { the game. }\end{array}$ & 769 & 4.22 & 1.82 & -0.02 & 0.09 & -1.25 & 0.18 \\
\hline I find the game's menus to be user friendly. & 770 & 5.79 & 1.20 & -1.46 & 0.09 & 2.42 & 0.18 \\
\hline $\begin{array}{l}\text { I am very interested in seeing how the events in } \\
\text { the game will progress. }\end{array}$ & 730 & 5.73 & 1.33 & -1.30 & 0.09 & 1.63 & 0.18 \\
\hline $\begin{array}{l}\text { I feel the game gives me enough freedom to act } \\
\text { how I want. }\end{array}$ & 751 & 5.52 & 1.54 & -1.06 & 0.09 & 0.37 & 0.18 \\
\hline $\begin{array}{l}\text { I am emotionally moved by the events in the } \\
\text { game. }\end{array}$ & 725 & 4.04 & 1.86 & -0.05 & 0.09 & -1.13 & 0.18 \\
\hline $\begin{array}{l}\text { If given the chance, I want to play this game } \\
\text { again. }\end{array}$ & 770 & 6.28 & 1.04 & -1.98 & 0.09 & 5.03 & 0.18 \\
\hline I enjoy the social interaction within the game. & 641 & 5.03 & 1.60 & -0.66 & 0.10 & -0.19 & 0.19 \\
\hline $\begin{array}{l}\text { I feel detached from the outside world while } \\
\text { playing the game. }\end{array}$ & 769 & 4.46 & 1.76 & -0.34 & 0.09 & -0.93 & 0.18 \\
\hline $\begin{array}{l}\text { I feel my curiosity is stimulated as the result of } \\
\text { playing the game. }\end{array}$ & 759 & 5.18 & 1.55 & -0.80 & 0.09 & -0.01 & 0.18 \\
\hline $\begin{array}{l}\text { I find the game's interface to be easy to } \\
\text { navigate. }\end{array}$ & 768 & 5.92 & 1.15 & -1.55 & 0.09 & 2.67 & 0.18 \\
\hline I think the game is visually appealing. & 770 & 6.11 & 1.07 & -1.64 & 0.09 & 3.34 & 0.18 \\
\hline $\begin{array}{l}\text { I feel the game's audio (e.g., sound effects, } \\
\text { music) enhances my gaming experience. }\end{array}$ & 753 & 5.62 & 1.58 & -1.32 & 0.09 & 1.05 & 0.18 \\
\hline $\begin{array}{l}\text { I can block out most other distractions when } \\
\text { playing the game. }\end{array}$ & 770 & 5.43 & 1.35 & -0.96 & 0.09 & 0.63 & 0.18 \\
\hline
\end{tabular}


APPENDIX DD

CFA STUDY: LIST OF ALL VARIABLES WITH MISSING VALUES

\begin{tabular}{|c|c|c|c|c|}
\hline \multirow[b]{2}{*}{ Item } & \multicolumn{2}{|c|}{ Missing Values } & \multirow[b]{2}{*}{ Mean } & \multirow[b]{2}{*}{ SD } \\
\hline & $n$ & Percent & & \\
\hline I enjoy the social interaction within the game. & 130 & $16.9 \%$ & 5.03 & 1.60 \\
\hline I can clearly understand the game's story. & 121 & $15.7 \%$ & 5.70 & 1.53 \\
\hline I can identify with the characters in the game. & 113 & $14.7 \%$ & 4.32 & 1.90 \\
\hline I am captivated by the game's story from the beginning. & 112 & $14.5 \%$ & 5.16 & 1.76 \\
\hline I like to play this game with other players. & 108 & $14.0 \%$ & 5.46 & 1.94 \\
\hline $\begin{array}{l}\text { I find the game supports social interaction (e.g., chat) } \\
\text { between players. }\end{array}$ & 107 & $13.9 \%$ & 4.88 & 2.01 \\
\hline I enjoy the fantasy or story provided by the game. & 95 & $12.3 \%$ & 5.67 & 1.47 \\
\hline I think the characters in the game are well developed. & 85 & $11.0 \%$ & 5.32 & 1.67 \\
\hline I am able to play the game with other players if I choose. & 77 & $10.0 \%$ & 5.69 & 1.98 \\
\hline I am emotionally moved by the events in the game. & 46 & $6.0 \%$ & 4.04 & 1.86 \\
\hline $\begin{array}{l}\text { I am very interested in seeing how the events in the game } \\
\text { will progress. }\end{array}$ & 41 & $5.3 \%$ & 5.73 & 1.33 \\
\hline I feel I can explore things in the game. & 37 & $4.8 \%$ & 5.52 & 1.66 \\
\hline I feel the game allows me to express myself. & 35 & $4.5 \%$ & 4.68 & 1.68 \\
\hline I enjoy the music in the game. & 27 & $3.5 \%$ & 5.43 & 1.65 \\
\hline $\begin{array}{l}\text { I feel the game constantly motivates me to proceed further } \\
\text { to the next stage or level. }\end{array}$ & 24 & $3.1 \%$ & 5.63 & 1.35 \\
\hline I feel the game allows me to be imaginative. & 23 & $3.0 \%$ & 5.07 & 1.60 \\
\hline I feel the game gives me enough freedom to act how I want. & 20 & $2.6 \%$ & 5.52 & 1.54 \\
\hline $\begin{array}{l}\text { I always know my next goal when I finish an event in the } \\
\text { game. }\end{array}$ & 20 & $2.6 \%$ & 5.48 & 1.51 \\
\hline $\begin{array}{l}\text { I feel the game's audio (e.g., sound effects, music) enhances } \\
\text { my gaming experience. }\end{array}$ & 18 & $2.3 \%$ & 5.62 & 1.58 \\
\hline I think the game's audio fits the mood or style of the game. & 18 & $2.3 \%$ & 6.07 & 1.12 \\
\hline I feel the game trains me well in all of the controls. & 15 & $1.9 \%$ & 5.50 & 1.39 \\
\hline I feel creative while playing the game. & 15 & $1.9 \%$ & 4.95 & 1.66 \\
\hline $\begin{array}{l}\text { I feel the game provides me the necessary information to } \\
\text { accomplish a goal within the game. }\end{array}$ & 13 & $1.7 \%$ & 5.77 & 1.24 \\
\hline $\begin{array}{l}\text { I feel my curiosity is stimulated as the result of playing the } \\
\text { game. }\end{array}$ & 12 & $1.6 \%$ & 5.18 & 1.55 \\
\hline I enjoy the sound effects in the game. & 11 & $1.4 \%$ & 5.54 & 1.60 \\
\hline I am in suspense about whether I will succeed in the game. & 8 & $1.0 \%$ & 4.89 & 1.81 \\
\hline I think it is easy to learn how to play the game. & 6 & $0.8 \%$ & 5.50 & 1.60 \\
\hline $\begin{array}{l}\text { I do not care to check events that are happening in the real } \\
\text { world during the game. }\end{array}$ & 5 & $0.6 \%$ & 4.07 & 1.87 \\
\hline
\end{tabular}


APPENDIX DD (continued)

CFA STUDY: LIST OF ALL VARIABLES WITH MISSING VALUES

\begin{tabular}{|c|c|c|c|c|}
\hline \multirow[b]{2}{*}{ Item } & \multicolumn{2}{|c|}{ Missing Values } & \multirow[b]{2}{*}{ Mean } & \multirow[b]{2}{*}{ SD } \\
\hline & $n$ & Percent & & \\
\hline I feel successful when I overcome the obstacles in the game. & 5 & $0.6 \%$ & 6.25 & 1.00 \\
\hline $\begin{array}{l}\text { I tend to spend more time playing the game than I have } \\
\text { planned. }\end{array}$ & 5 & $0.6 \%$ & 5.45 & 1.59 \\
\hline Sometimes I lose track of time while playing the game. & 5 & $0.6 \%$ & 5.92 & 1.37 \\
\hline $\begin{array}{l}\text { I find my skills gradually improve through the course of } \\
\text { overcoming the challenges in the game. }\end{array}$ & 4 & $0.5 \%$ & 6.04 & 1.08 \\
\hline I find the game's interface to be easy to navigate. & 3 & $0.4 \%$ & 5.92 & 1.15 \\
\hline $\begin{array}{l}\text { I do not need to go through a lengthy tutorial or read a } \\
\text { manual to play the game. }\end{array}$ & 3 & $0.4 \%$ & 5.55 & 1.61 \\
\hline I am likely to recommend this game to others. & 3 & $0.4 \%$ & 6.25 & 1.09 \\
\hline I think the game is unique or original. & 3 & $0.4 \%$ & 5.51 & 1.47 \\
\hline $\begin{array}{l}\text { I think the graphics of the game fit the mood or style of the } \\
\text { game. }\end{array}$ & 3 & $0.4 \%$ & 6.40 & 0.88 \\
\hline $\begin{array}{l}\text { I think the information provided in the game (e.g., onscreen } \\
\text { messages, help) is clear. }\end{array}$ & 3 & $0.4 \%$ & 5.93 & 1.13 \\
\hline I enjoy playing the game. & 3 & $0.4 \%$ & 6.60 & 0.75 \\
\hline $\begin{array}{l}\text { I feel detached from the outside world while playing the } \\
\text { game. }\end{array}$ & 2 & $0.3 \%$ & 4.46 & 1.76 \\
\hline I cannot tell that I am getting tired while playing the game. & 2 & $0.3 \%$ & 4.22 & 1.82 \\
\hline I feel very confident while playing the game. & 2 & $0.3 \%$ & 5.58 & 1.21 \\
\hline I want to do as well as possible during the game. & 2 & $0.3 \%$ & 6.22 & 1.03 \\
\hline I enjoy the game's graphics. & 2 & $0.3 \%$ & 6.09 & 1.04 \\
\hline I find the controls of the game to be straightforward. & 2 & $0.3 \%$ & 6.05 & 1.16 \\
\hline $\begin{array}{l}\text { I can block out most other distractions when playing the } \\
\text { game. }\end{array}$ & 1 & $0.1 \%$ & 5.43 & 1.35 \\
\hline I think the game is visually appealing. & 1 & $0.1 \%$ & 6.11 & 1.07 \\
\hline If given the chance, I want to play this game again. & 1 & $0.1 \%$ & 6.28 & 1.04 \\
\hline I find the game's menus to be user friendly. & 1 & $0.1 \%$ & 5.79 & 1.20 \\
\hline I feel bored while playing the game. & 1 & $0.1 \%$ & 2.35 & 1.39 \\
\hline $\begin{array}{l}\text { I temporarily forget about my everyday worries while } \\
\text { playing the game. }\end{array}$ & 1 & $0.1 \%$ & 5.59 & 1.40 \\
\hline $\begin{array}{l}\text { I always know how to achieve my goals/objectives in the } \\
\text { game. }\end{array}$ & 1 & $0.1 \%$ & 5.49 & 1.35 \\
\hline $\begin{array}{l}\text { I am very focused on my own performance while playing } \\
\text { the game. }\end{array}$ & 1 & $0.1 \%$ & 6.02 & 1.19 \\
\hline
\end{tabular}




\section{APPENDIX EE}

\section{FINAL VERSION OF THE GUESS}

Instructions: Based on your experience playing this game, please rate the following statements on a scale from "Strongly Disagree" to "Strongly Agree". Select "N/A" if a statement does not applied to the game that you are rating.

\begin{tabular}{|c|c|c|c|c|c|c|c|c|}
\hline Statement & $\begin{array}{l}\text { Strongly } \\
\text { Disagree }\end{array}$ & Disagree & $\begin{array}{c}\text { Somewhat } \\
\text { Disagree }\end{array}$ & $\begin{array}{l}\text { Neither } \\
\text { Agree } \\
\text { nor } \\
\text { Disagree } \\
\end{array}$ & $\begin{array}{l}\text { Somewhat } \\
\text { Agree }\end{array}$ & Agree & $\begin{array}{l}\text { Strongly } \\
\text { Agree }\end{array}$ & N/A \\
\hline Sometimes I lose track of time while playing the game. & $\bigcirc$ & O & O & $\bigcirc$ & O & O & O & $\bar{\partial}$ \\
\hline I enjoy the sound effects in the game. & $\bigcirc$ & $\bigcirc$ & $\bigcirc$ & $\bigcirc$ & $\bigcirc$ & O & O & $\bigcirc$ \\
\hline $\begin{array}{l}\text { I am very focused on my own performance while } \\
\text { playing the game. }\end{array}$ & $\bigcirc$ & $\bigcirc$ & $\bigcirc$ & $\bigcirc$ & $\bigcirc$ & $\bigcirc$ & $\bigcirc$ & $\bigcirc$ \\
\hline $\begin{array}{l}\text { I tend to spend more time playing the game than I have } \\
\text { planned. }\end{array}$ & O & O & O & $\bigcirc$ & $\bigcirc$ & O & O & $\bigcirc$ \\
\hline I think it is easy to learn how to play the game. & $\bigcirc$ & $\bigcirc$ & $\bigcirc$ & $\bigcirc$ & $\bigcirc$ & $\bigcirc$ & $\bigcirc$ & $\bigcirc$ \\
\hline I enjoy playing the game. & $\bigcirc$ & $\bigcirc$ & $\bigcirc$ & $\bigcirc$ & $\bigcirc$ & $\bigcirc$ & $\bigcirc$ & b \\
\hline $\begin{array}{l}\text { I am in suspense about whether I will succeed in the } \\
\text { game. }\end{array}$ & $\bigcirc$ & O & $\bigcirc$ & $\bigcirc$ & $\bigcirc$ & $\bigcirc$ & $\bigcirc$ & $\bigcirc$ \\
\hline $\begin{array}{l}\text { I am able to play the game with other players if I } \\
\text { choose. }\end{array}$ & $\bigcirc$ & $\bigcirc$ & $\bigcirc$ & $\bigcirc$ & $\bigcirc$ & O & $\bigcirc$ & $\bigcirc$ \\
\hline $\begin{array}{l}\text { I think the information provided in the game (e.g., } \\
\text { onscreen messages, help) is clear. }\end{array}$ & O & O & O & O & $\bigcirc$ & O & $\bigcirc$ & $\bigcirc$ \\
\hline I am captivated by the game's story from the beginning. & $\bigcirc$ & $\bigcirc$ & $\bigcirc$ & $\bigcirc$ & $\bigcirc$ & $\bigcirc$ & $\bigcirc$ & $\bigcirc$ \\
\hline $\begin{array}{l}\text { I think the graphics of the game fit the mood or style of } \\
\text { the game. }\end{array}$ & $\bigcirc$ & $\bigcirc$ & $\bigcirc$ & $\bigcirc$ & $\bigcirc$ & O & $\bigcirc$ & $\curvearrowright$ \\
\hline $\begin{array}{l}\text { I feel successful when I overcome the obstacles in the } \\
\text { game. }\end{array}$ & 0 & O & $\bigcirc$ & O & O & O & $\bigcirc$ & $\bigcirc$ \\
\hline $\begin{array}{l}\text { I always know my next goal when I finish an event in the } \\
\text { game. }\end{array}$ & $\bigcirc$ & $\bigcirc$ & $\bigcirc$ & $\bigcirc$ & $\bigcirc$ & $\bigcirc$ & $\bigcirc$ & $\bigcirc$ \\
\hline
\end{tabular}




\section{FINAL VERSION OF THE GUESS}

Instructions: Based on your experience playing this game, please rate the following statements on a scale from "Strongly Disagree" to "Strongly Agree". Select "N/A" if a statement does not applied to the game that you are rating.

\begin{tabular}{|c|c|c|c|c|c|c|c|c|}
\hline Statement & $\begin{array}{l}\text { Strongly } \\
\text { Disagree }\end{array}$ & Disagree & $\begin{array}{l}\text { Somewhat } \\
\text { Disagree }\end{array}$ & $\begin{array}{c}\text { Neither } \\
\text { Agree } \\
\text { nor } \\
\text { Disagree }\end{array}$ & $\begin{array}{l}\text { Somewhat } \\
\text { Agree }\end{array}$ & Agree & $\begin{array}{l}\text { Strongly } \\
\text { Agree }\end{array}$ & N/A \\
\hline I think the game is unique or original. & $\bigcirc$ & $\bigcirc$ & $\bigcirc$ & $\bigcirc$ & $\bigcirc$ & $\bigcirc$ & $\bigcirc$ & $\bigcirc$ \\
\hline $\begin{array}{l}\text { I do not care to check events that are happening in the } \\
\text { real world during the game. }\end{array}$ & $\bigcirc$ & $\bigcirc$ & O & $\bigcirc$ & $\bigcirc$ & $\bigcirc$ & $\bigcirc$ & O \\
\hline I think the game is fun. & $\bigcirc$ & $\bigcirc$ & $\bigcirc$ & $\bigcirc$ & $\bigcirc$ & $\bigcirc$ & $\bigcirc$ & $\bigcirc$ \\
\hline $\begin{array}{l}\text { I always know how to achieve my goals/objectives in } \\
\text { the game. }\end{array}$ & $\bigcirc$ & $\bigcirc$ & $\bigcirc$ & $\bigcirc$ & $\bigcirc$ & $\bigcirc$ & $\bigcirc$ & $\bigcirc$ \\
\hline I think the characters in the game are well developed. & $\bigcirc$ & $\bigcirc$ & $\bigcirc$ & $\bigcirc$ & $\bigcirc$ & $\bigcirc$ & $\bigcirc$ & $\bigcirc$ \\
\hline I find the controls of the game to be straightforward. & $\bigcirc$ & $\bigcirc$ & $\bigcirc$ & $\bigcirc$ & $\bigcirc$ & $\bigcirc$ & $\bigcirc$ & $\bigcirc$ \\
\hline I enjoy the game's graphics. & $\bigcirc$ & $\bigcirc$ & $\bigcirc$ & $\bigcirc$ & $\bigcirc$ & $\bigcirc$ & $\bigcirc$ & $\bigcirc$ \\
\hline I want to do as well as possible during the game. & $\bigcirc$ & $\bigcirc$ & $\bigcirc$ & $\bigcirc$ & O & $\bigcirc$ & $\bigcirc$ & $\bigcirc$ \\
\hline $\begin{array}{l}\text { Whenever I stopped playing the game I cannot wait to } \\
\text { start playing it again. }\end{array}$ & $\bigcirc$ & $\bigcirc$ & $\bigcirc$ & $\bigcirc$ & $\bigcirc$ & $\bigcirc$ & $\bigcirc$ & D \\
\hline I enjoy the fantasy or story provided by the game. & $\bigcirc$ & $\bigcirc$ & $\bigcirc$ & $\bigcirc$ & $\bigcirc$ & $\bigcirc$ & $\bigcirc$ & $\bigcirc$ \\
\hline I feel very confident while playing the game. & $\bigcirc$ & $\bigcirc$ & $\bigcirc$ & $\bigcirc$ & $\bigcirc$ & $\bigcirc$ & $\bigcirc$ & $\bigcirc$ \\
\hline I am likely to recommend this game to others. & $\bigcirc$ & $\bigcirc$ & $\bigcirc$ & $\bigcirc$ & $\bigcirc$ & $\bigcirc$ & $\bigcirc$ & $\bigcirc$ \\
\hline $\begin{array}{l}\text { I temporarily forget about my everyday worries while } \\
\text { playing the game. }\end{array}$ & $\bigcirc$ & $\bigcirc$ & $\bigcirc$ & $\bigcirc$ & $\bigcirc$ & $\bigcirc$ & $\bigcirc$ & $\bigcirc$ \\
\hline I feel creative while playing the game. & $\bigcirc$ & $\bigcirc$ & $\bigcirc$ & $\bigcirc$ & $\bigcirc$ & $\bigcirc$ & $\bigcirc$ & $\bigcirc$ \\
\hline I can identify with the characters in the game. & $\bigcirc$ & $\bigcirc$ & $\bigcirc$ & $\bigcirc$ & $\bigcirc$ & $\bigcirc$ & $\bigcirc$ & $\bigcirc$ \\
\hline I feel the game allows me to be imaginative. & $\bigcirc$ & O & $\bigcirc$ & O & $\bigcirc$ & $\bigcirc$ & $\bigcirc$ & $\bigcirc$ \\
\hline
\end{tabular}




\section{FINAL VERSION OF THE GUESS}

Instructions: Based on your experience playing this game, please rate the following statements on a scale from "Strongly Disagree" to "Strongly Agree". Select "N/A" if a statement does not applied to the game that you are rating.

\begin{tabular}{|c|c|c|c|c|c|c|c|c|}
\hline Statement & $\begin{array}{l}\text { Strongly } \\
\text { Disagree }\end{array}$ & Disagree & $\begin{array}{l}\text { Somewhat } \\
\text { Disagree }\end{array}$ & $\begin{array}{c}\text { Neither } \\
\text { Agree } \\
\text { nor } \\
\text { Disagree } \\
\end{array}$ & $\begin{array}{l}\text { Somewhat } \\
\text { Agree }\end{array}$ & Agree & $\begin{array}{l}\text { Strongly } \\
\text { Agree }\end{array}$ & N/A \\
\hline $\begin{array}{l}\text { I feel the game provides me the necessary information } \\
\text { to accomplish a goal within the game. }\end{array}$ & $\bigcirc$ & $\bigcirc$ & $\bigcirc$ & $\bigcirc$ & $\bigcirc$ & $\bigcirc$ & $\bigcirc$ & $\bigcirc$ \\
\hline $\begin{array}{l}\text { I think the game's audio fits the mood or style of the } \\
\text { game. }\end{array}$ & $\bigcirc$ & $\bigcirc$ & $\bigcirc$ & $\bigcirc$ & $\bigcirc$ & $\bigcirc$ & $\bigcirc$ & O \\
\hline I like to play this game with other players. & $\bigcirc$ & $\bigcirc$ & $\bigcirc$ & $\bigcirc$ & $\bigcirc$ & $\bigcirc$ & $\bigcirc$ & O \\
\hline $\begin{array}{l}\text { I do not need to go through a lengthy tutorial or read a } \\
\text { manual to play the game. }\end{array}$ & $\bigcirc$ & $\bigcirc$ & $\bigcirc$ & $\bigcirc$ & $\bigcirc$ & $\bigcirc$ & $\bigcirc$ & D \\
\hline I feel bored while playing the game. & $\bigcirc$ & $\bigcirc$ & $\bigcirc$ & $\bigcirc$ & $\bigcirc$ & $\bigcirc$ & $\bigcirc$ & $\bigcirc$ \\
\hline $\begin{array}{l}\text { I find the game supports social interaction (e.g., chat) } \\
\text { between players. }\end{array}$ & $\bigcirc$ & $\bigcirc$ & $\bigcirc$ & $\bigcirc$ & $\bigcirc$ & $\bigcirc$ & $\bigcirc$ & \\
\hline $\begin{array}{l}\text { I feel the game constantly motivates me to proceed } \\
\text { further to the next stage or level. }\end{array}$ & $\bigcirc$ & $\bigcirc$ & $\bigcirc$ & $\bigcirc$ & $\bigcirc$ & $\bigcirc$ & $\bigcirc$ & O \\
\hline I feel the game trains me well in all of the controls. & $\bigcirc$ & $\bigcirc$ & $\bigcirc$ & $\bigcirc$ & $\bigcirc$ & $\bigcirc$ & $\bigcirc$ & $\bigcirc$ \\
\hline I feel the game allows me to express myself. & $\bigcirc$ & $\bigcirc$ & $\bigcirc$ & $\bigcirc$ & O & $\bigcirc$ & $\bigcirc$ & $\bigcirc$ \\
\hline I enjoy the music in the game. & $\bigcirc$ & $\bigcirc$ & $\bigcirc$ & $\bigcirc$ & $\bigcirc$ & $\bigcirc$ & $\bigcirc$ & $\bigcirc$ \\
\hline $\begin{array}{l}\text { I find my skills gradually improve through the course of } \\
\text { overcoming the challenges in the game. }\end{array}$ & $\bigcirc$ & $\bigcirc$ & $\bigcirc$ & $\bigcirc$ & $\bigcirc$ & $\bigcirc$ & $\bigcirc$ & $\bigcirc$ \\
\hline I can clearly understand the game's story. & $\bigcirc$ & $\bigcirc$ & $\bigcirc$ & $\bigcirc$ & $\bigcirc$ & $\bigcirc$ & $\bigcirc$ & $\bigcirc$ \\
\hline I feel I can explore things in the game. & $\bigcirc$ & $\bigcirc$ & $\bigcirc$ & 0 & 0 & 0 & $\bigcirc$ & $\bigcirc$ \\
\hline $\begin{array}{l}\text { I cannot tell that I am getting tired while playing the } \\
\text { game. }\end{array}$ & 0 & 0 & $\bigcirc$ & $\bigcirc$ & 0 & $\bigcirc$ & 0 & $\bigcirc$ \\
\hline
\end{tabular}




\section{APPENDIX EE (continued)}

\section{FINAL VERSION OF THE GUESS}

Instructions: Based on your experience playing this game, please rate the following statements on a scale from "Strongly Disagree" to "Strongly Agree". Select "N/A" if a statement does not applied to the game that you are rating.

Statement
$\begin{aligned} & \text { I find the game's menus to be user friendly. } \\ & \text { Disagree }\end{aligned}$

